\title{
REC.FIVED
}

NOV 171995

OSTI

OAK RIDGE

$\mathrm{Y}-12$

PLANT

MARTIN MARUETIA

\section{BEHAVIOR OF STRUCTURAL CLAY TULE INFILLED FRAMES}

Prepared for the

Center for Natural Phenomena Engineering

December 18, 1994

Oak Ridge Y-12 Plant

Oak Ridge, Tennessee 37831

managed by

Martin Marietta Energy Systems, Inc.

for the

U.S. DEPARTMENT OF ENERGY

under contract DE-AC05-840R21400
MANAGEDBY

MARTIN MARIETTA ENERGY SYSTEMS, INC.

FOR THE UNITED STATES

DEPARTMENT OF ENERGY

UCN-13672 (2 10-80) 


\section{DISCLAIMER}

This report was prepared as an account of work sponsored by an agency of the United States Government. Neither the United States Government nor any agency thereof, nor any of their employees, makes any warranty, express or implied, or assumes any legal liability or responsibility for the accuracy, completeness, or usefulness of any information, apparatus, product, or process disclosed, or represents that its use would not infringe privately owned rights. Reference herein to any specific commercial product, process, or service by trade name, trademark, manufacturer, or otherwise, does not necessarily constitute or imply its endorsement, recommendation, or favoring by the United States Government or any agency thereof. The views and opinions of authors expressed herein do not necessarily state or reflect those of the United States Government or any agency thereof.

\section{COPYRIGHT NOTICE}

The abmittod manuccript has been authored by a contretor of the U.S. Govermmene under contruct DBACOS-84OR21400. Accordingly, the U.S. Covernmed retrins a prid-up, pocexchurve, irrevocable, worldwide licenese to publinh or reproduce the publichod form of this contribution, prepare derivative works, distribute copies to the public, and perform publicly and diplay publicly, or allow others to do so, for U.S. Governmed purposes. 


\title{
BEHAVIOR OF STRUCTURAL CLAY TILE INFILLED FRAMES
}

\author{
Roger D. Flanagan \\ Central Engineering Services \\ Martin Marietta Energy Systems, Inc.
}

Prepared for the

Center for Natural Phenomena Engineering

December 18, 1994

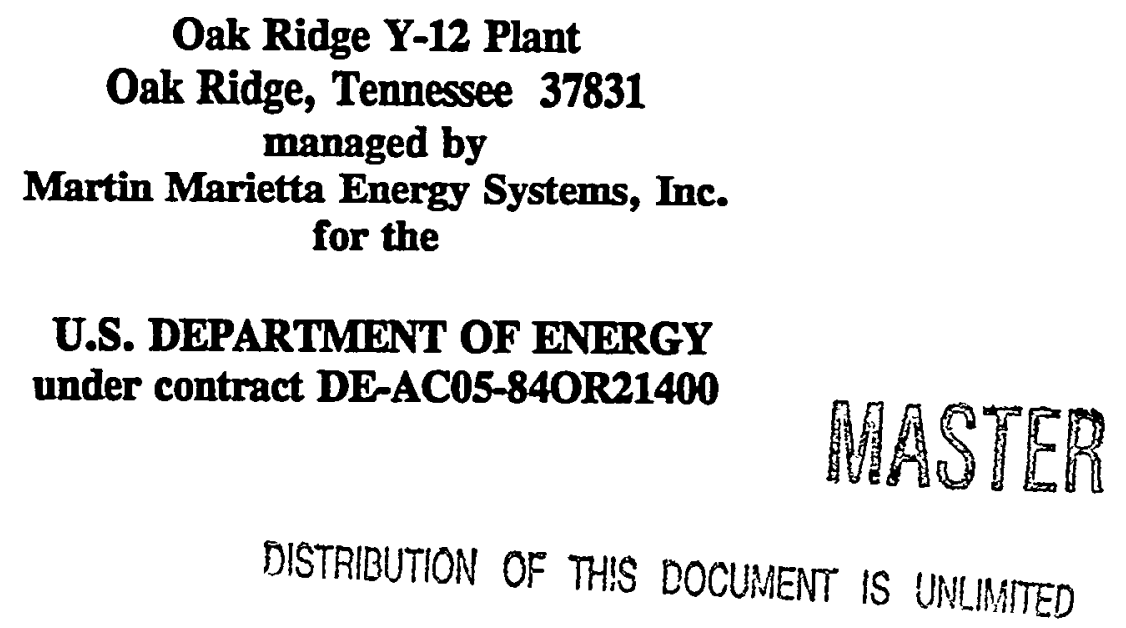




\section{DISCLAIMER}

Portions of this document may be illegible in electronic image products. Images are produced from the best available original document. 


\title{
BEHAVIOR OF STRUCTURAL CLAY TILE INFILLED FRAMES
}

\author{
A Dissertation \\ Presented for the \\ Doctor of Philosophy \\ Degree \\ The University of Tennessee, Knoxville
}

Roger D. Flanagan

December 1994

DISTEDUTION OF THIS DOCUMENT IS INLIMITED

De. 


\section{DEDICATION}

This dissertation is dedicated to my loving and enduring family

Joy

Eric Michael and Laurel Hope

Mr. R. Murl Flanagan

Mrs. Nancy Dunbar Flanagan

Beverly 


\section{ACKNOWLEDGEMENTS}

The author wishes to express his gratitude to the doctoral committee for their helpful suggestions in planning and preparing this dissertation: Dr. Richard M. Bennett (major professor), Dr. Edwin G. Burdette, Dr. David W. Goodpasture, and Dr. William J. McClain. A special note of appreciation to Dr. Richard M. Bennett for his invaluable guidance and insight throughout this course of research.

Thanks are extended to Martin Marietta Energy Systems, Inc. for providing the opportunity for this research: Dr. James E. Beavers, W. Dale Jones, Chris Stoddart, P. J. Anderson, Montgomery Lokey, Terry Domm, and Jim Seneker. Thanks are also extended to others helping with portions of the laboratory testing or data reduction: George Barclay, Kurt Boyd, Chris Columber, Joele Fowler, Doug Ferguson, Joey Hawn, Bob Painter, and Mike Tenbus.

Finally, thanks are given for the patience and constant encouragement provided by my wife, Joy, and my children, Eric and Hope. Without their support, this accomplishment would not have been possible. 


\begin{abstract}
Steel frames infilled with structural clay tile have been used in commercial and industrial buildings for most of this century. Often these buildings are located in moderate to high seismic zones and are likely to experience earthquake forces. Little prior research has been conducted to investigate the behavior of clay tile infills under lateral loading.

Twenty-one large-scale clay tile infilled frames were tested to determine their behavior and correlate the results with other available experimental data. The infills greatly increased the in-plane stiffness and strength of the otherwise flexible framing. Two in-plane failure mechanisms were observed, diagonal cracking and corner crushing.

Under uniform out-of-plane load, the infills cracked along the mortar joints and developed membrane forces. Tremendous out-of-plane capacity was observed as the panels arched vertically and then horizontally, remaining stable after ultimate capacity was reached. Under sequential and combined bi-directional loadings, the panels remained stable with little interaction of the in-plane and out-of-plane behavior, particularly in the frame member forces.

Analytical comparisons of measured versus predicted stiffness, ultimate capacity, and frame member forces were performed. A numerical model based on a piecewise linear equivalent strut was developed. Recommendations for evaluation of clay tile infills subjected to seismic loads were proposed.
\end{abstract}




\section{TABLE OF CONTENTS}

CHAPTER

PAGE

1. INTRODUCTION $\ldots \ldots \ldots \ldots \ldots \ldots \ldots \ldots \ldots \ldots \ldots \ldots \ldots \ldots \ldots \ldots$

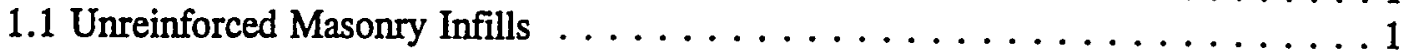

1.2 Historical Use of Structural Clay Tile $\ldots \ldots \ldots \ldots \ldots \ldots \ldots \ldots \ldots$

1.3 Scope of Research $\ldots \ldots \ldots \ldots \ldots \ldots \ldots \ldots \ldots \ldots$

2. REVIEW OF THE LITERATURE $\ldots \ldots \ldots \ldots \ldots \ldots \ldots \ldots \ldots \ldots \ldots$

2.1 In-Plane Behavior of Infilled Frames $\ldots \ldots \ldots \ldots \ldots \ldots \ldots \ldots$

2.2 Out-of-Plane Behavior of Infilled Frames $\ldots \ldots \ldots \ldots \ldots \ldots \ldots \ldots \ldots \ldots$

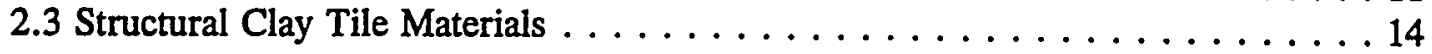

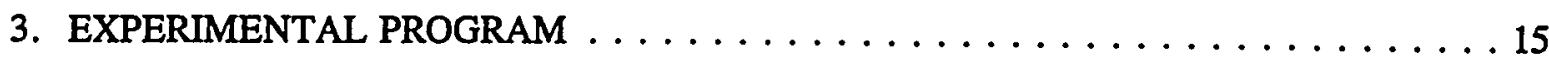

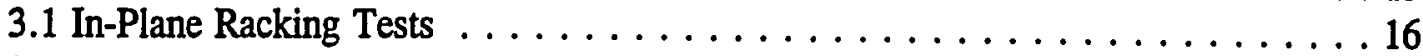

3.2 Uniform Lateral Load Tests . . . . . . . . . . . . . . . . . . . . 28

3.3 Bi-Directional Tests . . . . . . . . . . . . . . . . 33

3.3.1 Sequential Test - Lateral Drift Followed by In-Plane Racking . . . . . 33

3.3.2 Sequential Test - In-Plane Racking Followed by Uniform Lateral Load . 35

3.3.3 Sequential Test - Uniform Lateral Load Followed by In-Plane Racking . 36

3.3.4 Combined Test - In-Plane Racking and Uniform Lateral Load . . . . 36

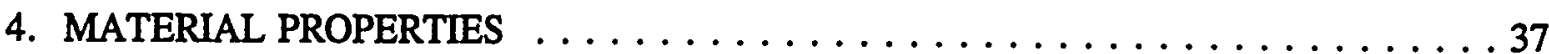

4.1 Manufacture of Structural Clay Tile . . . . . . . . . . . . 37

4.2 Properties of Structural Clay Tile Units $\ldots \ldots \ldots \ldots \ldots \ldots \ldots \ldots \ldots$

4.3 Properties of Structural Clay Tile Prisms $\ldots \ldots \ldots \ldots \ldots \ldots \ldots \ldots \ldots 6$

4.4 Properties of Infill Mortar . . . . . . . . . . . . . . . 50

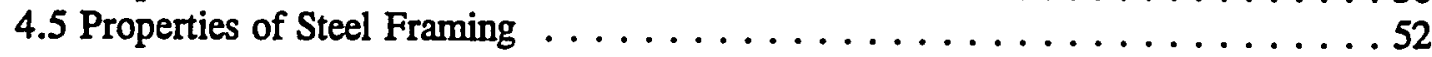

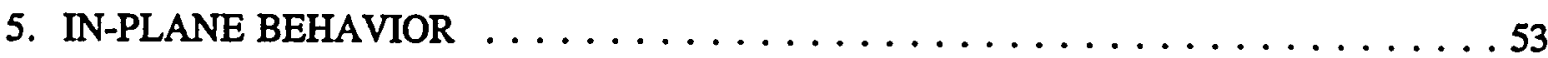

5.1 Experimental Results ................... 53

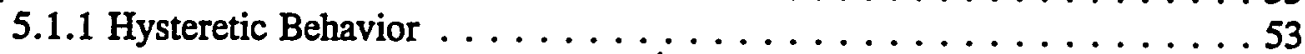

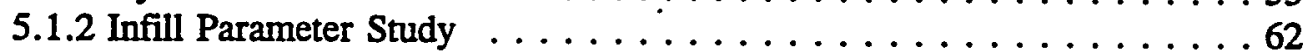

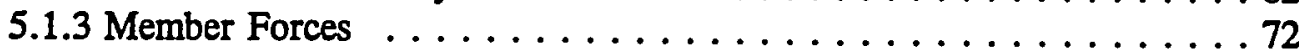

5.2 Analytical Correlation . . . . . . . . . . . . . . . . 78

5.2.1 Ultimate Capacity Prediction . . . . . . . . . . . . . . 79

5.2.2 Hysteretic Modeling Using a Nonlinear Compressive Strut . . . . . . 84

5.2.3 Hysteretic Modeling Using a Piecewise Linear Compressive Strut . . . . 85

5.2.4 Member Force Prediction . . . . . . . . . . . . . . 90

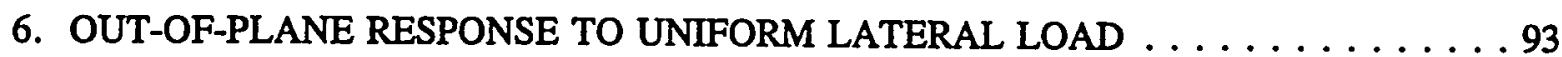

6.1 Panel Load-Deformation Behavior $\ldots \ldots \ldots \ldots \ldots \ldots \ldots \ldots \ldots \ldots$

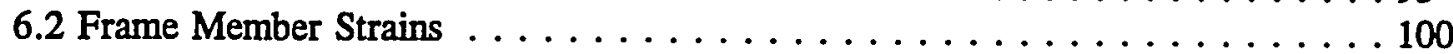

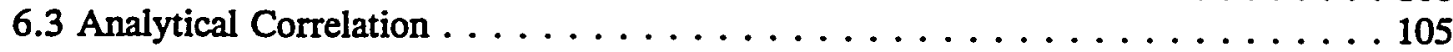


7. BI-DIRECTIONAL BEHAVIOR . . . . . . . . . . . . . . . . . . . . . . 109

7.1 Lateral Drift Followed by In-Plane Racking . . . . . . . . . . . . . . . . . 109

7.2 In-Plane Racking Followed by Uniform Lateral Load . . . . . . . . 120

7.3 Uniform Lateral Load Followed by In-Plane Racking . . . . . . . . . . 122

7.4 In-Plane Racking and Uniform Lateral Load Combined . . . . . . . . . . 126

8. CONCLUSIONS AND RECOMMENDATIONS $\ldots \ldots \ldots \ldots \ldots \ldots \ldots \ldots \ldots$

8.1 Structural Clay Tile Infill Behavior $\ldots \ldots \ldots \ldots \ldots \ldots \ldots \ldots \ldots \ldots \ldots$

8.2 Infilled Frame Member Forces . . . . . . . . . . . . . . . . . . . . 139

8.3 Numerical Analysis of Structural Clay Tile Infills $\ldots \ldots \ldots \ldots \ldots \ldots \ldots$

8.5 Recommendations . . . . . . . . . . . . . . . . . 141

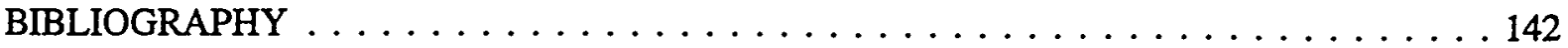

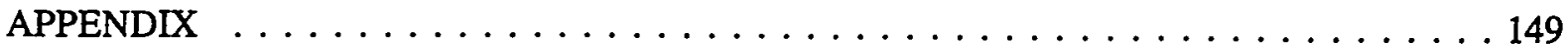

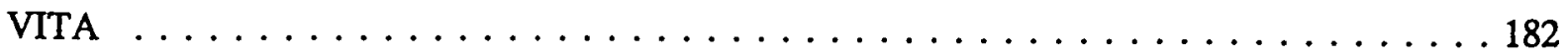




\section{LIST OF TABLES}

TABLE

PAGE

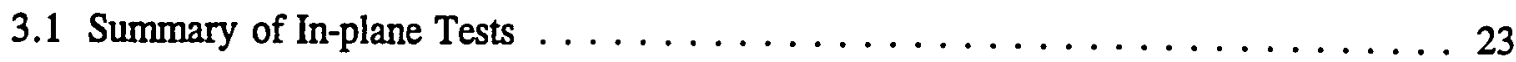

3.2 Summary of Uniform Lateral Load Tests $\ldots \ldots \ldots \ldots \ldots \ldots \ldots$

3.3 Summary of Bi-Directional Tests $\ldots \ldots \ldots \ldots \ldots \ldots \ldots \ldots \ldots \ldots \ldots \ldots \ldots$

4.1 ASTM C 34-91 Physical Requirements for Structural Clay Tile . . . . . . . . 39

4.2 Comparison of Gross Compressive Strengths $\ldots \ldots \ldots \ldots \ldots \ldots \ldots$

4.3 Comparison of Net Compressive Strengths $\ldots \ldots \ldots \ldots \ldots \ldots \ldots \ldots 4$

4.4 Comparison of Net Modulus of Elasticity (Vertical Cells) $\ldots \ldots \ldots \ldots$. . . . 46

4.5 Summary of Prism Compression Test Results $\ldots \ldots \ldots \ldots \ldots \ldots \ldots \ldots$

4.6 Mean Compressive Strength of Infill Mortar $\ldots \ldots \ldots \ldots \ldots \ldots \ldots \ldots \ldots$

4.7 Mean Yield Stress and Strain of Steel Frames $\ldots \ldots \ldots \ldots \ldots \ldots \ldots \ldots$

5.1 Summary of In-Plane Capacities $\ldots \ldots \ldots \ldots \ldots \ldots \ldots \ldots \ldots \ldots \ldots \ldots \ldots \ldots$

5.2 Predicted Strength of Clay Tile Infilled Frames $\ldots \ldots \ldots \ldots \ldots \ldots \ldots$

5.3 Typical Values of $\mathrm{C}$ for Varying In-Plane Drift Displacements $\ldots \ldots \ldots \ldots 7$

7.1 In-Plane Ultimate Load and Initial Stiffness $\ldots \ldots \ldots \ldots \ldots \ldots \ldots$ 


\section{LIST OF FIGURES}

FIGURE

PAGE

1.1 Production of Hollow Building Tile $\ldots \ldots \ldots \ldots \ldots \ldots \ldots \ldots \ldots \ldots$

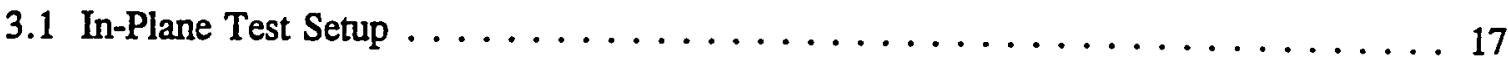

3.2 Single Wythe Panel Construction Details $\ldots \ldots \ldots \ldots \ldots$

3.3 Double Wythe Panel Construction Details $\ldots \ldots \ldots \ldots \ldots \ldots$

3.4 In-Plane Test Instrumentation and Control Schematic . . . . . . . . . . . 20

3.5 Typical In-Plane Displacement Time History . . . . . . . . . . . . . . 20

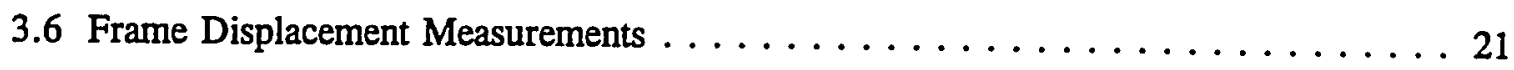

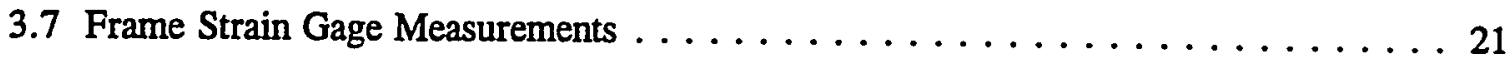

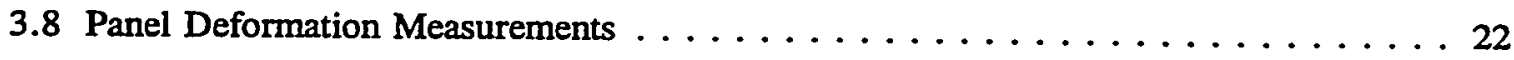

3.9 Summary of In-Plane Testing Specimens and Ultimate Capacities . . . . . . . . . 24

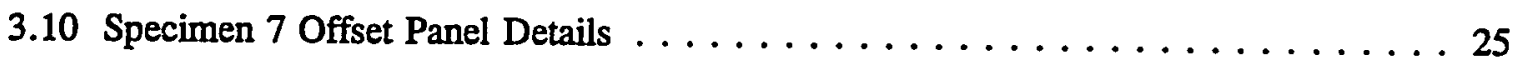

3.11 Specimen $21 b$ - Upper Course Repair . . . . . . . . . . . . . . 26

3.12 Specimen $10 \mathrm{~b}-$ Upper Corner Retrofit $\ldots \ldots \ldots \ldots \ldots \ldots$

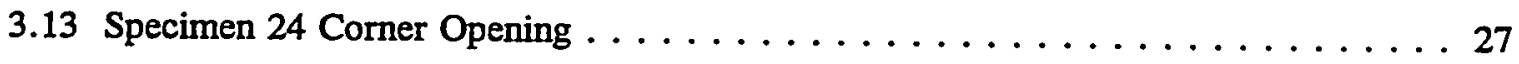

3.14 Summary of Uniform Lateral Load Testing Specimens and Ultimate Capacities . . 29

3.15 Uniform Lateral Load Test Setup $\ldots \ldots \ldots$. . . . . . . . . . . . . . 29

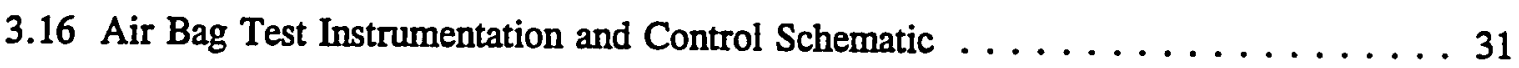

3.17 Typical Air Bag Pressure Time History $\ldots \ldots \ldots \ldots \ldots \ldots \ldots \ldots \ldots \ldots$

3.18 Air Bag Test Displacement Measurements . . . . . . . . . . . . . . 32

3.19 Air Bag Test Strain Gage Locations . . . . . . . . . . . . . . 32

3.20 Bi-Directional Testing Specimen Summary and Ultimate Capacities . . . . . . . . 34 
3.21 Out-of-Plane Drift Test Setup $\ldots \ldots \ldots \ldots \ldots \ldots \ldots \ldots \ldots \ldots \ldots \ldots \ldots \ldots \ldots$

4.1 Physical Measurements of Structural Clay Tile $\ldots \ldots \ldots \ldots \ldots$

4.2 Unit Tile Compressive Strength Tests $\ldots \ldots \ldots \ldots \ldots$

4.3 Unit Tile Stress-Strain Relationship (Vertical Cores) $\ldots . \ldots \ldots$. . . . . . . . 45

4.4 Prism Compression Stress-Strain Relationship (Cores Normal to Load) . . . . . . 48

4.5 Prism Compression Stress-Strain Relationship (Cores Parallel to Load) . . . . . . 48

4.6 Prism Testing (Cores Normal to Load) $\ldots \ldots \ldots . \ldots . \ldots . \ldots . \ldots$

4.7 Prism Testing (Cores Parallel to Load) $\ldots \ldots \ldots$. . . . . . . . . . . . . . 49

5.1 Partial In-Plane Hysteresis of Infill $17 \ldots \ldots \ldots \ldots \ldots \ldots$

5.2 Complete Hysteresis of Specimen $17 \ldots \ldots \ldots \ldots \ldots \ldots \ldots \ldots \ldots \ldots \ldots \ldots \ldots$

5.3 Specimen 17 Panel Diagonal Hysteresis $1 \ldots \ldots \ldots \ldots$

5.4 Specimen 17 Panel Diagonal Hysteresis $2 \ldots \ldots \ldots \ldots$

5.5 Specimen 17 Panel Horizontal Hysteresis $\ldots \ldots \ldots \ldots \ldots \ldots$

5.6 Specimen 17 Panel Vertical Hysteresis $\ldots \ldots \ldots \ldots \ldots \ldots$

5.7 Comparison of Infilled Frame and Bare Frame $\ldots \ldots \ldots \ldots \ldots$

5.8 Specimen 17 Relative Column/Panel Displacement $\ldots \ldots \ldots \ldots$

5.9 Comparison of Relative and Absolute Displacement $\ldots \ldots \ldots \ldots$

5.10 Infill 17 Banded Crack Pattern Under Push Load $\ldots \ldots \ldots$

5.11 Infill 17 Corner Crushing Failure $\ldots \ldots \ldots \ldots$

5.12 Hysteretic Energy Dissipation $\ldots \ldots \ldots \ldots 1$

5.13 Infilled Frame In-Plane Hysteresis $\ldots \ldots \ldots \ldots \ldots$

5.14 Bare Frame In-Plane Hysteresis $\ldots \ldots \ldots \ldots$

5.15 Comparison of Infill 10a and 21a With Bare Frame . . . . . . . . . . 69

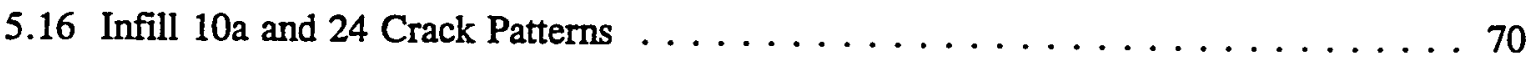


5.17 Infill 2 Partial Strain Time History for Left Column Base

5.18 Nonlinear Compressive Strut Properties $\ldots \ldots \ldots \ldots \ldots \ldots \ldots \ldots$

5.19 Comparison of Nonlinear Strut Analyses with Infilled Frame Test $17 \ldots \ldots 6$

5.20 Equivalent Compressive Strut $\ldots \ldots \ldots \ldots \ldots \ldots \ldots \ldots \ldots \ldots \ldots$

5.21 Infilled Frame 17 Piecewise Linear Strut Analysis $\ldots \ldots \ldots \ldots . \ldots . . .89$

5.22 Henderson et al. (1993) Piecewise Linear Strut Analysis . . . . . . . . . 89

5.23 Henderson et al. (1993) Strut Analysis with Added Stiffness . . . . . . . . . 89

5.24 Infilled Frame Column Moments $\ldots \ldots \ldots \ldots \ldots \ldots \ldots \ldots \ldots$

5.25 Prediction of Infilled Frame 17 Column Moments $\ldots \ldots \ldots \ldots \ldots \ldots$

6.1 Infilled Frame 18 and 25 Crack Patterns on Exterior Face $\ldots \ldots \ldots \ldots 4$

6.2 Specimen 18 Condition After Lateral Loading $\ldots \ldots \ldots \ldots \ldots$

6.3 Specimen 18 Pressure Versus Displacement $\ldots \ldots \ldots \ldots \ldots \ldots \ldots \ldots$

6.4 Specimen 22 Pressure Versus Displacement $\ldots \ldots \ldots \ldots \ldots \ldots \ldots \ldots$

6.5 Specimen 25 Pressure Versus Displacement $\ldots \ldots \ldots \ldots \ldots \ldots \ldots$

6.6 Failure Mechanism of Top and Bottom Course Tiles $\ldots \ldots \ldots \ldots \ldots 7$

6.7 Specimen 18 Displaced Shape at Ultimate Capacity $\ldots \ldots \ldots \ldots \ldots . \ldots . . \ldots 9$

6.8 Specimen 25 Displaced Shape at Ultimate Capacity $\ldots \ldots \ldots \ldots \ldots 10 \ldots$

6.9 Diagram of Lateral Force Transfer to Frame $\ldots \ldots \ldots \ldots \ldots \ldots \ldots \ldots$

6.10 Infilled Frame Strain Values at Peak Capacity . . . . . . . . . . . 102

6.11 Infilled Frame 18 Strain Time History Relationships $\ldots \ldots \ldots \ldots \ldots \ldots$

6.12 Comparison of Lateral Load Tests with Equation $6.1 \ldots \ldots \ldots \ldots \ldots$

6.13 Comparison of Lateral Load Tests With Dawe and Seah (1989b) . . . . . . 107

7.1 Specimen 11 Out-of-Plane Drift Crack Map $\ldots \ldots \ldots \ldots \ldots \ldots \ldots \ldots$

7.2 Specimen 11 Drift Displacements Near Top of Infill $\ldots \ldots \ldots \ldots \ldots \ldots$ 
7.3 Specimen 11 Out-of-Plane Drift Hysteresis

7.4 Specimen 11 Displaced Shape at Peak Out-of-Plane Drift Load . . . . . . . . . 112

7.5 Specimen 13 Out-of-Plane Drift Crack Map . . . . . . . . . . . . . 115

7.6 Specimen 13 Beam Curvature Drift Hysteresis $\ldots \ldots \ldots \ldots \ldots \ldots$

7.7 Specimen 13 Cantilever Curvature Drift Hysteresis $\ldots \ldots \ldots \ldots \ldots \ldots$

7.8 Specimen 13 Displaced Shape at Peak Beam Curvature Drift Load . . . . . . . 116

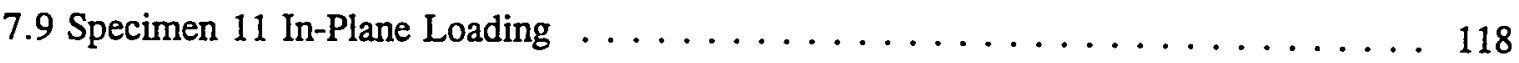

7.10 Specimen 13 In-Plane Loading $\ldots \ldots \ldots \ldots \ldots \ldots \ldots \ldots \ldots \ldots \ldots \ldots \ldots$

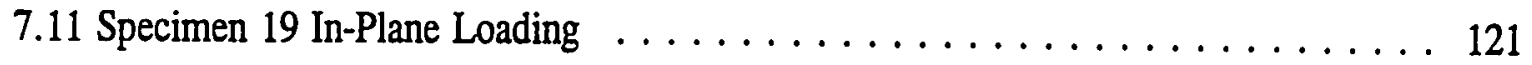

7.12 Specimen 19 Uniform Lateral Loading $\ldots \ldots \ldots \ldots \ldots \ldots \ldots$

7.13 Comparison of Specimens 18 and 19 Midpanel Displacements . . . . . . . . . . 121

7.14 Specimen 19 Displaced Shape Under Lateral Loading . . . . . . . . . . . . . 123

7.15 Specimen 20 Uniform Lateral Loading . . . . . . . . . . . . . . . . . . 124

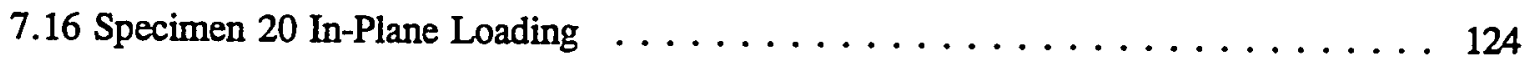

7.17 Specimen 20 Out-of-Plane Midheight Displacements . . . . . . . . . . . 124

7.18 Specimen 20 Displaced Shape at Peak Uniform Lateral Load . . . . . . . . . 125

7.19 Specimen 23 In-Plane Racking Force and Out-of-Plane Uniform Pressure . . . . . 127

7.20 Specimen 23 In-Plane Beam and Out-of-Plane Midpanel Displacements . . . . . 127

7.21 Specimen 23 Crack Map After Loading $2 \ldots \ldots \ldots \ldots \ldots$. . . . . . . . 130

7.22 Specimen 23 Crack Map After Loading $8 \ldots \ldots \ldots \ldots$

7.23 Specimen 23 Out-of-Plane Displaced Shape During Loading $6 \ldots \ldots \ldots$. . . . . 131

7.24 Comparison of Average Strains Near Left Column Base $\ldots \ldots \ldots \ldots$

7.25 Comparison of Left Column Strains Near Midheight (Inside) $\ldots \ldots \ldots$. . . . . 132

7.26 Comparison of Left Column Strains Near Midheight (Outside) . . . . . . . . . 132 
7.27 Specimen 23 After Testing $\ldots \ldots \ldots \ldots \ldots \ldots \ldots \ldots \ldots \ldots \ldots \ldots \ldots \ldots$

7.28 Specimen 23 In-Plane Hysteresis $\ldots \ldots \ldots \ldots \ldots \ldots \ldots$

7.29 Specimen 23 Uniform Lateral Load Hysteresis . . . . . . . . . . . . . . . . . 134

7.30 Specimen 23 Moments Near Right Column Base . . . . . . . . . . . . . 135

7.31 Specimen 23 Moments Near Left Column Base . . . . . . . . . . . . . . . . 135

7.32 Specimen 23 Moments Near Left Column Midheight $\ldots \ldots \ldots \ldots \ldots$ 


\section{CHAPTER 1}

\section{INTRODUCTION}

\subsection{Unreinforced Masonry Infills}

Many buildings throughout the United States are comprised of structural frames infilled with unreinforced brick, clay tile, or concrete masonry. Infill construction has been prevalent since the late $1800 \mathrm{~s}$. It has been estimated, for example, that there are as many as 1500 masonry infill buildings in the Los Angeles area today. Frequently the masonry walls were intended to serve as internal partitions or external cladding and the structures were designed without considering the walls in the overall behavior of the building. In some instances, attempts were made to consider the masonry panels in supporting gravity loads. Rarely were lateral load effects considered in the original design of these infill structures. This omission is due to the absence of building code provisions for lateral loads at the time of construction and the lack of understanding of infilled frame behavior even at present.

Whether placed by design or inadvertent construction, unreinforced masonry infilled frames are a complex structural system. Depending on boundary conditions, panels believed to be non-structural partitions may respond structurally and redistribute lateral shear unexpectedly. Masonry panels built as infills add considerable mass and stiffness to the framing, altering the lateral response of the structure. Tightly constructed infills confine the masonry, adding significant strength to the framing system. Such infills may also provide desirable lateral bracing, controlling the lateral drift.

Recent legislative action and increased public awareness concerning natural disasters have heightened the attention of building officials and engineers concerning unreinforced masonry construction. Two notable examples of public policy which have expanded the emphasis on such 
existing facilities are the reauthorization of the United States National Earthquake Hazards Reduction Program (NEHRP 1990) and the unreinforced masonry retrofit ordinance of the City of Los Angeles (LABC 1985). Regulations such as these have created a flurry of activity in evaluating and retrofitting existing unreinforced masonry structures.

Building codes for new construction (ICBO 1992) do not allow the use of unreinforced masonry in resisting lateral forces in moderate to high seismic areas. National standards for evaluating existing buildings (ATC 1987, ATC 1989a, ATC 1989b, BSSC 1992) rely primarily on experimental testing for development of unreinforced infill capacity. Engineers who are evaluating the safety of unreinforced masonry infill structures subjected to earthquakes or extreme winds face an interesting dilemma. Evaluating framed structures without considering the added lateral stiffness of the infills is inappropriate. Evaluating these structures without considering the added lateral capacity of the infills is overly conservative. Performing in-situ testing of infills sufficient to develop seismic capacity is expensive. Isolating the masonry panels from the framing or removing them and providing other lateral bracing is also quite costly and, in some instances, may not significantly increase the seismic resistance of the building.

Although various techniques are being utilized to evaluate unreinforced infills, there is a lack of consistency in methodology (MMES, 1992; NCEER, 1994). For complicated geometry and loading, there is a lack of understanding of infilled framing behavior. It follows that a rational method of evaluating infill construction is needed. To gain wide acceptance within the engineering community, such a method must accurately model infill behavior and be incorporated in appropriate standards for evaluating and designing infill structures. The method must offer performance criteria for unreinforced masonry infills that correspond with the limit states observed in infill testing. 


\subsection{Historical Use of Structural Clay Tile}

Masonry infill research has focused primarily on brick and concrete masonry materials. Somewhat overlooked is the behavior of clay tile infilled frames. Structural clay tile is a machine extruded clay product that was first produced in the United States in about 1875. While clay tile is an outgrowth of much older clay products, it is distinguished by hollow units having parallel cores and thin webs and faceshells. Structural clay tile was originally used in building floors and as fireproofing for steel frame construction.

Due to its relative light weight, large unit size and ease of construction, the use of structural clay tile expanded to load-bearing walls, wall facings, silos, columns, etc. During the early 1900s, structural clay tile was used as an infill in many buildings throughout the United States. For example, the Oakland, California City Hall Building was constructed of clay tile in 1912 and is now considered a historic structure. Clay tile has been used extensively in other notable structures such as the California Palace of the Legion of Honor and the New York Chrysler Building.

Figure 1.1 shows production data taken from the U.S. Department of Commerce Census of Manufacturers and includes load-bearing wall tile, nonload-bearing wall tile, silo and corncrib tile, but not facing and other clay tile products. Clay tile manufacture peaked in the late 1920s, with as many as 385 establishments producing clay tile products in 38 states. As with other building products, production decreased dramatically with the onset of the depression. After the depression era and as World War II began, large public works projects revitalized the industry. Examples of clay tile facilities for war housing include Fort Benning, Georgia and the Women's Army Auxiliary Corps Barracks in Des Moines, Iowa. Large defense plants such as the Y-12 Plant in Oak Ridge, Tennessee were also constructed primarily of structural clay tile. However, in recent years, clay tile has been used less frequently as the use of concrete masonry has increased. 


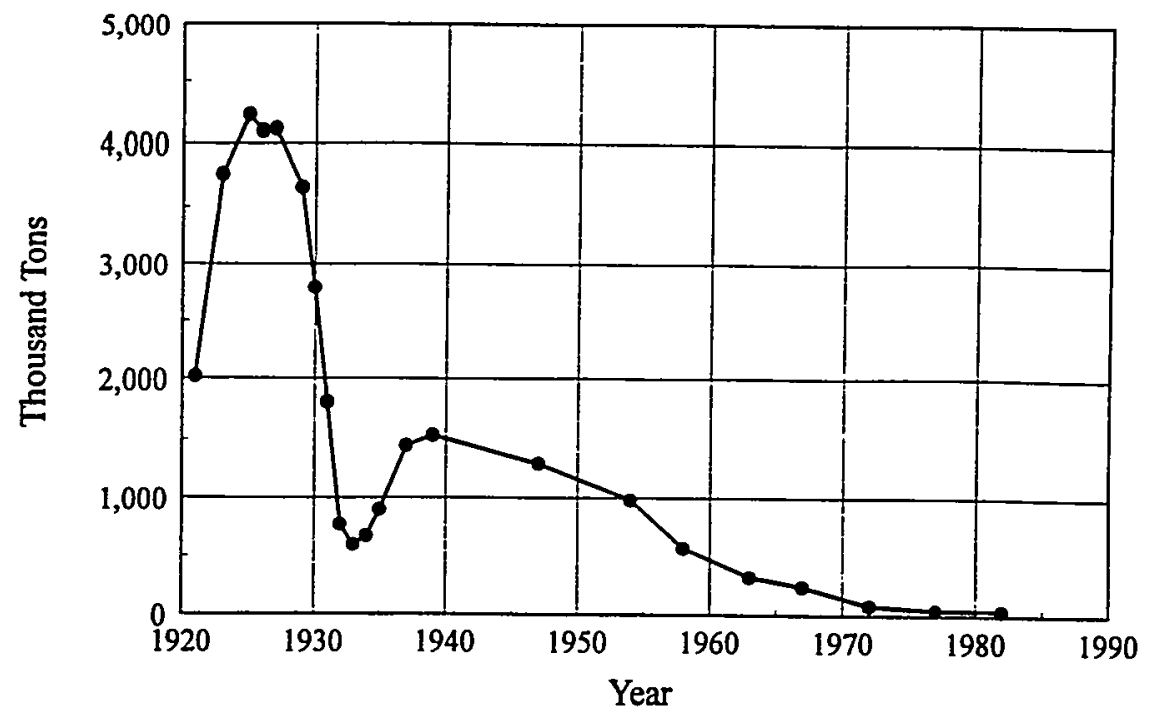

Figure 1.1 Production of Hollow Building Tile

\subsection{Scope of Research}

The purpose of the current research was to investigate the behavior of masonry infills and provide experimental data for validating proposed analytical techniques. The scope of the experimental work was limited to a particular type of construction: steel framing infilled with structural clay tile walls. The testing was designed to investigate many of the varying conditions of geometry and loading that might affect infill behavior. Results of the tests were evaluated with existing numerical methods. Conclusions and recommendations regarding the evaluation of unreinforced clay tile infills are given. The research results provide new insight into the behavior of clay tile infills and have a broader applicability to other forms of masonry infill construction. 


\section{CHAPTER 2}

\section{REVIEW OF THE LITERATURE}

\subsection{In-Plane Behavior of Infilled Frames}

Structural frames infilled with masonry walls have been shown to provide significant in-plane strength and stiffness in resisting lateral loads. Laboratory in-plane tests of clay brick, concrete masonry, and micro-concrete infills have been conducted separately by several researchers. For comparison with current testing, prior research on steel framing is highlighted. For this construction, the rigidity of the masonry infill stiffens the more flexible steel framing. The steel framing confines the more brittle masonry allowing greater ultimate strength and displacement of the infill wall than it would withstand without being enclosed in the steel framing.

Early research on the in-plane behavior of concrete encased steel frames infilled with brick and clinker-block was conducted by Wood $(1958,1978)$. The infill testing was part of a greater study of frame stability and included monotonic racking tests of near full-scale specimens. Several failure modes were reported. A shear or shear rotation mechanism was observed in tests with strong frame members. These failure modes included panel cracking followed by plastic hinges forming at the frame joints, rigid body rotation of unrestrained panel corners, and diagonal tension failure in the panel. Large frame and panel distortions were observed in these tests. For stronger walls, the panel distortions were accompanied by plastic hinges forming along the beam length. For weaker frames (and stronger walls) compression bands in the brickwork were observed as the infill developed significant diagonal cracks. Diagonal compression or corner crushing failures were then observed. It is important to note that the strength and stiffness of 
even the weaker encased frames was quite high as compared with the bare steel framing. Also, the large frame distortions resulting from the composite action indicate a relatively strong infill material.

Polyakov $(1960,1963)$ investigated various parameters affecting the behavior of infilled steel frames. He performed 65 large-scale tests varying masonry units, mortar, method of loading (monotonic or cyclic), and wall openings. In addition to individual panels, he tested a three-story three-bay frame of about one quarter scale. Monotonic load-unload cycles to ultimate capacity were performed with a hydraulic jack at a single upper joint of this test structure. Diagonal cracking occurred first in the corner panel nearest the load input, but similar cracking appeared in the other panels as the loading progressed. Good comparison was made of the deformation characteristics of the 9 panel specimen with a single identical panel used for calibration. Polyakov concluded that the multistory multibay infill system behaved as a group of individually braced frames and not as a single monolith.

Based on infill tests by Wood (1958) and Benjamin and Williams (1958), Holmes (1961) proposed a linear equivalent strut equal to one third of the panel diagonal length for computing ultimate stiffness and strength. Later, Holmes (1963) proposed semi-empirical methods for the capacity of infills based on model tests of concrete filled framing under combined lateral and vertical loading. He concluded that the presence of vertical load increased the diagonal cracking load, but decreased the ultimate crushing load.

Stafford-Smith $(1962,1966,1969)$ investigated the behavior of relatively small mortar filled steel frames subjected to diagonal and racking loads. For these specimens he observed two dominant failure modes; diagonal cracking and corner crushing. Much of this research focused on determining the contact length at the frame/infill boundary and thus approximating an effective equivalent strut width. He proposed relationships for the contact length and equivalent 
compressive strut width based on the relative stiffness of the column and infill, the length and height proportions of the infill, the stress/strain relationship of the infill, and the value of diagonal load acting on the infill. His expression for contact length was developed from classical beam on elastic foundation solutions (Hetenyi, 1946) assuming elastic isotropic properties and was correlated with small tests of steel framing infilled entirely with mortar.

Stafford-Smith (1968) also investigated the effect of combined vertical pressure and racking loads on infills. He concluded that a moderate vertical load increases the panel horizontal stiffness and strength due to a greater contact area resulting in more even distribution of stress in the masonry. The optimum vertical pressure was found to be about one half that of a purely vertical failure load. For combined loading panels with vertical load less than one half the ultimate strength, failure modes were similar to those for horizontal loading only. For combined loading panels with vertical load greater than one half the ultimate strength, the failure modes were similar to those of vertical loading only, i.e., general compression failure sometimes preceded by vertical cracks.

Mainstone $(1970,1971,1974)$ performed a series of experiments similar to those of Stafford-Smith. The infills were model brick or micro-concrete in steel framing. Using StaffordSmith's formulation for $\lambda \mathrm{h}$, Mainstone proposed a set of empirical equations for equivalent strut stiffness. These empirical equations result in a single linear stiffness. Mainstone also concluded that infill capacity might be determined using an appropriate strain limit of the infill diagonal. A strain limit of 0.004 was suggested as a reasonable value for some infills.

Klingner and Bertero (1978) tested a one-third scale subassemblage of an 11 story infilled frame building. This three story prototype consisted of reinforced concrete framing with fully grouted and doubly reinforced concrete masonry infills. Repeated cycles of static load reversal gradually decreased the strength of the infills to that of the bare frames. It was concluded that 
the increase in strength and energy dissipation afforded by the infill exceeded the potentially detrimental effects of increased inertial forces due to the added stiffness of the infill.

Liauw and Kwan (1983) performed a series of small model micro-concrete infill tests. Based on the experimental work, they developed a plastic collapse theory for masonry infills. The plastic collapse load is dependent on the properties of the infill, the aspect ratio, and the relative stiffness of the frame to infill. Three failure modes were identified for non-integral frames: corner crushing with failure in the columns, corner crushing with failure in the beams, and diagonal crushing with failure toward the interior of the panel. Good analytical correlation with test results was found.

Riddington (1984) investigated the influence of initial gaps on infilled frame behavior. He tested a series of approximately half-scale specimens with no gaps, top gaps, and top and side gaps. Significantly lower stiffness and slightly lower ultimate capacities were observed for the frames with initial gaps. Similar to previous research, diagonal cracking and corner crushing failure modes were found. Riddington concluded that initial gaps were largely undesirable and that the practice of providing initial gaps between masonry and concrete frames to offset creep effects should be reconsidered.

Dhanasekar et al. (1985) tested steel framing with grouted brick infills to verify a biaxial masonry constitutive model. The specimens were tested under increasing monotonic racking load. The capacity of infills with stiffer frames were somewhat larger than those with weaker frames. This was attributed to greater contact length along the stiffer frame. After initial failure of the infill, the composite stiffness approached that of a corresponding bare frame, yet it continued to resist a proportion of lateral load by frictional shear on the planes of failure.

Klingner et al. (1987) performed an investigation of the 1985 New Mexico City earthquake. They found that modern medium-rise and high-rise structures with masonry infills 
generally performed better than otherwise similar structures without infills. Masonry infills generally appeared not to have been designed as structural elements. The infills were usually unreinforced and were not connected to the surrounding frames. In some instances, the infills suffered severe damage, however, they appeared in many cases to have prevented building collapse.

Dawe and Seah (1989a) investigated the behavior of concrete masonry infilled steel frames by testing 28 large-scale specimens with monotonic racking loads. Their intention was to study a broad spectrum of characteristics that might effect infill stiffness and strength. Major observations from the testing are as follows: (1) in general, off-diagonal cracking led to reduced capacity, thus, narrow bands of tension cracking along the diagonal are desirable; (2) tightly packed mortar between the infill and column flanges increased initial stiffness but did not affect initial panel cracking load or capacity; (3) Panel-to-column ties increased the initial stiffness but did not affect initial panel cracking load or capacity; (4) reduction of panel-to-frame interface bond with a polyethylene membrane resulted in lower first panel crack load and ultimate capacity; (5) horizontal joint reinforcement reduced random cracking in the panel but did not affect capacity of the infilled frame; (6) reinforcement of the compression diagonal increased the first major cracking load and the ultimate load; (7) bond beams increased the precracking stiffness and increased the initial major panel cracking load to near ultimate; (8) a $20 \mathrm{~mm}$ gap between the panel and top beam significantly reduced the infill stiffness and strength; (9) openings in panels reduced the initial major crack load and ultimate capacity; and (10) vertical reinforcing around openings increased the initial stiffness but not the initial major panel crack load or ultimate capacity.

El-Ouali et al. (1991) performed cyclic static tests of seven half-scale infills. Lime and sand bricks, concrete bricks, and clay bricks were used in the specimens. They observed a 
general decrease in rigidity of the infilled frame with repeated cyclic loading. Cracking was generally stabilized within three cycles of the same imposed displacement.

Schuller et al. (1994) performed in-plane testing of reinforced concrete moment resisting frames infilled with hollow or solid concrete masonry units. Strong and weak frames were tested. Vertical load was applied to the columns and in some instances to the top beam. Static monotonic and cyclic loadings were employed. Preliminary observations were that stronger infills exhibited higher load resistance and better energy dissipation capability. However, the post peak strength of stronger infills dropped more rapidly than weaker infills as the displacement increased. Stronger infills were also recognized to be more likely to cause brittle shear failure in the concrete columns.

Mander et al. $(1993,1994)$ studied the effect of brick infill on steel framing. A threestory three-bay frame subassemblage was tested statically with the center bay infilled in each story. For the cyclic in-plane loading, good energy absorption capabilities were observed for the infill with relative stability between successive hysteretic loops of the same displacement magnitude. Primary diagonal strut action was observed in the infill and secondary struts developed as the loading continued. In-plane strength relationships based solely on the prism compressive strength were provided. Both reinforced and unreinforced ferrocement retrofits were applied to the infills after initial testing. For the unreinforced ferrocement retrofit, only a slight strengthening was achieved but additional energy dissipation was reported. Ferrocement retrofit with diagonal reinforcement strengthened the panels by about $40 \%$ with continued hysteretic energy absorption. Most of the strength increase was due to the tensile capacity of the reinforcement, however, a portion of the increased lateral capacity was attributed to additional confining action of the diagonal strut. 
Infills may have particular benefit in moderate seismic zones. The October 12, 1992 Cairo, Egypt earthquake demonstrated the positive attributes of infilling in a moderate earthquake region (Adham, 1994). Reinforced concrete buildings with unreinforced masonry infills performed well in this earthquake. The infills served to increase the stiffness of flexible frame buildings on soft soils, and provided a redundant load path for both horizontal and vertical loads. Similar behavior was seen in March 13, 1992 Erzincan, Turkey earthquake (Bruneau and Saatcioglu, 1994). The infills controlled the seismic drift, and, in many cases, resisted the seismic forces elastically. Several problems were noted where lack of infills in a lower floor created a soft story, and debris from damaged infills blocked exits.

\subsection{Out-of-Plane Behavior of Infilled Frames}

Experimental testing of concrete masonry infills subjected to out-of-plane panel loadings has been performed by several investigators. Thomas (1953) tested large-scale brick panels bounded by concrete encased steel framing. The infill-to-frame interface consisted of filling the panel perimeter with mortar. Sixteen points of lateral load were used to simulate uniform distribution. Significant capacity after panel cracking was observed. The importance of panel edge restraint and vertical load in developing post-cracking capacity was noted. One infill was tested with both top and side gaps, yielding a much lower capacity.

McDowell et al. (1956) were among the first to define arching action as the mechanism by which masonry exhibits much greater strength than predicted by conventional bending analysis. Their research involved lateral load tests of brick beams constrained axially between rigid supports. One-way arching developed as the beams were loaded at the third points. Failure occurred as the compression zones (ends and center of the span) of the arch crushed. 
Gabrielson and Kaplan (1977) examined arching of unreinforced masonry walls under blast loadings in a shock tunnel. The brick panels cracked in flexure but withstood tremendous additional forces due to arching. After cracking, specimens resisted maximum equivalent accelerations greater than $1 \mathrm{~g}$ as subsequent rebound shock pulses were applied. Some panels exhibited "rigid arching" where the panels were tightly fitted between rigid supports and developed a symmetrical arch which failed by crushing. Other panels exhibited "gapped arching" where the panels were separated from a support by a small gap and developed an unsymmetrical arch which failed by tensile spalling. Gabrielson and Kaplan also cited examples of arching action in several structures surviving the 1967 Caracas and the 1971 San Fernando earthquakes.

Dawe and Seah (1989b) tested nine large-scale concrete masonry infilled steel frames. Monotonic uniform lateral loading was provided with air bags. Significant arching behavior was observed for each specimen, even a dry-stacked mortarless infill. Dawe and Seah proposed a modified fracture line method of calculating the ultimate strength of infill paneis subjected to uniform out-of-plane loading. This procedure incorporated arching effects and the effect of frame stiffness and deformation. Tensionless infill properties and a plastic stress block for masonry in compression at regions of contact along yield lines and at panel boundaries were assumed. Various fracture line patterns were proposed based on the infill boundary conditions.

In a comparison with experimental results, this method proved quite accurate in predicting the ultimate capacity. From a series of analytical parametric studies they concluded that variations in compressive strength of the masonry and confining frame restraint would significantly alter the ultimate capacity of the infill. The effects of modulus of elasticity, face shell thickness, and relative air bag size were found to be less significant.

Abrams et al. (1993) conducted tests of large-scale clay and concrete block infills in concrete frames. These tests focused on the transverse behavior and strength of previously 
damaged infills. Specimens were first subjected to in-plane load reversals and then subjected to monotonic static lateral pressures using an air bag. The effect of varying mortar type and infill height-to-thickness ratio were investigated. It was concluded that the effect of prior in-plane damage can reduce the out-of-plane strength of slender brick panels by as much as one half. Although few data points were obtained to support the conclusion, it was suggested that the transverse strength may be proportional to the inverse of the square of the height-to-thickness ratio.

Mander $(1993,1994)$ tested brick infilled steel frames under out-of-plane dynamic sine sweep motion. Portions of the specimens were tested with and without prior in-plane loading. Significant out-of-plane capacity was observed with some loss of strength due to prior in-plane loading. Virgin panels with height to thickness ratios of 18 withstood out-of-plane response accelerations of approximately $10 \mathrm{~g}$.

Hill (1994) tested three in-situ unreinforced concrete masonry infills and one in-situ unreinforced clay tile infill out-of-plane using point loads distributed with bearing plates. The goal was to generate full-scale test data from these actual building structures. Significant panel thrust forces developed from arching as indicated in the measurable floor displacements.

Most research on out-of-plane loading of masonry infills has centered on uniform panel loads which attempt to emulate wind or inertial effects of the wall (Lawrence, 1979). However, Benedetti and Benzoni (1984) have suggested that out-of-plane inter-story drift may be a more severe loading of walls of typical masonry buildings than inertial loading. During a seismic event, in-plane forces create out-of-plane drift displacements in orthogonal walls. While the contribution to in-plane stiffness by orthogonal walls is typically ignored, the relative top-bottom displacements of the orthogonal walls must be considered. Stability of the orthogonal walls must be maintained as they drift out-of-plane. Considering an earthquake component in the building's 
other principal direction, the in-plane capacity of walls subjected to orthogonal drift displacements must also be determined.

Henderson et al. (1993) tested two full-scale clay tile infills under lateral drift and inplane racking load. The specimens were nominally 24 feet by 28 feet and were composed of double wythe clay tile masonry enclosed in steel framing with pilasters encasing the columns. The results of these tests indicated significant strength and stiffness contribution of the infill to the steel frame system with little degradation of in-plane strength due to prior lateral drift.

\subsection{Structural Clay Tile Materials}

Some information on structural clay tile materials is available in the public literature. The majority of the information found describes testing of tile units and small assemblages (ASTM Committee C-10 Report, 1924; ASTM Committee C-10 Report, 1926; Parsons, 1931; Plummer, 1962; Hathcock and Skillman, 1918). Some testing of larger assemblages and wall sections have been performed (Matthys, 1972; Johnson and Matthys, 1973; Parsons and Watstein, 1937; Stang et al., 1926; SCPI, 1967; SCPI, 1969; Whittemore and Hathcock, 1923; and Whittemore et al., 1938). Little testing of structural framing infilled with clay tile was found. Some historical data on the behavior of infilled framing in natural disasters is also available. A comprehensive review of building performance in the 1906 San Francisco and 1925 Santa Barbara earthquakes indicated reasonable performance of clay tile infills that were properly constructed (CPIC, 1929). 


\section{CHAPTER 3}

\section{EXPERIMENTAL PROGRAM}

To evaluate the behavior of clay tile infills, an experimental program was formulated. The test specimens consisted of clay tile infilled frames of approximately half-scale. The clay tile infill specimens were sized to be large enough to refiect the behavior of the building infilled frames without requiring the use of scaled masonry units. Research by Fattal (1977) has indicated that for concrete masonry units there are no specimen size effects for panels greater than $32^{\prime \prime} \times 32$ " (four courses high, two units wide). The dimensions of the tested clay tile infills varied, but the minimum nominal dimension was 8 feet incorporating at least seven tile units.

Masonry infill structures have been characterized in terms of in-plane and out-of-plane behavior. The in-plane response may be compared to that of shear wall structures in which the lateral loads are transferred in the plane of the walls and into the foundation. Under seismic loading, the out-of-plane response of an infill is comprised of the inertial effects of the mass of the wall (including attachments) and the inter-story drift effects. In this context, inter-story drift is the out-of-plane relative top-bottom displacements of the panel resulting from the in-plane deformations of steel framing, shear walls, or infills orthogonal to the panel.

The objective of the experimental program was to test a broad range of steel frame specimens infilled with clay tile to determine their structural behavior and the sensitivity of the behavior to a variety of geometric and construction parameters. In-plane and out-of-plane loadings were used individually, in sequential load combinations, and in combined loading conditions.

In addition to the large-scale infills, supporting tests of clay tile prisms, unit tiles, and mortar specimens were performed. Prism tests were conducted to determine the ultimate 
compressive strength and basic stress-strain relationship of the masonry. Various unit tile tests were conducted to aid in comparing the current testing with past research. Mortar specimens were tested in compression to provide a quality control measure of the mortar incorporating the materials and the variation in masonry workmanship.

\subsection{In-Plane Racking Tests}

Eleven steel frames infilled with clay tile were tested to failure in the plane of the panels. Two of the infills were tested twice, one repaired and the other retrofitted prior to retesting. All of the infills consisted of solid panels except one which had a 2' by 2' opening in the upper corner. Figure 3.1 shows the in-plane test setup of a typical solid panel. The test specimens consisted of portal frames infilled with clay tile masonry of either single wythe or double wythe construction. Single wythe panels were constructed of nominally $8^{n}$ thick tile units and double wythe panels were constructed of $8^{n}$ and $4^{n}$ tile units creating a nominally $13^{n}$ thick wall.

The panels were built with running bond using ASTM type $\mathrm{N}$ masonry cement. Mix proportions by volume of the masonry cement and natural river sand were approximately 1:2.5. The clay tiles were laid with their cores horizontal (side construction) using approximately $3 / 4$ " full bed joint and only faceshell mortar in the head joints. A full width of mortar was placed between the concrete structural floor and the bottom course of each panel. With the exception of one weak column interface test, each infill was bonded to the column and beam by snugly packing mortar between the steel and the tile. Mortar was not placed between the panel and the flanges of the enclosing columns. No reinforcement was used in the masonry. With the exception of one offset panel test, each infill was constructed with the centerline of the panel and the framing coincident. The panels were cured in the ambient temperature and moisture conditions of the testing laboratory for a minimum of 30 days prior to testing. 


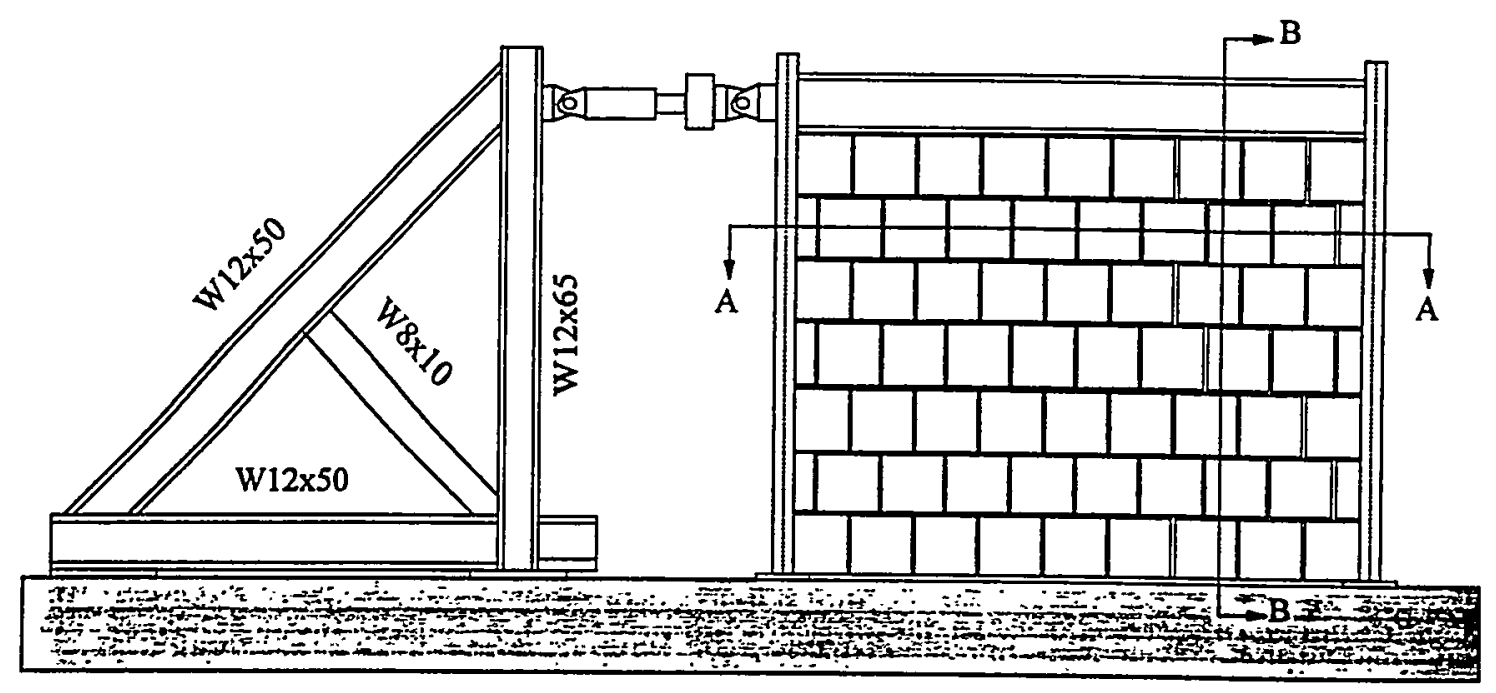

Figure 3.1 In-Plane Test Setup

The specimen frames were constructed of A36 steel with the columns welded continuously to $1^{\prime \prime} \times 2^{\prime}-6^{\prime \prime} \times 2^{\prime}-6$ " baseplates using a $1 / 4^{\prime \prime}$ fillet weld. The baseplates were anchored to the concrete structural floor using 1-1/4" tie rods. Tube sections covering the baseplates and extending to tie down locations beyond the frame were anchored to the floor to provide additional base restraint and uplift capacity. Beam to column connections were framed using double clip angles, resulting in a partially restrained connection. The connection consisted

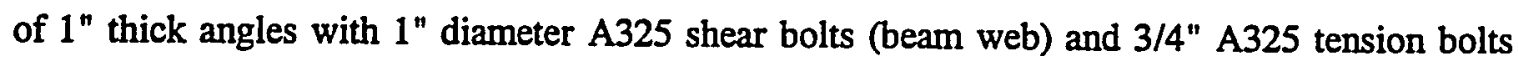
(column flange). The bolt spacing was $3.25^{\mathrm{n}}$ for single wythe specimens and $3.0^{\prime \prime}$ for double wythe specimens. The bolts were installed as slip critical connections using the turn-of-the nut method (RCSC, 1988). The connection was designed to transfer the infills' predicted ultimate load in tension without significant prying action. Details of typical frames infilled with single and double wythe panels are shown in Figures 3.2 and 3.3 respectively. 

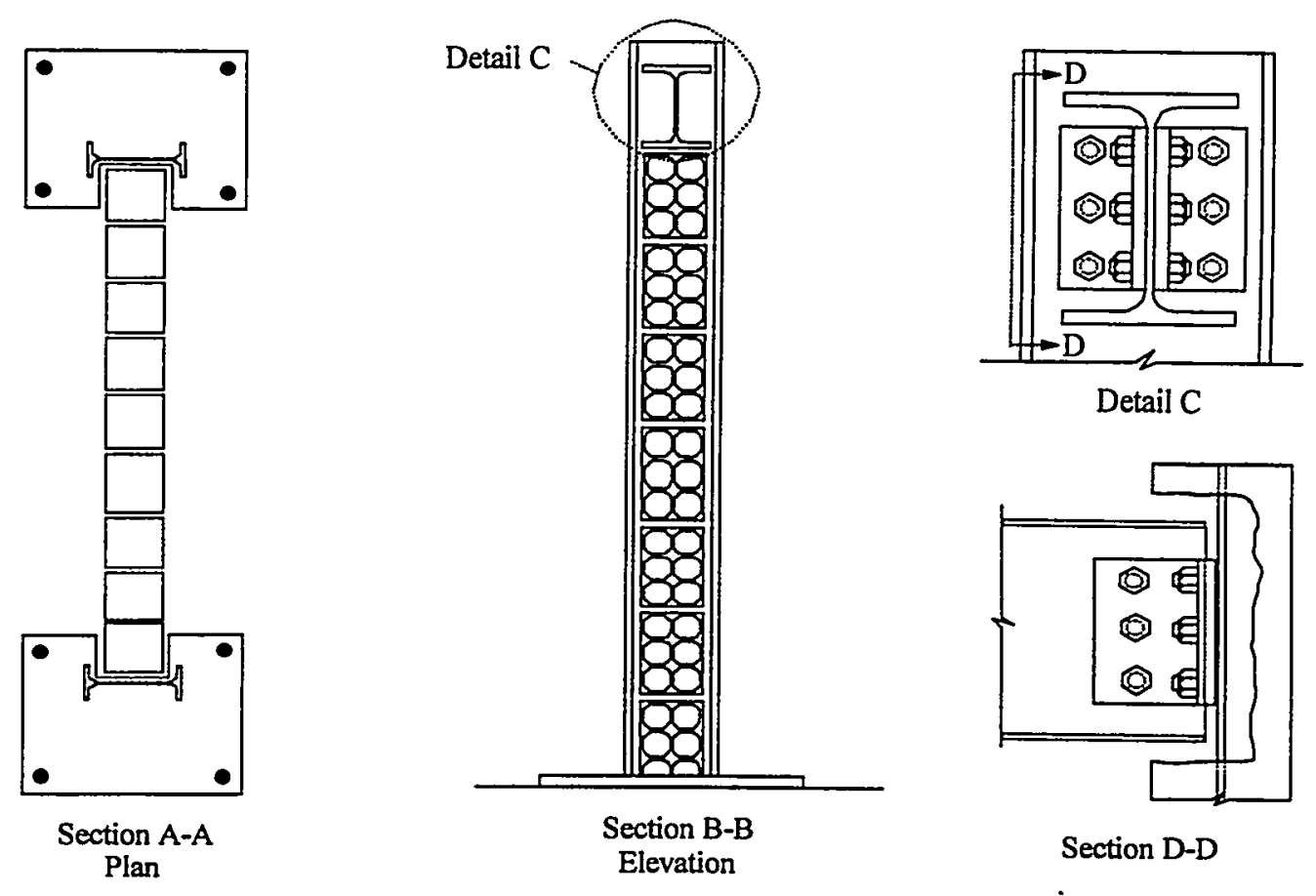

Figure 3.2 Single Wythe Panel Construction Details
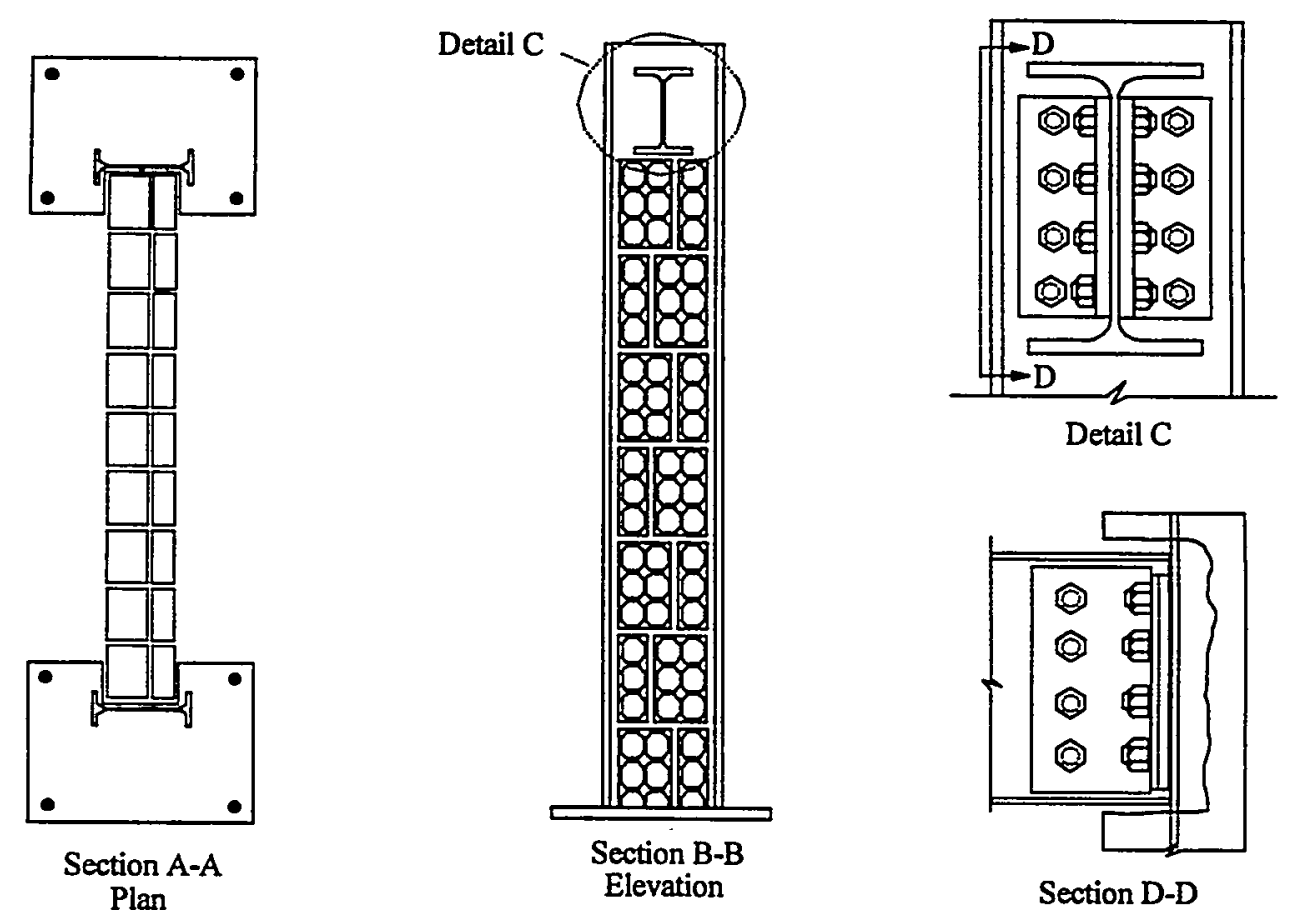

Figure 3.3 Double Wythe Panel Construction Details 
The triangular truss reaction frame was similarly attached to the concrete floor. Orthogonal movement of the specimens was prevented by use of an out-of-plane bracing frame. The bracing frame was attached to the top flange of the specimen beam with a guided connection. Thus, the specimen frame was allowed to move freely in the plane of the wall and was restrained orthogonally. Use of the bracing frame was discontinued after it was evident in several in-plane tests that there was no tendency for out-of-plane movement.

The specimen frame was connected to the reaction frame with a hydraulic actuator, load cell and two clevis attachments. A closed-loop servo-hydraulic system was used to control the actuator. Details of the loading apparatus are supplied in the instrumentation and control diagram of Figure 3.4. The specimens were loaded by imposing cyclic static displacements in the plane of the wall and at the centerline of the beam. The displacements were increased in amplitude to investigate the response throughout the full range of loading. Typically, two or three loading cycles were used for each displacement increment to stabilize the response, Figure 3.5.

The test frames were instrumented with linear variable displacement transducers (LVDTs) and strain gages; see Figures 3.6 through 3.8. Absolute horizontal displacements of both columns were measured near the top, base and midheight of the infill. Relative horizontal displacements between the columns and infill were measured at the same locations. Average axial strains of each side of the columns were obtained at these locations by wiring two strain gages in a quarter bridge configuration. Absolute horizontal displacements were measured at the centerline of the beams. Average axial strains in the beam flanges were measured at two locations near the beam ends and for some specimens at the beam midpoint. Relative vertical displacements between the beam lower flange and the infill were measured near the ends and center of the panel. For some specimens, absolute vertical displacements were also measured at these locations. 


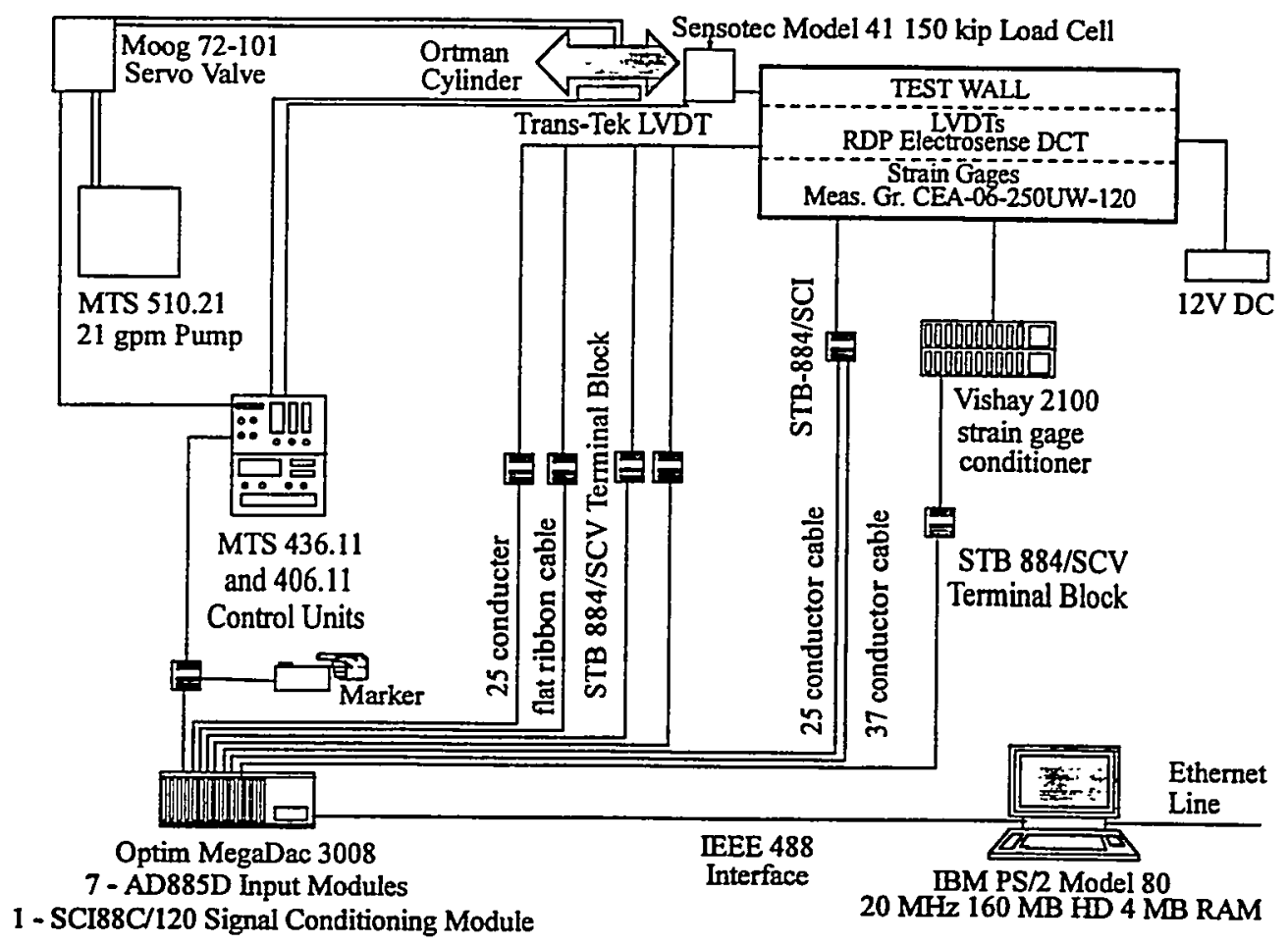

Figure 3.4 In-Plane Test Instrumentation and Control Schematic

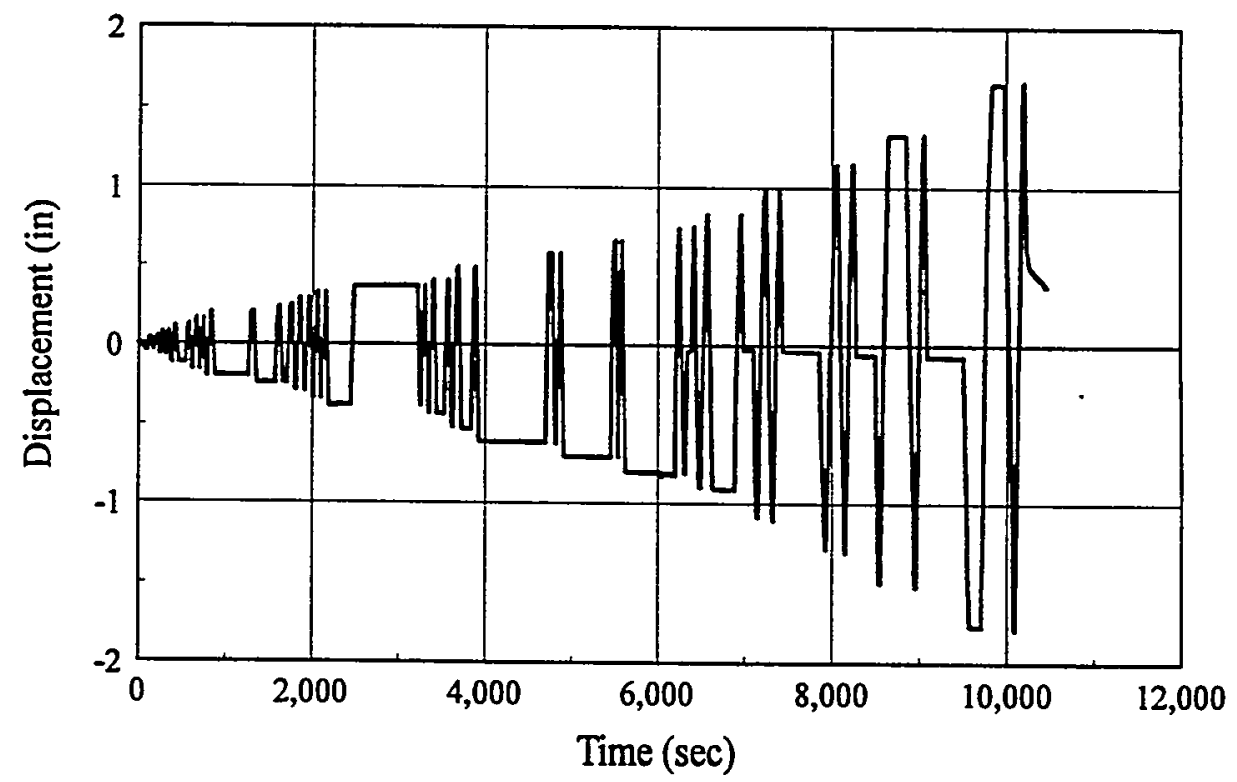

Figure 3.5 Typical In-Plane Displacement Time History 


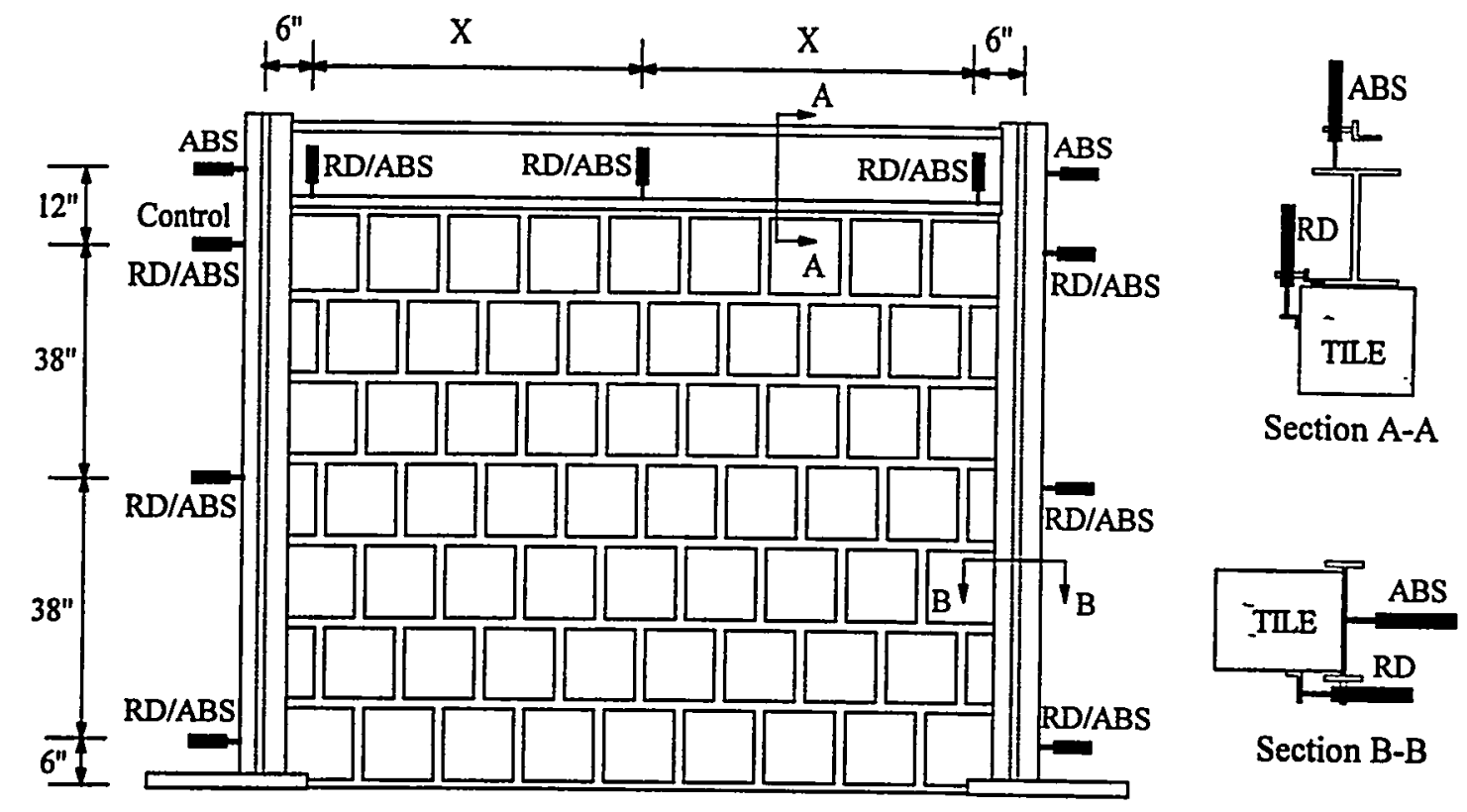

Figure 3.6 Frame Displacement Measurements

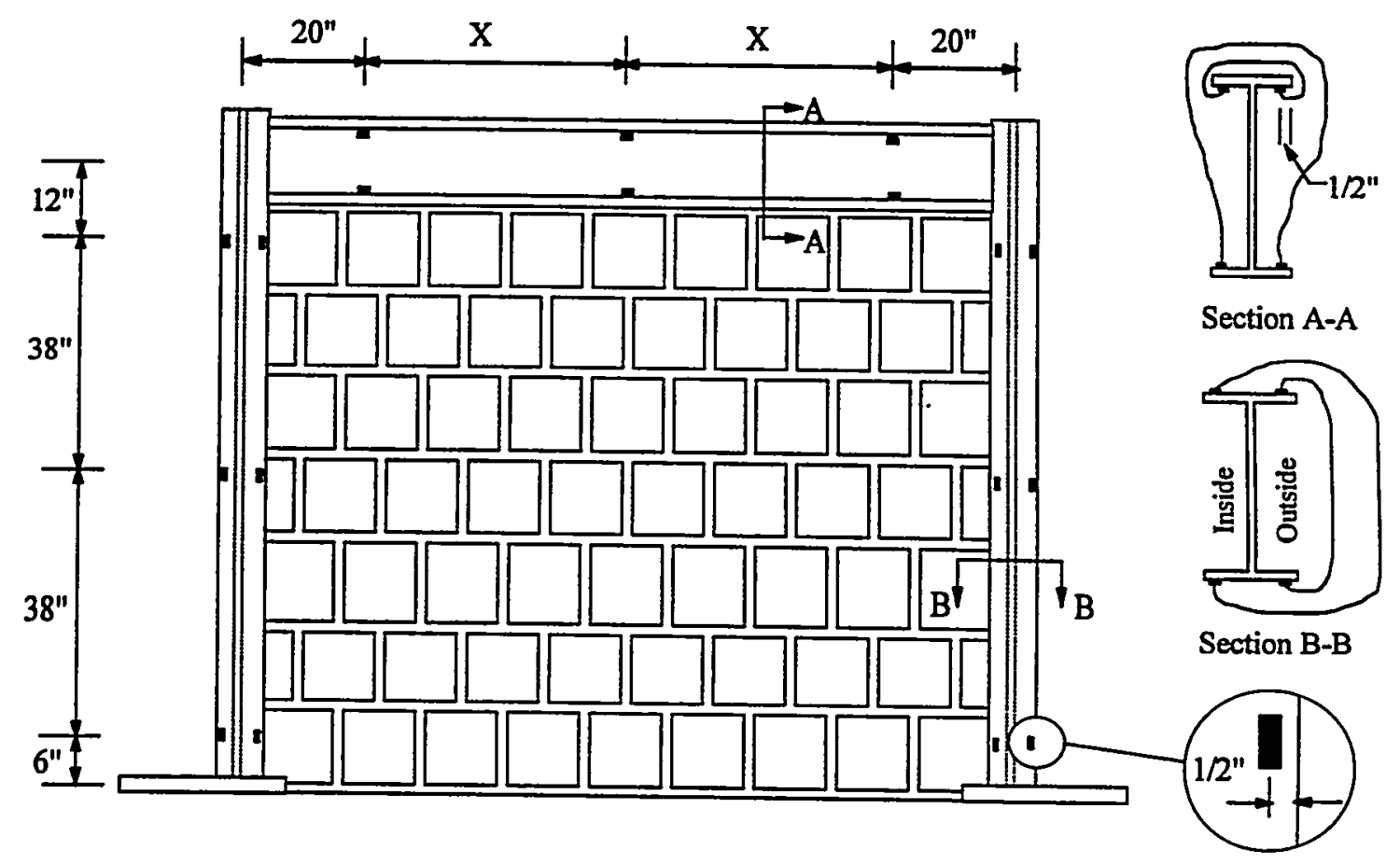

Figure 3.7 Frame Strain Gage Measurements 


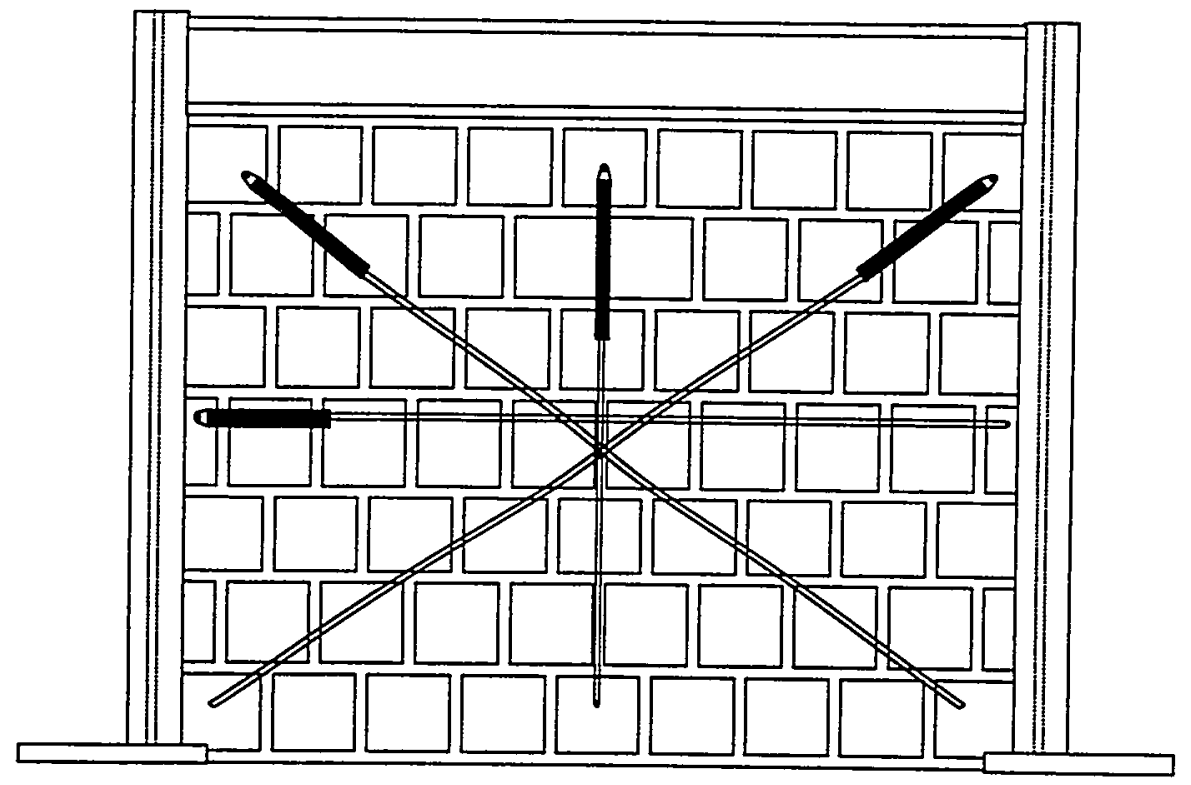

Figure 3.8 Panel Deformation Measurements

Finally, panel deformations were measured along horizontal, vertical, and both diagonals. All data channels were continuously recorded with a multi-channel data acquisition system at a rate of 1 sample per second.

Table 3.1 and Figure 3.9 give summaries of the thirteen in-plane test specimens. Tests specimens 1, 2 and 3 were single wythe 8 " thick infills constructed with the panel placed inside the column flanges and against the column web (weak axis column bending for loads in the plane of the wall). The panels had an approximate aspect ratio of 1.0. The column sizes were varied to determine the effect of different frame stiffness on infill behavior. Specimen 9 was constructed with the panel placed against the column flange (i.e. strong axis column bending for loads in the plane of the wall). This specimen represented an extreme instance of relative panel to frame stiffness as compared to typical construction. 
Table 3.1 Summary of In-Plane Tests

\begin{tabular}{|c|c|c|c|c|c|c|c|}
\hline $\begin{array}{l}\text { Test } \\
\text { No. }\end{array}$ & $\begin{array}{l}\text { Panel } \\
\text { Thick } \\
\text { (in) }\end{array}$ & $\begin{array}{l}\text { Panel } \\
\text { Length } \\
\text { (in) }\end{array}$ & $\begin{array}{l}\text { Panel } \\
\text { Height } \\
\text { (in) } \\
\end{array}$ & $\begin{array}{l}\text { Column } \\
\text { Size }\end{array}$ & $\begin{array}{l}\text { Beam } \\
\text { Size }\end{array}$ & $\lambda \mathrm{h}$ & $\begin{array}{l}\text { Description } \\
\text { (including column } \\
\text { orientation) }\end{array}$ \\
\hline 1 & 7.67 & 88 & 88 & W10x12 & W12 $2 \times 35$ & 9.6 & Single wythe; weak axis \\
\hline 2 & 7.67 & 88 & 88 & $\mathrm{~W} 10 \times 30$ & W12×35 & 5.8 & Single wythe; weak axis \\
\hline 3 & 7.67 & 88 & 88 & $\mathrm{~W} 10 \times 45$ & $\mathrm{~W} 12 \times 35$ & 4.3 & Single wythe; weak axis \\
\hline 4 & 13 & 88 & 88 & W16x26 & W18x76 & 8.3 & Double wythe; weak axis \\
\hline 5 & 13 & 88 & 88 & W16x40 & W18x46 & 6.3 & Double wythe; weak axis \\
\hline 7 & 4.67 & 88 & 88 & W10x30 & W12x35 & 5.1 & $\begin{array}{l}\text { Single wythe; weak axis; } \\
3.5^{n} \text { offset using } 8^{n} \text { tile }\end{array}$ \\
\hline 9 & 7.67 & 88 & 88 & $\mathrm{~W} 10 \times 30$ & W12x35 & 3.2 & Single wythe; strong axis \\
\hline $10 \mathrm{a}$ & 7.67 & 112 & 88 & W10x30 & W12 $\times 35$ & - & $\begin{array}{l}\text { Single wythe; weak axis; } \\
\text { column/panel gap = } 1^{n}\end{array}$ \\
\hline $10 \mathrm{~b}$ & 7.67 & 112 & 88 & W10×30 & W12 235 & - & Panel 10 a retrofit \\
\hline 17 & 7.67 & 136 & 88 & $\mathrm{~W} 10 \times 30$ & W12x35 & 5.7 & Single wythe; weak axis \\
\hline $21 \mathrm{a}$ & 7.67 & 112 & 88 & $\mathrm{~W} 10 \times 30$ & W12×35 & 5.8 & Single wythe; weak axis \\
\hline $21 b$ & 7.67 & 112 & 88 & W10x30 & W12x35 & - & Panel 21a repair \\
\hline 24 & 7.67 & 112 & 88 & W10x30 & W12×35 & - & $\begin{array}{l}\text { Single wythe; weak axis; } \\
\text { corner opening - 2' x 2' }\end{array}$ \\
\hline
\end{tabular}

A parameter, $\lambda h$, developed by Stafford-Smith and Carter (1969), was used to measure the relative panel to frame stiffness. The parameter is given by

$$
\lambda h=h \sqrt[4]{\frac{E_{m} t \sin 2 \theta}{4 E_{s} I_{c o l} h^{\prime}}}
$$

where $E_{m}$ is the elastic modulus of the masonry, $E_{s} I_{c o l}$ is the flexural rigidity of the column, $\theta$ is the slope of the infill diagonal to the horizontal, $t$ is the infill thickness, $h^{\prime}$ is the infill height, and $h$ is the frame height. Values of $\lambda h$ for each of the test specimens are given in Table 3.1. 

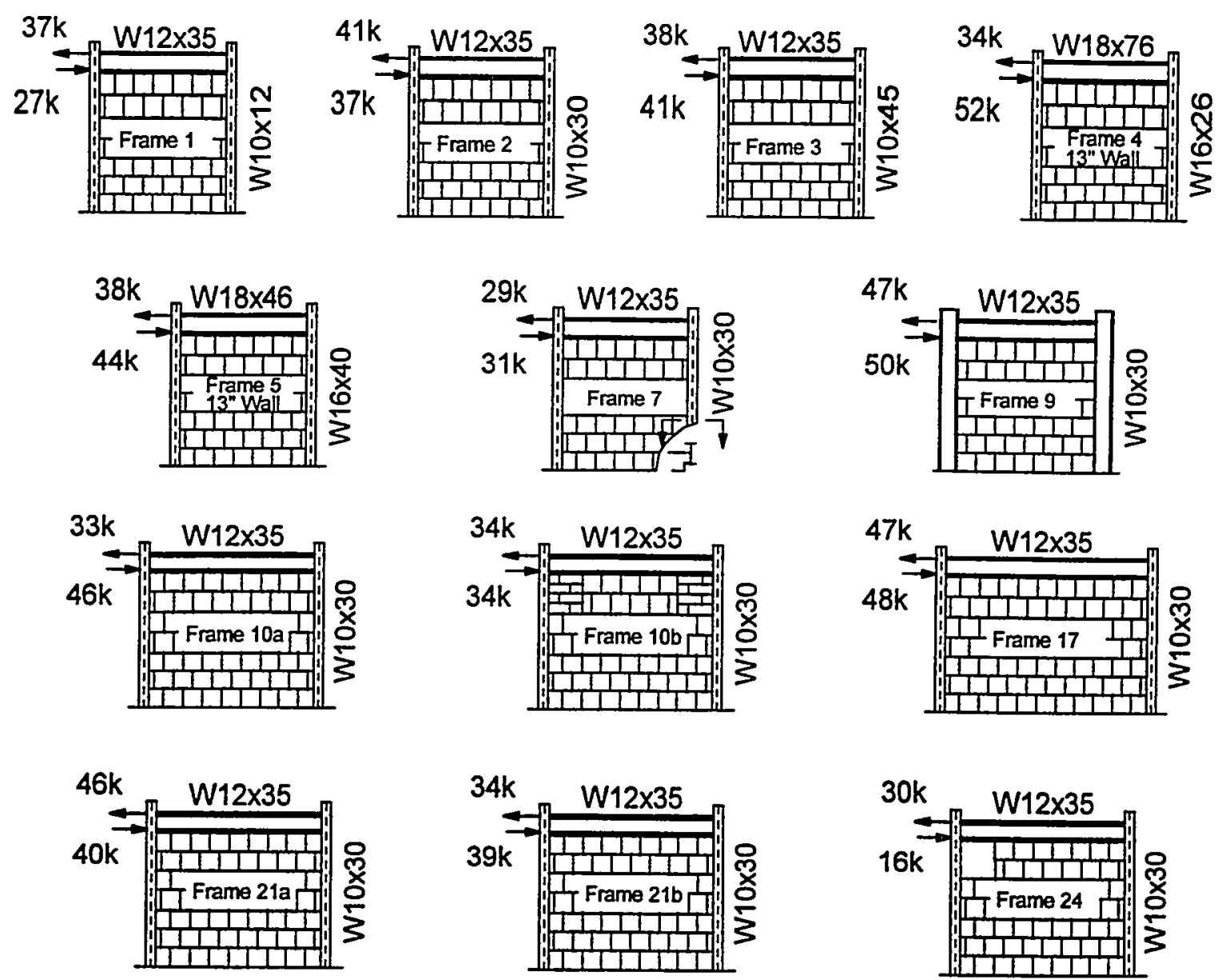

Figure 3.9 Summary of In-Plane Testing Specimens and Ultimate Capacities

Specimens 4 and 5 were designed to investigate the behavior of double wythe panels for two different frame stiffnesses. Both specimens had an aspect ratio of approximately 1.0 and were constructed with the infill placed between the column flanges and against the column web. As shown in Figure 3.3, the 13" thick double wythe panels were constructed of 8" and 4" tile with approximately 1-5/8" gap between them. The 13 " walls had no vertical collar joint except occasional mortar that falls into the cavity. The position of the 8 " and $4 "$ tiles were alternated between courses providing some keying of the masonry units. 


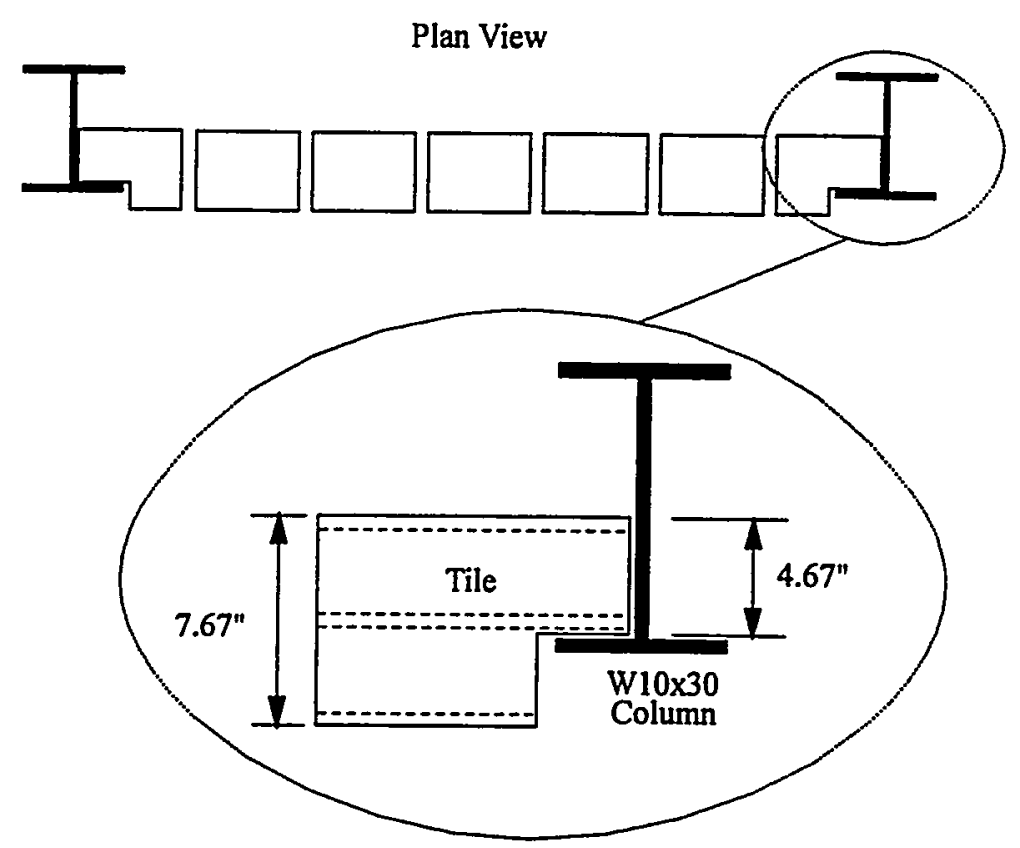

Figure 3.10 Specimen 7 Offset Panel Detail

Specimen 7 was similar to specimen 2 except that the infill was offset approximately $3.5^{\text {" }}$ from the frame centerline. As indicated in Figure 3.10, the tiles adjoining the steel frame were cut such that the infill was bearing only on the column web. This configuration resulted in an effective wall thickness of $4.67^{n}$ confined in the framing.

To account for variations in panel size, specimen 2, 21a, and 17 were constructed similarly, but with different lengths. Although these specimens were the same height, three different panel aspect ratios of approximately 1.0, 1.25, and 1.5 were studied. After in-plane testing to failure, specimen 21a was repaired for retesting and labeled specimen $21 \mathrm{~b}$. The damaged tile of panel 21a were primarily in the upper two courses, particularly the corners. All damaged tile in the upper courses were replaced with undamaged units, see Figure 3.11. Damaged mortar joints in other areas of the panel were tuck pointed. No attempt was made to repair the column/panel boundary with the exception of the top two courses which were replaced. The repaired specimen was then tested in-plane to failure. 


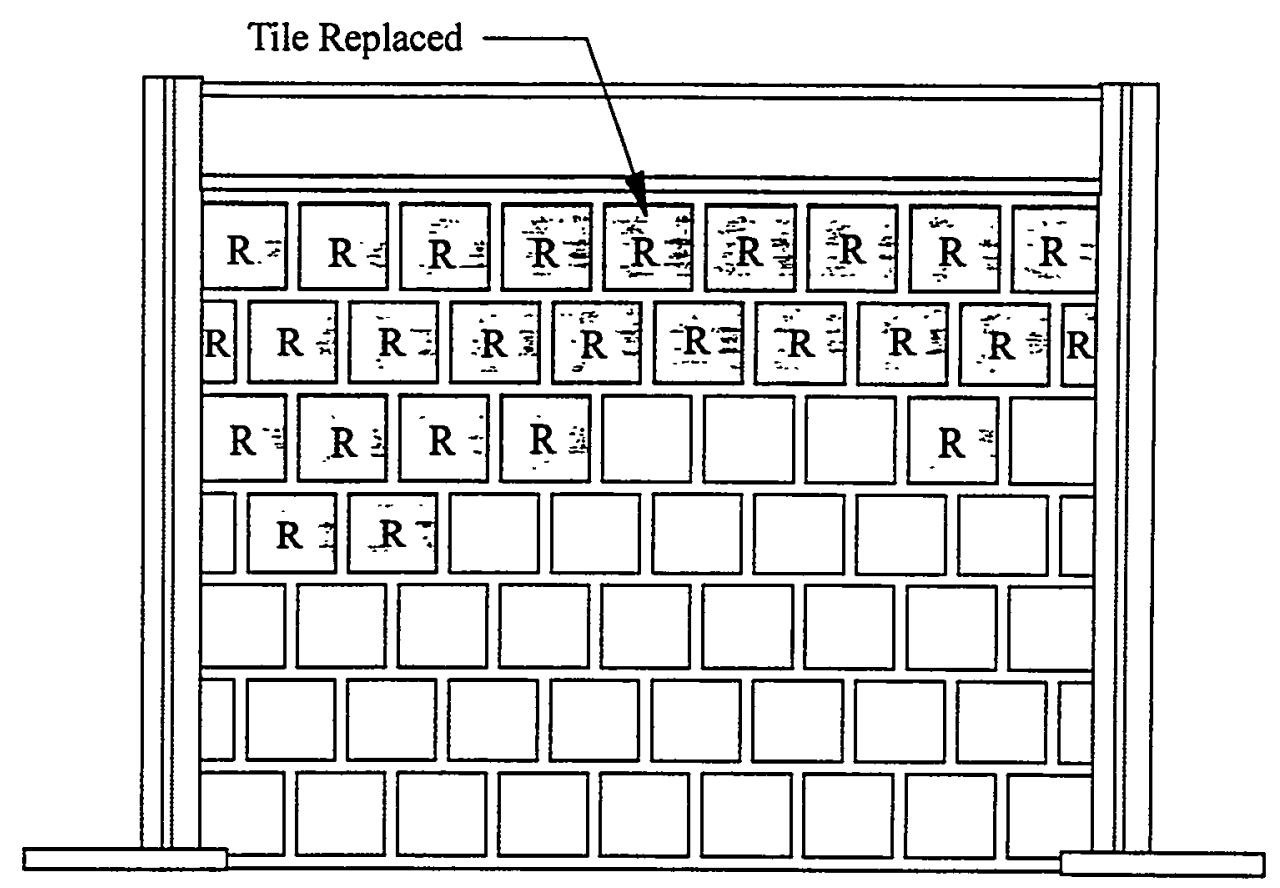

Figure 3.11 Specimen 21b - Upper Course Repair

Because the integrity of hidden column/panel boundaries are often in question, specimen 10a was designed to include a 1 " gap between the column web and the masonry. The specimen was otherwise similar to specimen 21a. After testing in-plane to failure, specimen 10a was retrofitted by replacing the damaged tiles of both upper corners with solid concrete masonry units and type $S$ mortar. Figure 3.12 gives details of the retrofitted panel which was labeled specimen 10b. The retrofitted panel was then tested in-plane to failure.

Several researchers have investigated the effect of panel window and door openings on infill behavior. A common opening in large industrial facilities is at the upper corner of the panel for heating, ventilating and air conditioning or other large utility piping. To investigate this condition, specimen 24 was constructed with a nominal 2' $x$ 2' opening in the upper (loaded) corner, Figure 3.13. The specimen was then loaded cyclically in-plane to failure. 


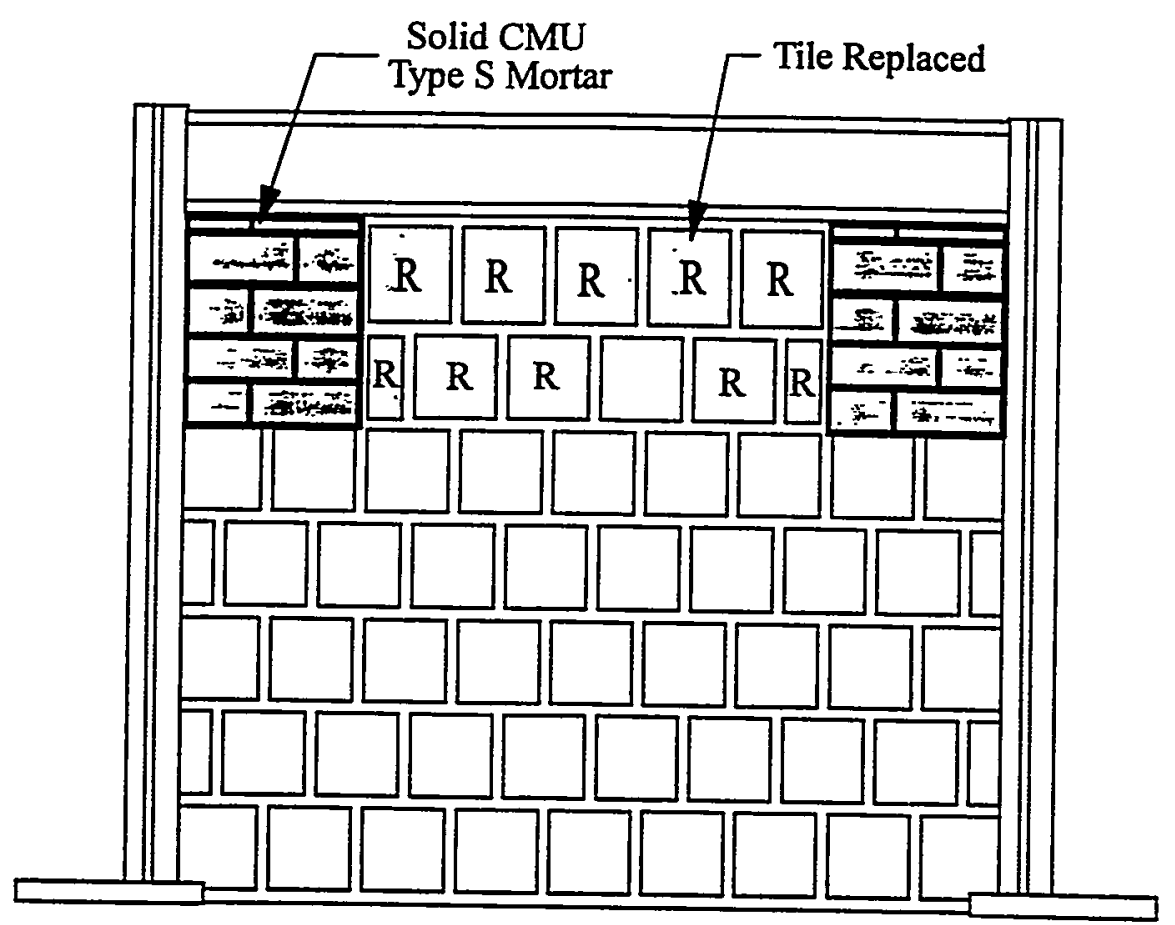

Figure 3.12 Specimen 10b - Upper Corner Retrofit

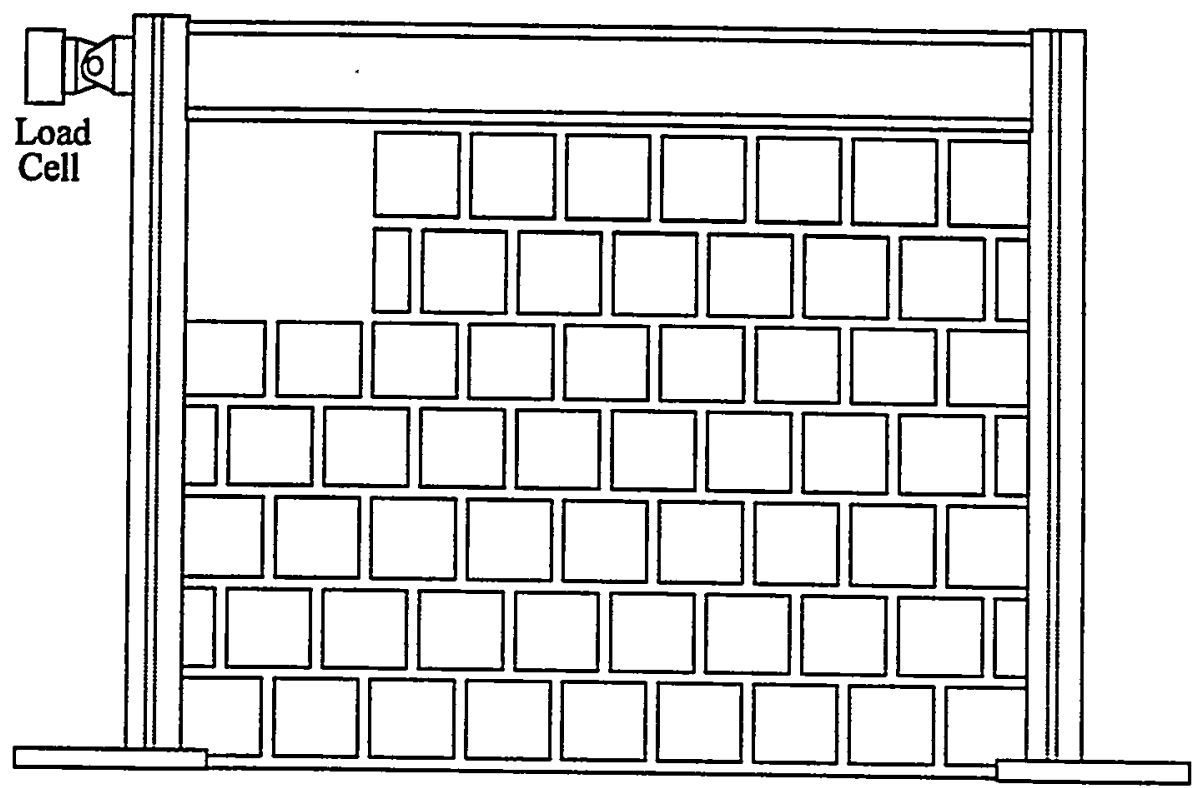

Figure 3.13 Specimen 24 Corner Opening 


\subsection{Uniform Lateral Load Tests}

Three structural clay tile infilled frames were tested out-of-plane to failure using uniform lateral loading. The tests were designed to simulate inertial effects of the infill normal to its plane. Each infill was nominally $8^{\prime}$ by $8^{\prime}$. The details of construction were the same as previously described for the in-plane tests. Each specimen consisted of a different wall thickness. Two single wythe walls, a 4" and an 8", were tested and one 13 " double wythe wall was tested. Table 3.2 and Figure 3.14 summarize the three tests. For each specimen a gap existed between the infill and the flanges of the bounding frame.

The uniform lateral loading was applied using an air bag. The air bag consisted of an inflatable bladder enclosed in canvas. Two nozzles penetrated the air bag; one used as an air inlet/outlet and one used for connecting a pressure transducer. The deflated size of the air bag was approximately $82^{\prime \prime} \times 82^{n}$ and was rated for 7 psi pressure. The air bag covered nearly the entire area of the exposed masonry infill when fully inflated.

Table 3.2 Summary of Uniform Lateral Load Tests

\begin{tabular}{|c|c|c|c|c|c|c|}
\hline $\begin{array}{l}\text { Test } \\
\text { No. }\end{array}$ & $\begin{array}{l}\text { Panel } \\
\text { Thick } \\
\text { (in) }\end{array}$ & $\begin{array}{l}\text { Panel } \\
\text { Length } \\
\text { (in) }\end{array}$ & $\begin{array}{l}\text { Panel } \\
\text { Height } \\
\text { (in) }\end{array}$ & $\begin{array}{l}\text { Column } \\
\text { Size }\end{array}$ & $\begin{array}{l}\text { Beam } \\
\text { Size }\end{array}$ & $\begin{array}{l}\text { Description } \\
\text { (including column } \\
\text { orientation) }\end{array}$ \\
\hline 18 & 7.67 & 88 & 88 & W10 1030 & W12x35 & Single wythe; weak axis \\
\hline 22 & 13 & 88 & 88 & W16x40 & W18x76 & Double wythe; weak axis \\
\hline 25 & 3.66 & 88 & 88 & W10x30 & W12x35 & Single wythe; weak axis \\
\hline
\end{tabular}

A self-equilibrating reaction frame was used to support the uniform lateral pressure as it was applied to the infill. Figure 3.15 shows details of the air bag test setup. Two reaction columns were anchored to the structural floor at their base and to the specimen framing near the 

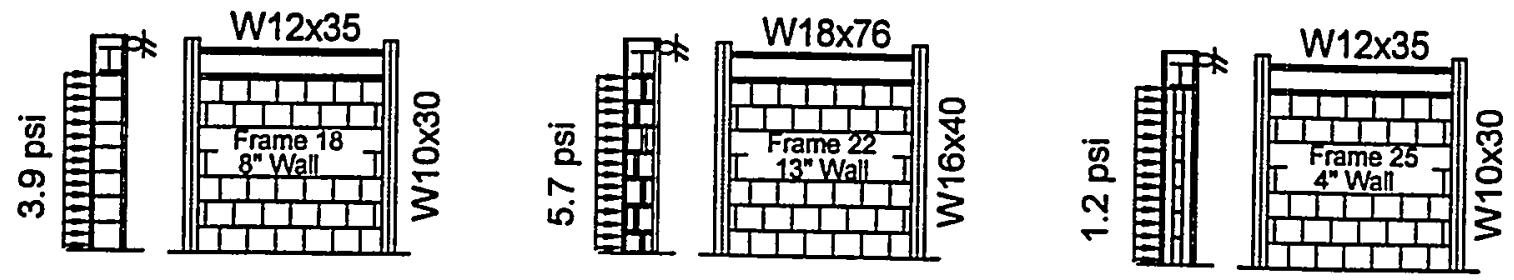

Figure 3.14 Summary of Uniform Lateral Load Testing Specimens and Ultimate Capacities

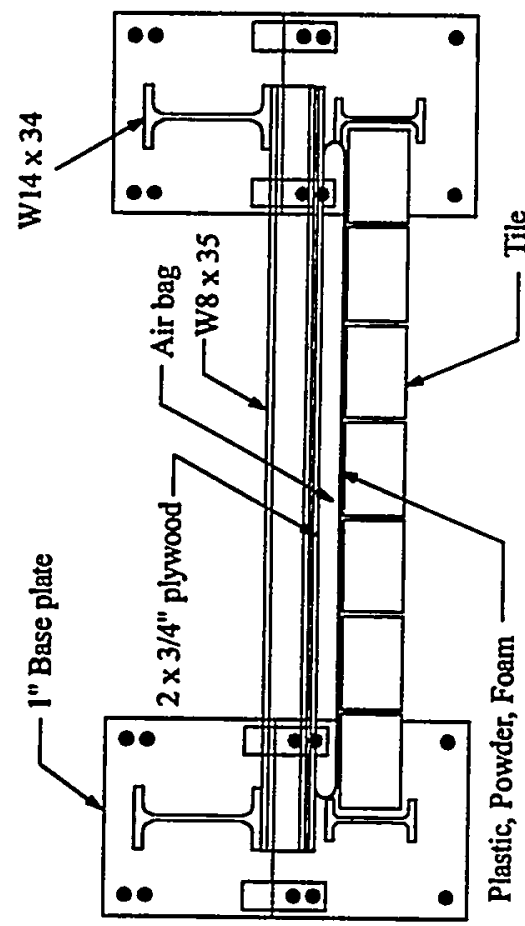

Plan

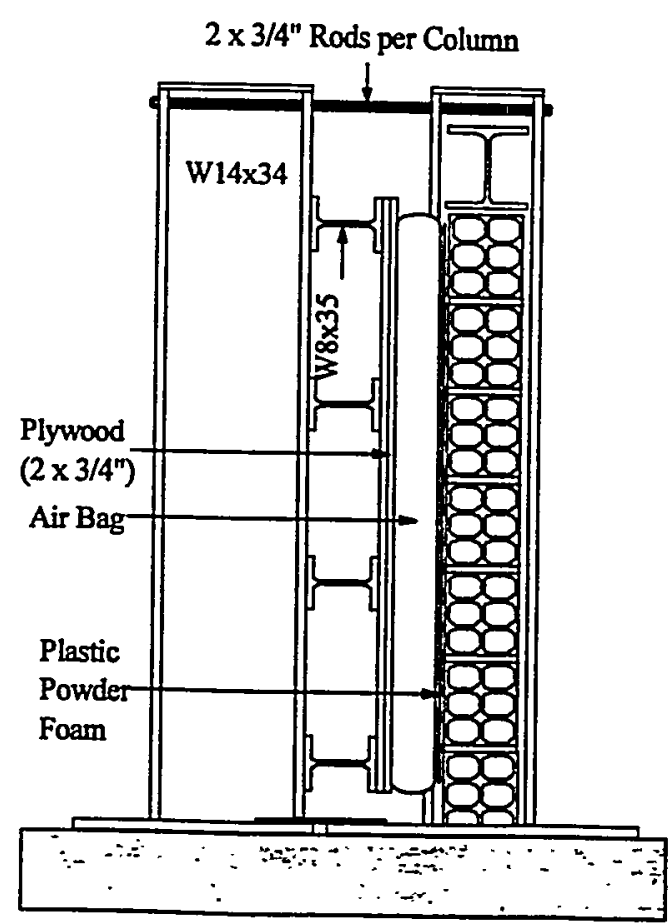

Elevation

Figure 3.15 Uniform Lateral Load Test Setup

column top. A plywood surface supported by small wide flange sections was attached to the reaction columns. The air bag was hung from the lab ceiling using grommets around its perimeter. The plywood surface attached to the reaction frame provided a smooth uniform surface for the air bag to rest upon. On the specimen side of the air bag, two layers of heavy 
plastic ( $3 \mathrm{mil})$ with talcum powder between them were placed between the air bag and the masonry panel. Additionally a $1 / 2$ " foam sheet was placed between the infill and the plastic to prevent puncturing of the plastic or air bag from rough tile surfaces.

Lab air at 100 psi was stepped down to 10 psi with a regulator which fed into an open/close valve. The open/close valve fed into a tee which either entered the air bag or connected to a release valve. As seen in the instrumentation and control schematic of Figure 3.16 , pressure gages were located at both the regulator and the open/close valve allowing air pressure to be supplied and drained from the bag in a controlled fashion.

Static load-unload cycles were applied to the specimens until ultimate pressures were determined and overall panel stability deteriorated. Figure 3.17 shows a typical pressure loading history for the uniform lateral load tests.

The test specimens were instrumented with LVDTs and strain gages; see Figures 3.18 and 3.19. Absolute panel and framing displacements normal to the infill were measured at various locations using a reference frame attached to the structural floor. Measurements were taken at locations along the panel edge and nearby on the framing to record panel slip. Absolute displacements in the plane of the framing were measured near the center of the beam and the center of both columns. Strain gages were mounted near the center of each column to determine the magnitude of thrust forces in the plane of the panel. Two locations along the beam length were selected to mount strain gages. Near one end of the beam strain gages were used to determine upward thrusts (beam strong axis bending) and on the other end of the beam strain gages were used to determine outward thrusts (beam weak axis bending). All data channels were recorded with a multi-channel data acquisition system at a rate of 1 sample per second. 


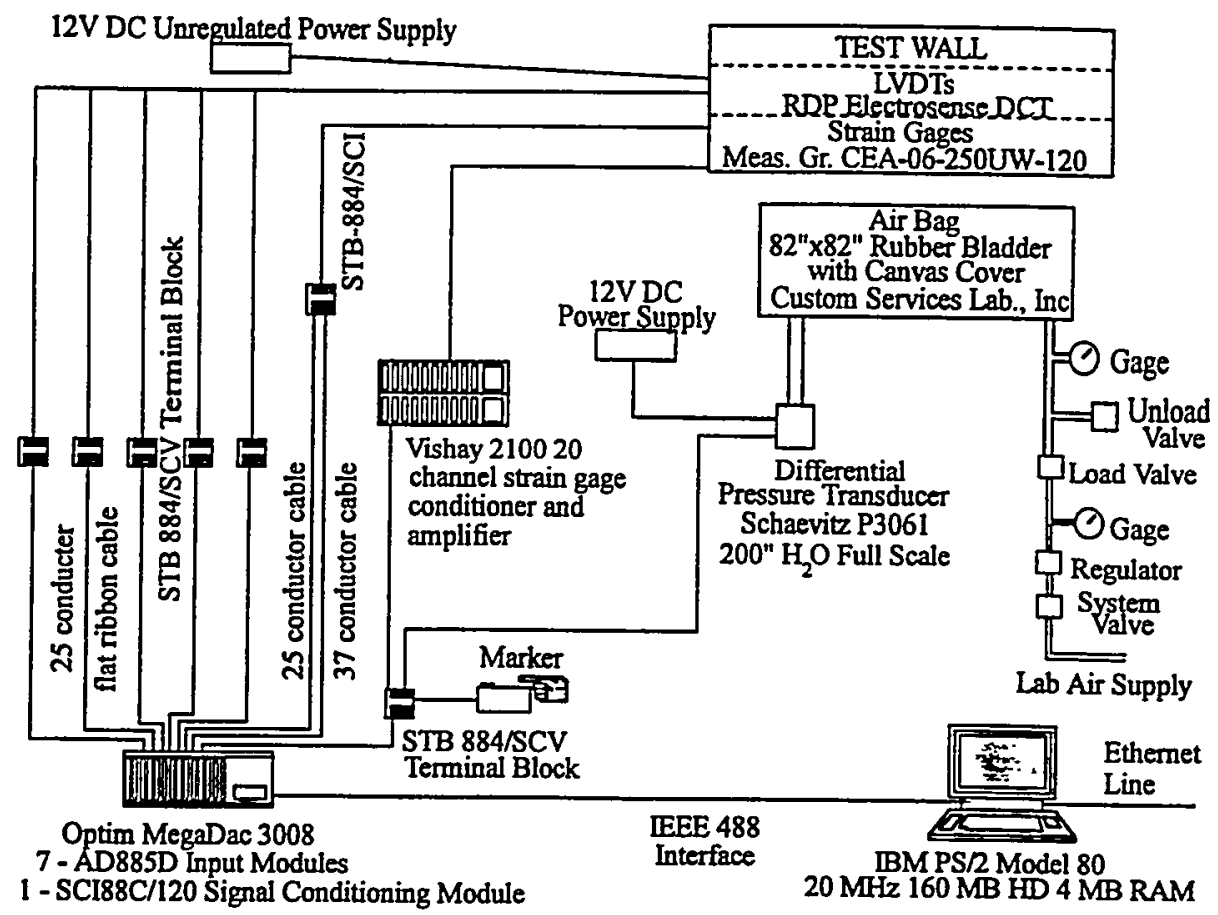

Figure 3.16 Air Bag Test Instrumentation and Control Schematic

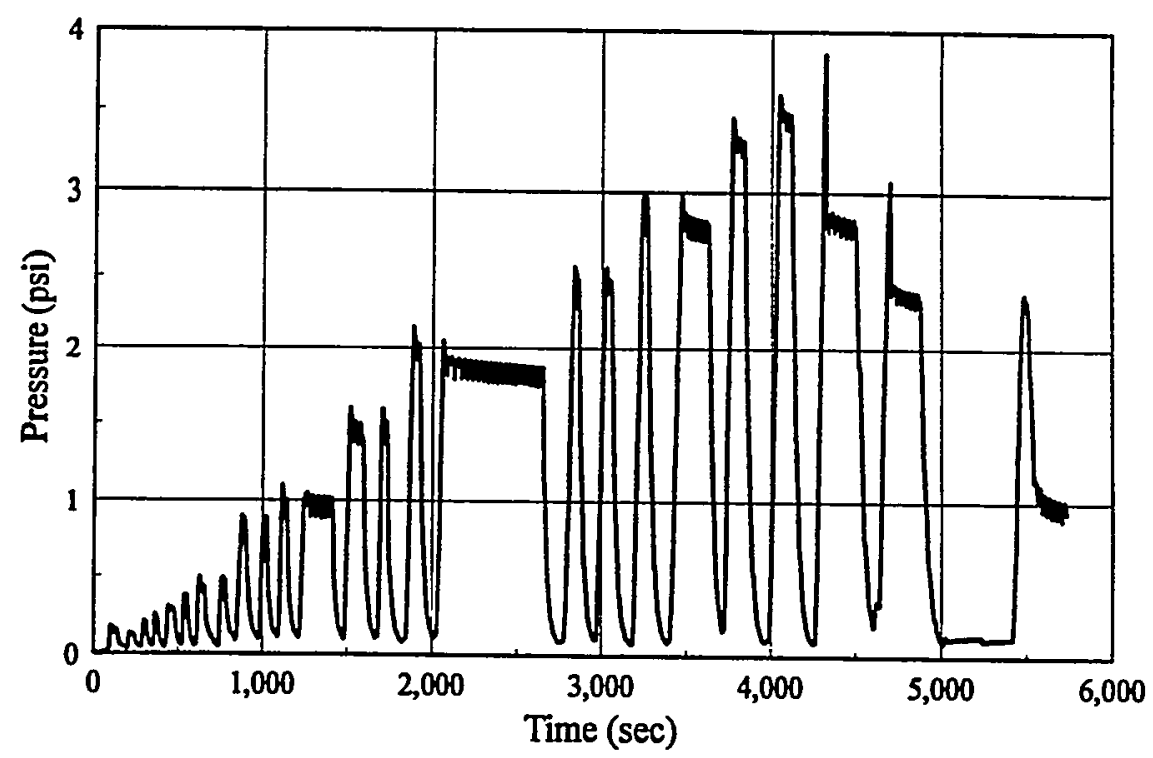

Figure 3.17 Typical Air Bag Pressure Time History 


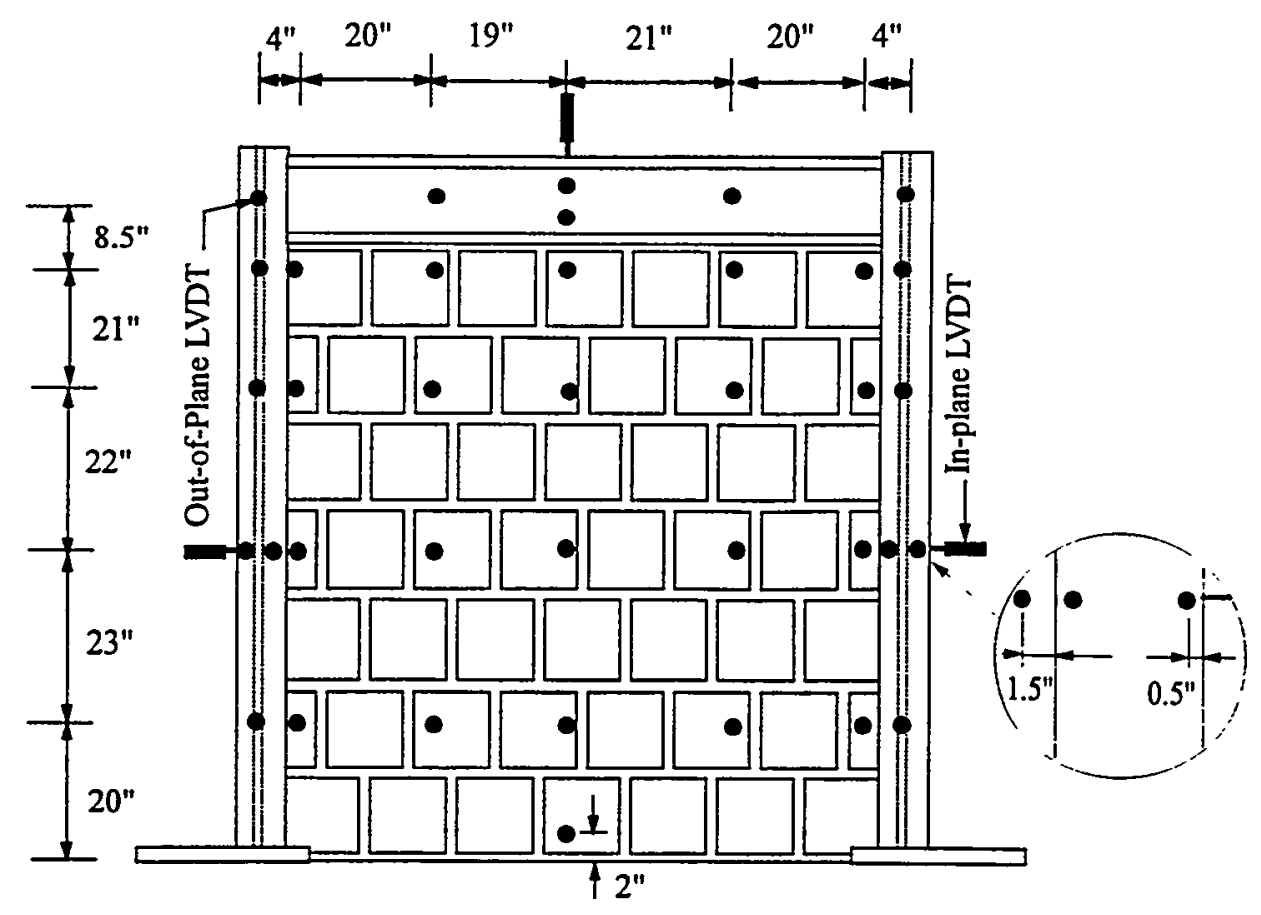

Figure 3.18 Air Bag Test Displacement Measurements
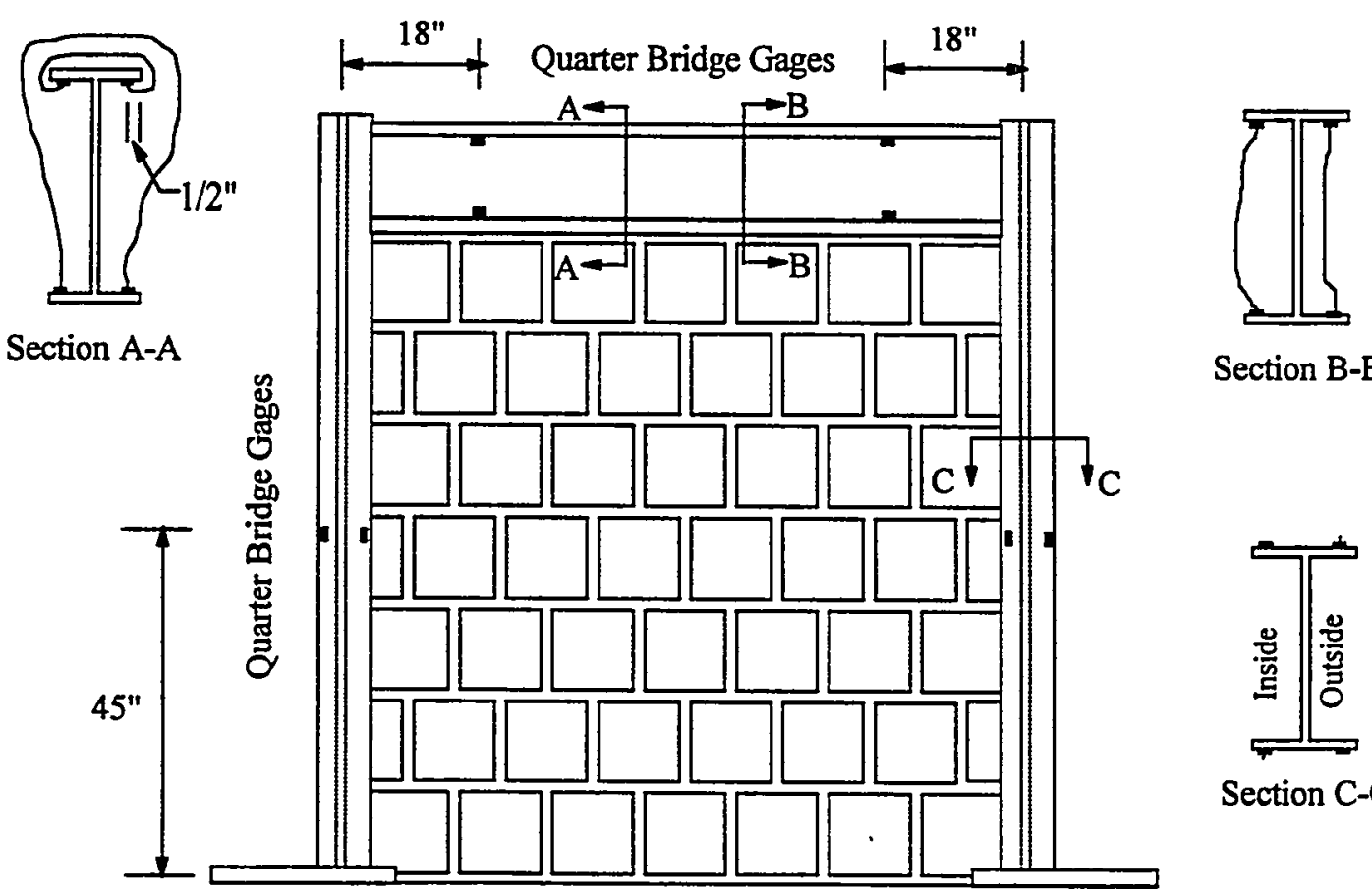

Section B-B

Figure 3.19 Air Bag Test Strain Gage Locations 


\subsection{Bi-Directional Tests}

Both sequential and combined loading bi-directional tests were performed, Figure 3.20 and Table 3.3. In the sequential tests, load cycles were applied in one direction up to a predetermined limit and the specimen was unloaded. Subsequent tests were then performed as load was applied in another direction. For the combined loading tests, load was applied to the infill in orthogonal directions simultaneously.

\subsubsection{Sequential Load Test - Lateral Drift Followed by In-Plane Racking}

Three types of sequential loading tests were performed. The first type investigated the effect of out-of-plane inter-story drift on the in-plane capacity of clay tile infills. Two specimens, number 11 and 13, were first subjected to cyclic out-of-plane displacements followed by in-plane loading until failure. Both specimens were similar in construction to specimen 2 which was used as a control specimen.

The out-of-plane drift loading was performed using a hydraulic actuator. The control schematic would be similar to that of the in-plane loadings with the instrumentation similar to the out-of-plane loadings. The drift loading consisted of gradually increasing cyclic displacements. Two deformed shapes representative of orthogonal drift were selected to define the out-of-plane loading. A cantilever curvature (fixed base and free top) with loading near the top and a simple beam curvature (fixed base and restrained top) with loading near midheight were used to produce severe drifts, Figure 3.21. Specimen 11 was tested using the cantilever drift loading. Specimen 13 was first tested using the beam drift loading. Next, the upper restraint was removed and the specimen was loaded out-of-plane as a cantilever with the actuator at midheight.

Low amplitude vibration tests were performed on both specimens before and after the outof-plane drift loads. Impact points were alternated on the specimen to check reciprocity and output readings were taken at several locations on the infill and bounding frame. After 
Table 3.3 Summary of Bi-Directional Tests

\begin{tabular}{|c|c|c|c|c|c|c|}
\hline $\begin{array}{l}\text { Test } \\
\text { No. }\end{array}$ & $\begin{array}{c}\text { Panel } \\
\text { Thick } \\
\text { (in) }\end{array}$ & $\begin{array}{l}\text { Panel } \\
\text { Length } \\
\text { (in) }\end{array}$ & $\begin{array}{l}\text { Panel } \\
\text { Height } \\
\text { (in) } \\
\end{array}$ & $\begin{array}{l}\text { Column } \\
\text { Size }\end{array}$ & $\begin{array}{l}\text { Beam } \\
\text { Size }\end{array}$ & $\begin{array}{l}\text { Description } \\
\text { (including column } \\
\text { orientation) }\end{array}$ \\
\hline 11 & 7.67 & 88 & 88 & $\mathrm{~W} 10 \times 30$ & W12x35 & $\begin{array}{l}\text { Single wythe; weak axis; } \\
\text { Drift then Racking }\end{array}$ \\
\hline 13 & 7.67 & 88 & 88 & W10x30 & W12x35 & $\begin{array}{l}\text { Single wythe; weak axis; } \\
\text { Drift then Racking }\end{array}$ \\
\hline 19 & 7.67 & 88 & 88 & W10x30 & $\mathrm{W} 12 \times 35$ & $\begin{array}{l}\text { Single wythe; weak axis; } \\
\text { Racking then Air Bag }\end{array}$ \\
\hline 20 & 7.67 & 88 & 88 & W10x30 & W12x35 & $\begin{array}{l}\text { Single wythe; weak axis; } \\
\text { Air Bag then Racking }\end{array}$ \\
\hline 23 & 7.67 & 88 & 88 & $\mathrm{~W} 10 \times 30$ & W12x35 & $\begin{array}{l}\text { Single wythe; weak axis; } \\
\text { Air Bag and Racking }\end{array}$ \\
\hline
\end{tabular}

Out-of-Plane

Followed by In-Plane
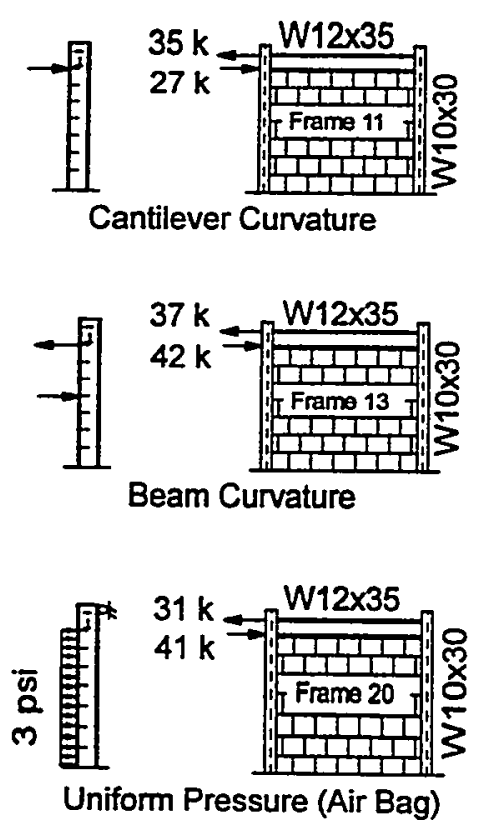

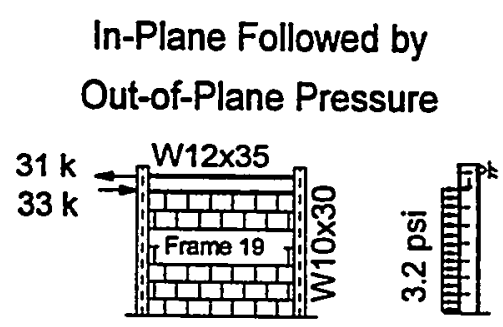

Out-of-Plane and In-Plane Combined

$20 \mathrm{k}$

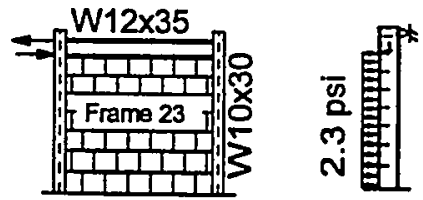

Figure 3.20 Bi-Directional Testing Specimen Summary and Ultimate Capacities 


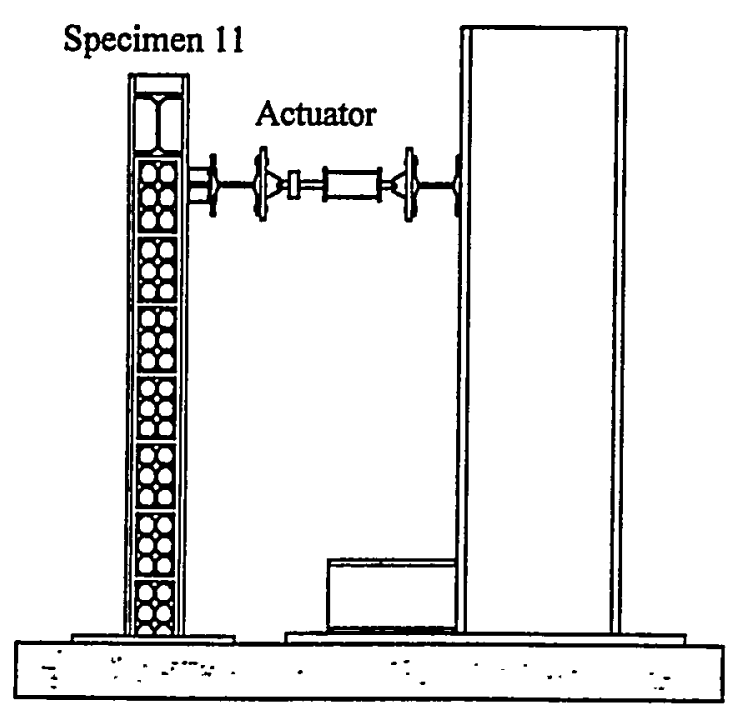

Cantilever Curvature

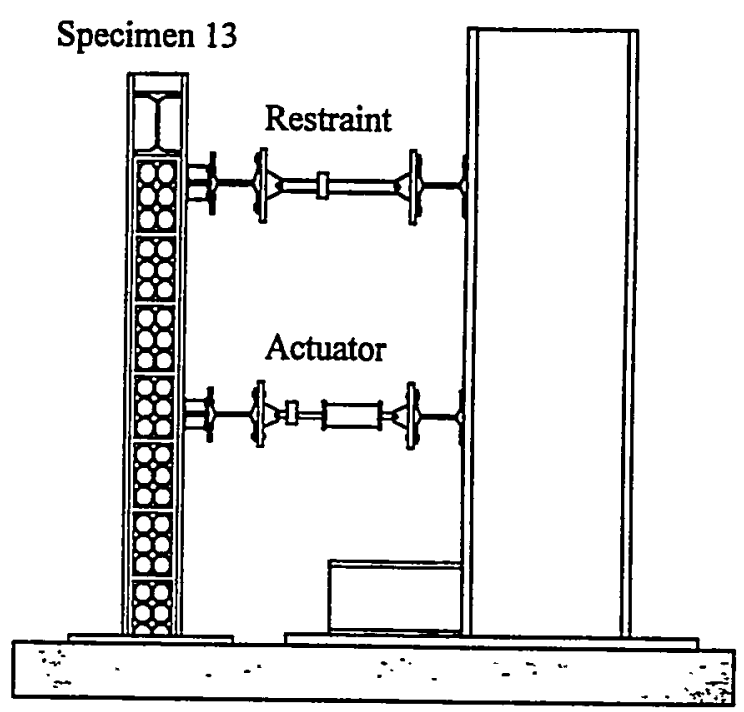

Beam Curvature

Figure 3.21 Out-of-Plane Drift Test Setup

completion of the drift loading, each specimen was loaded in-plane until failure in a similar fashion as specimen 2 .

\subsubsection{Sequential Load Test - In-Plane Racking Followed by Uniform Lateral Load}

The second type of sequential load test investigated the effect of in-plane racking on the uniform lateral capacity of clay tile infills. Specimen 19 was first subjected to in-plane racking loads and then loaded with uniform lateral pressure until failure. The specimen was similar in construction to specimens 2 and 18 which were used as control specimens. As in the other inplane tests, the loading consisted of incremental increasing cyclic displacements applied at the beam centerline. The in-plane loading was terminated at approximately $75 \%$ of ultimate capacity. The test instrumentation was similar to specimen 2 .

The uniform out-of-plane loading was applied with an air bag in a similar manner as specimen 18. The test instrumentation was also similar to that of specimen 18 . 


\subsubsection{Sequential Load Test - Uniform Lateral Load Followed by In-Plane Racking}

The third type of sequential load test investigated the effect of uniform lateral loading on the in-plane behavior of clay tile infills. Specimen 20 was first subjected to uniform lateral pressures and then loaded with in-plane racking loads until failure. The specimen was similar in construction to specimens 2 and 18 which were used as control specimens. The uniform lateral pressure and test instrumentation and controls were similar to that of specimen 18. The in-plane racking loads and test instrumentation and controls were similar to that of specimen 2 . The uniform out-of-plane loading was terminated at approximately $75 \%$ of the ultimate panel capacity.

\subsubsection{Combined Load Test - In-Plane Racking and Uniform Lateral Load}

Specimen 23 was subjected to uniform lateral pressures and in-plane racking loads simultaneously. The specimen was similar in construction to specimens 2 and 18 which were used as control specimens. The loading, test instrumentation, and controls were similar to those of specimens 2 and 18 except that fewer channels for in-plane relative displacement and out-ofplane absolute displacement were used for the combined test. The combined loading was accomplished by applying out-of-plane pressures as an in-plane displacement was held. Several pressure load-unload cycles were applied at each in-plane drift selected. In-plane drifts were selected at various limit states of the panel. 


\section{CHAPTER 4}

\section{MATERIAL PROPERTIES}

\subsection{Manufacture of Structural Clay Tile}

The fundamentals of the manufacturing process of structural clay tile have not changed significantly since the introduction of the product. However, specific fabrication details, material additives and processing have changed dramatically. Enhancements in the manufacture of clay tile have led to increased strength and economy of current products.

Clay tile consists of clay, water, grog, and various chemical additives. The clay is ground in a crusher and particles passing a prescribed screen (typically \#12) are used for manufacture. In general, a finer clay results in a denser and stronger tile. However, as the clay size becomes too small, firing does not dry the tile uniformly and it may warp.

The clay particles are combined in a mixer/extruder with water, grog, and any chemical additives. Grog consists of crushed tile, brick and other waste masonry products that pass the prescribed screen. The grog provides sufficient voids in the tile to allow proper drying and reduces the overall shrinkage and potential cracking of the tile.

Two chemical admixtures common in clay tile are Lignosulphonate and barium carbonate. Lignosulphonate has two properties that are important to clay tile manufacture. First, it is hydrophilic or intensifies the effect of water in the clay tile mixture. This allows the clay to become plastic (workable) without the addition of large amounts of water. The more water that can be extracted from the clay tile during firing, the better the clay particle bond and the stronger the tile. Thus, it is desirable to add a minimum amount of water, producing a stronger clay tile product. Second, Lignosulphonate acts as a binder of clay particles which increases the green 
strength of the tile. The green strength is the strength of the tile immediately after mixing and before it is dried and fired. A higher green strength allows easier manufacture, particularly during extrusion, cutting and subsequent handling prior to firing.

Natural clay contains soluble sulfates which migrate to the surface of the tile during firing and produce a white haze or scumming effect on the surface of the tile. Barium carbonate reacts with the sulfates in clay during the firing process to produce barium sulfate, which remains in suspension. Thus, the scumming effect is reduced. The barium content also helps prevent other impurities from surfacing in the firing process which create blemishes as they blister in the extreme heat of the kiln.

After the clay compound is mixed, it is forced through augers to compress the mixture and the tile is extruded through a dye, cut and placed in a drying area. String or tunnel dryers reduce the moisture content of the tile to the point at which no more shrinkage is expected. The clay tile is then fired in a down draft beehive kiln or more modern tunnel kiln. The consistency and control of the firing process is very important to the quality and strength of the clay tile.

\subsection{Properties of Structural Clay Tile Units}

Specifications for structural clay load-bearing wall tile are contained in ASTM C 34. Specifications for nonload-bearing wall tile are contained in ASTM C 56. ASTM C 34 was first issued as a tentative specification in 1921, adopted in 1926, and published in 1927 . The specification has undergone a number of revisions since then, however, many of the important requirements that relate to structural performance have not changed from 1921 to the present.

The 1921 specification required side construction tile to have an ultimate compressive strength based on gross area of 700 psi and 1500 psi on the gross area for end construction tile. The 1927 specification introduced three classes of tile: hard, medium, and soft. Minimum 
compressive strength requirements were given for each class. Because there existed considerable doubt as to the strength of clay tile, these requirements were confirmed by U.S. Bureau of Standards tests of 57 manufacturers of structural clay tile (ASTM C-10, 1926).

In the 1936 specification, these classes were reduced to the two grades, LBX and LB. Grade LBX tile is suitable for general use in masonry construction and adapted for use in masonry exposed to weathering. Grade LB tile is suitable for general use in masonry not exposed to frost action, or for use in exposed protected masonry. These grades and their strength requirements are the same as in the current (1991) revision of ASTM C 34, Table 4.1.

Table 4.1 ASTM C 34-91 Physical Requirements for Structural Clay Tile

\begin{tabular}{|c|c|c|c|c|}
\hline \multirow{2}{*}{ Grade } & \multicolumn{4}{|c|}{ Minimum Compressive Strength Based on Gross Area (psi) } \\
\cline { 2 - 5 } & \multicolumn{2}{|c|}{ End Construction Tile } & \multicolumn{2}{c|}{ Side Construction Tile } \\
\cline { 2 - 5 } & $\begin{array}{c}\text { Average of 5 } \\
\text { Tests }\end{array}$ & Individual & $\begin{array}{c}\text { Average of 5 } \\
\text { Tests }\end{array}$ & Individual \\
\hline \hline LBX & 1400 & 1000 & 700 & 500 \\
\hline LB & 1000 & 700 & 700 & 500 \\
\hline
\end{tabular}

The minimum number of cells required in $4^{\prime \prime} \times 12^{\prime \prime} \times 12^{\prime \prime}$ units in the 1921 specification was 3 , and the minimum number of cells for an $8^{n} \times 12^{n} \times 12^{n}$ unit was 6 . These are consistent with current requirements of a minimum of 1 cell in the direction of the wall thickness for 4 " tile and 2 cells in the direction of the wall thickness for $8^{n}$ tile.

The 1921 tentative specification required at least $45 \%$ net area in a plane parallel to the ends of the tile. By 1936, this had changed to dimension requirements for the shells and webs. For end construction, the outer surfaces were required to be at least $3 / 4^{\text {" }}$ thick, and the inner webs at least $1 / 2^{\prime \prime}$ thick. These are the same as the requirements of the current ASTM C 34 
specification. For side construction, the 1936 specification required the width of any cell, measured in the direction of the wall thickness, not to exceed 5 times the average over-all thickness of either the upper or lower bearing shells. This has gone through various changes, and the present requirements for side construction are a $5 / 8$ " minimum thickness for the shells and a $1 / 2$ " thickness for the webs. The maximum cell width measured in the direction of wall thickness has been decreased from 5 to 4.5 times the average over-all thickness of either the upper or lower bearing shells. If the cell width is less than 4 times the average over-all thickness of either bearing surface, the thickness requirements of the shells and webs are waived.

Two types of clay tile were used in this study, a nominal 4 " and nominal 8 "thick unit (4"x12"x12" and $8 " \times 12^{\prime \prime} \times 12^{\prime \prime) . ~ B o t h ~ t h e s e ~ t i l e ~ u n i t s ~ a r e ~ u s e d ~ p r i m a r i l y ~ i n ~ s i d e ~ c o n s t r u c t i o n ~}$ (cores horizontal in a wall), and were manufactured in 1987. While these sizes have historically been the standard for wall construction, currently, the standard structural clay tile wall unit is $5^{\prime \prime} \times 8^{\prime \prime} \times 12^{\prime \prime}$, and is used in end construction.

Mean dimensions of the tile units are shown in Figure 4.1. Weights are based on the ambient air-dried conditions. Significant uniformity in the clay tile is evident in the low coefficients of variation of the physical measurements $(2.2 \%$ or less $)$. The tile dimensions are similar to those reported by other researchers of the same nominal size. Johnson and Matthys (1973) reported an averaged cored area of $49 \%$ for $4 "$ tile and $62.5 \%$ for 8 " tile. Johnson and Matthys also reported comparable low coefficients of variation for unit tile weight.

The initial rate of absorption (IRA) of the clay tile is less uniform in nature and is about twice as high along wire cut edges as on the smooth extruded face of the tile. IRAs of 3.29 and $2.70 \mathrm{~g} / \mathrm{min} / 30 \mathrm{in}^{2}$ were observed for $4 "$ and $8^{\prime \prime}$ tiles with cells horizontal. IRAs of 5.22 and 5.32 $\mathrm{g} / \mathrm{min} / 30 \mathrm{in}^{2}$ were observed for $4 "$ and 8 " tiles with cells vertical. The overall average of the 4" and $8^{\prime \prime}$ tile for cores vertical and cores horizontal was $4.1 \mathrm{~g} / \mathrm{min} / 30 \mathrm{in}^{2}$. This value is consistent 

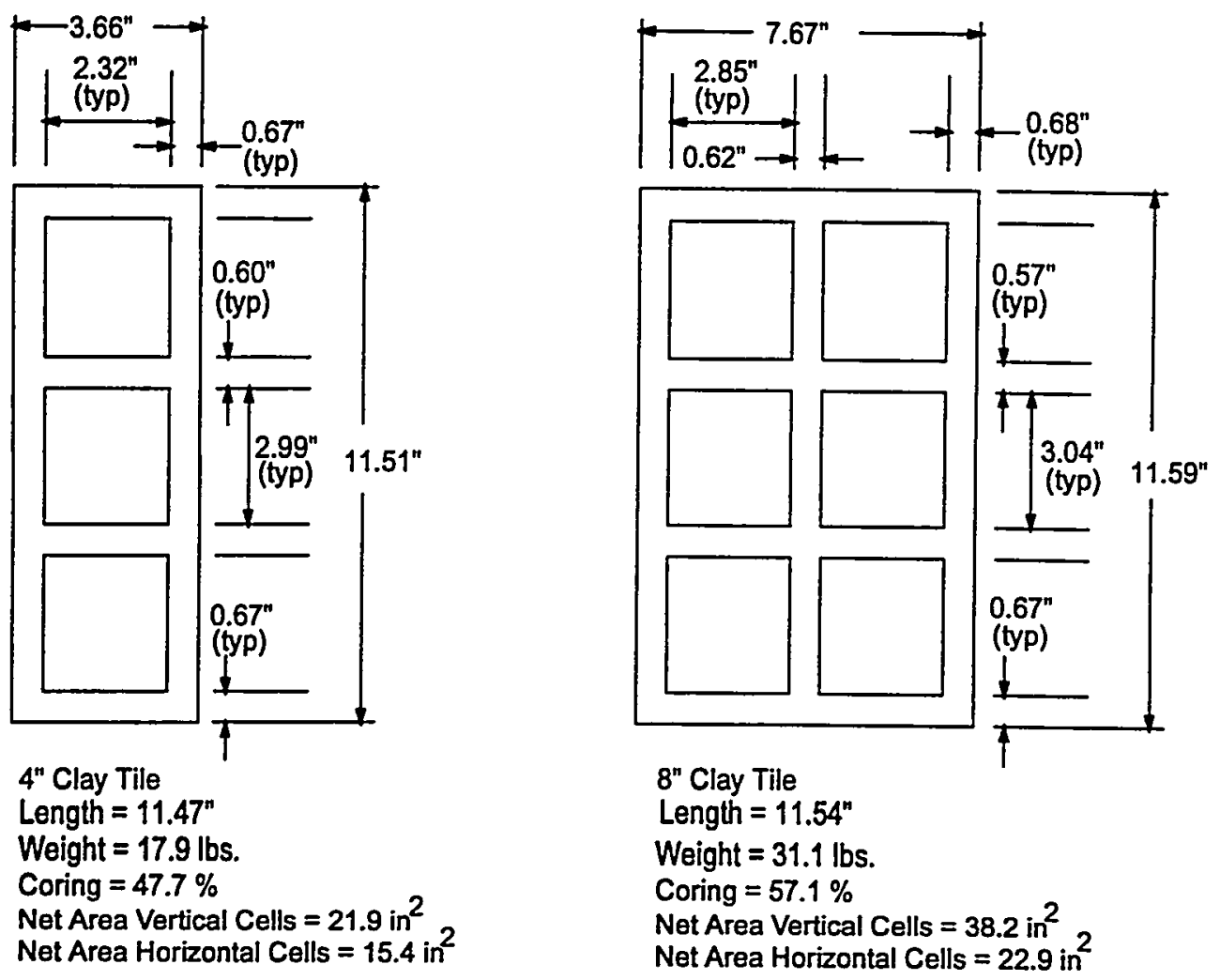

Figure 4.1 Physical Measurements of Structural Clay Tile

with an average IRA of 3.9 reported for $4^{n}$ facing tile by the Structural Clay Tile Products Institute (SCPI, 1967). Johnson and Matthys (1973) reported an average IRA of $10.2 \mathrm{~g} / \mathrm{min} / 30 \mathrm{in}^{2}$ for horizontal cell units and $26.3 \mathrm{~g} / \mathrm{min} / 30 \mathrm{in}^{2}$ for vertical cell units.

The IRA does not provide any strength information for the unit. Rather, it has been correlated to the adhesion or bond strength between the mortar and the masonry unit. The values observed for the clay. tile are low compared to the optimum range of $5-20 \mathrm{~g} / \mathrm{min} / 30 \mathrm{in}^{2}$ recommended by Plummer (1962). Since the initial rate of absorption tests of the clay tile were performed on ambient air-dried specimens stored indoors, it follows that they should not be dampened prior to construction. 
The compressive strength of individual clay tile units was determined by gradually applying an axial compressive load to full-size tile specimens until failure. Two variations of this test were performed, one with the compressive force parallel to the axis of the tile cores (cores vertical) and the other with the force normal to the axis of the cores (cores horizontal). In each instance, the specimens were capped with a gypsum compound (Hydrocal). Supplementing ASTM C 67-91, the specimens were instrumented with strain gages to measure strain parallel and perpendicular to the load. Prior to placement of the strain gages, the voids of the clay tile surface were sealed with an epoxy and then smoothed with fine grain sand paper.

A comparison of average compressive strengths to those reported in other research is presented in Table 4.2 based on gross area and Table 4.3 based on net area. Matthys' (1972) results are from preliminary tests conducted to determine which tiles to use in assemblage testing. Only the results for similar units to those of the present study are included. The one exception is the $4 "$ vertical units, which had a similar cross-section, but were only $4-1 / 2^{n}-5^{n}$ high. The results from Johnson and Matthys (1973) are for tile from the same manufacturer as tile labeled Matthys A for the 4" vertical and Matthys B for the 8" vertical and horizontal units. Hathcock and Skillman (1918) did not record gross areas; gross ultimate strengths were obtained using nominal dimensions. Compressive strengths given by the ASTM C-10 (1924) committee are from tests performed at the U. S. Bureau of Standards with the Hollow Building Tile Association.

The results of the compressive tests of newer tile are substantially higher than those of most prior research. This reflects the improvements in the grinding and firing process. The results, though, are consistent with net compressive strengths (average $=13.1 \mathrm{ksi}$ ) of heavy duty hollow clay units tested by SCPI (1969) with vertical cells. The results are slightly lower than net compressive strengths (average $=17.4 \mathrm{ksi}$ ) of $4^{\prime \prime}$ facing tile tested with cores horizontal (SCPI, 1967). 
Table 4.2 Comparison of Gross Compressive Strengths

\begin{tabular}{|c|c|c|c|c|}
\hline \multirow{2}{*}{ Source } & \multicolumn{4}{|c|}{ Gross Compressive Strengths (ksi) } \\
\hline & 4" Horiz & 4" Vert & 8" Horiz & 8" Vert \\
\hline Current Research 1987 Tile & 3.30 & 5.84 & 2.14 & 5.16 \\
\hline $\begin{array}{l}\text { Flanagan et al. (1993a) } 1991 \text { Tile } \\
\text { 1940s Tile }\end{array}$ & $\begin{array}{l}3.71 \\
1.73 \\
\end{array}$ & $\begin{array}{l}7.92 \\
4.69\end{array}$ & $\begin{array}{l}2.27 \\
1.50\end{array}$ & $\begin{array}{l}4.55 \\
3.83\end{array}$ \\
\hline $\begin{array}{c}\text { Matthys (1972) A } \\
\text { B } \\
\text { C } \\
\text { F }\end{array}$ & & $\begin{array}{l}3.29 \\
3.77 \\
3.72 \\
8.10 \\
\end{array}$ & $\begin{array}{l}1.09 \\
1.02 \\
0.47\end{array}$ & $\begin{array}{l}3.86 \\
2.78 \\
2.12\end{array}$ \\
\hline Johnson \& Matthys (1973) & & 4.79 & 1.18 & 2.76 \\
\hline Whittemore \& Hathcock (1923) & & & 1.24 & 2.32 \\
\hline $\begin{array}{c}\text { Stang et al. (1926) } 3 \\
1 \\
4 \\
5 \\
\end{array}$ & & 1.74 & $\begin{array}{l}0.50 \\
0.33 \\
1.74 \\
\end{array}$ & $\begin{array}{l}1.83 \\
1.27 \\
2.84\end{array}$ \\
\hline Whittemore et al. (1938) & & & 1.59 & 3.54 \\
\hline Hathcock \& Skillman (1918) & 1.45 & 2.77 & 1.03 & 2.65 \\
\hline $\begin{array}{c}\text { ASTM C-10 } \\
(1924) \mathrm{L} \\
\mathrm{J} \\
\mathrm{D}\end{array}$ & $\begin{array}{l}1.86 \\
0.70 \\
2.63\end{array}$ & $\begin{array}{l}4.06 \\
1.79 \\
5.30\end{array}$ & $\begin{array}{l}0.98 \\
0.71 \\
1.56\end{array}$ & $\begin{array}{l}2.72 \\
1.26 \\
2.99\end{array}$ \\
\hline
\end{tabular}

Failure of the clay tile in compression was very abrupt and at times nearly explosive due to the energy release as the specimens fractured. Horizontal units failed by splitting between the face shells and webs, Figure 4.2. The vertical cell units failed abruptly and with complete destruction of the unit. Specimen fragments were scattered throughout the test area which necessitated the construction of a complete enclosure to contain the debris. These failure modes and the necessity of containment are consistent with the findings reported by Matthys (1972). The results of the compressive strength tests show that the unit clay tile stress-strain relationships are quite linear until just prior to failure, Figure 4.3. Slight deviations from linearity near the 
Table 4.3 Comparison of Net Compressive Strengths

\begin{tabular}{|c|c|c|c|c|}
\hline \multirow{2}{*}{ Source } & \multicolumn{4}{|c|}{ Net Compressive Strengths (ksi) } \\
\cline { 2 - 5 } & 4 4" Horiz & 4 " Vert & 8" Horiz & 8" Vert \\
\hline \hline Current Research 1987 Tile & 8.96 & 11.29 & 8.22 & 12.10 \\
\hline Flanagan et al. (1993a) 1991 Tile & 9.07 & 14.36 & 8.41 & \\
1940s Tile & 5.25 & 8.80 & & 9.14 \\
\hline Matthys (1972) A & & 7.23 & 4.18 & 8.88 \\
B & & 6.12 & 3.53 & 5.94 \\
F & & 5.67 & 1.72 & 4.74 \\
\hline Johnson \& Matthys (1973) & & 13.95 & & \\
\hline Whittemore \& Hathcock (1923) & & 10.50 & 4.10 & 5.90 \\
\hline Stang et al. (1926) 3 & & & 5.46 & 5.01 \\
\hline 4 & & 3.72 & & \\
5 & & & 2.21 & 4.47 \\
\hline D & & & 1.29 & 2.74 \\
\hline Whittemore et al. (1938) & & & & 6.47 \\
\hline Hathcock \& Skillman (1918) & 5.52 & 6.61 & 4.89 & 6.35 \\
\hline ASTM C-10 (1924) L & 7.14 & 9.20 & 4.35 & 6.36 \\
\hline
\end{tabular}

ultimate load are due to cracking, which typically occurs at approximately $70 \%$ of the ultimate load. Net modulii of elasticity of $4^{\prime \prime}$ and $8^{\prime \prime}$ tiles tested with vertical cells are compared in Table 4.4.

Influenced by the behavior of brick masonry, Plummer (1962) suggested that Poisson's ratio for structural clay tile might vary from 0.05 to 0.10 . The current research findings are significantly higher. For both 4" and 8" units, Poisson's ratio varied from 0.16 to 0.18 for horizontal cores. Similarly, Poisson's ratio varied from 0.15 to 0.25 for vertical cores. These findings are, however, lower than a poisson's ratio of 0.31 reported by Matthys (1972). 


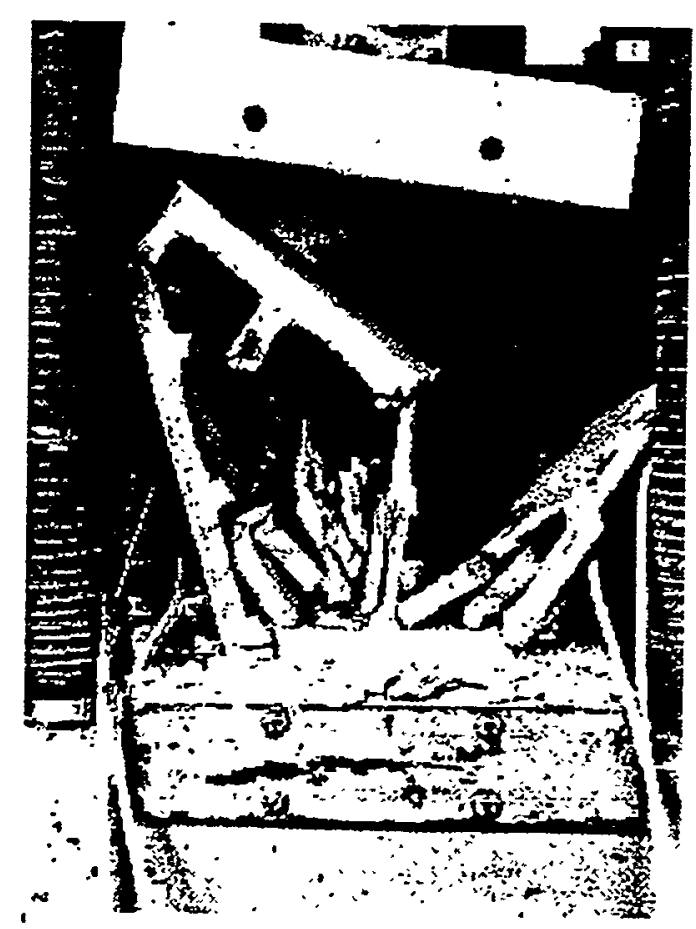

Figure 4.2 Unit Tile Compressive Strength Tests

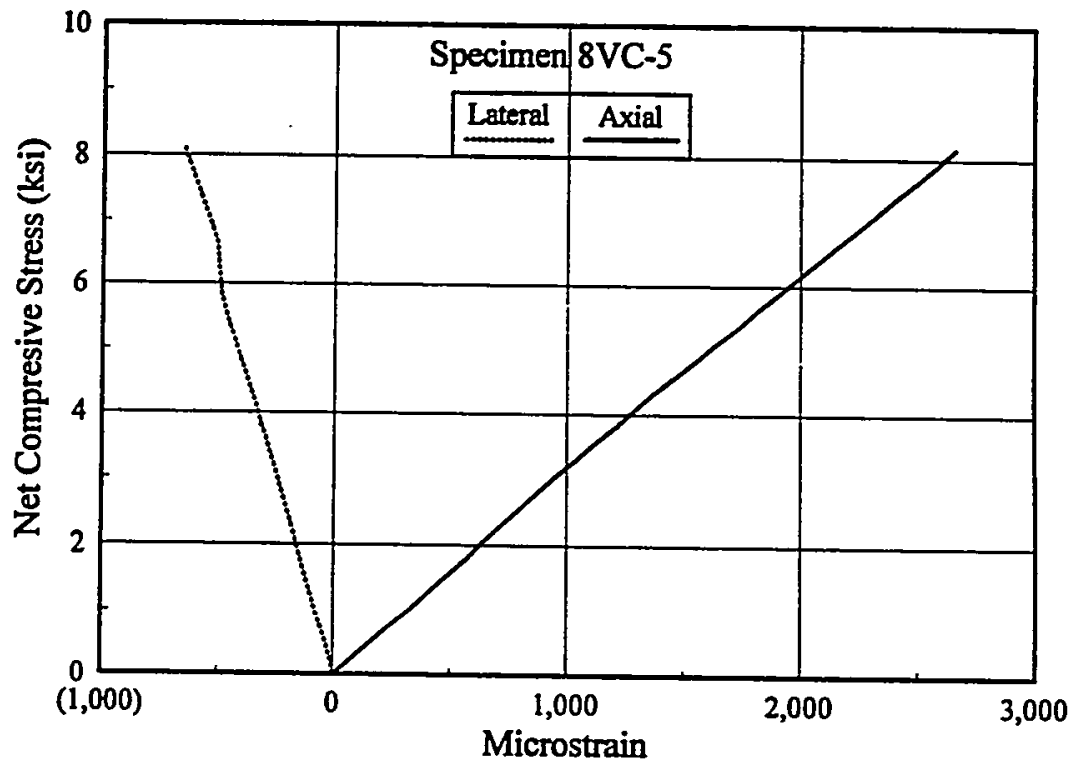

Figure 4.3 Unit Tile Stress-Strain Relationship (Vertical Cores) 
Table 4.4 Comparison of Net Modulus of Elasticity (Vertical Cells)

\begin{tabular}{|c|c|c|}
\hline \multirow{2}{*}{ Source } & \multicolumn{2}{|c|}{ Net Modulus of Elasticity (ksi) } \\
\cline { 2 - 3 } & 4 " Vertical & $8^{\prime \prime}$ Vertical \\
\hline Current Research 1987 Tile & 3,440 & 3,350 \\
\hline Flanagan et al. (1993a) 1991 Tile & 3,460 & 3,300 \\
1940s Tile & 3,760 & 3,820 \\
\hline Hathcock \& Skillman (1918) & 4,560 & 3,580 \\
\hline Matthys (1972) & 4,330 & 3,000 \\
\hline Whittemore \& Hathcock (1923) & & 3,110 \\
\hline Stang et al. (1926) 1 & & 2,880 \\
4 & & 2,145 \\
5 & & 5,750 \\
\hline
\end{tabular}

Wide ranges of strength of clay tile have been reported in the literature. However, Whittemore and Hathcock (1923) concluded that considerable differences in unit strength did not affect wall strengths. Parsons (1931) suggested that the compressive strength of an end constructed wall is proportional to the square root of the unit tile compressive strength. For side construction, the unit strength may have more of an effect on wall compressive strength, but insufficient data was available to develop a relationship. Other factors, such as the ratio of the thickness of bearing shells to span between vertical supports and design features affecting the bearing area at bed joints, have just as much influence on wall strength in side construction.

\subsection{Properties of Structural Clay Tile Prisms}

Masonry prisms constructed as 2' by 4' assemblages were tested under uniaxial compression to develop constitutive properties of the clay tile infills. Details of the prism testing are contained in Boyd (1993). The prisms were constructed and cured in a similar manner to the infill panels and consisted of $8^{\prime \prime}$ thick single wythe and $13^{\prime \prime}$ thick double wythe masonry. The 
prisms were tested at various angles of the compressive load with respect to the bed joint. Results of prisms tested at 0 and 90 degrees are summarized below. The specimens were built using side construction and the 0 degree (cores parallel to the load) specimens rotated for testing.

The behavior is markedly different in the instance where the compressive force is normal to the cores of the specimen versus being parallel to the specimen cores. As indicated in the stress-strain relationship of Figure 4.4, failure of prisms with the cores normal to the load is abrupt following a relatively linear behavior. Conversely, Figure 4.5 indicates a more gradual failure mechanism with significant postpeak capacity for prisms with the tile cores parallel to the compressive force. Table 4.5 gives a summary of the compressive test results for prisms of both orientations based on gross area. Modulus data is given as a least-squares linear fit of data over a range of 5-50\% of ultimate load. Photographs of the prisms before testing and after ultimate load are shown in Figures 4.6 and 4.7 for $8^{\prime \prime}$ prisms with the cores normal and parallel to the load.

Table 4.5 Summary of Prism Compression Test Results

\begin{tabular}{|c|c|c|c|c||}
\hline \multirow{2}{*}{ Parameter } & \multicolumn{2}{|c|}{$8^{\mathrm{n}}$ Single Wythe Prisms } & \multicolumn{2}{c|}{$13^{\mathrm{n}}$ Double Wythe Prisms } \\
\cline { 2 - 5 } & $\begin{array}{c}\text { Cores parallel } \\
\text { to load }\end{array}$ & $\begin{array}{c}\text { Cores normal } \\
\text { to load }\end{array}$ & $\begin{array}{c}\text { Cores parallel } \\
\text { to load }\end{array}$ & $\begin{array}{c}\text { Cores normal } \\
\text { to load }\end{array}$ \\
\hline \hline $\mathrm{f}_{\mathrm{m}}^{\prime}(\mathrm{psi})$ & 436 & 810 & 372 & 332 \\
\hline $\mathrm{E}_{\mathrm{m}}(\mathrm{ksi})$ & 329 & 768 & 410 & 731 \\
\hline Strain at $\mathrm{f}_{\mathrm{m}}^{\prime}$ & 0.00222 & 0.00135 & 0.00125 & 0.00088 \\
\hline
\end{tabular}



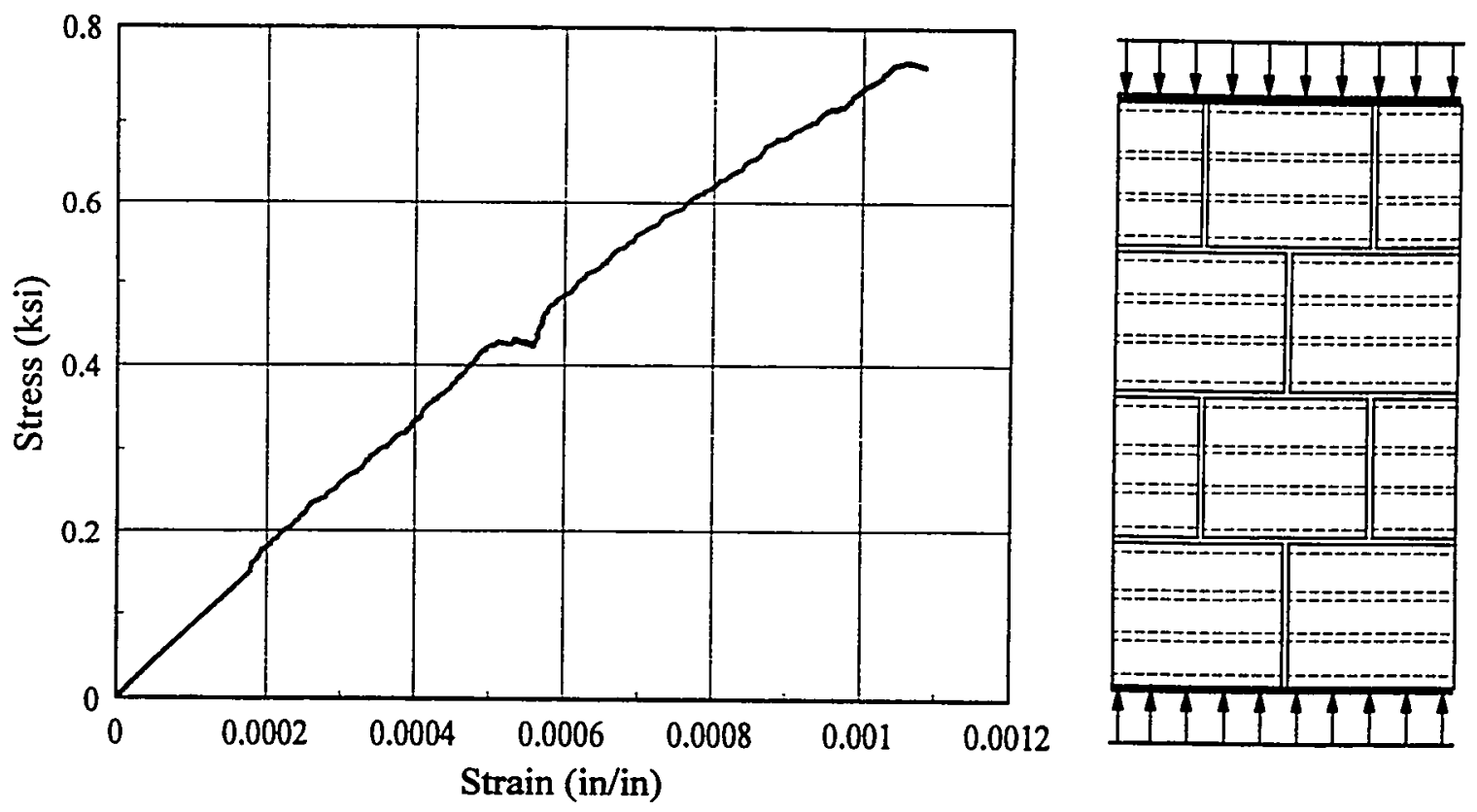

Figure 4.4 Prism Compression Stress-Strain Relationship (Cores Normal to Load)
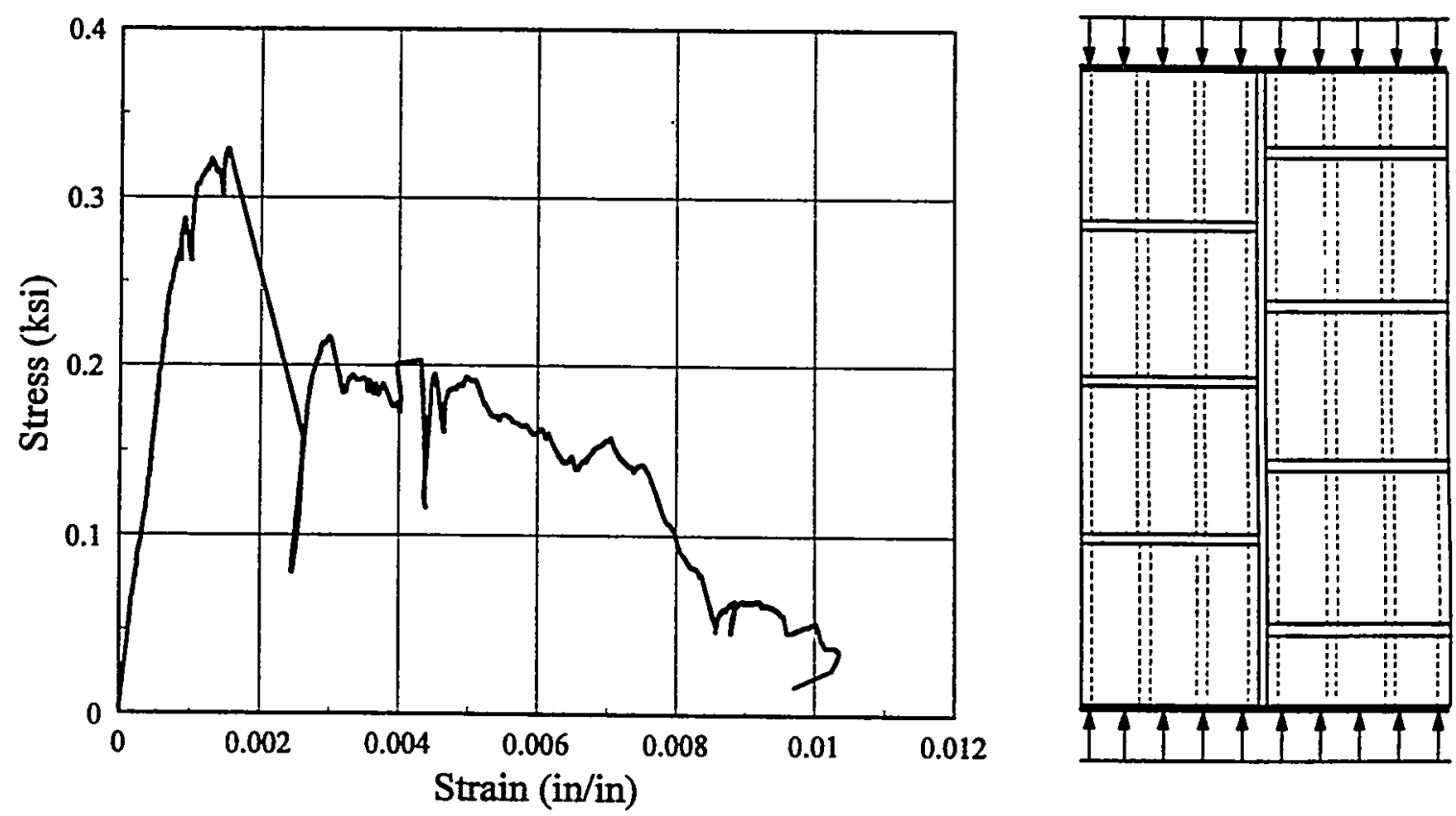

Figure 4.5 Prism Compression Stress-Strain Relationship (Cores Parallel to Load) 

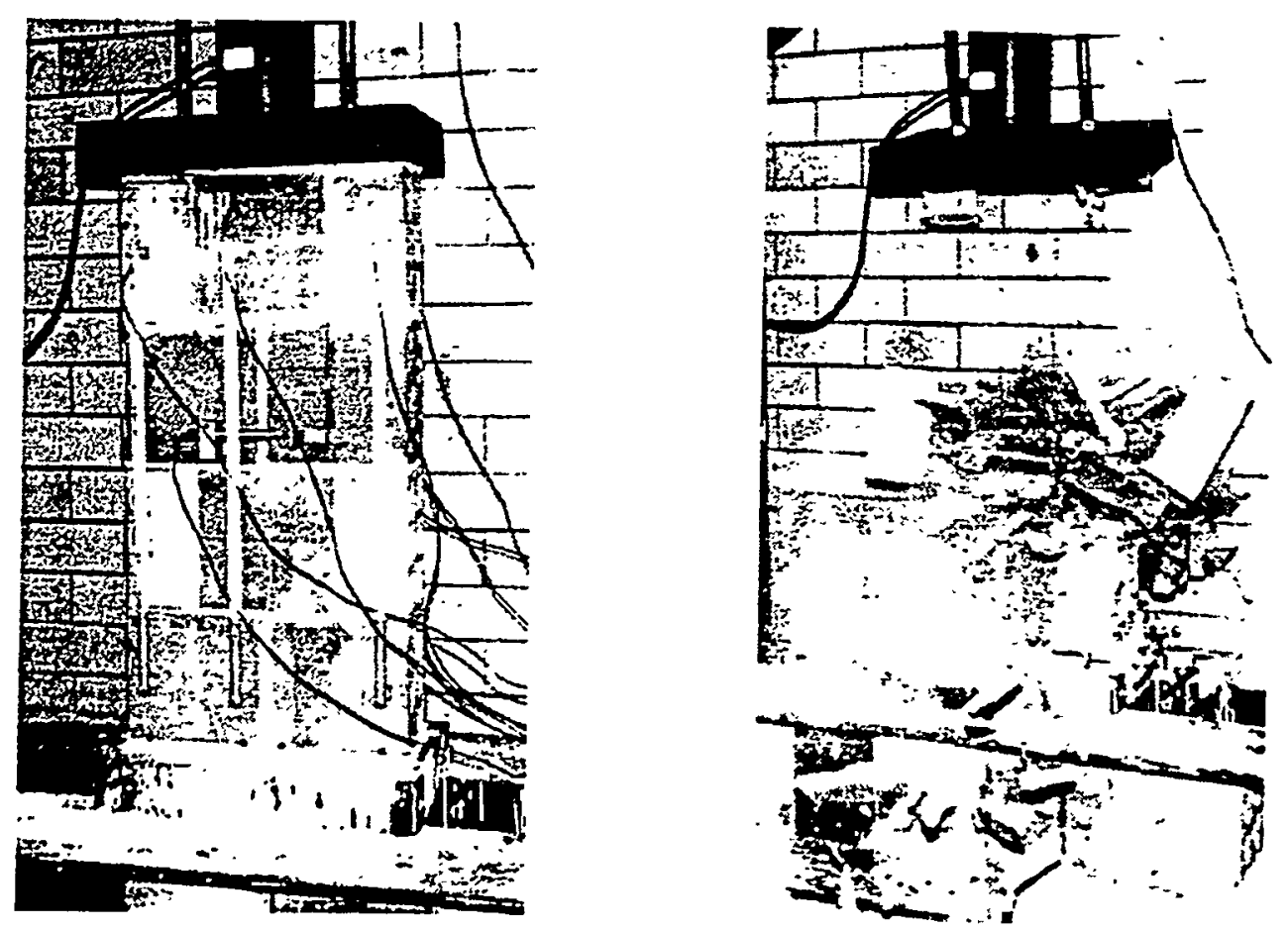

Figure 4.6 Prism Testing (Cores Normal to Load)
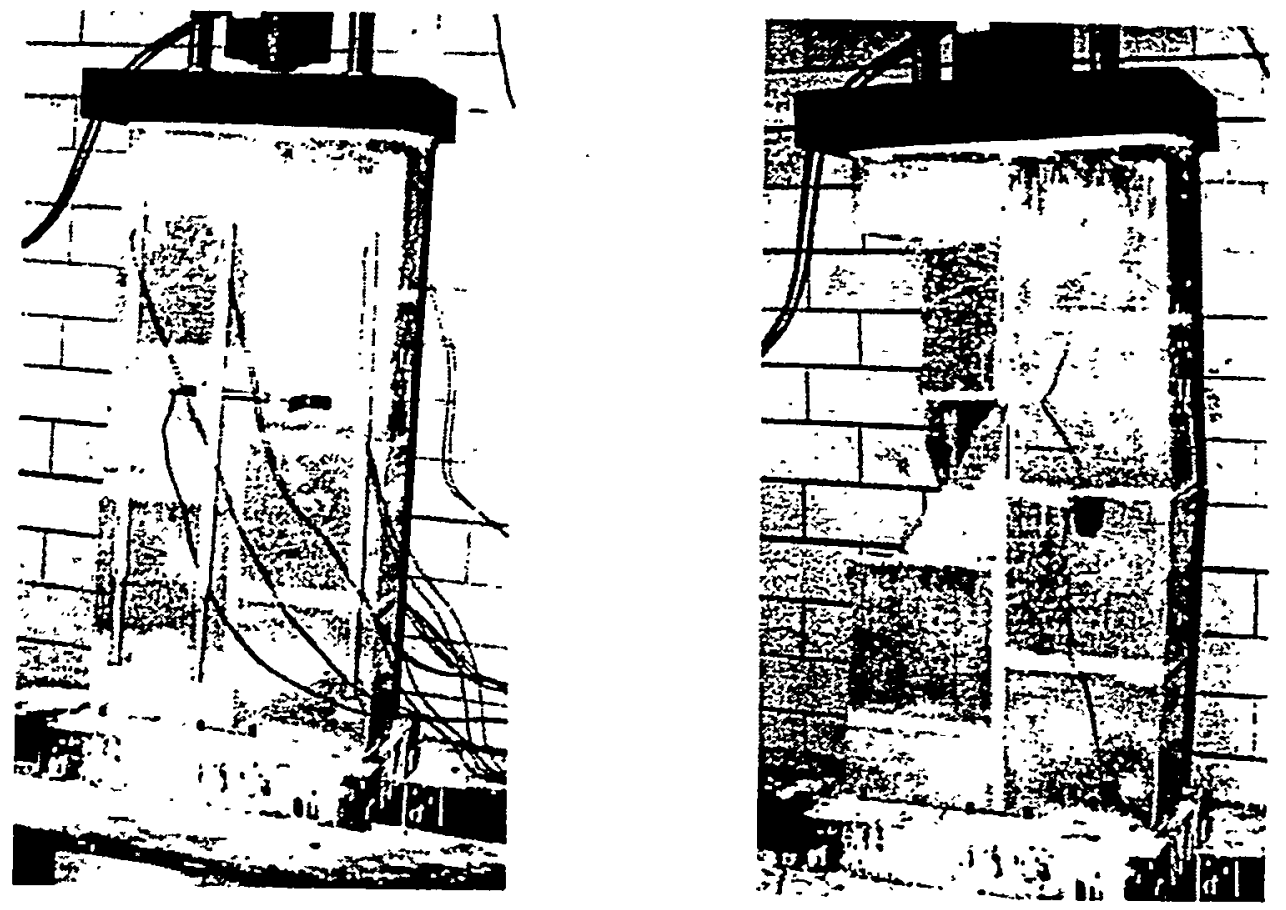

Figure 4.7 Prism Testing (Cores Parallel to Load) 


\subsection{Properties of Infill Mortar}

Mortar tests were conducted for each of the infill specimens. As previously indicated, the clay tile masonry was constructed with type $\mathrm{N}$ mortar of approximately 1:2.5 mix proportions of mortar cement and natural river sand. The only exception to this was the type $\mathrm{S}$ mortar used in the retrofit of specimen $10 \mathrm{~b}$.

The infills were allowed to cure in the ambient temperature and moisture conditions of the laboratory testing facility. Mortar cubes (2"x2"x2") were molded according to ASTM C10988 and were allowed to cure two days in the laboratory testing facility before being placed in a moist room for the remaining time until testing. Mortar cube specimens were tested according to ASTM C780-91 at approximately 30 days curing and on the days of infill or prism testing.

Results of the mortar compression testing are shown in Table 4.6. No significant change in mortar strength was observed beyond 30 days curing. Typically, four sets of 3-cube mortar samples were taken from mortar batches used in the construction of an infill panel. One cube of each set was tested at 30 days and the other two cubes were tested on the day of the infill testing. Variation in mortar strength was somewhat lower for a single mortar batch than for several batches of an entire panel. Coefficients of variation of compressive strength of a single mortar batch were typically less than $5 \%$.

The prism compression tests were cured in a similar fashion as the infill panels (Boyd, 1993). Mean compressive strengths of the 8 " prism mortars were $2428 \mathrm{psi}(\mathrm{COV}=29 \%)$ and $1931 \mathrm{psi}(\mathrm{COV}=23 \%)$ for cores normal to the load and cores parallel to the load respectively. Mean compressive strengths of the $13^{n}$ prism mortars were $1807 \mathrm{psi}(\mathrm{COV}=18 \%)$ and 1723 psi $(\mathrm{COV}=14 \%)$ for cores normal to the load and cores parallel to the load respectively. Other mortar details, including bond strength, are given in Columber (1994). 
Table 4.6 Mean Compressive Strength of Infill Mortar

\begin{tabular}{|c|c|c|c|c|c|c|}
\hline Specimen & Infill Test & $\begin{array}{c}\text { Strength } \\
\text { @ 30d } \\
\text { (psi) }\end{array}$ & $\begin{array}{c}\text { COV } \\
(\%)\end{array}$ & $\begin{array}{c}\text { Age @ } \\
\text { Infill Test } \\
\text { (days) }\end{array}$ & $\begin{array}{l}\text { Strength } \\
\text { (psi) }\end{array}$ & $\begin{array}{l}\text { COV } \\
(\%)\end{array}$ \\
\hline 1 & In-plane Racking & 1810 & 20.4 & 75 & 1800 & 24.4 \\
\hline 2 & In-Plane Racking & 1910 & 20.9 & 30 & 1910 & 20.9 \\
\hline 3 & In-Plane Racking & 1480 & 32.6 & 66 & 1530 & 30.4 \\
\hline 4 & In-Plane Racking & 1900 & 26.7 & 30 & 1900 & 26.7 \\
\hline 5 & In-Plane Racking & 2070 & 17.4 & 59 & 2360 & 15.4 \\
\hline 7 & In-Plane Racking & 2080 & 11.9 & 56 & 2310 & 12.5 \\
\hline 9 & In-Plane Racking & 1370 & 17.5 & 30 & 1370 & 17.5 \\
\hline $10 \mathrm{a}$ & In-Plane Racking & - & - & 45 & 2460 & 14.7 \\
\hline $10 \mathrm{~b}$ & In-Plane Racking - N & - & - & 33 & 1870 & 7.8 \\
\hline $10 \mathrm{~b}$ & In-Plane Racking - $S$ & NA & NA & 33 & 3390 & 8.9 \\
\hline 11 & Out-of-Plane Drift & 1940 & 3.7 & 47 & 2030 & 6.1 \\
\hline 11 & In-Plane Racking & 1940 & 3.7 & 58 & 2330 & 23.8 \\
\hline 13 & Out-of-Plane Drift & 2700 & 5.8 & 33 & 2690 & 3.6 \\
\hline 13 & In-Plane Racking & 2700 & 5.8 & 45 & 2890 & 5.0 \\
\hline 17 & In-Plane Racking & 3040 & 10.7 & 30 & 3040 & 10.7 \\
\hline 18 & Out-of-Plane Pressure & - & - & 31 & 1530 & 24.6 \\
\hline 19 & In-Plane Racking & 2050 & 10.6 & 51 & 2110 & 7.7 \\
\hline 19 & Out-of-Plane Pressure & 2050 & 10.6 & 58 & 2270 & 11.0 \\
\hline 20 & Out-of-Plane Pressure & 2190 & 9.2 & 39 & 2040 & 8.0 \\
\hline 20 & In-Plane Racking & 2190 & 9.2 & 55 & 2270 & 6.0 \\
\hline $21 \mathrm{a}$ & In-Plane Racking & 1780 & 21.6 & 41 & 1730 & 17.0 \\
\hline $21 \mathrm{~b}$ & In-Plane Racking & 1780 & 21.6 & 25 & 1660 & 17.2 \\
\hline 22 & Out-of-Plane Pressure & - & - & 32 & 1700 & 17.2 \\
\hline 23 & Racking and Pressure & 1240 & 6.1 & 27 & 1190 & 7.8 \\
\hline 24 & In-Plane Racking & 1460 & 24.2 & 38 & 1540 & 23.6 \\
\hline 25 & Out-of-Plane Pressure & 1460 & 24.2 & 59 & 1660 & 22.3 \\
\hline
\end{tabular}




\subsection{Properties of Steel Framing}

Properties of the steel framing were obtained from mill certification test reports. The test frames were procured from three different steel suppliers/manufacturers. All of the specimen beams and columns were specified as ASTM A36 Grade steel, but as can be seen in Table 4.7, the mean yield stress $\left(\sigma_{y}\right)$ ranged from $15 \%$ to $58 \%$ greater than 36,000 psi. The modulus of elasticity of the steel $\left(E_{s}\right)$ used in the computation of mean yield strain $\left(\epsilon_{y}\right)$ was $29,000,000$ psi.

Table 4.7 Mean Yield Stress and Strain of Steel Frames

\begin{tabular}{|c|c|c|c|c|}
\hline \multirow[t]{2}{*}{ Specimen } & \multicolumn{2}{|c|}{ Mean Yield Stress $\left(\sigma_{y}, p s i\right)$} & \multicolumn{2}{|c|}{ Mean Yield Strain $\left(\epsilon_{y}, \times 10^{6}\right)$} \\
\hline & Beam & Columns & Beam & Columns \\
\hline 1 & 41400 & 46600 & 1430 & 1610 \\
\hline 2 & 48100 & 50200 & 1660 & 1730 \\
\hline 3 & 41400 & 41800 & 1430 & 1440 \\
\hline 4 & 48100 & 54100 & 1660 & 1870 \\
\hline 5 & 41400 & 43200 & 1430 & 1490 \\
\hline 7 & 48100 & 50200 & 1660 & 1730 \\
\hline 9 & 48100 & 47700 & 1660 & 1650 \\
\hline $10 a \& 10 b$ & 41400 & 51800 & 1430 & 1790 \\
\hline 11 & 48100 & 50200 & 1660 & 1730 \\
\hline 13 & 48100 & 50200 & 1660 & 1730 \\
\hline 17 & 41400 & 50200 & 1430 & 1730 \\
\hline 18 & 56800 & 51700 & 1960 & 1780 \\
\hline 19 & 56800 & 51700 & 1960 & 1780 \\
\hline 20 & 56800 & 51700 & 1960 & 1780 \\
\hline $21 \mathrm{a} \& 21 \mathrm{~b}$ & 41400 & 51800 & 1430 & 1790 \\
\hline 22 & 41400 & 43200 & 1430 & 1490 \\
\hline 23 & 56800 & 51700 & 1960 & 1780 \\
\hline 24 & 41400 & 51800 & 1430 & 1790 \\
\hline 25 & 56800 & 51700 & 1960 & 1780 \\
\hline
\end{tabular}




\section{CHAPTER 5}

\section{IN-PLANE BEHAVIOR}

\subsection{Experimental Results}

The in-plane behavior of clay tile infills was studied by applying static cyclic racking forces to specimens representing typical field construction. The construction of clay tile masonry tightly within a bounding steel frame results in a complex interaction of the two structural systems. In the case of the steel framing, the rigidity of the infill stiffens the steel framing while the framing confines the masonry panel allowing greater strength and ductility. Thus, the combined system displays many of the enhancing properties typical of composite construction but with significant nonlinearities due to cracking in the masonry and sliding along the frame and panel boundaries.

\subsubsection{Hysteretic Behavior}

The in-plane behavior of the steel frames infilled with clay tile was similar for each of the specimens tested. Typical behavior is presented with the partial in-plane hysteresis of specimen 17, Figure 5.1. For convenience, only the hysteretic loops corresponding to a significant limit state are shown. Preliminary findings of these in-plane tests are contained in Flanagan et al. (1993b) and Flanagan and Bennett (1993). A detailed description of the loaddeflection behavior of specimen 2 and 17 is also contained in Barclay (1993).

Six limit states of the infills are identified in Figure 5.1. Although, these limit states occurred at different load and displacement levels for other specimens, similar behavior was observed. As the incremental increasing displacements were applied to the frames, mortar cracking and separation along the top of the panel was observed, followed by compression 


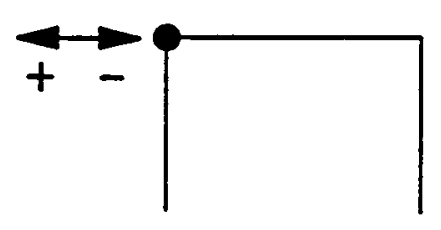

1 - Diagonal Mortar Joint Cracks

2 - Off Diagonal Mortar Cracks

3 - Mortar Crushing, Tile Cracking

4 - Tile Splitting (Ultimate Load)

5 - Tile Faceshell Spalling

6 - Loss of Upper Course Tiles

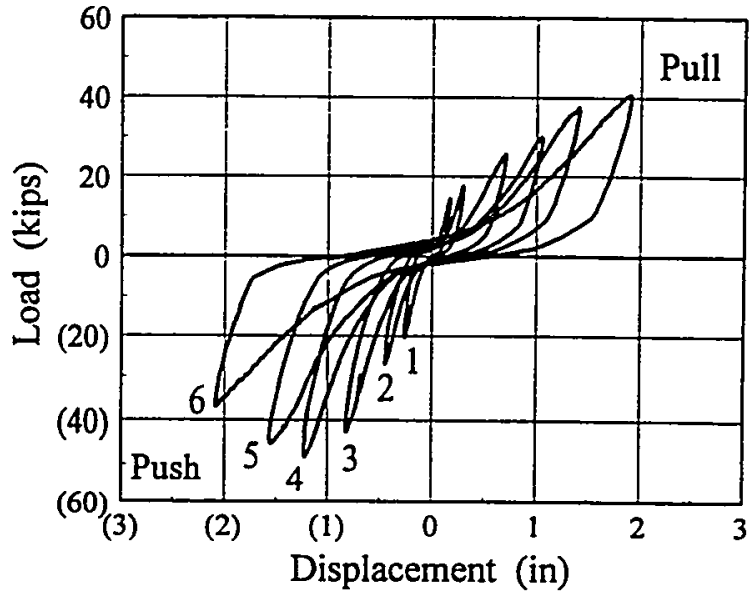

Figure 5.1 Partial In-Plane Hysteresis of Infill 17

cracking in the mortar joints of the upper corners. Next, diagonal mortar joint cracks developed in both directions of the cyclic loading (point 1). In the ensuing load cycles, parallel off-diagonal cracks developed (point 2), as the initial diagonal crack width was reduced. Subsequently, mortar crushing and tile cracking occurred in the upper corners (point 3). Ultimate capacity of the infilled frames was reached coincidentally with splitting of the upper corner tiles along the intersection of the web and faceshell (point 4). Finally, the upper course tiles split (point 5) and the corner crushing continued as whole tiles were destroyed in the upper corners (point 6).

In-plane stiffness of the steel framing is increased dramatically with the addition of clay tile infill. Under increasing displacement cycles, the secant stiffness reduced gradually from the beginning of the loading. The hysteretic loops were stable in that the second cycle of a given displacement typically followed the path of the first. For larger specimens there was a noticeable reduction in stiffness coincident with the onset of initial panel diagonal cracking. Panel diagonal cracking occurred at a gross shear stress of approximately $\sqrt{f}_{\mathrm{m}}^{\prime}(21 \mathrm{psi})$. A full-scale clay tile infill tested by Henderson et al. (1993) cracked at a similar level. For all specimens, there was a marked shift in stiffness as ultimate capacity of the infill was reached. 
Panel deformation along the diagonals was quite small prior to the formation of a large stair-step mortar joint crack. After panel cracking occurred, the diagonals exhibited a hysteresis somewhat like the panel overall drift, only at much smaller displacements, Figures 5.2 to 5.4. Greater displacement was observed along the panel diagonals when they were in tension. This is due to the opening of cracks normal to the diagonal tension. A significant portion of subsequent panel diagonal displacement is attributed to measuring the opening and closing of these cracks. Theses cracks may develop more readily in the single bay infill specimens than in multi-bay infills with adjacent panel support. Dividing the maximum diagonal push displacement $(0.22$ ") of specimen 17 by the diagonal length yields a "strain" value of 0.0015 which is similar to the prism strain at ultimate compressive strength.

Panel horizontal and vertical displacements remained positive or elongating during both directions of the hysteretic loading, Figure 5.5 and 5.6. The tightly constructed infill tended to expand horizontally and vertically during both cycles of loading. Again, the measurement of the horizontal or vertical component of the diagonal cracks is observed.

At small displacements, the infilled frame hysteretic curve was almost linear and nearly identical to that of the bare frame. Larger displacements caused the infill to engage, greatly increasing the stiffness of the combined system. This two-stage stiffness exhibited at moderate to high loading is displayed in Figure 5.7, which overlays the infilled frame load cycle at ultimate capacity with the bare frame test at a similar displacement.

The pinched behavior of the infill hysteresis is more directly exemplified by the relative frame to infill displacements of Figure 5.8. Here the nearly flat portion at the center of the curve signifies the opening and closing of the interface gap between the column and infill. An overlay of relative column/panel displacement and absolute column displacement near ultimate capacity 


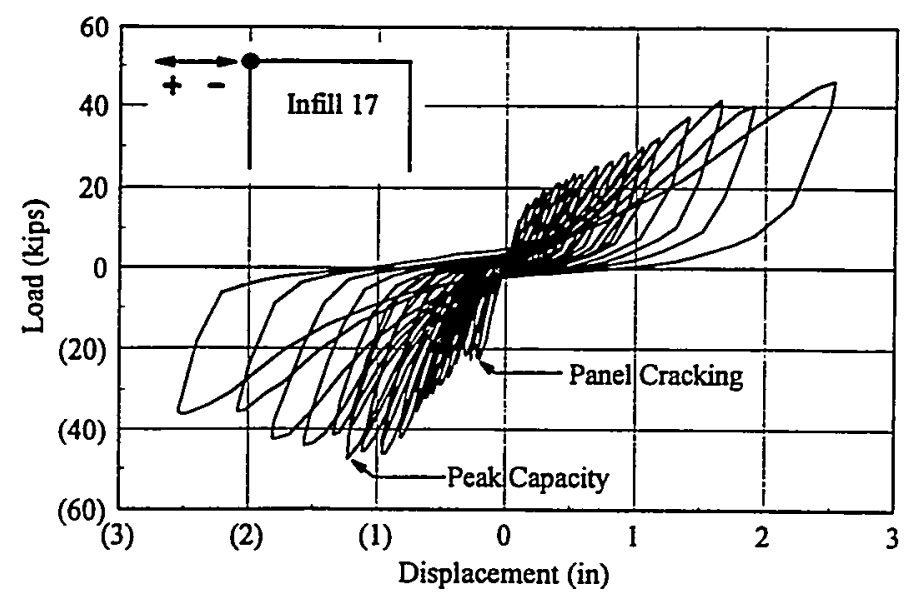

Figure 5.2 Complete Hysteresis of Specimen 17

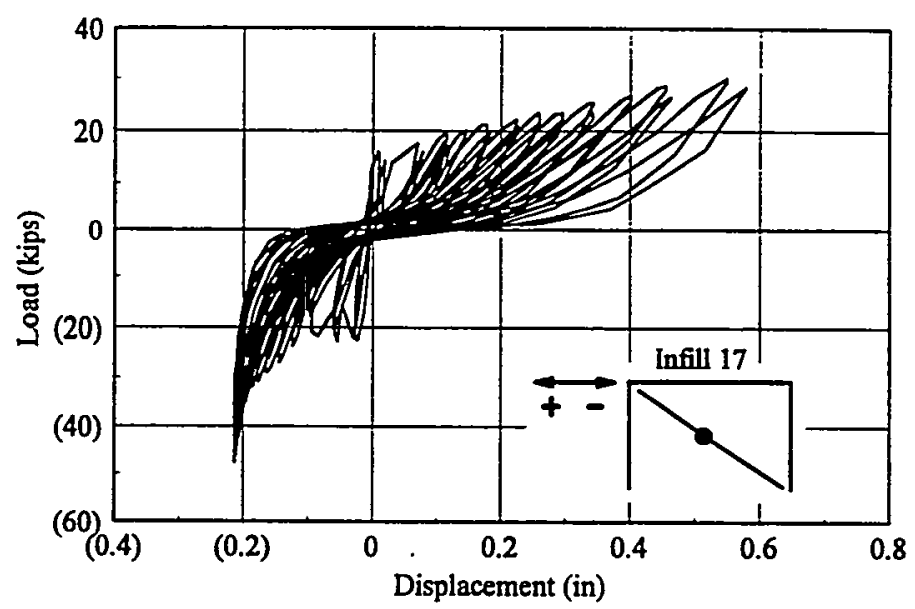

Figure 5.3 Specimen 17 Panel Diagonal Hysteresis 1

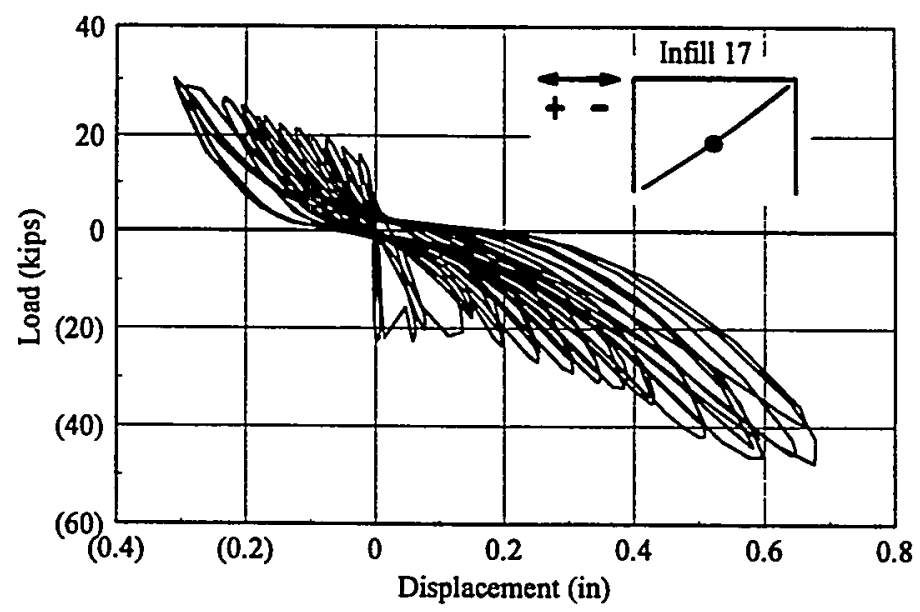

Figure 5.4 Specimen 17 Panel Diagonal Hysteresis 2 


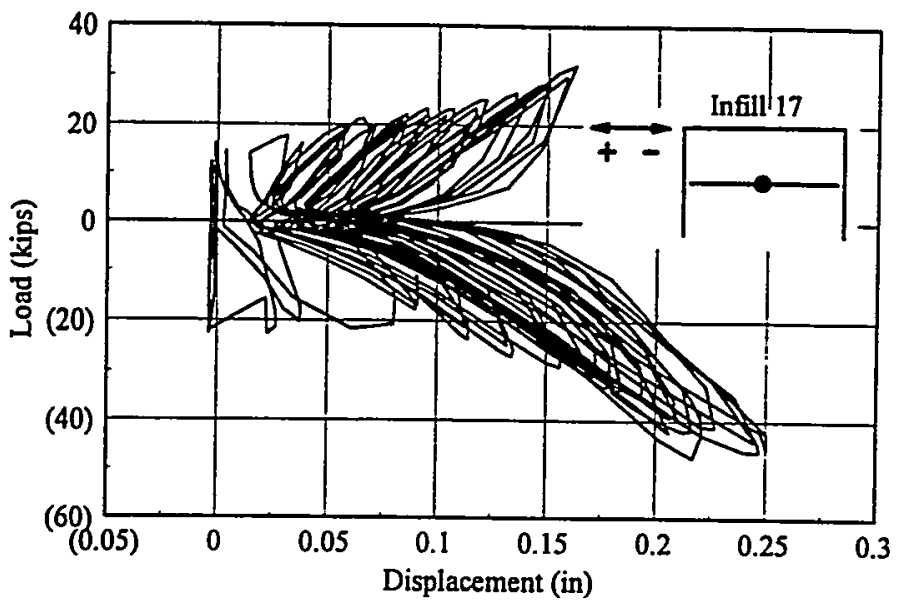

Figure 5.5 Specimen 17 Panel Horizontal Hysteresis

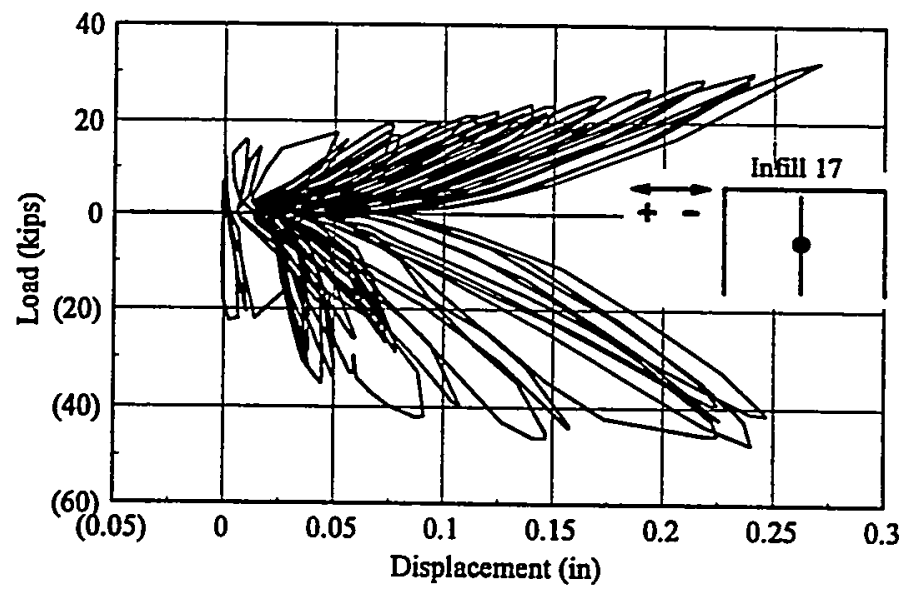

Figure 5.6 Specimen 17 Panel Vertical Hysteresis

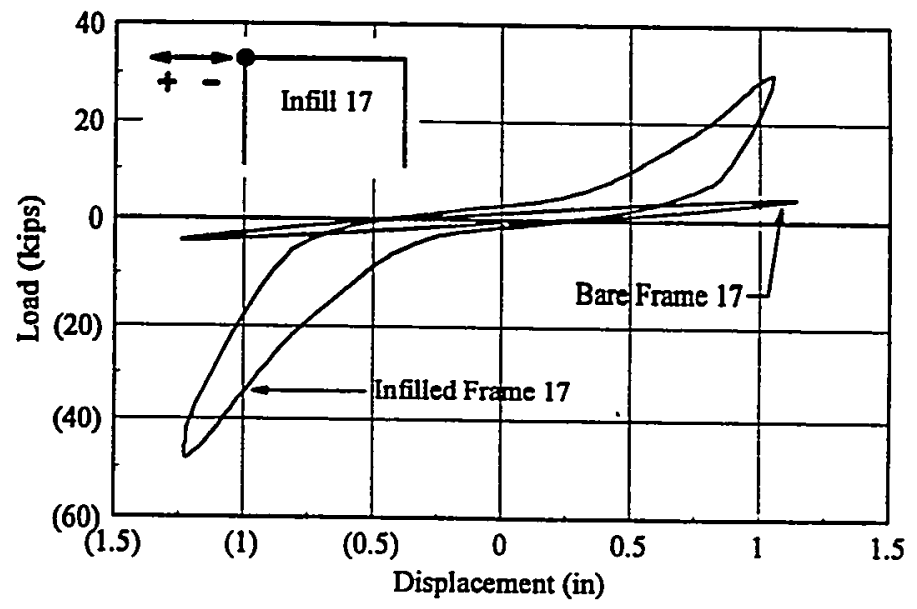

Figure 5.7 Comparison of Infilled Frame and Bare Frame 


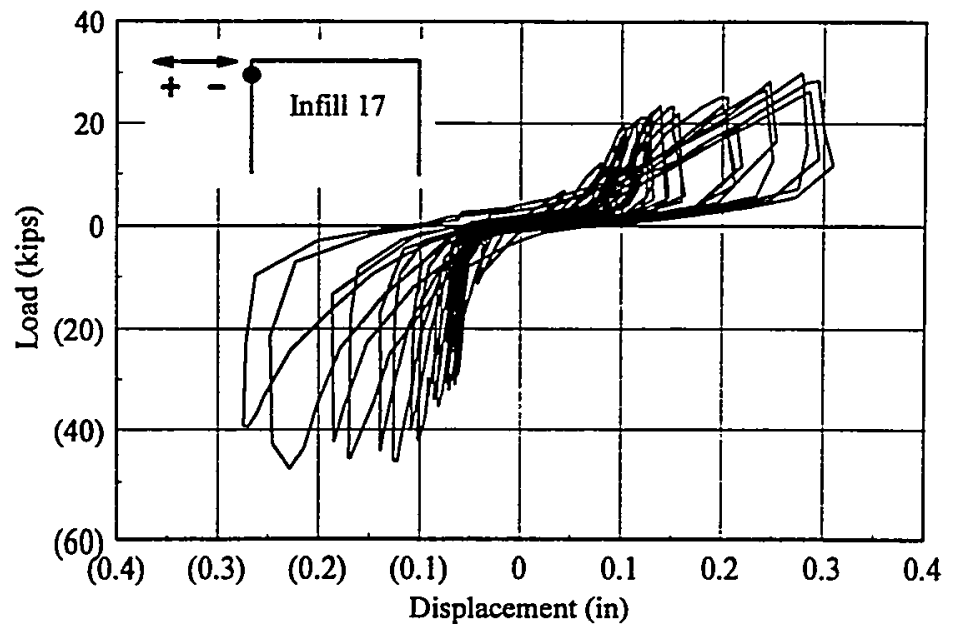

Figure 5.8 Specimen 17 Relative Column/Panel Displacement

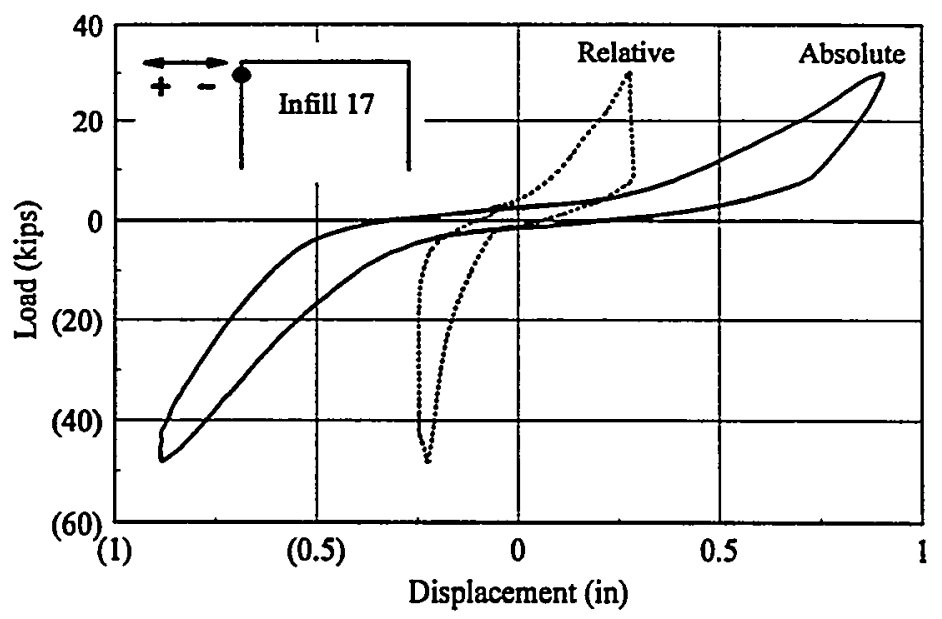

Figure 5.9 Comparison of Relative and Absolute Displacement

is shown in Figure 5.9. The flat zone of low stiffness of the absolute displacement curve is greater than that of the relative displacement curve, indicating some plastic deformation in the masonry after the column/panel gap was closed. The pinching is attributed partly to interface degradation at the frame/panel boundary, but primarily to plastic deformations of the masonry. Similar plastic deformations were observed in load-unload cycles of prism tests. 
Two distinct failure mechanisms were observed in the in-plane testing. The first was panel cracking which has been correlated to the gross shear strength $\left(\sqrt{f^{\prime}}{ }_{m}\right)$ of the masonry. The second was corner crushing which was seemingly independent of the panel size and resulted in loss of tiles in the upper corners. Figure 5.10 gives the crack pattern of Frame 17 after major panel cracking has occurred but before ultimate capacity is reached. Figure 5.11 shows the upper corner region of Frame 17 after ultimate capacity has been reached and the corner tiles split along the inner webs and spalled from the panel. At this point there is considerable postpeak capacity as evident in the continued loading cycles of Figure 5.2. Loading was continued for this specimen until displacement transducers were near their limit and the column strains reached yield. A partial height infill developed with the effective loss of the upper two courses of tile as the postpeak loading continued.

The in-plane hysteretic behavior and failure patterns of the double wythe infills were similar to those of the single wythe infills. For specimens 4 and 5 , panel cracking was followed by a local crushing failure in the upper comers of the infill. A significant separation of the wythes of the upper courses was observed as the tiles of each wythe failed independently in the corner crushing mode. This follows logically as there was no appreciable collar joint or other special binding condition to prevent the wythes from responding separately. Although the tiles of a given wythe would fail prior to those of an adjacent wythe, no significant out-of-plane stability of the courses was observed. Prior to ultimate capacity, the double wythe construction responded in a somewhat composite manner due to the equal confinement of the wythes under in-plane loading.

During earthquake loading, detrimental effects may often be minimized by a structure's ability to dissipate energy. Figure 5.12 compares the hysteretic energy dissipation of bare and infilled frames. Slightly lower energy dissipation was observed for the second and third cycles 


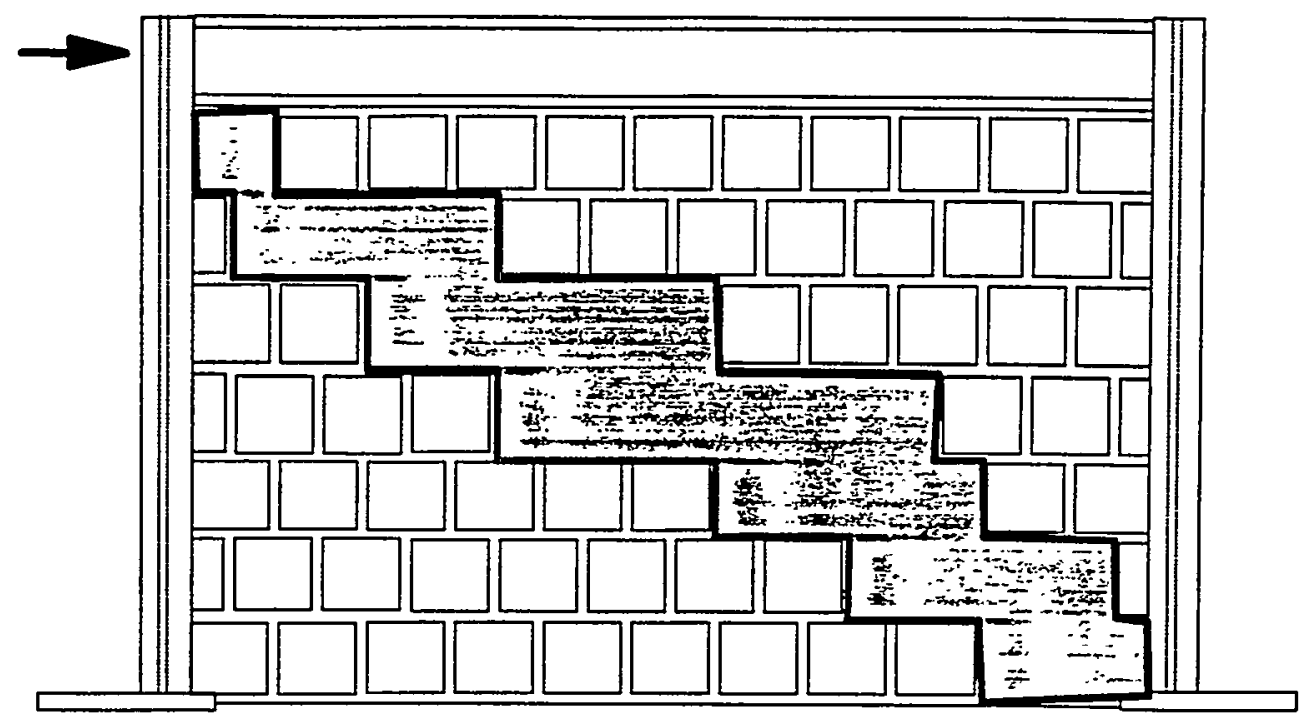

Figure 5.10 Infill 17 Banded Crack Pattern Under Push Load

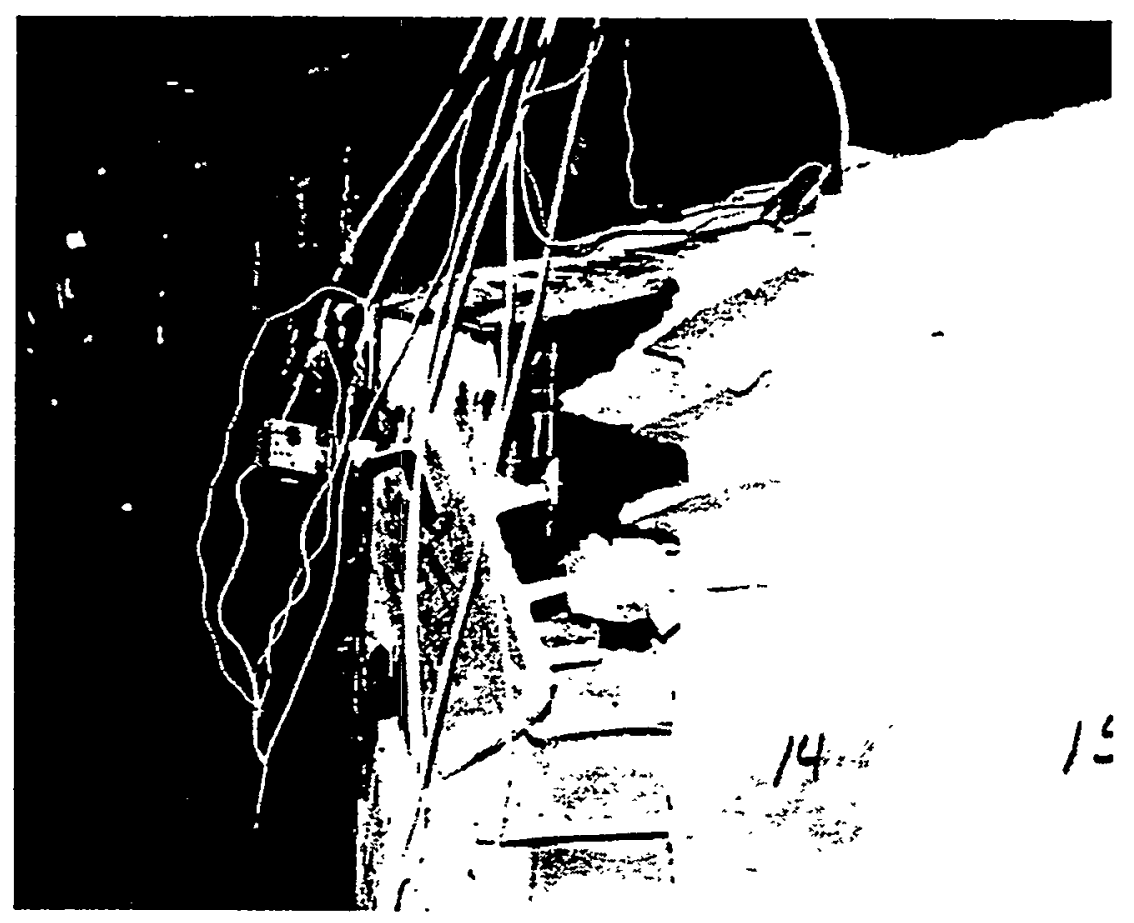

Figure 5.11 Infill 17 Corner Crushing Failure 

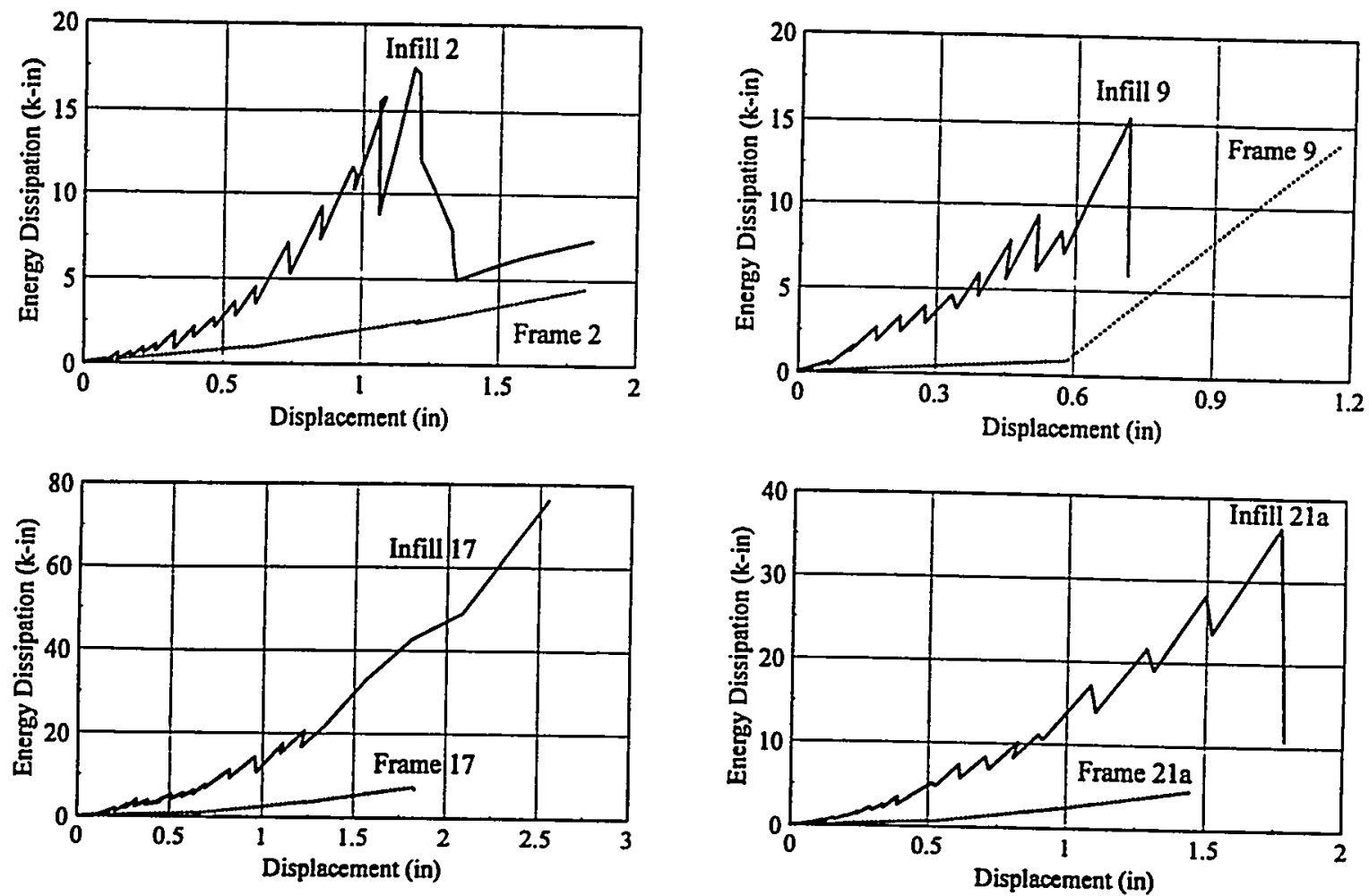

Figure 5.12 Hysteretic Energy Dissipation

of a given infill displacement. Relating infilled frame to bare frame energy dissipation, specimen 2 reached a maximum ratio of 6.7 at 1.2 inches displacement. Beyond this point, the damage to the infill quickly reduced the energy dissipation nearly to that of the bare frame. Specimens 9 and $21 \mathrm{a}$ behaved similarly, except that fewer postpeak cycles were performed on the infills. The maximum energy dissipation for these shorter panels was typically $2-4$ cycles after the peak inplane capacity was reached.

The ratio of infilled frame to bare frame energy dissipation of specimen 17 was 5.8 at 1.8 inches. No bare frame loading cycles were performed at greater displacements. As indicated in Figure 5.12, infilled frame 17 reached a maximum energy dissipation of $76 \mathrm{k}$-in at 2.5 inches displacement with no apparent reduction as the test was completed. The continued energy dissipation of infilled frame 17 well past ultimate capacity is consistent with the greater length of the panel and the localized damage in the masonry. 


\subsubsection{Infill Parameter Study}

Several engineering conditions including varying frame stiffness, single and double wythe construction, varying panel aspect ratio, offset panels, weak column/infill interface, and corner openings were evaluated in the in-plane tests. Two infills were retested to evaluate repair and retrofit techniques.

Specimens $1,2,3$, and 9 were tested to determine the effect of varying frame stiffness on in-plane behavior of 8 " single wythe clay tile infills. Similarly, specimens 4 and 5 were comprised of two different frame stiffnesses for 13" double wythe clay tile infills. Complete load-displacement responses measured at the beam centerline are given in Figure 5.13. The loaddisplacement response of specimen 17 was presented in Figure 5.2. Summaries of in-plane capacities and displacements and diagonal compression strains at those capacities are given in Table 5.1. Bare frame capacity and net panel capacity are also included.

The in-plane displacements were measured at the beam centerline and are coincident with ultimate capacity. The diagonal compression strains were computed from the shortening of the panel diagonal at or near ultimate capacity. Significant infill cracking and other nonlinear behavior is incorporated in this pseudo "strain".

The presence of the clay tile infills dramatically increased the lateral strength of the otherwise unbraced frames. The ratio of infilled frame to bare frame capacity varied considerably from 124 to 5 for specimens 1 and 9 respectively. In the case of specimen 9 , the columns were turned with the infill butting against the flanges providing strong axis bending in the plane of the panel. Given the size of the cross-section and the fact that each test panel was approximately $1 / 2$ the height of typical walls in the field, specimen 9 represented an extreme condition of column strength and relative frame to infill stiffness. 

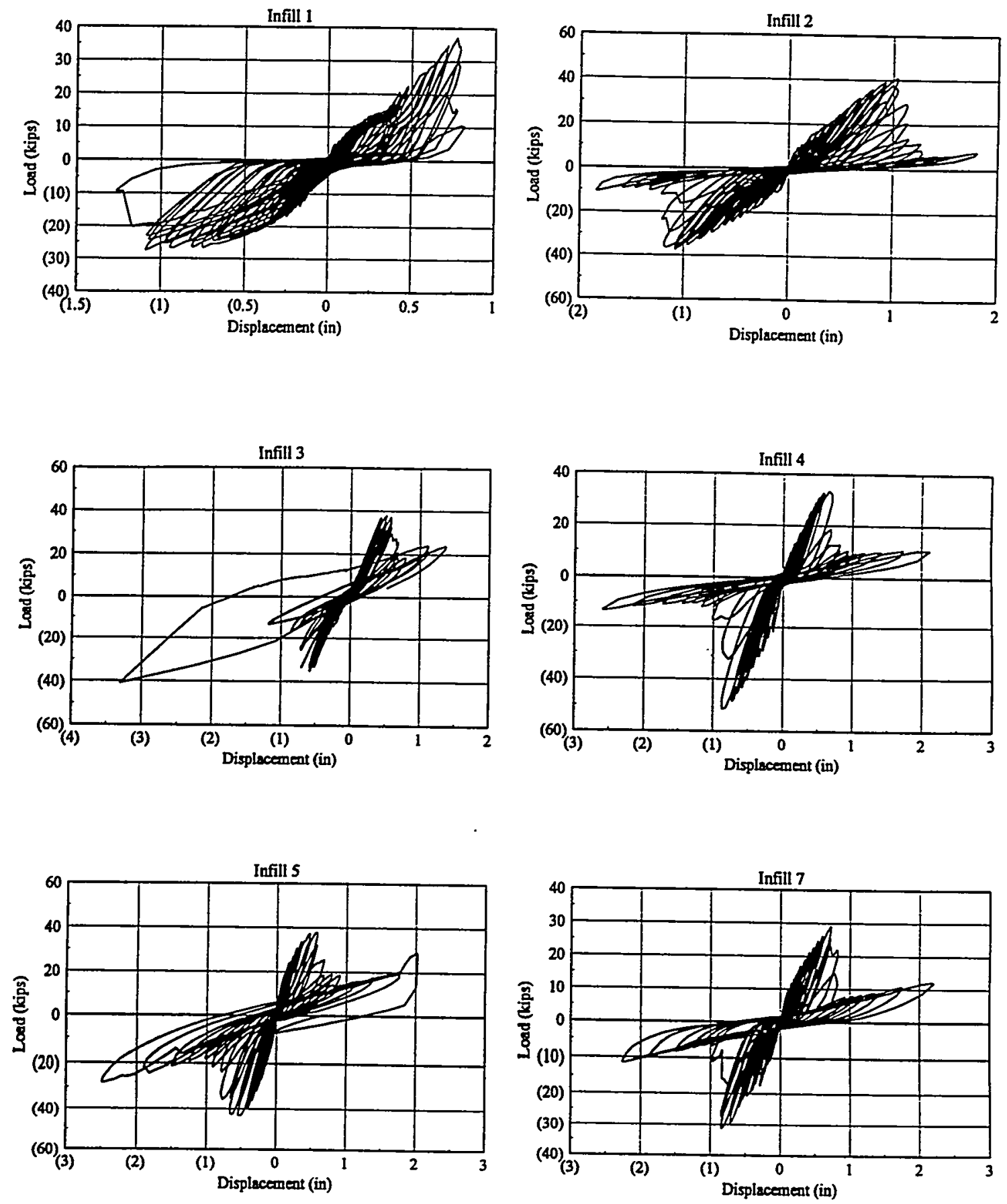

Figure 5.13 Infilled Frame In-Plane Hysteresis 

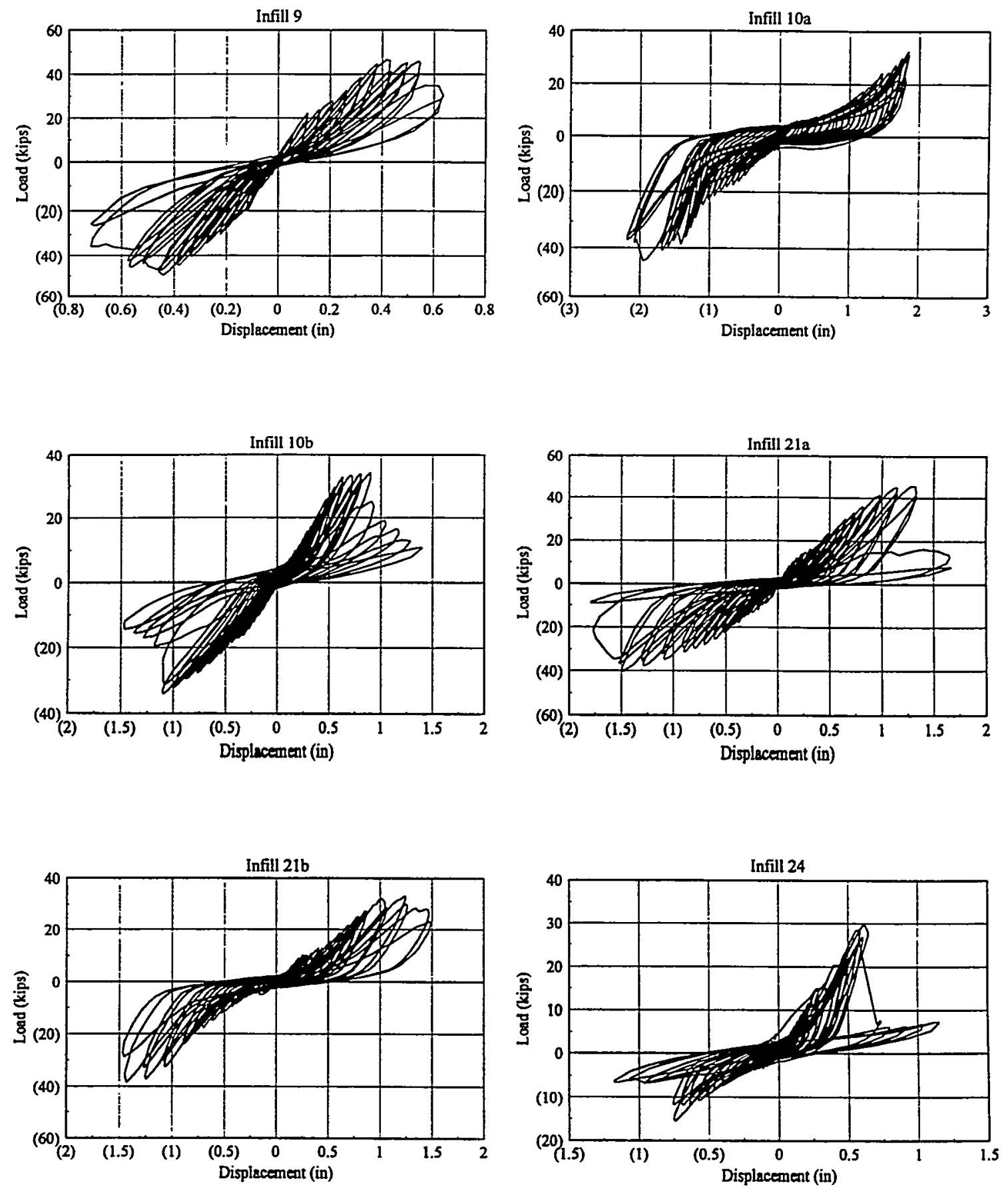

Figure 5.13 Continued 
Table 5.1 Summary of In-Plane Capacities

\begin{tabular}{|c|c|c|c|c|c|c|c|c||}
\hline \multirow{2}{*}{ Test } & \multicolumn{3}{|c|}{ Push Capacity } & \multicolumn{3}{c|}{ Pull Capacity } & \multirow{2}{*}{$\begin{array}{c}\text { Bare Frame } \\
\text { Capacity } \\
\text { (k) }\end{array}$} & $\begin{array}{c}\text { Net Panel } \\
\text { Capacity } \\
\text { (k) }\end{array}$ \\
\hline \hline 1 & 27.4 & 1.08 & 0.0036 & $\underline{37.2}$ & 0.77 & 0.0031 & 0.3 & 36.9 \\
\hline 2 & 37.4 & 1.04 & 0.0024 & $\underline{41.2}$ & 1.08 & 0.0026 & 2.3 & 38.9 \\
\hline 3 & $35.5^{1}$ & $0.62^{1}$ & 0.0017 & $\underline{37.9}$ & 0.50 & 0.0022 & 3.4 & 34.5 \\
\hline 4 & $\underline{51.8}$ & 0.83 & 0.0018 & 34.5 & 0.68 & 0.0010 & 3.5 & 48.3 \\
\hline 5 & $\underline{43.7}$ & 0.53 & 0.0013 & 37.9 & 0.57 & 0.0012 & 4.2 & 39.5 \\
\hline 7 & $\underline{31.4}$ & 0.84 & 0.0014 & 29.0 & 0.73 & 0.0010 & 1.8 & 29.6 \\
\hline 9 & $\underline{49.7}$ & 0.45 & - & 46.9 & 0.43 & 0.0015 & 9.3 & 40.4 \\
\hline $10 \mathrm{a}$ & $\underline{45.8}$ & 1.97 & 0.0035 & 32.5 & 1.84 & 0.0010 & 7.2 & 38.6 \\
\hline $10 \mathrm{~b}$ & 34.1 & 1.10 & 0.0038 & $\underline{34.3}$ & 0.90 & 0.0043 & 3.3 & 31.0 \\
\hline 17 & 48.2 & 1.22 & 0.0015 & 46.7 & 2.52 & 0.0021 & 3.3 & 44.9 \\
\hline $21 \mathrm{a}$ & 40.4 & 1.48 & 0.0042 & $\underline{46.4}$ & 1.31 & 0.0031 & 4.8 & 41.6 \\
\hline $21 \mathrm{~b}$ & $\underline{38.6}$ & 1.44 & 0.0054 & 33.5 & 1.24 & 0.0042 & 5.3 & 33.3 \\
\hline 24 & 15.7 & 0.75 & 0.0010 & $\underline{30.0}$ & 0.64 & 0.0008 & 2.3 & 27.7 \\
\hline \hline
\end{tabular}

Teak load of $41.1^{k}$ recorded at $3.26^{\mathrm{h}}$ during hydraulic control problem

A comparison of the $8^{n}$ single wythe infills $1,2,3$, and 9 , indicates that no significant changes in panel capacity resulted from marked variations in the frame stiffness. This is best indicated by the net panel capacities given in Table 5.1. The net panel capacity is simply the peak capacity of the infilled frame minus the capacity of the bare frame at an equal displacement. As with the infilled frames, the bare frame capacities were determined experimentally by conducting racking tests on the frame after removing the infill material. The relatively minor effect of frame stiffness on in-plane capacity is perhaps due to the panel rotation/deformation and column/infill interface softening that occurs prior to the upper corner crushing failure.

For the $13^{\prime \prime}$ double wythe infills 4 and 5 , the in-plane capacity was slightly less for specimen 5 which had the stiffer steel frame. The failure mechanisms of both infills were 
similar, but specimen 5 reached peak capacity at a much lower displacement level. The steel framing of specimen 5 was approximately twice the stiffness of specimen 4 and less than half the stiffness of specimen 9. Similar comparisons may be made for the relative panel to frame stiffness $(\lambda \mathrm{h})$ as indicated in Table 3.1. The lower net panel capacity of infilled frame 5 may be attributed to variations in the construction process and in the masonry material.

Increases in frame stiffness resulted in stiffer infilled frames which reached peak capacity at lower displacement levels. For both single and double wythe infills, lower panel compressive strains were measured for the stiffer frames, Table 5.1. The range of ductility of the postpeak behavior did not appear heavily influenced by frame stiffness. Similar levels of damage and stiffness reduction were observed in the postpeak cycles of loading. For specimen 3, control problems were experienced with the hydraulic system after peak cyclic capacity ( 37.9 kips at $0.5^{\prime \prime}$ displacement) was reached. The specimen was inadvertently loaded at a much faster rate and reached a new peak load of 41.1 kips at a displacement of $3.26^{\prime \prime}$. The results of this inadvertent loading indicate significant reserve dynamic strength of partially damaged infills.

Specimens $2,21 \mathrm{a}$, and 17 were tested to evaluate the effect of varying infill aspect ratio. The specimens were the same height but with different lengths resulting in approximate aspect ratios of $1: 1,1: 1.25$, and $1: 1.5$ respectively, Table 3.1 . Ultimate infill and net panel capacity increased with increasing panel length and aspect ratio. For the longer specimen 17 , the panel was less able to rotate and develop bands of diagonal cracks along both directions of loading as in the instance of shorter panels. The result was a smaller "strain" measuring panel distortion and crack widening along the diagonal, Table 5.1. A more definitive panel cracking failure at approximately 20 kips was observed in this specimen, Figure 5.2, after which there was a slight decrease in load for several cycles. Ultimate capacity under compressive load was governed by a local corner crushing mode of failure, Figure 5.11. A more ductile failure occurred for this 
longer specimen as shown in the gradual postpeak capacity reduction. It is believed that this behavior more closely represents full-scale field conditions.

Specimen 7 was tested to investigate the behavior of infill paneis constructed with an offset from the centerline of the framing. The loading was applied through the frame centerline at an eccentricity of approximately 3.5", Figure 3.1. This resulted in enclosure of approximately $65 \%$ of the panel area within the framing. Considerable spalling of mortar was observed on the compression side of the wall due to the out-of-plane component of the eccentric in-plane load. Negligible out-of-plane displacements were recorded.

With the exception of the offset, panel 7 was otherwise similar to specimen 2 which was used as a control. Panel strains were approximately 50\% of those of infill 2 and in-plane drift displacements were about $75 \%$ of those of infill 2. The in-plane initial stiffness was $70 \%$ of that of specimen 2 and the in-plane ultimate capacity was $75 \%$ of that of specimen 2 . Thus, the inplane stiffness and strength of the eccentric infill partly enclosed in the framing was approximately that of a concentrically constructed infill times the ratio of the net area enclosed over the total net area.

Specimen 10a was constructed with a 1" gap between the panel and the steel columns. This specimen was otherwise similar to specimen 21a which was used as a control. As shown in Figures 5.13 and 5.14, the specimen was much softer in the early stages of loading, but the stiffness was considerably greater than that of the bare frame. Figure 5.15 provides more detail with an overplot of infill 10a and $21 \mathrm{a}$ at the 1 "displacement cycle along with the bare frame at the $1.5^{\mathrm{n}}$ displacement cycle. The positive sliding contact of infill 10a along the beam interface provides added stiffness. After closing the $1^{n}$ gap, the specimen increased stiffness markedly until peak capacity was reached. The ultimate capacity was nearly the same as that of specimen 21a having no column/infill gap, Table 5.1. 

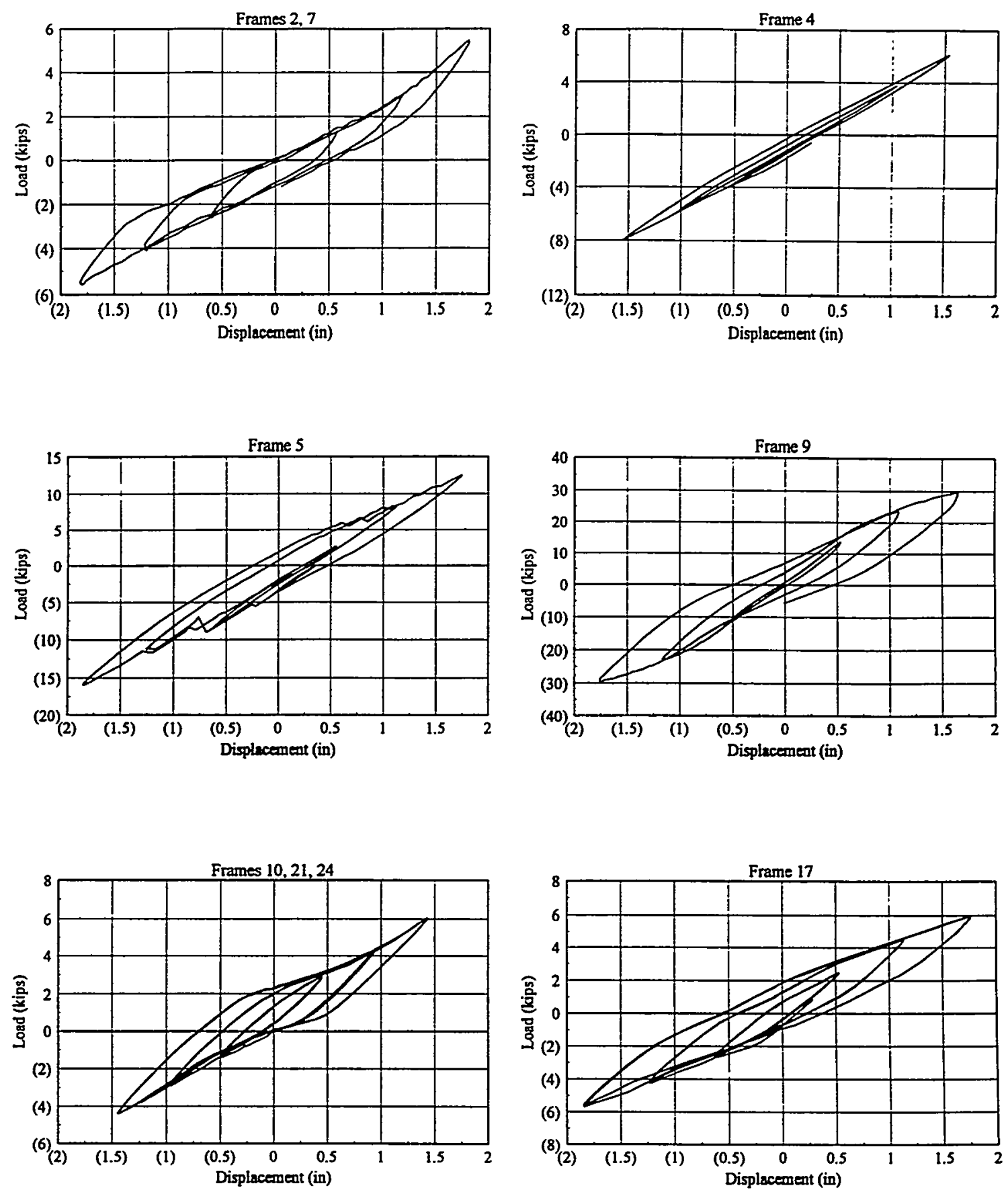

Figure 5.14 Bare Frame In-Plane Hysteresis 


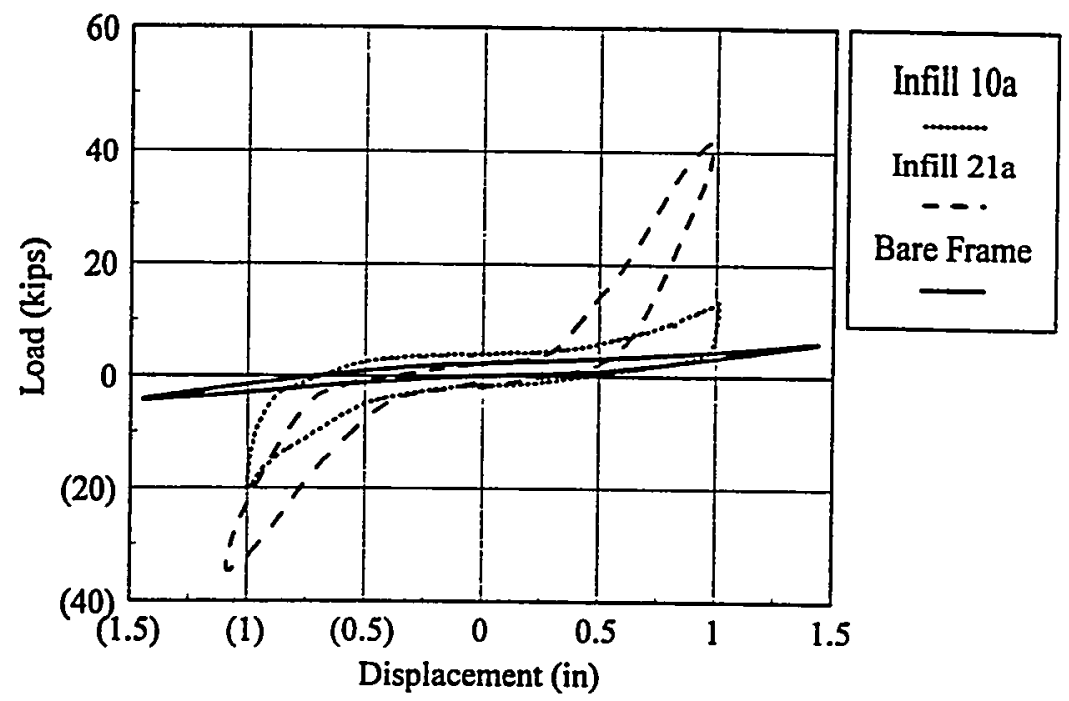

Figure 5.15 Comparison of Infill 10a and 21a With Bare Frame

Panel cracking patterns for specimen 10a are shown in Figure 5.16 and are somewhat different than the typical diagonal stair step cracks observed in other infills without initial column interface gaps. A diagonal crack developed in the lower portion of the panel as the racking loads pushed the specimen. For the reverse load, a more vertical crack propagated from the top of the panel toward the lower portion of the column base as the racking load pulled the specimen. The results of the nonsymmetric cracking are evident in the dramatically different panel strain levels for loading in the two directions, Table 5.1.

An opening in the upper loaded corner of infill specimen 24 resulted in a soft hysteretic curve for the push cycles of the in-plane loading. Infill 24 was similar to the solid infill 21a which was used as a control. The push cycles of specimen 24 were similar to those of the weak interface test, specimen 10a. The stiffer pull cycles of the in-plane hysteresis were similar to those of a solid panel, specimen 21a. Figure 5.16 shows the panel crack patterns and the locations of panel diagonal LVDTs with respect to the opening. Low levels of panel strain were measured as panel cracking was almost unnoticeable during the push cycles of loading. Panel 

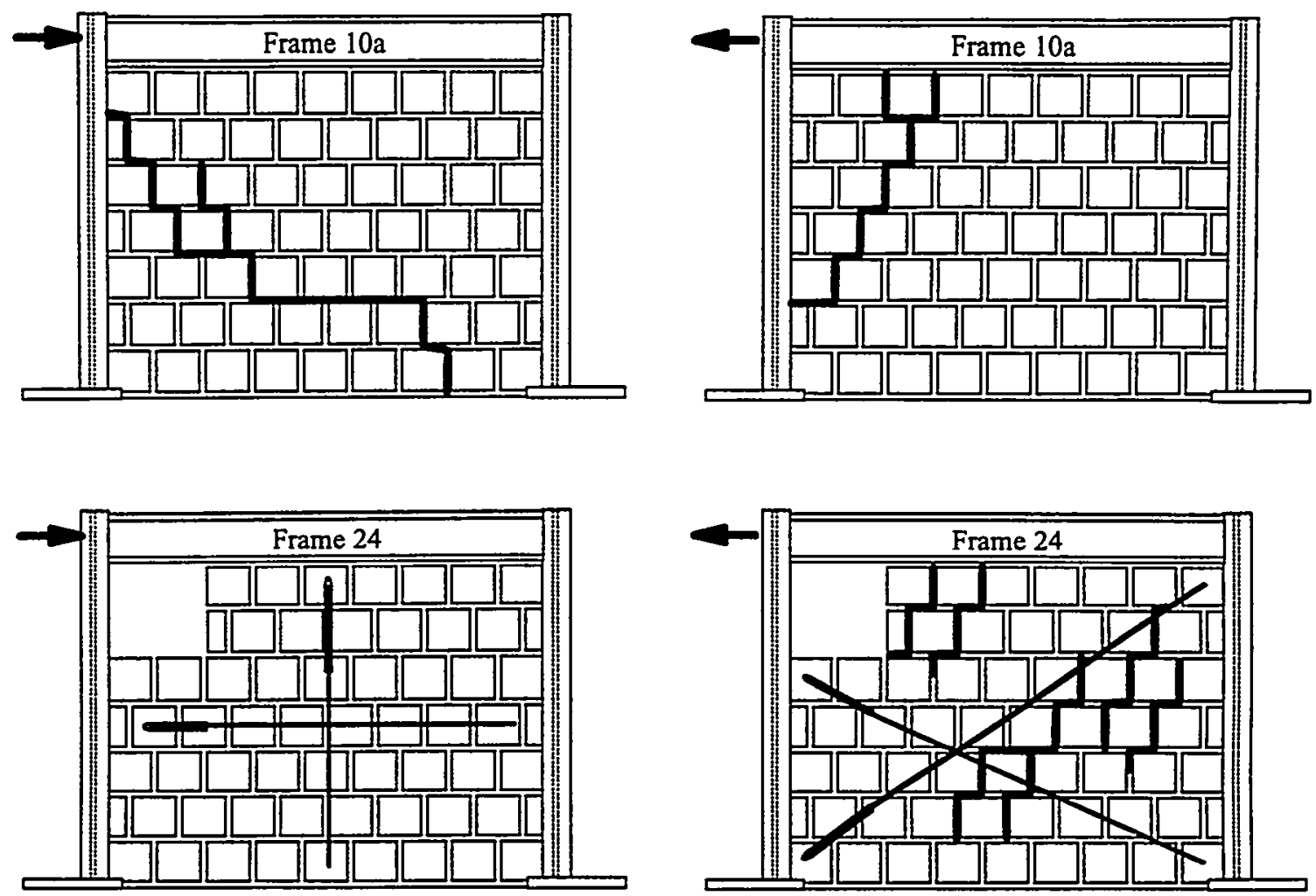

Figure 5.16 Infill 10a and 24 Crack Patterns

cracking under pull cycles was more similar to the solid panel, control specimen 21a, but with additional diagonal cracking near the opening. Lower levels of panel strain were also measured for the pull cycles of loading due to the location of the panel LVDTs with respect to the panel cracking.

The infill tiles around the opening failed first indicating significant vertical pressure in the upper courses adjacent to the opening. The corner opposite the opening failed in the usual corner crushing mode during pull cycles. A more dramatic postpeak strength degradation was observed for the panel with an opening. Comparing the results to specimen 21a, the presence of the corner opening on the loaded side of the panel reduced the ultimate in-plane capacity by approximately $25 \%$ in the pull direction and over $50 \%$ in the push direction. 
Two infill panels were repaired and retested to assess the effectiveness of the repair. All damaged tile of specimen 21a were replaced with new tile and the mortar joints tuck pointed, Figure 3.11. The damaged tile were primarily in the upper two courses of the infill. The infill was renumbered $21 \mathrm{~b}$ and was tested with a similar in-plane loading history as the original specimen. The repaired infill $21 \mathrm{~b}$ exhibited a somewhat softer and more pinched in-plane hysteresis early in the loading. Displacements at ultimate capacity were similar to infill 21 , however, panel strains were approximately $30 \%$ higher. The peak capacity of the repaired infill was approximately $80 \%$ of the previously undamaged infill.

The second panel repaired was specimen 10a. Solid concrete masonry units with type $S$ mortar were placed in the upper corners of the specimen and other damaged tiles of the top two courses were replaced with new tiles, Figure 3.12. This repaired specimen was renumbered 10b and tested with a similar in-plane loading history as the original infill. No attempt was made to fill the column/panel gap with the exception of the upper corner repair area. The in-plane hysteresis was quite similar to that of specimen 21a which indicates that the presence of a solid connection in the upper corners is sufficient in developing the compression diagonals. Thus, the retrofit increased the infill stiffness to that of a solid panel with no weak column/infill interface.

Tiles in the upper courses and near the solid concrete masonry retrofit failed first by splitting of the faceshells from the webs. Small evidence of crushing was observed in the stronger concrete masonry, but it did not govern the behavior of the panel. Ultimate strength of the retrofitted panel $10 \mathrm{~b}$ was approximately $75 \%$ of the undamaged panel 10a. Specimen 10b panel strains were more uniform than specimen 10a which had the interface gap along the entire height of the panel. The panel strains of specimen 10b were similar to those of specimen 21a which had no interface gap. Again, the positive effect of the solid connection in the upper corners of the infill is noted. 


\subsubsection{Member Forces}

Infilled frame forces were computed from the strain data recorded on the steel columns

and beams. Moments in the plane of the infilled steel frame are presented in Appendix A as a function of both beam centerline displacement and load. Infill specimens 2, 9, 17 and 21a are selected for illustrative purposes. General locations of the moments are indicated in the figures and exact locations are shown in Figure 3.7. An indication of the curvature is given for positive and negative values of moment. Positive curvature is associated with tension on the inside of the frame. Negative values of load and displacement are for loads pushing on the infilled frame. Similarly, moments computed from the strain data of the bare frame in-plane tests are given in Appendix A.

Infilled frame moments near the base of the left and right columns were generally linear with respect to displacement. The magnitude of the infilled frame moments near the column base was typically equal to those of the bare frame for a given displacement. Infilled and bare frame moments having similar magnitude but different curvature were observed for displacements in opposing directions. This is consistent with the hypothesis that strut forces are transferred into the floor through the infill, not the columns. If there were bearing on the columns, moments would be different between the bare frame and the infilled frame for a given displacement, but they are not. Therefore gaps along the column base are not nearly as important as gaps near the column top.

Infilled frame 17 moments began to depart from linearity as large displacements and plastic strains were reached. Infilled frame moments of the figures are for constant elastic modulus even though plastic behavior occurred in the last few loading cycles. This behavior corresponded to high damage levels in the upper corners of the infill and the development of a partial height infill. 
Infilled frame moments at the base of the columns are not linear as a function of load. This is also somewhat true of the bare frame moments, indicating partial rotational restraint in the connections. The infilled frame moment-load hystereses display similar characteristics as the infill load-deflection hystereses. An overall softening of the infill is indicated as moments increase nonlinearly with increasing load. A noticeable increase in frame moments occurs with the onset of panel cracking (e.g. specimen 17). Symmetry of the infill response is observed as moments near the base of both left and right columns are similar in magnitude for a given load or displacement.

Near the midheight of the columns, infilled frame moments are nearly linear with respect to displacement. Surprisingly, the moments are not more linear as the column tends to move away from the infill than as the column tends to move into the infill under reversed loading. This illustrates that the column moments are not just a function of bearing along the infill interface, but are also a function of the column displacement and rotational capacity of the connections.

Infilled frame moments near the column midheight of infilled frame 9 have the same curvature for opposing beam centerline displacements (or loads). This occurred because frame 9 was quite stiff with its strong axis orientation in the plane of the wall and had a more restrained beam-column connection relative to the other frames.

Infilled and bare frame moments near the top of the columns are heavily influenced by the moment capacity of the beam-column connection. This is evident in the open hysteretic loops of the bare frames which indicate slippage in the connection after its moment capacity is reached. For higher drifts, the bare frame moments increase after initial rotation of the connection and as bearing develops in the bolts of the connection providing reserve rotational restraint at high displacement. 
Infilled frame moments are similar to bare frame moments, except near the column top when pushing into the infill. There is generally an increase in the moment near the top of the columns as the infill bears on the column. In later stages of the loading and when pulling away from the panel, the moments are the same as the bare frame moments. This indicates that the infill shear is transferred along the panel top and very little shear is transferred along the columns. This shear transfer is confirmed by the capacity and stiffness developed in infill $10 \mathrm{a}$ which had an initial 1" gap along the columns.

As expected, the bare frame moments near the ends of the beams were similar to the moments near the tops of the columns. However, the beams of the infilled frames remained essentially in upward curvature throughout all phases of the cyclic in-plane loading. This is due to the expansion of the infill during both push and pull cycles.

Near the end of the cyclic loading, the upper course of the shorter infills are heavily damaged and the upward pressure relieved resulting in near zero moment in the beams. For longer specimens (e.g. specimen 17) exhibiting only upper corner damage of the infill at high loads, the reduction in upward thrusts and moments in the beams are more gradual. Again, the importance of the panel top interface is evident for the beam to adequately confine the infill.

Axial forces of infilled and bare frames 2, 9, 17, and 21a are presented in Appendix A. Many of the curves are not centered near zero force because the bare frames were tested after the infills and the zero displacement finish point for the infill tests did not necessarily correspond to zero load. General locations of the axial forces are indicated in the figures and exact locations are shown in Figure 3.7. Positive axial force corresponds to tension in the frame members. Axial forces computed for the steel members are more sensitive to the precise location of the strain gages than are computed moments. This is because axial forces are derived from the small difference between absolute strain measurements at the extremes of the cross-section while 


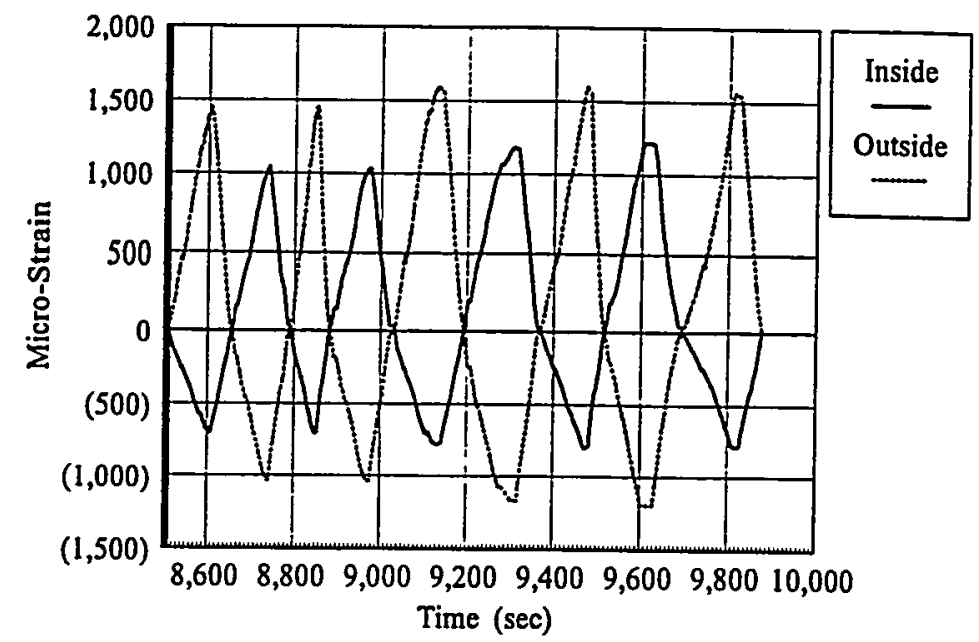

Figure 5.17 Infill 2 Partial Strain Time History for Left Column Base

moments are derived from the larger summation of absolute strains at the extremes of the crosssection, Figure 5.17.

The contribution of the infill is quite evident as the infilled frame axial forces are examined. The infill provides diagonal compressive strut behavior under both directions of loading and limits the axial compressive forces in the columns significantly.

Near the base of the right column, the axial force is nearly zero when pushing on the infilled frame. This axial force increases in tension along the height of the column (midheight and top locations). This is due to diagonal tension forces in the infill perpendicular to the compression strut pushing outward and upward on the column. During the pull cycle of loading, the infilled frame axial force near the base of the right column is approximately equal to the load, or slightly higher.

Similarly, the infilled frame axial force near the base of the left column is approximately equal to the applied load when pushing on the infilled frame. For the pull cycles of loading, the axial force near the base of the left column of the infilled frame is approximately zero with an 
increase in tension over the height of the column. Again, this is apparently due to diagonal tension forces in the panel.

The infilled frame axial forces in the columns are in general agreement with simple equivalent strut theory. The infill effectively braces the windward column like a diagonal strut while the leeward column carries little load. Without the contribution to bracing of the masonry infill, the axial forces in the bare frame columns reflect classical frame theory with the behavior a function of column base and beam-column connection capacity.

Observing the results of varying length infills (specimens 2, 21a, 17), there is little change in infilled frame axial force in the left column for a given load, although theoretically the axial force would decrease with increasing panel length. The diagonal compressive strut appears to form from the top corner to a more fixed point along the base, not necessarily the bottom corner. Since the axial force is slightly greater than the applied load, the strut would be at an angle greater than 45 degrees. From the data, it appears that a 55 degree angle may be more appropriate for infilled frame 17 . The formation of a compressive strut at a fixed point along the base is also observed in specimen 10a which had no initial column bearing due to a 1 " gap.

Near the left end of the beam, the axial force is similar to the applied load in both cycles of loading. However, for the longer specimens (17 and 21a), the axial force near the right end of the beam remains in tension during both push and pull cycles. For the stiffer and shorter specimen 9, the beam remained in compression during the push stroke and in tension during the pull stroke.

During the pull stroke, infilled frame axial forces in the beam near the left and right ends are approximately the same as the applied load. This indicates a direct axial load transfer through the beam with little shear transfer by friction along the top of infill. However, near the left end of the beam the axial compression forces are somewhat smaller than the applied load in the push 
stroke. In this instance the load transfer mechanism to the infill is a combination of column bearing and friction along the top interface. For stiffer columns (specimen 9), a greater portion of the load transfer is through column bearing.

Near the right end of the beam, the infilled frame axial forces of the longer specimens (17 and 21a) remain in tension during the push cycles of loading. Again, a more complex load transfer mechanism to the infill is indicated including bearing and friction. Infilled frame 21 , which was instrumented at midspan, illustrates the dramatic change of axial force from compression to tension along the beam length during the push strokes. For example, at a push load of $30 \mathrm{kips}$, the beam has a $30 \mathrm{kip}$ compression force at the left, a $13 \mathrm{kip}$ compression force at the center, and a 13 kip tension force at the right. This is apparently due to upward and outward movements of the infill caused by diagonal tension perpendicular to the compression strut.

In the post-cracked condition, the infill attempts to rotate and conform to the deflected shape of the bounding frame. The presence of column bearing and top interface friction mechanisms of load transfer may explain the relatively high capacity of the larger specimens late in the loading cycles. Here partial height infills develop after the corners of the panels are destroyed leaving bearing on the columns at lower heights and friction along the remaining portion of the beam/infill interface. Likewise, the absence of friction along the top may explain the dramatic reduction in capacity and post peak behavior of infills with top gaps (Dawe, 1989a). 


\subsection{Analytical Correlation}

Seismic analyses of complex industrial facilities are typically performed using equivalent static or response spectra techniques. Three dimensional analysis is also common for structures having significant mass or geometric eccentricity. Methods for evaluating clay tile infills should be compatible with these techniques and be reasonable in the amount of computational effort required. This rationale typically leads to incorporating the infills as two-dimensional in-plane components for analysis along the axis of the walls. While several in-plane approximations of the infill might be used, the model commonly adopted is an equivalent diagonal compressive strut bracing the frame (MMES, 1992).

Certain conditions are required for a compressive strut to develop; for example, compressive strut behavior might not fully develop in infills with openings or in partial height infills. Attention to detail in modeling is also important. The use of a nonsymmetric (single) strut may produce erroneous axial forces at the reentrant corners of a structure. Dual compression only strut members are necessary for nonsymmetric openings, specimen 24 .

Two major limit states have been identified for the in-plane behavior. Diagonal cracking occurs early in the loading of an undamaged panel at a shear stress of approximately $\sqrt{f}_{\mathrm{m}}^{\prime}$. Thus, an initial compressive strut stiffness is derived for extremely low stress levels in the masonry. As the loading continues, the panel capacity is limited by corner crushing. For these higher stress levels, the infill stiffness degrades due to continued cracking and plastic deformations and the strut model must be modified to approximate in-plane stiffness far down the damage curve.

To predict infilled frame capacity, three methods were used and the results compared with the experimental data (Section 5.2.1). In the first method, an arbitrary equivalent strut area is assumed and the capacity is based on two-dimensional rigid frame behavior. The capacity of the strut is limited by the ultimate compressive strength and strain of the masonry. The second 
method assumes a linear contact stress between the panel and frame near the corners and computes the capacity based on plastic collapse theory of frames. The third method assumes an equivalent strut braces the frame and accounts for partially restrained connections by reducing the contribution of frame capacity. The strut area is determined from contact stresses along the frame, adapted from beam on elastic foundation solutions. The strut's contribution to overall capacity is limited by the compressive strength of the masonry and the frame's contribution is limited by the displacement corresponding to the panel ultimate strain.

Two approaches for using compressive strut techniques to model degrading infill stiffness are also compared with the experimental data. First, is an approach which varies the modulus of the strut resulting in a nonlinear analysis technique (Section 5.2.2). Second, is an approach which varies the effective area of the strut and requires a piecewise linear iterative solution (Section 5.2.3).

\subsubsection{Ultimate Capacity Prediction}

Three methods were used to approximate the ultimate in-plane capacity of the infilled frames. The first method, developed by Holmes (1961), defines the ultimate horizontal load capacity $(\mathrm{H})$ as:

$$
H=\frac{24 E I \varepsilon d}{(h)^{3}\left(1+\frac{I}{I_{o}} \cot \theta\right) \cos \theta}+A f_{m}^{\prime} \cos \theta
$$

in which EI is the flexural rigidity of the columns, $\epsilon$ is the failure strain of the infill, $d$ is the length of the panel diagonal, $h^{\prime}$ is the height of the panel, $I_{0}$ is the moment of inertia of the columns, $\mathrm{I}$ is the moment of inertia of beam, $\theta$ is the angle of the infill diagonal with respect to horizontal, $A$ is the area of the equivalent diagonal strut, and $f_{m}^{\prime}$ is the crushing strength of the infill material. The first term of the equation gives the load that is carried by the steel framing and the second term gives the load carried by the diagonal compressive strut of the infill. 
Holmes assumed the area (A) of the equivalent diagonal strut as $t d / 3$, where $t$ is the thickness of the infill. This equation overestimates the capacity of the clay tile infills significantly, Table 5.2. This is primarily due to the gross approximation of the strut width as $\mathrm{d} / 3$. For these computations, $\epsilon$ was taken as the maximum panel diagonal strain measured in the respective infill specimens. For the offset panel, specimen 7 , the thickness of the infill was taken as the portion enclosed in the frame (4.67"). The ultimate compressive strength of the masonry, $\mathrm{f}_{\mathrm{m}}^{\prime}$, was taken from the prism specimens with the load parallel to the cores. Although the state of stress at the corner of the panel is two dimensional, it is believed that the stress strain relationship in the horizontal direction of the panel is more representative of the behavior of the infill at high displacement levels. This is particularly significant since the masonry strength and modulus in the horizontal direction is approximately half that of the vertical direction.

Table 5.2 Predicted Strength of Clay Tile Infilled Frames

\begin{tabular}{|c|c|c|c|c|}
\hline \multirow{2}{*}{ Specimen \# } & \multicolumn{4}{|c|}{ Lateral Capacity (kips) } \\
\cline { 2 - 5 } & Experimental & Holmes & Liauw & Equation 5.5 \\
\hline 1 & 37.2 & 99.2 & 20.1 & 25.8 \\
\hline 2 & 41.2 & 104.0 & 33.2 & 46.2 \\
\hline 3 & 37.9 & 111.3 & 49.7 & 62.3 \\
\hline 4 & 51.8 & 143.6 & 36.8 & 45.8 \\
\hline 5 & 43.7 & 146.3 & 44.8 & 61.2 \\
\hline 7 & 31.4 & 62.6 & 27.0 & 32.2 \\
\hline 9 & 49.7 & 122.1 & 101.0 & 92.0 \\
\hline 17 & 48.2 & 156.1 & 44.7 & 47.7 \\
\hline $21 \mathrm{a}$ & 40.4 & 133.6 & 43.3 & 47.3 \\
\hline $\begin{array}{c}\text { Henderson } \\
\text { et al. (1993) }\end{array}$ & 64.0 & 453.1 & 70.9 & 69.5 \\
\hline
\end{tabular}


The second method used to predict ultimate infilled frame capacity is the plastic collapse theory developed by Liauw and Kwan (1983). This method is based on rigid frames so it is expected to envelope the results of the experimental program. Three failure modes are proposed with the resulting collapse shear $\left(\mathrm{H}_{w}\right)$ for a panel determined as:

$$
\frac{H_{u}}{\gamma_{p} f_{m}^{\prime} t h^{\prime}}=\min \left\{\begin{array}{c}
\sqrt{\frac{2\left(M_{p j}+M_{p c}\right)}{\gamma_{p} f_{m}^{\prime} t(h)^{2}}} \\
\frac{1}{\tan \theta} \sqrt{\frac{2\left(M_{p j}+M_{p b}\right)}{\gamma_{p} f_{m}^{\prime} t(h)^{2}}} \\
\frac{4 M_{p j}}{\gamma_{p} f_{m}^{\prime} t(h)^{2}}+\frac{1}{6}
\end{array}\right\}
$$

in which $M_{p c}$ is the plastic moment capacity of the column, $M_{p b}$ is the plastic moment capacity of the beam, and $\mathrm{M}_{\mathrm{pj}}$ is the plastic moment capacity of the joint, which is the smaller value of $M_{p c}$ and $M_{p b}$. Again, $t$ is the gross thickness of the infill, $h$ is the height of the infill, and $f_{m}^{\prime}$ is the compressive strength of the masonry. The first two equations proposed are comer crushing modes, with failure in the columns and beams respectively. These failure modes were thought to be typical of frames that are weak relative to the infill. The third equation proposed is a diagonal crushing mode, in which the infilled panel is not strong enough to develop plastic hinges in the columns or beams. This failure mode was thought to be typical of frames that are strong relative to the infill.

To account for the non-ideal plasticity of the masonry (Wood, 1978), a material penalty factor is used to reduce the infill crushing stress. The penalty factor is determined as: 


$$
\gamma_{p}=2.663 m^{2}-1.371 m+0.406
$$

The parameter $\mathrm{m}$ is determined from:

$$
m=\frac{8 M_{p j}}{f_{m}^{\prime}\left(l^{\prime}\right)^{2}}
$$

Equation 5.4

in which $\mathrm{I}^{\prime}$ is the length of the panel.

Liauw's plastic collapse method was used to predict the ultimate capacity of the clay tile infilled steel frames, Table 5.2. The results correlate reasonably with the experimental capacities with the exception of the stiffer specimen 9, which is grossly overestimated. Typically, predictions for the shorter specimens were controlled by the third, diagonal crushing mode equation, and predictions for the longer specimens were controlled by the first corner crushing mode equation. While the numerical comparisons with experimental capacities were close, the behavior of the clay tile infills did not necessarily match the behavior associated with the first and third plastic collapse equations. In the tests, the shorter specimens failed in a corner crushing mode not diagonal shear. Only specimen 17 reached plastic strains in the columns (midheight) as a partial height infill developed.

The third method used to predict the ultimate capacity of the infills is a simplification of Holmes' equations:

$$
P_{u}=\frac{6 E I}{h^{3}} \delta+A f_{m}^{\prime} \cos \theta
$$

in which $\mathrm{EI}$ is the flexural rigidity of the columns, $\mathrm{h}$ is the column height to the beam centerline, $\delta$ is the column in-plane displacement taken at the beam centerline, A is the area of the panel 
equivalent compression strut, $\mathrm{f}_{\mathrm{m}}^{\prime}$ is the masonry compressive strength, and $\theta$ is the angle of the infill diagonal with respect to horizontal. The first part of the equation represents the contribution of the framing if simply connected and the second part of the equation represents the contribution of the infill to the lateral load resistance of the system. Actual frame displacements at ultimate load were used for $\delta$ in the computations of Table 5.2. Again, $\mathrm{f}_{\mathrm{m}}^{\prime}$ was taken as that parallel to the tile cores or in the horizontal plane of the wall.

The strut area was determined using a two-dimensional beam on elastic foundation solution developed by Stafford-Smith and Carter (1969). The area of the strut is given by:

$$
A=\frac{\pi t}{4 \lambda \cos \theta}
$$

in which $t$ is the infill gross thickness and $\theta$ is the angle of the infill diagonal with respect to horizontal. In the original formulation by Stafford-Smith and Carter, the constant in the denominator was 2 for rigid frames. Here, the factor 4 has been used to account for partially restrained connections. The parameter $\lambda$ is a measure of the relative stiffness of the frame with respect to the panel and is computed from:

$$
\lambda=\sqrt[4]{\frac{E_{m} t \sin 2 \theta}{4 E I h^{\prime}}}
$$

in which $E_{m}$ is the gross elastic modulus of the masonry, $t$ is the gross panel thickness, $\theta$ is the angle of the infill diagonal with respect to horizontal, EI is the flexural rigidity of the columns, and $h^{\prime}$ is the panel height. $E_{m}$ was taken as the modulus in the horizontal direction of the wall. As can be seen in Table 5.2, the results of Equation 5.5 compare well with the experimental results. Only the stiffer specimen 9 deviates considerably from the experimental results. Equation 5.5 provides the capacity of a fixed base, pinned frame braced by a 
compressive strut. This formulation is a reasonable approximation of the actual specimen conditions which include considerable base restraint and marginal beam-column restraint.

\subsubsection{Hysteretic Modeling Using a Nonlinear Compressive Strut}

Results of the in-plane testing were compared to a compressive strut formulation in which the stiffness (modulus) of the infill varies and a nonlinear analysis results. The finite element program ABAQUS was used to carry out these analyses. The steel frame was modeled using $2 \mathrm{D}$ plane stress elements with elastic-plastic properties based on the yield stresses given in the mill test reports. Base and beam-column connections were modeled with rotational springs having properties approximated by the methodology of Frye and Morris (1975) and Kishi and Chen (1986) and refined to match the results of in-plane bare frame tests. The infill was replaced by two compression only diagonal struts having an arbitrary stress-strain relationship. A plasticity material model was used to incorporate isotropic strain hardening and softening of the compression struts (ABAQUS, 1993).

Two stress-strain relationships representing a stiffer and a more flexible infill were used in the analyses as indicated in Figure 5.18. The stiffer compressive strut properties were derived from average data of the 8 " prism specimens (cores parallel to load) tested by Boyd (1993). The area of the compressive struts were derived from the known capacities of the tests and the average ultimate compressive strength of the prisms. The capacity prediction equations previously discussed might well have been used in lieu of actual capacities.

The more flexible compressive strut properties incorporate a reduction of the prism stiffness. From Figures 5.3 and 5.8, the column top relative displacements are about $\sqrt{2}$ times greater than the panel compressive displacements. Thus local interface deformations are $\sqrt{2}$ times panel shortening. To account for this in an average sense, the prism strains were multiplied by $(1+\sqrt{2})$ to produce the more flexible properties. 

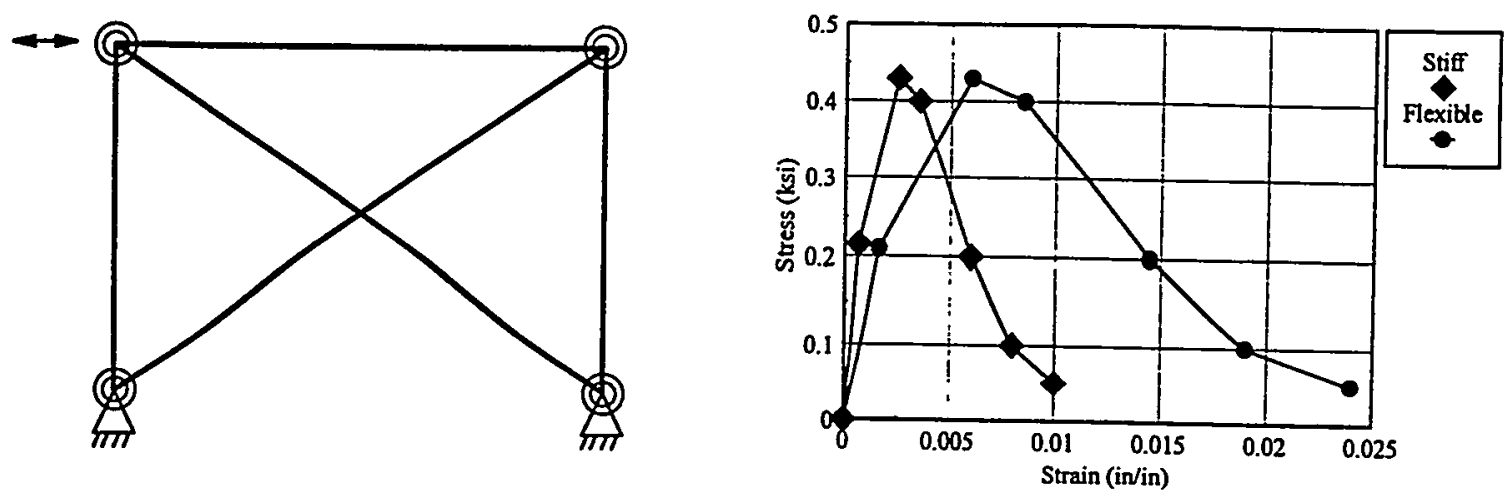

Figure 5.18 Nonlinear Compressive Strut Properties

Both compressive strut properties were used to approximate the degrading stiffness of the infill. The results of the two analyses are compared in Figure 5.19 with portions of the actual test hysteresis of specimen 17. Six hysteretic loops representative of the infill behavior states (Figure 5.1) were used as input to these analyses. The model with stiffer infill properties overestimates the stiffness of the combined infilled frame system. However, the model with more flexible infill properties does a reasonable job of approximating the hysteretic behavior, particularly during the push (negative load) cycles of the test. From the in-plane tests, it is believed that interface softening early in the loading and plastic strain or crushing of the masonry joints later in the loading accounts for much of the degrading stiffness.

\subsubsection{Hysteretic Modeling Using a Piecewise Linear Compressive Strut}

Results of the in-plane testing were compared to a compressive strut formulation in which the area of the strut varies and a piecewise linear analysis results. The compression strut formulation used is similar to that developed by Stafford-Smith and Carter (1969). The method has been extended beyond initial stiffness prediction to include various limit states and nonlinear behavior of the infill (Flanagan and Bennett, 1994a). In this method, the contribution to lateral stiffness is computed using Equations 5.8 to 5.11; see Figure 5.20 for parameter details. 

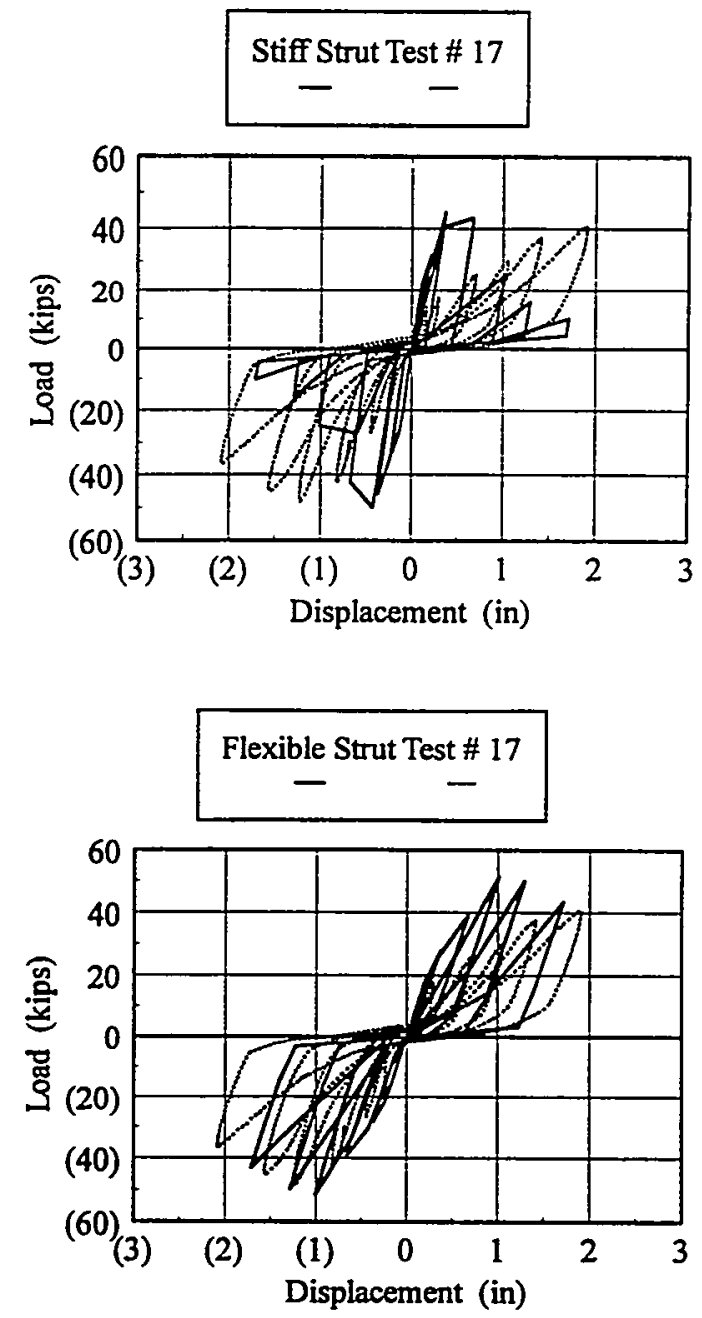

Figure 5.19 Comparison of Nonlinear Strut Analyses With Infilled Frame Test 17

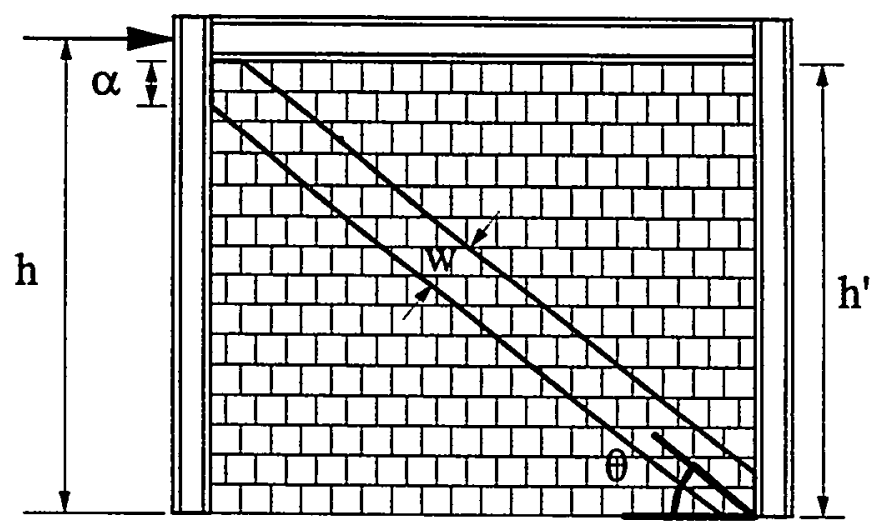

Figure 5.20 Equivalent Compressive Strut 
The length of column bearing on the infill, $\alpha$ (in), is given by

$$
\alpha=\frac{\pi}{C \lambda}
$$

where

$$
\lambda=\sqrt[4]{\frac{E_{m} t \sin 2 \theta}{4 E_{s} I_{c} h^{\prime}}}
$$

in which $E_{m}$ is the gross elastic modulus of the masonry (psi), $E_{s} I_{c}$ the flexural rigidity of the column (psi, in $\left.{ }^{4}\right), \theta$ the slope of the infill diagonal to the horizontal, $t$ the infill gross thickness (in), and $h^{\prime}$ the infill height (in). The width of the equivalent strut, $w$ (in), is

$$
w=\frac{\alpha}{\cos \theta}
$$

and the area of the equivalent strut, a $\left(\mathrm{in}^{2}\right)$ by

$$
a=w t
$$

The parameter $\mathrm{C}$ is an indicator of the limit state of the infill and varies with the in-plane drift displacement. Typical values of $\mathrm{C}$ observed in the in-plane testing are given in Table 5.3.

Table 5.3 Typical Values of C for Varying In-Plane Drift Displacements

\begin{tabular}{|c|c|l|}
\hline C & Displacement (in) & Typical Infill Damage \\
\hline \hline 5 & $0.0-0.05$ & None \\
\hline 7 & $0.05-0.2$ & Diagonal Mortar Joint Cracking \\
\hline 11 & $0.2-0.4$ & Off Diagonal Mortar Joint Cracking \\
\hline 14 & $0.4-0.6$ & Banded Diagonal Mortar Joint Cracking \\
\hline 16 & $0.6-0.8$ & Corner Mortar Crushing and Tile Cracking \\
\hline 18 & $0.8-1.0$ & Tile Faceshell Splitting (Primarily Corner Regions) \\
\hline- & $1.5 \times$ Disp @ Ultimate & Tile Faceshell Spalling \\
\hline
\end{tabular}


For very stiff columns, this strut formulation predicts significantly high contact lengths. This leads to ultimate capacity prediction at smaller displacement levels which is substantiated in the experimental results. For example, in specimen 9, the limit states of off diagonal cracking and banded diagonal cracking were barely observed before corner crushing and tile cracking occurred. Having performed a numerical parametric study, it is suggested that the length of contact, $\alpha$ in Equation 5.8, be limited to $15-20 \%$ of the panel height (h'). Similarly, based on current test results and those presented in Henderson et al. (1993), an upper limit of 50 kips for $8 "$ infills and 60 kips for 13" infills may be appropriate in addition to the limits of Section 5.2.1.

Beyond peak capacity the in-plane strength is assumed to reduce to $75 \%$ of peak at an in-plane drift of 1.5 times the displacement at peak. Postpeak testing of the infills indicates significant capacity well beyond this displacement. However, this displacement serves as a practical limit in predicting repairable damage levels of the masonry as well as an indicator of potential damage to the columns. This method has been successfully applied to the evaluation of large, complex clay tile infill structures (Flanagan and Bennett, 1994a).

Specimen 17 is used to illustrate this nonlinear compressive strut method. As Figure 5.21 indicates, the results compare well with the envelope of observed in-plane hysteretic behavior. Again, the masonry elastic modulus parallel to the tile cores is used in the computation. Other in-plane tests have compared reasonably well with this piecewise linear analysis method including a full scale test reported by Henderson et al. (1993), Figure 5.22. This full-scale test included a large pilaster around the columns, which would be expected to increase the initial stiffness of the system early in the load history. After cracking, the effect of the pilaster on the system stiffness would diminish. Figure 5.23 shows the result of incorporating a small amount (1\%) of the pilaster gross moment of inertia in the piecewise linear strut procedure. A significant increase in initial stiffness results, but with similar degrading stiffness characteristics. 


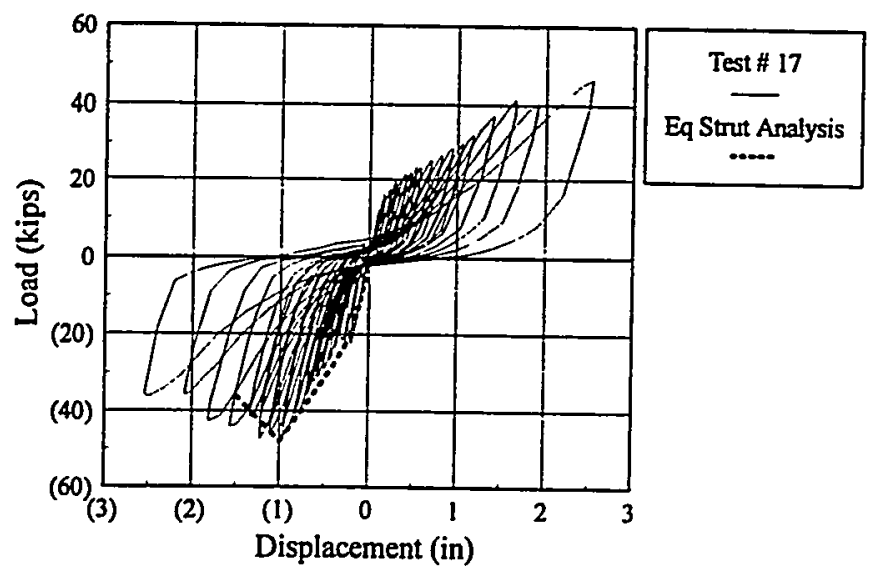

Figure 5.21 Infilled Frame 17 Piecewise Linear Strut Analysis

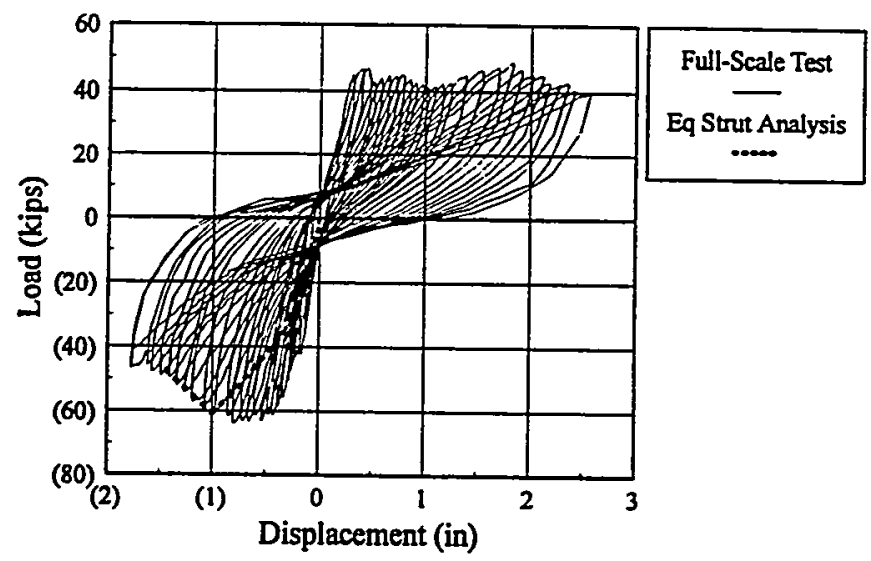

Figure 5.22 Henderson et al. (1993) Piecewise Linear Strut Analysis

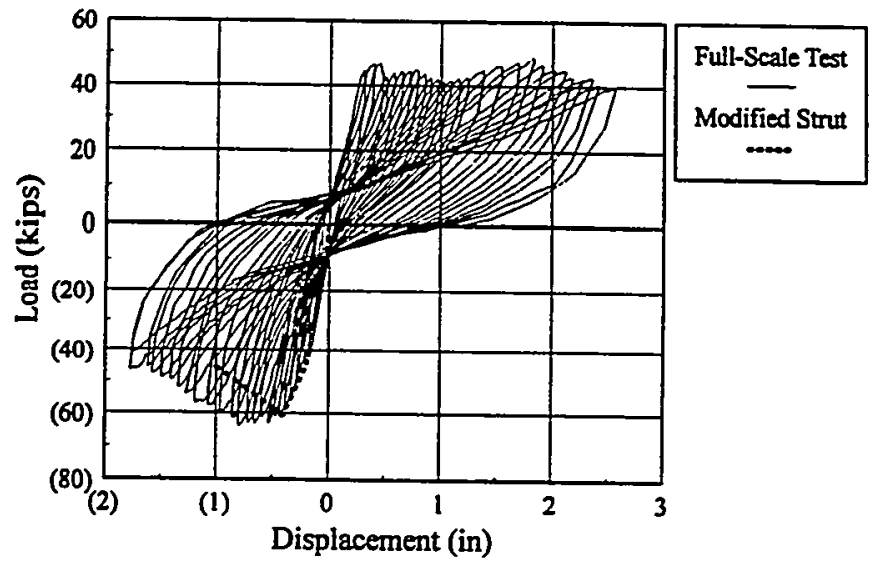

Figure 5.23 Henderson et al. (1993) Strut Analysis With Added Stiffness 


\subsubsection{Member Force Prediction}

Column axial forces may be estimated based on the results of an equivalent strut. The equivalent strut gives approximate tension in the windward columns for checking overturning, etc. There will be some tension in the leeward column counteracting gravity loads, but lateral loads from the other direction will most likely be critical. Beam axial forces are typically transferred through the floor diaphragm. These forces result in small stress levels and are typically not critical.

Column moments are most influenced by the drift displacements of the frame. From the bare frame tests, the moment capacity of the beam-column connections are small and the contact stresses along the column/infill boundary are concentrated near the column top. Assuming fixed base connections and the only forces on the column are due to drift and contact with the infill, the moments in the left column are approximated by the relationships in Figure 5.24. Using the numerical procedure defined in Section 5.2.3, the contact length for each major limit state may be found. These, with the known moment capacity at the joint, allow for computation of moments along the column height for the racking load sequence. Figure 5.25 presents the results of the column moment estimates for infilled frame specimen 17. Relatively good correlation

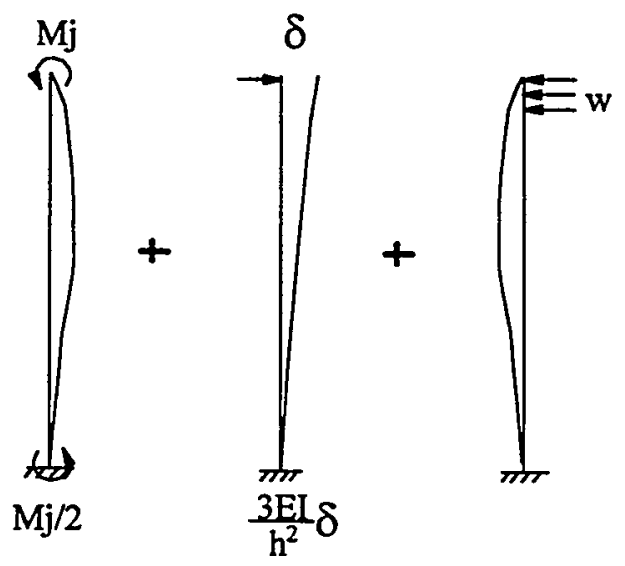

Figure 5.24 Infilled Frame Column Moments 

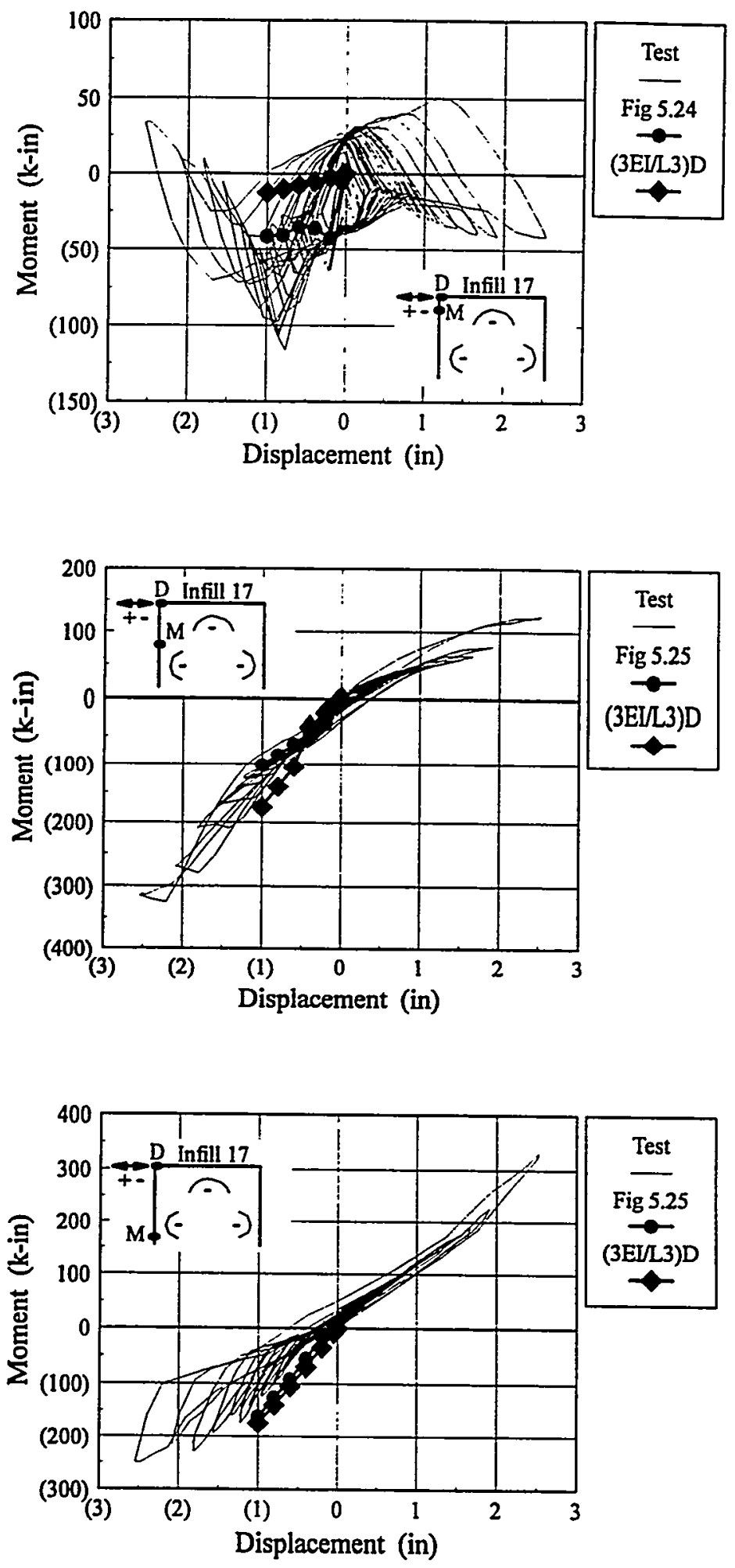

Figure 5.25 Prediction of Infilled Frame 17 Column Moments 
between experimental and predicted results of Figure 5.24 is observed. Except at the very top, the column moments also agree with those based solely on simple cantilever drift. The top column moments are small compared to the base and the simpler procedure based on in-plane drift of a cantilever is typically sufficient. 


\section{CHAPTER 6}

\section{OUT-OF-PLANE RESPONSE TO UNIFORM LATERAL LOAD}

\subsection{Panel Load-Deformation Behavior}

Three clay tile infills were tested out-of-plane with a uniform lateral loading supplied by an air bag. The tests were designed to simulate the inertial effects of the panel normal to its plane. The specimens were nominally $8 \mathrm{ft}$ by $8 \mathrm{ft}$ using similar steel framing. Two single wythe walls, 4" (Frame 25) and 8" (Frame 18) thickness, were tested and one 13" thick double wythe wall (Frame 22) was tested. Load-unload cycles of increasing pressure were applied to the infill.

The out-of-plane load-deformation of the infills was characterized by cracking in the mortar joints early in the tests, followed by the development of membrane forces in the panel as fracture lines divided the panel into separate segments, Figure 6.1. As the segments moved out of the plane of the wall and rotated about their boundaries, arching developed until failure in the masonry occurred along the boundaries. The development of arching action requires significant in-plane panel edge restraint to resist thrust forces in the plane of the infill. Typically, vertical arching occurred until failure of the top and bottom course tiles. Following failure of these courses, horizontal arching developed enabling the walls to maintain stability, Figure 6.2.

Static load-unload cycles were applied to the specimens until ultimate capacities were reached and overall panel stability began to deteriorate. Typically two cycles were performed at each increasing pressure increment. Pressure versus midpanel displacement relationships are shown in Figures 6.3-6.5. Failure in the upper and lower courses consisted of tile faceshell splitting horizontally. This indicated a combined compression and shear failure as compared to the crushing failures observed in similar tests of concrete and brick masonry. Figure 6.6 shows 

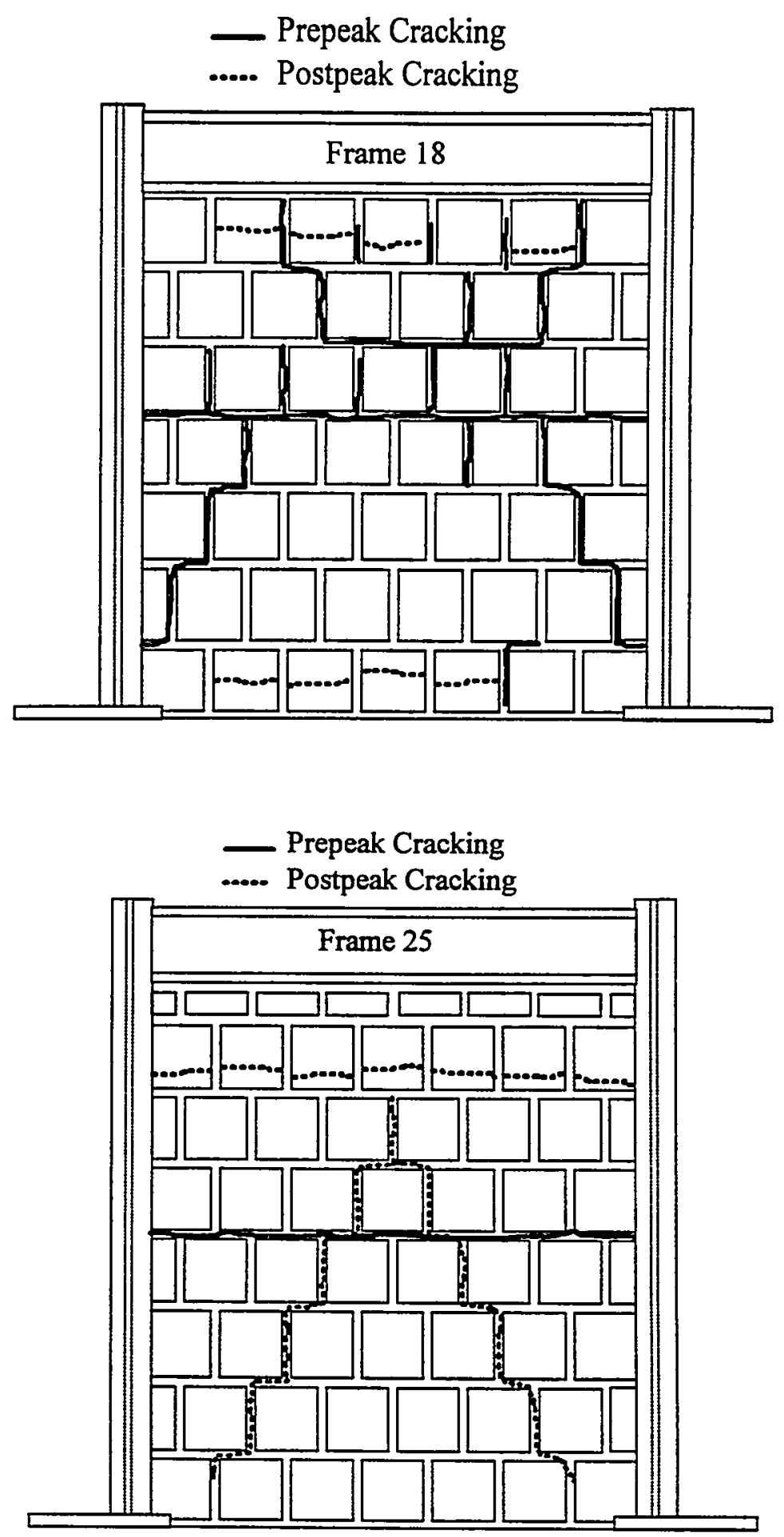

Figure 6.1 Infilled Frame 18 and 25 Crack Patterns on Exterior Face 


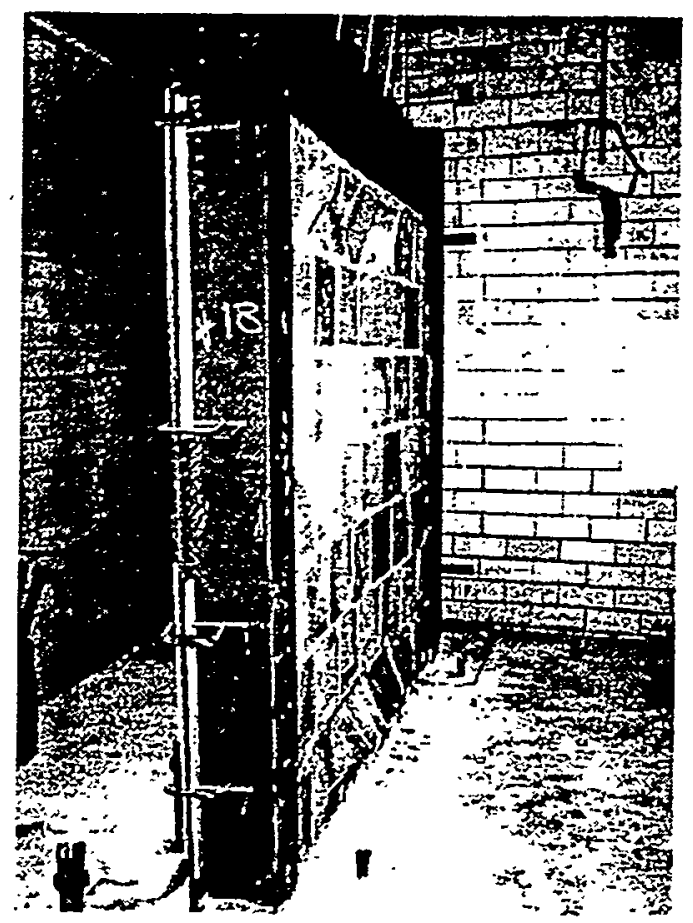

Figure 6.2 Specimen 18 Condition After Lateral Loading

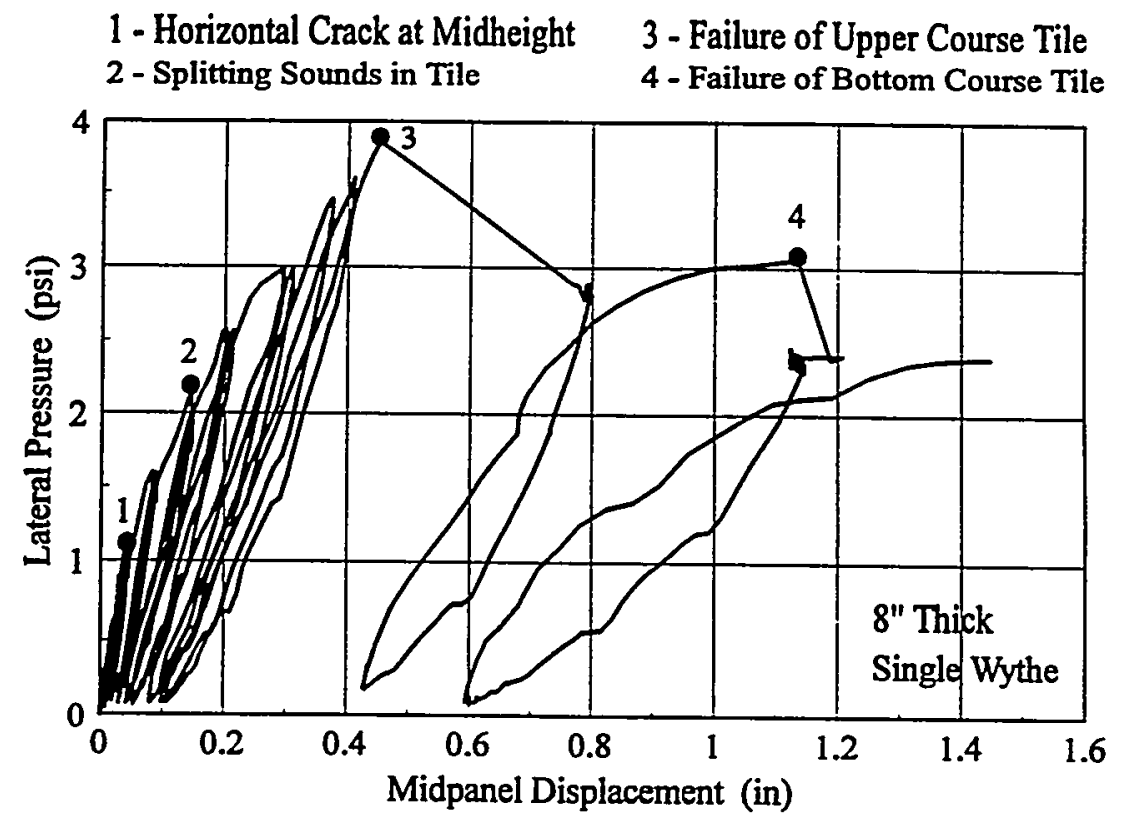

Figure 6.3 Specimen 18 Pressure Versus Displacement 


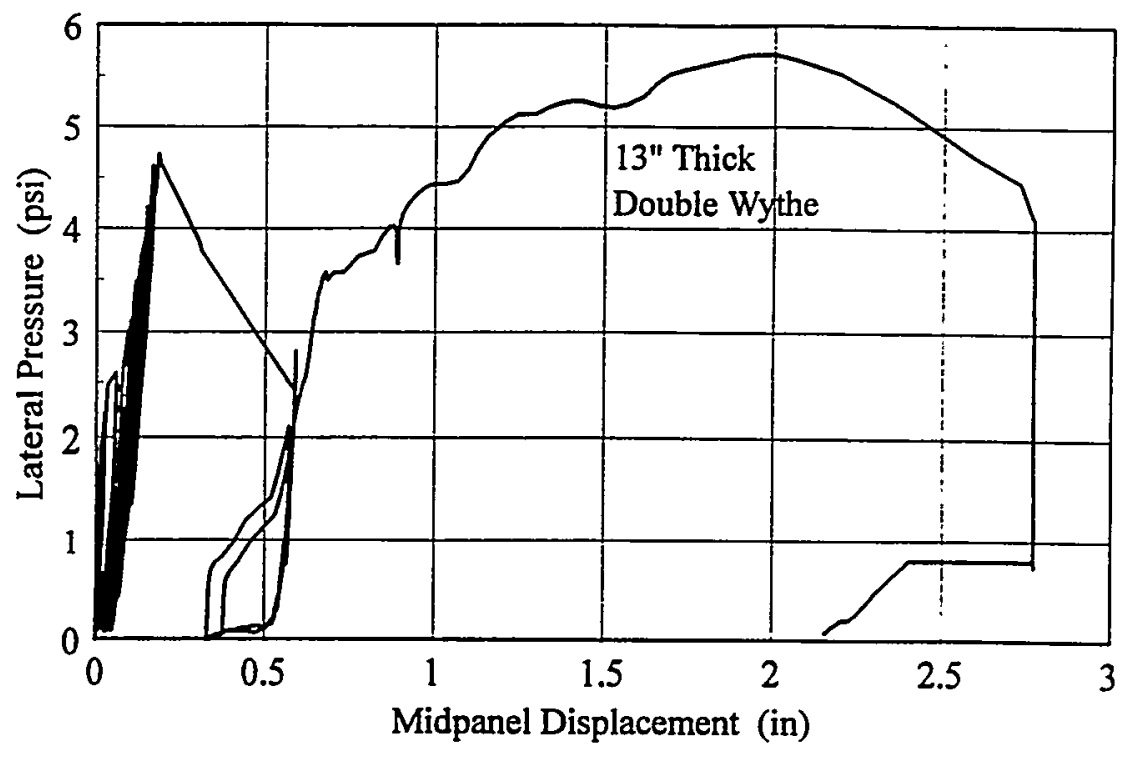

Figure 6.4 Specimen 22 Pressure Versus Displacement

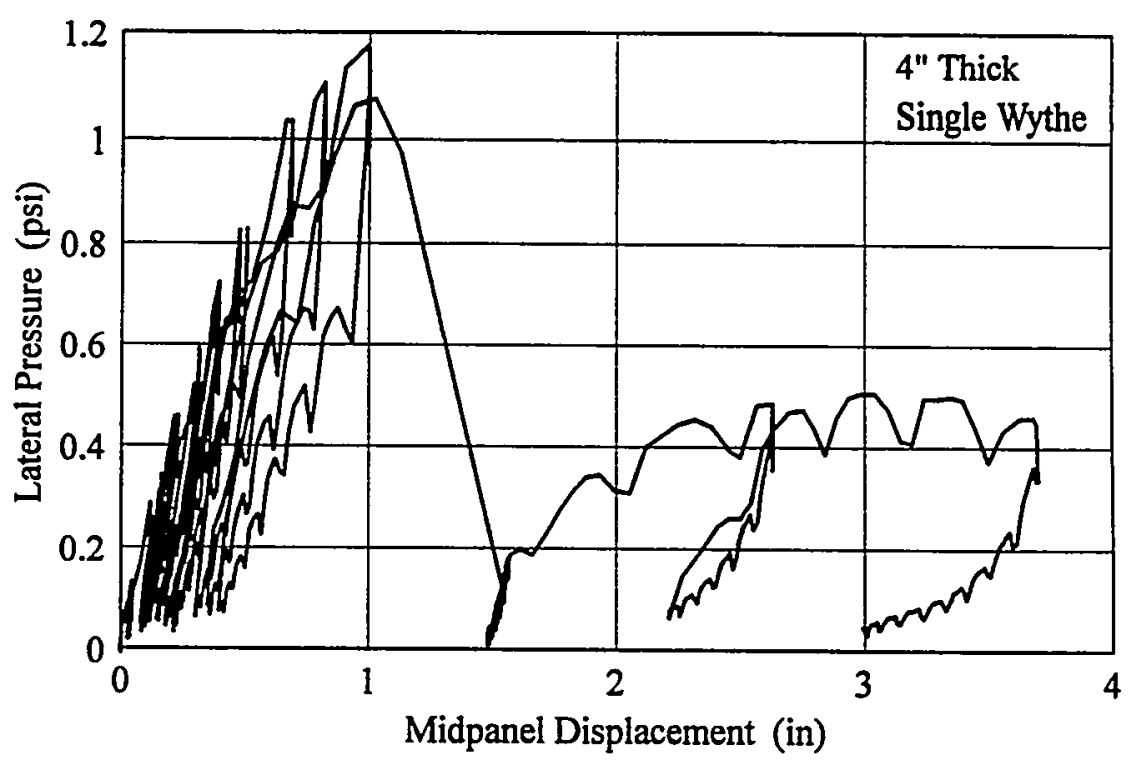

Figure 6.5 Specimen 25 Pressure Versus Displacement 


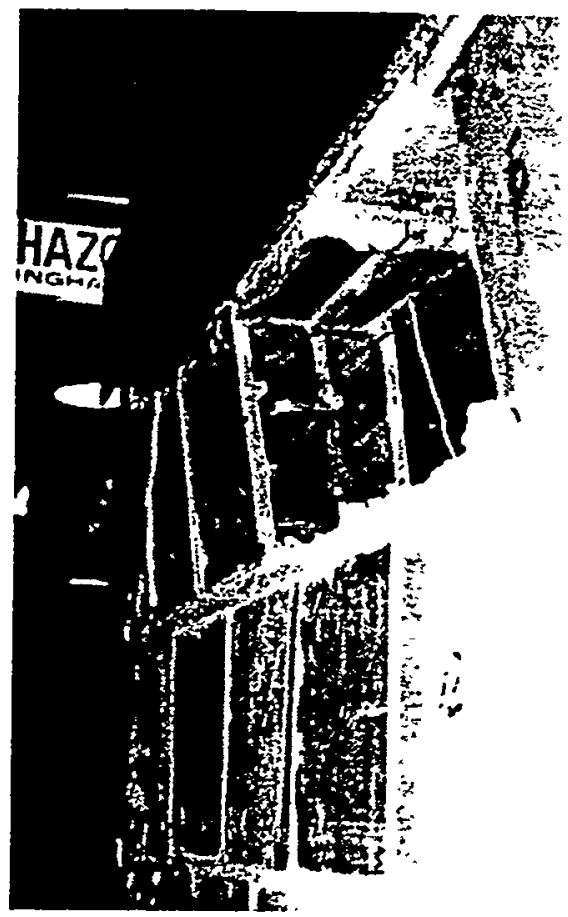

Figure 6.6 Failure Mechanism of Top and Bottom Course Tiles

a close-up of the failure of specimen 18 after portions of the tile have been removed. A detailed account of the load history of all three specimens follows.

Specimen 18 exhibited linear behavior at low pressure (0-0.3 psi) with no noticeable cracking. From 0.3 to $1.0 \mathrm{psi}$, a hairline crack was noticed primarily in the bed joint above the fourth course. This crack became more pronounced and diagonal cracks began developing at pressures near $2.0 \mathrm{psi}$. Also near $2.0 \mathrm{psi}$, popping sounds were heard indicating distress in the interior of the tile. From 2.0 to $3.5 \mathrm{psi}$, the nonlinear behavior continued as arching action developed noticeably in the panel. Near 3.9 psi, loud popping was heard as the panel experienced a sudden increase in displacement and loss of pressure to $2.8 \mathrm{psi}$. Several of the top course faceshells split on the exposed side of the panel and the upper portion of the panel shifted outward into the column flange. The specimen was unloaded and then reloaded. Near 3.1 psi, more popping was heard as the bottom course faceshells split and the lower portion of the panel 
shifted outward into the column flange. Again the specimen was unloaded and reloaded. Considerable capacity still existed in the damaged panel as it reached $2.4 \mathrm{psi}$. At this point, the test was concluded to prevent damage to the air bag system and the displacement transducers. Details of the panel deformed shape at peak capacity are shown in Figure 6.7.

It was more difficult to monitor the behavior of the double wythe wall of specimen 22 as the instrumentation was mounted on the outer wythe. The progressive damage of the wythe next to the air bag could only be surmised from noises heard during the test. From 0 to $2.0 \mathrm{psi}$, the outer wythe responded somewhat linearly. Only faint cracking noises were heard at approximately $1.5 \mathrm{psi}$. Near $2.5 \mathrm{psi}$, louder popping was heard and hairline cracks were noticed in the bed joint above the fourth course. There was a corresponding increase in midpanel displacement at this point. Vertical cracks were noticed in the head joints of the upper course at $3.0 \mathrm{psi}$. From 3.0 to $4.6 \mathrm{psi}$, the nonlinear behavior continued although the displacements in the outer wythe were relatively small. Hairline cracks in several bed joints and head joints near the center of the panel widened. At 4.6 psi much popping and cracking could be heard. The upper portion of the specimen shifted outward and the pressure was reduced to $2.5 \mathrm{psi}$. A large bed joint crack formed below the top course and one of the upper course tiles cracked. Inspection from above the specimen indicated that the upper course faceshells had split from the webs. The specimen was unloaded and reloaded to $3.9 \mathrm{psi}$. Finally the pressure was increased and a ultimate capacity of $5.7 \mathrm{psi}$ was recorded. During the later portions of the test, the outer wythe was in contact with the column flange which would aid in the development of arching action. Also, during the later portions of the test, the specimen appeared to arch horizontally. Although the behavior was not linear, specimen 25 exhibited no noticeable distress from 0 to 0.2 psi. Near $0.2 \mathrm{psi}$, a hairline crack in the bed joint above the fourth course was noticed. From 0.2 to $1.2 \mathrm{psi}$, this horizontal crack widened and vertical arching became more pronounced. 

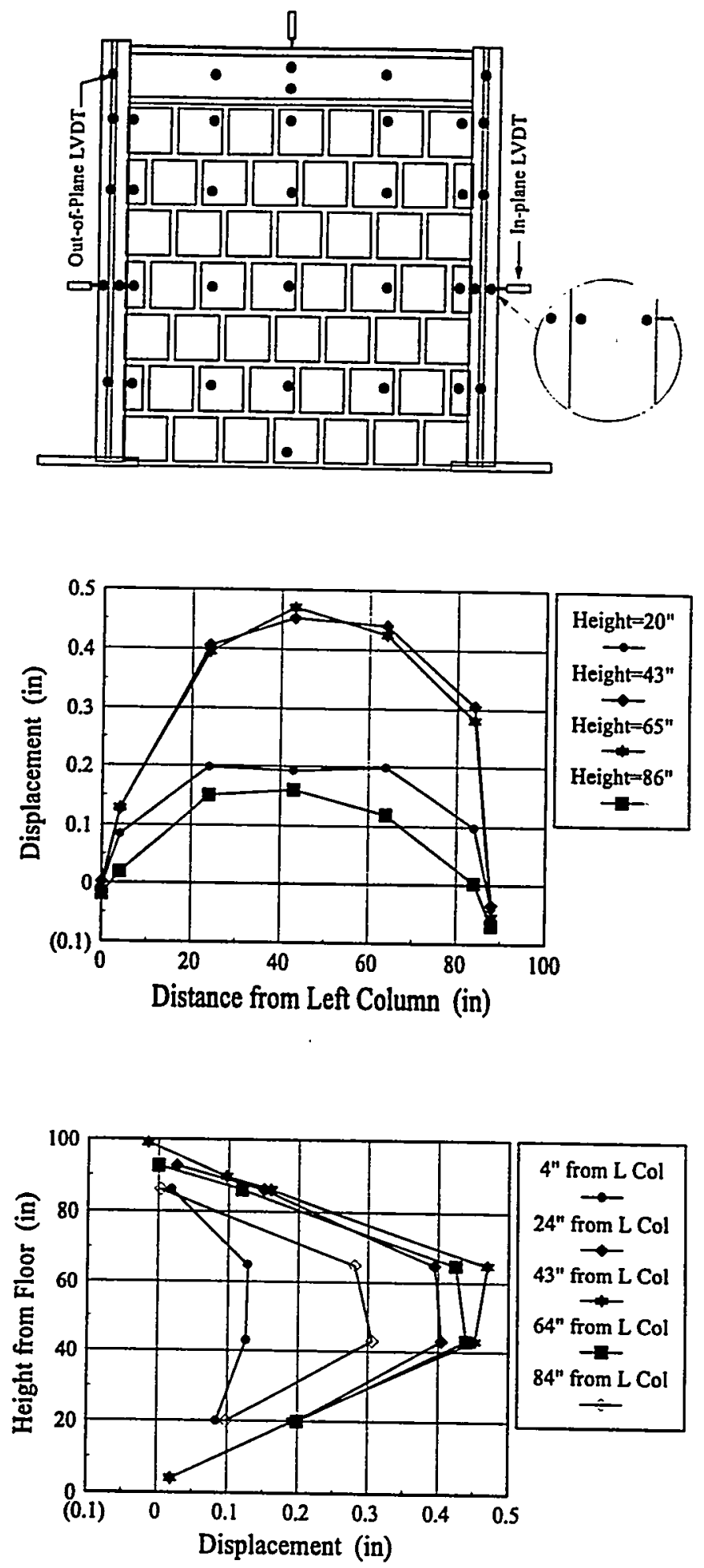

Figure 6.7 Specimen 18 Displaced Shape at Ultimate Capacity (3.9 psi) 
The panel gradually slipped along the column boundary as each pressure cycle was applied, remaining partially deformed after successive loadings. Figure 6.8 gives the displaced shape of the specimen at the ultimate capacity of $1.17 \mathrm{psi}$. There were only slight audible popping or cracking sounds from specimen 25 . During the second cycle to $1.2 \mathrm{psi}$, the top course faceshells split and the panel shifted outward at approximately $1.1 \mathrm{psi}$. The panel did not slip far enough to engage the column flanges. The pressure reduced and the panel was unloaded and reloaded for two cycles to $0.5 \mathrm{psi}$. Diagonal cracks formed as the panel began arching horizontally. The specimen remained relatively stable, although quite damaged.

\subsection{Frame Member Strains}

Frame member strains were measured near column midheight and beam quarter points as indicated in Figure 3.19. The state of strain in the frame is complex due to outward thrusting forces as the panel arches and attempts to expand along the boundaries. The strain in the frame is due to friction forces acting in the direction of the air bag pressure and in-plane forces acting along the plane of the deforming panel, Figure 6.9. Thus, bending and torsion are induced in the frame members. Figure 6.10 provides a numerical summary of the strain values at significant times in the testing. Positive strain values indicate tension. For specimens 18 and 25 , strains at ultimate capacity are given and strains are given for specimen 22 at a local peak capacity early in the loading.

Observations from the column strains are as follow. First, the columns are always in tension, resisting the upward thrust on the beams. Second, the column strains increase dramatically after ultimate capacity of the panel is reached, Figure 6.11. This is due to increased bending in the columns and the onset of horizontal arching after failure of the top and bottom course tiles. Third, the primary bending of the columns is outward and from front to back, 

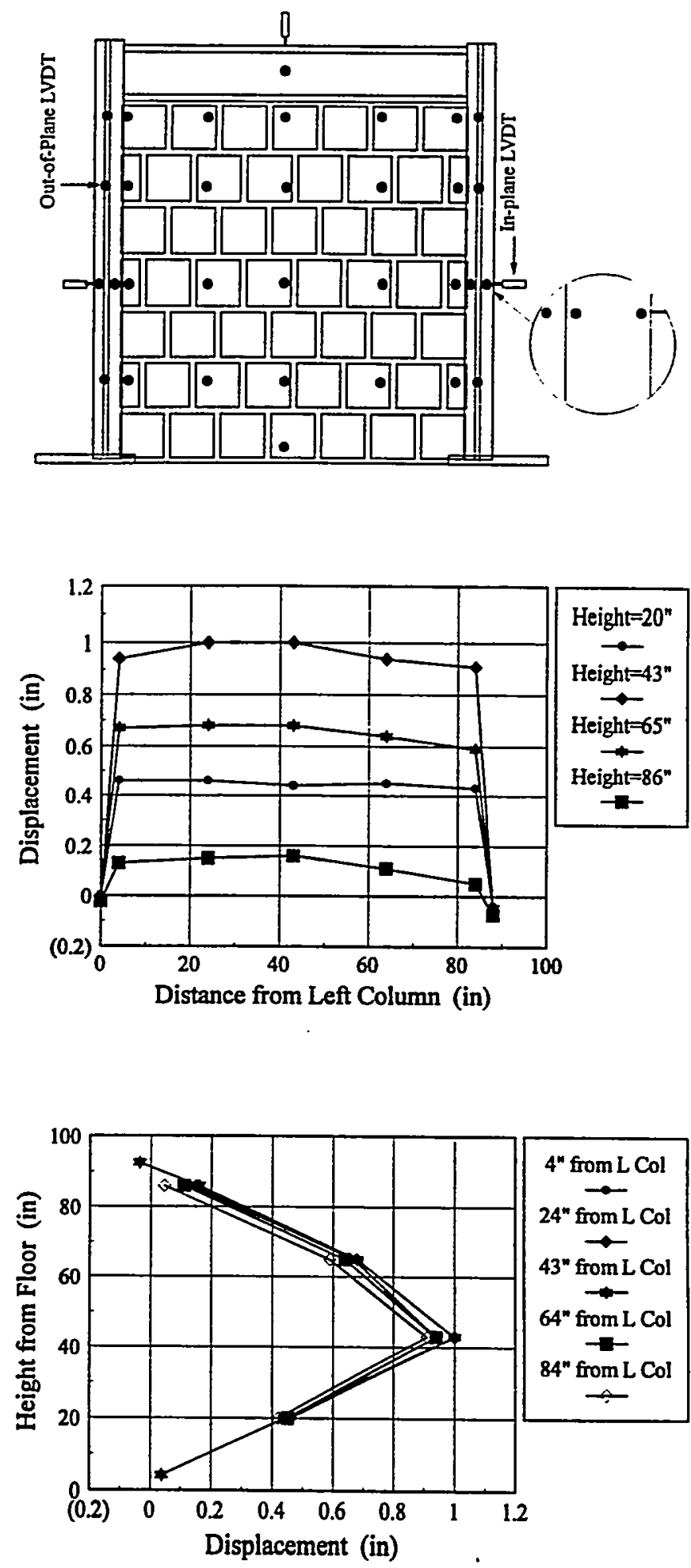

Figure 6.8 Specimen 25 Displaced Shape at Ultimate Capacity (1.2 psi) 


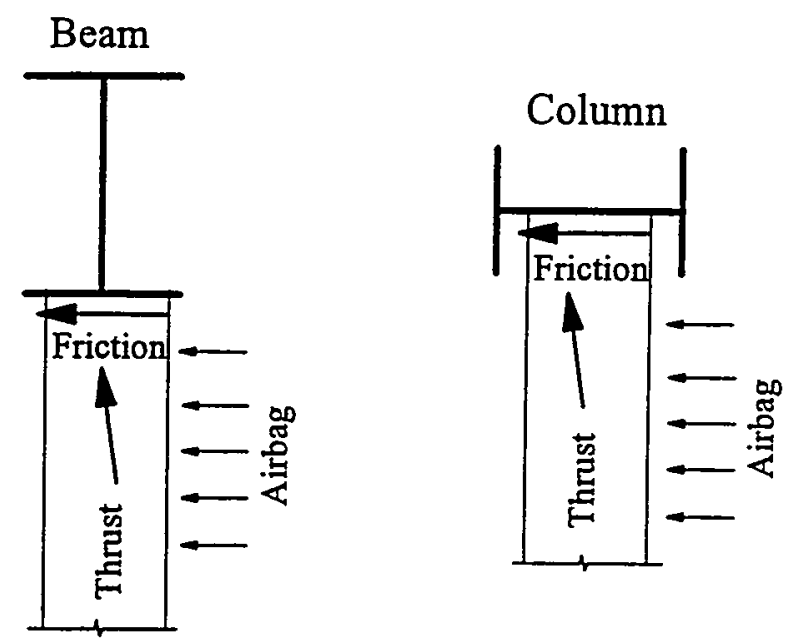

Figure 6.9 Diagram of Lateral Force Transfer to Frame

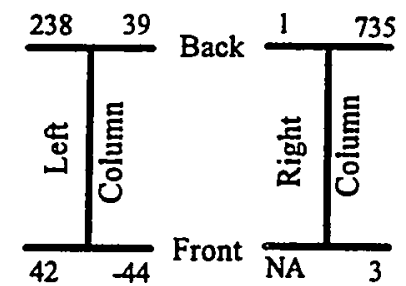

Specimen 18

Time $=4314 \mathrm{sec}$

$\mathrm{P}=3.85 \mathrm{psi}$

Disp $=0.45$ in

\begin{tabular}{|c|c|c|c|}
\hline \multirow{2}{*}{\multicolumn{2}{|c|}{114 Top }} & Beam & $\begin{array}{c}238 \\
\text { Back }\end{array}$ \\
\hline & & & $\begin{array}{c}\text { Front } \\
-228\end{array}$ \\
\hline
\end{tabular}

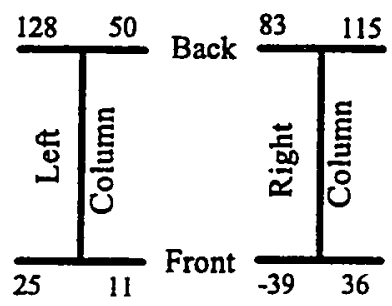

Specimen 22

Time $=4180 \mathrm{sec}$

$\mathrm{P}=4.74 \mathrm{psi}$

Disp $=0.18$ in

\begin{tabular}{|llcc|}
\hline \hline 45 & Top & Beam & 91 \\
& & Back \\
& & \\
& & \\
& & Front \\
-7 & Bottom & -65 \\
\hline
\end{tabular}

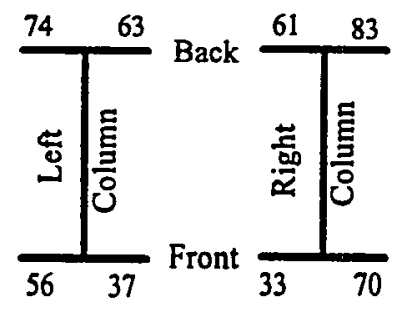

Specimen 25

Time $=2325 \mathrm{sec}$

$\mathrm{P}=1.17 \mathrm{psi}$

Disp $=1.00$ in

\begin{tabular}{|lll|}
\hline 118 Top & Beam & 89 \\
& & Back \\
& & \\
& & Front \\
& & -57 \\
\hline
\end{tabular}

Figure 6.10 Infilled Frame Strain Values at Peak Capacity 

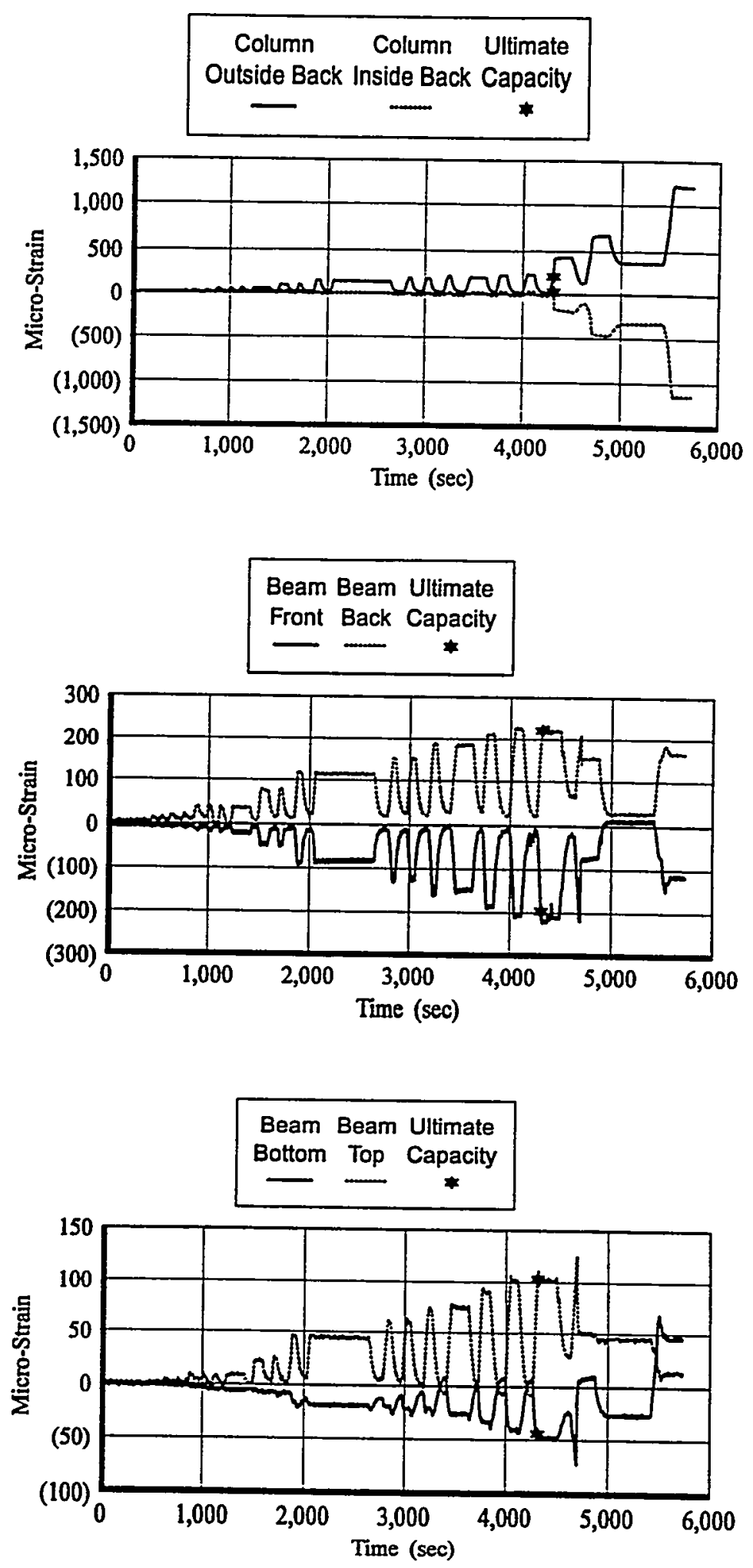

Figure 6.11 Infilled Frame 18 Strain Time History Relationships 
Figure 6.10. This is more obvious in specimen 18 , for which there was horizontal arching from the beginning, than specimen 25 , for which only vertical arching developed prior to ultimate capacity.

Observations from the beam strains are as follows. First, the beams are always in tension, resisting the outward thrust of the columns. Second, the beams exhibit upward bending due to in-plane thrust forces. Third, the beams undergo out-of-plane (weak axis) bending as lateral load is transferred from the panel to the beam through friction. Fourth, maximum strains in the beams occurred near ultimate capacity (vertical arching). The strains in the beam reduce after ultimate capacity due to damage along the beam-panel interface as horizontal arching develops.

Note that frame strains are generally low except in the columns late in the loading. Typical yield strains for the frames average 1750 micro-strain, Table 4.7. Therefore, sufficient in-plane restraint is easily developed in the framing without relying on the contribution of adjacent panels. For typical seismic evaluation, panel capacity may be all that requires detailed evaluation.

The in-plane thrust loads of the panel do not necessarily result in uniform loading along the column height or beam length. Dawe and Seah (1989b) have indicated that a higher force exists near the column or beam ends. However, an equivalent outward thrust load on the on the frame may be approximated. Converting the maximum strains of infilled frame 18 late in the loading into member forces gives $163 \mathrm{k}$-in outward moment near column midheight and $72 \mathrm{k}$-in upward moment near beam left quarter point. Comparing the column to a simply supported beam, these moments correspond to a $0.17 \mathrm{k} /$ in uniform outward load (15 kips total). Similarly, considering the beam simply supported, these moments correspond to a $0.075 \mathrm{k} / \mathrm{in}$ uniform upward load (6.5 kips total). 


\subsection{Analytical Correlation}

Results of the uniform lateral load tests were compared with an empirical relationship developed by Dawe and Seah (1989b). This relationship was originally developed for concrete masonry infills and incorporates arching action of the infill supported on all four boundaries with varying stiffnesses of the bounding frame. In this method, the uniform lateral load capacity, $q$ (psi), of an individual infill is determined from

$$
q=0.8 f_{m}^{\prime 0.75} t^{2}\left(\frac{\alpha}{l^{2.5}}+\frac{\beta}{h^{\prime 2.5}}\right)
$$

in which $f_{m}^{\prime}$ is the masonry gross compressive strength (psi), $t$ is the infill gross thickness (in), $\mathrm{h}^{\prime}$ is the infill height (in), and $\mathrm{l}^{\prime}$ the infill length (in). The parameter $\alpha$ is a measure of the relative stiffness of the bounding columns

$$
\alpha=\frac{1}{h^{\prime}}\left(E_{s} I_{c} h^{\prime 2}+G_{s} J_{c} t h^{\prime}\right)^{0.25}<35
$$

Equation 6.2

in which $E_{s}$ is the steel frame modulus of elasticity (psi), $I_{c}$ is the steel column moment of inertia $\left(\mathrm{in}^{4}\right), \mathrm{G}_{\mathrm{s}}$ is the steel frame shear modulus (psi), and $\mathrm{J}_{\mathrm{c}}$ the steel column torsional constant ( $\left.\mathrm{in}^{4}\right)$. The parameter $\beta$ is a measure of the relative stiffness of the bounding beam

$$
\beta=\frac{1}{l^{\prime}}\left(E_{s} I_{b} l^{\prime 2}+G_{s} J_{b} t l^{\prime}\right)^{0.25}<35 \quad \text { Equation } 6.3
$$

in which $I_{b}$ is the beam moment of inertia (in ${ }^{4}$ ) and $J_{b}$ is the steel beam torsion constant (in ${ }^{4}$ ).

Figure 6.12 presents a comparison of this uniform lateral capacity formulation for various $\mathrm{h} / \mathrm{t}$ ratios versus the results of three static pressure tests. Also included is the result of a full-scale in-situ air bag test reported by Fricke et al. (1992). Masonry strength variations for the three panel thicknesses leads to the different curves of Figure 6.12. The masonry strengths used in the calculations are from the prism tests (Boyd, 1993) with the compressive load normal to the cores. 


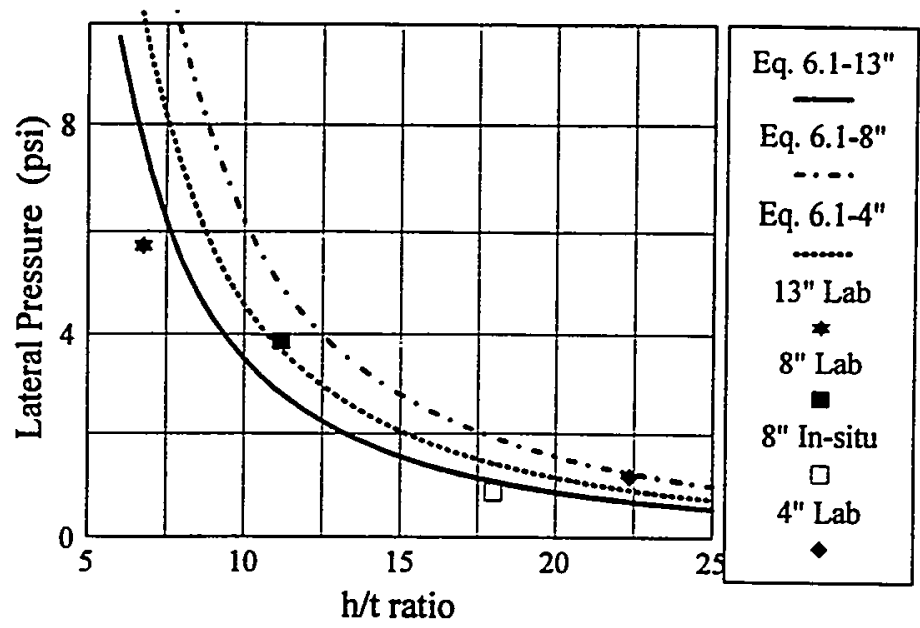

Figure 6.12 Comparison of Lateral Load Tests With Equation 6.1

Good correlation exists between the empirical Equation 6.1 and the laboratory and in-situ air bag tests. Specimen 22 was the most overestimated, however, this panel had an extremely low $\mathrm{h} / \mathrm{t}$ ratio when compared to typical field conditions. For low $\mathrm{b} / \mathrm{t}$ ratios, panel behavior may be less influenced by membrane forces as are thick plates and shells.

The load-deformation relationship of the laterally loaded infills was compared to a more rigorous arching formulation presented by Dawe and Seah (1989b). This formulation was used to develop Equation 6.1 through a series of parametric studies. The method extends yield-line analysis of restrained concrete slabs to infills by accounting for the voided masonry and the flexibility of the bounding frame. Figure 6.13 presents the results of this method for specimens 18,22 , and 25 . In each case, the solution is given for one-way vertical arching for which slippage is assumed along the columns as a horizontal fracture occurs at midheight. Good correlation exists with specimen 25 while the response of specimen 18 is slightly overpredicted. The method approximates the behavior of double wythe specimen 22 only prior to collapse of the collar joint. 

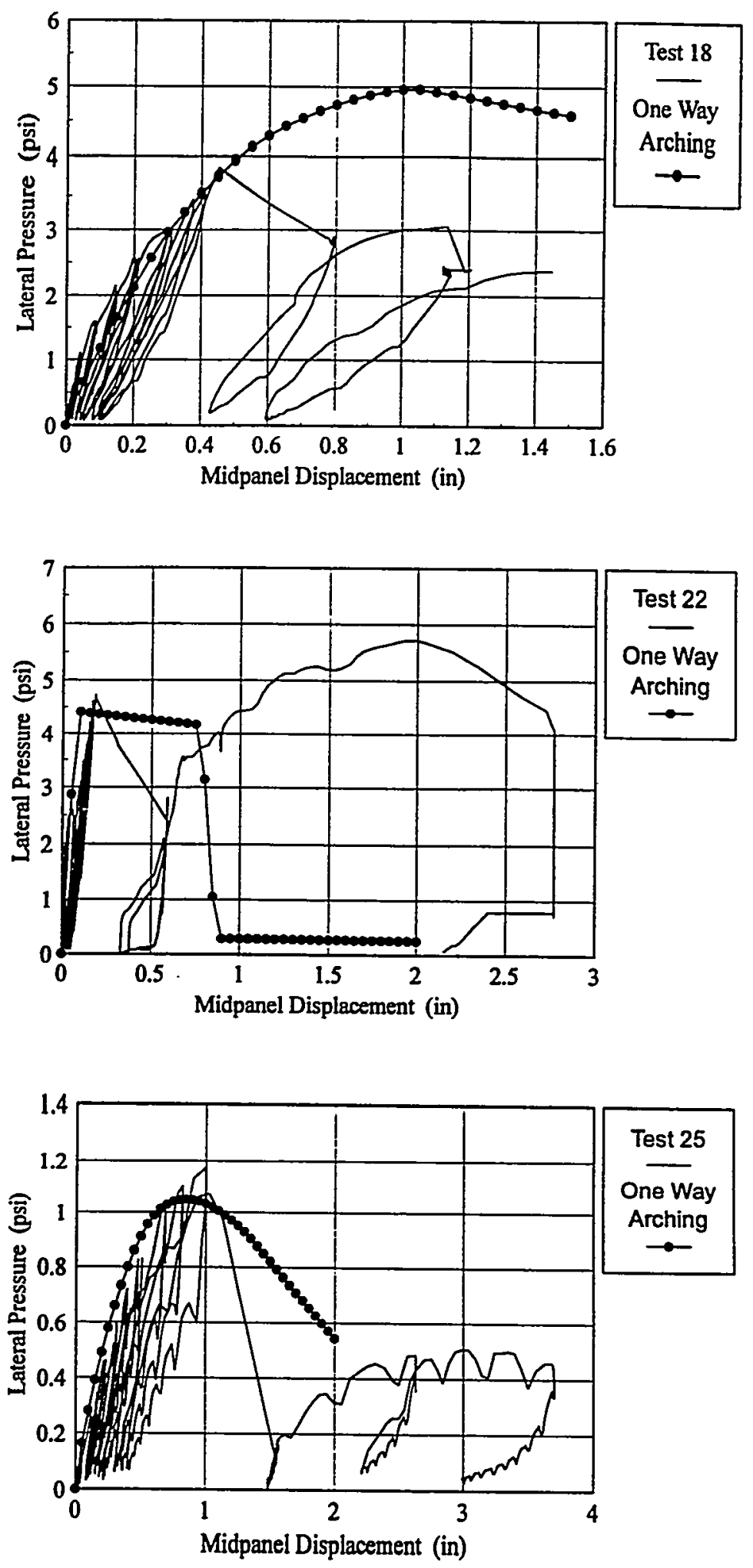

Figure 6.13 Comparison of Lateral Load Tests With Dawe and Seah (1989b) 
The ultimate strain, compressive strength, and assumed stress block coefficients dramatically affect these analyses. Average values from the prism testing were used and a compressive stress block factor of 0.7. Another factor affecting the capacity is the mode of failure. As noted previously, a combined compression and shear failure was observed in the upper and lower course tiles. This failure mode is quite different than more ductile concrete masonry. The presence of horizontal cores in the tile may also tend to decrease the shear resistance as compared to concrete masonry. 


\section{CHAPTER 7}

\section{BI-DIRECTIONAL BEHAVIOR}

To assess the interaction of in-plane and out-of-plane forces as well as understand the behavior of damaged infills, several bi-directional tests were performed on clay tile infills. First, sequential load tests were performed on two specimens by imposing lateral drift followed by inplane racking. A second type of sequential load test was conducted on one specimen with inplane racking forces followed by uniform lateral loading. A third type of sequential load test was performed on another specimen by imposing uniform lateral loads followed by in-plane racking. Finally, a combined in-plane racking and uniform lateral load test was conducted.

\subsection{Lateral Drift Followed By In-Plane Racking}

Infill walls of building structures subjected to earthquake motions must resist forces both in-plane and out-of-plane. Seismic ground motions induce in-plane inertial forces in the walls which create out-of-plane drift displacements in orthogonal walls. While the contribution to inplane stiffness by orthogonal walls is typically ignored in analysis, the relative top-bottom displacements of the orthogonal walls must be considered. Stability of the orthogonal walls must be maintained as they drift out-of-plane. Considering an earthquake component in the building's other principal direction, the in-plane capacity of walls subjected to orthogonal drift displacements must also be determined.

The effect of out-of-plane inter-story drift on the in-plane capacity of clay tile infilled frames was evaluated by performing two additional large-scale static tests. Preliminary results of these tests are given in Flanagan and Bennett (1992). Test specimens 11 and 13 were first 
subjected to cyclic out-of-plane displacements imposed either at the top or at midheight of the infill. Both specimens were then loaded in-plane to failure. The results were compared to a third identical specimen (number 2) that was only loaded in-plane to failure. Results of the in-plane testing of specimen 2 are given in Chapter 5.

Different structural forms may be used in conjunction with infilled frames. Structural elements orthogonal to the infills might be comprised of other infills, braced frames, moment resistant frames, shear walls, steel trusses, etc. Two deformed shapes representative of these structural elements were selected for the out-of-plane drift loading. First, a cantilever curvature (fixed base and free top) with loading near the top of the infill was used. Second, a simple beam curvature (fixed base and restrained top) with loading near midheight of the infill was used.

Specimen 11 was loaded using the cantilever mode of out-of-plane loading, Figure 3.21. A peak load of 12.8 kips was applied with a corresponding displacement of 1.30 inches measured near the top of the infill. This displacement is approximately 1.7 percent of the wall height at the point it was measured. The specimen exhibited a pronounced horizontal crack along the base and hairline cracks along the bed joints of lower courses, Figure 7.1. The vertical interface between the panel and frame boundary remained intact as the infill wall moved with the columns.

Test measurements indicate nearly identical out-of-plane movement of the frame and infill for a given height. This is illustrated in Figure 7.2 which overlays the column, panel edge and midpanel displacements of the top course of the infill. The complete hysteresis of the drift loading is presented in Figure 7.3 The displacements shown are taken from the center of the beam at midpanel. Out-of-plane displacements of the entire panel are plotted in Figure 7.4. The linear relationship over height indicates the base rotation that occurred during the drift loading. 


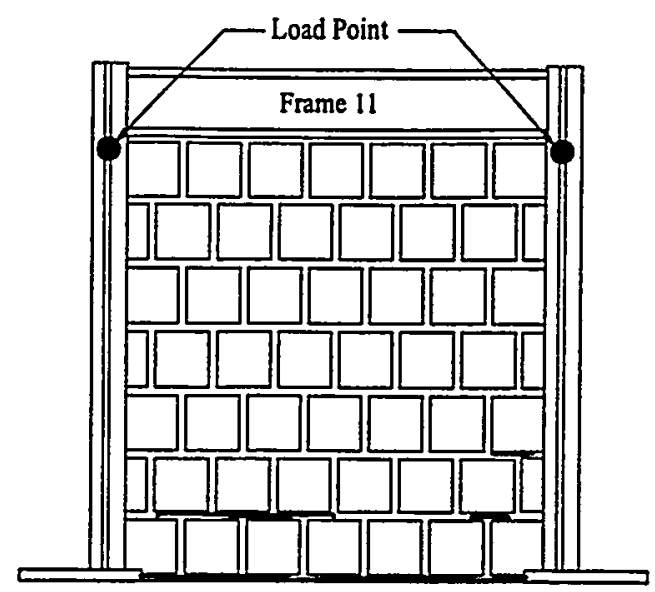

Figure 7.1 Specimen 11 Out-of-Plane Drift Crack Map

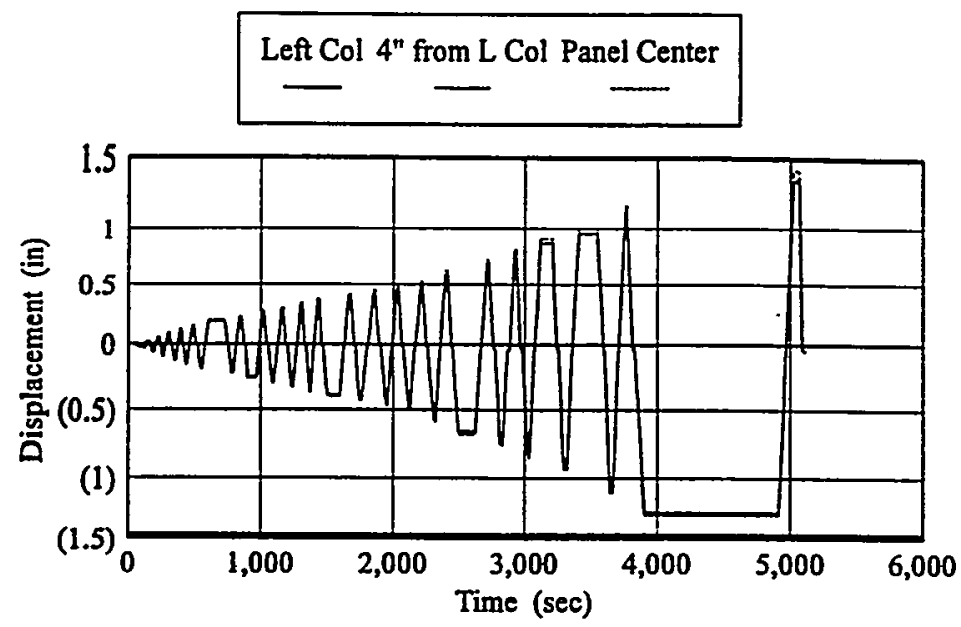

Figure 7.2 Specimen 11 Drift Displacements Near Top of Infill

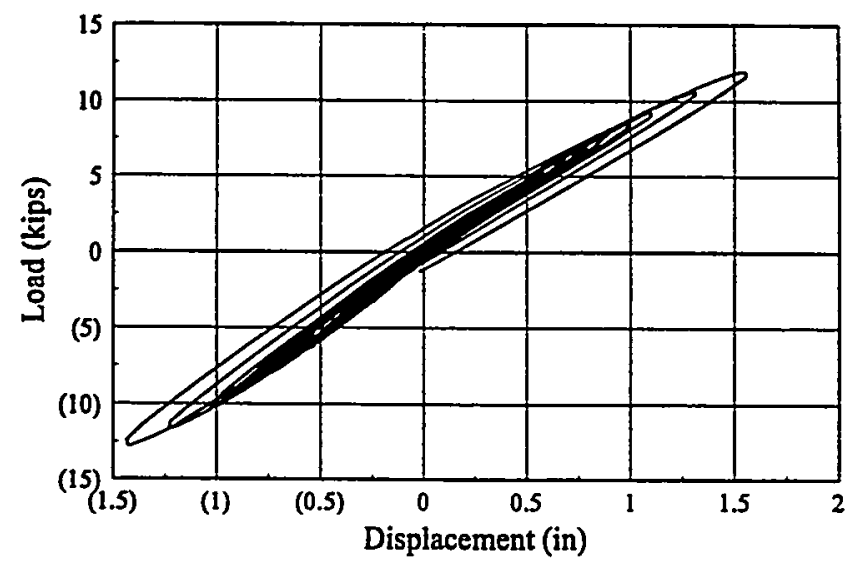

Figure 7.3 Specimen 11 Out-of-Plane Drift Hysteresis 

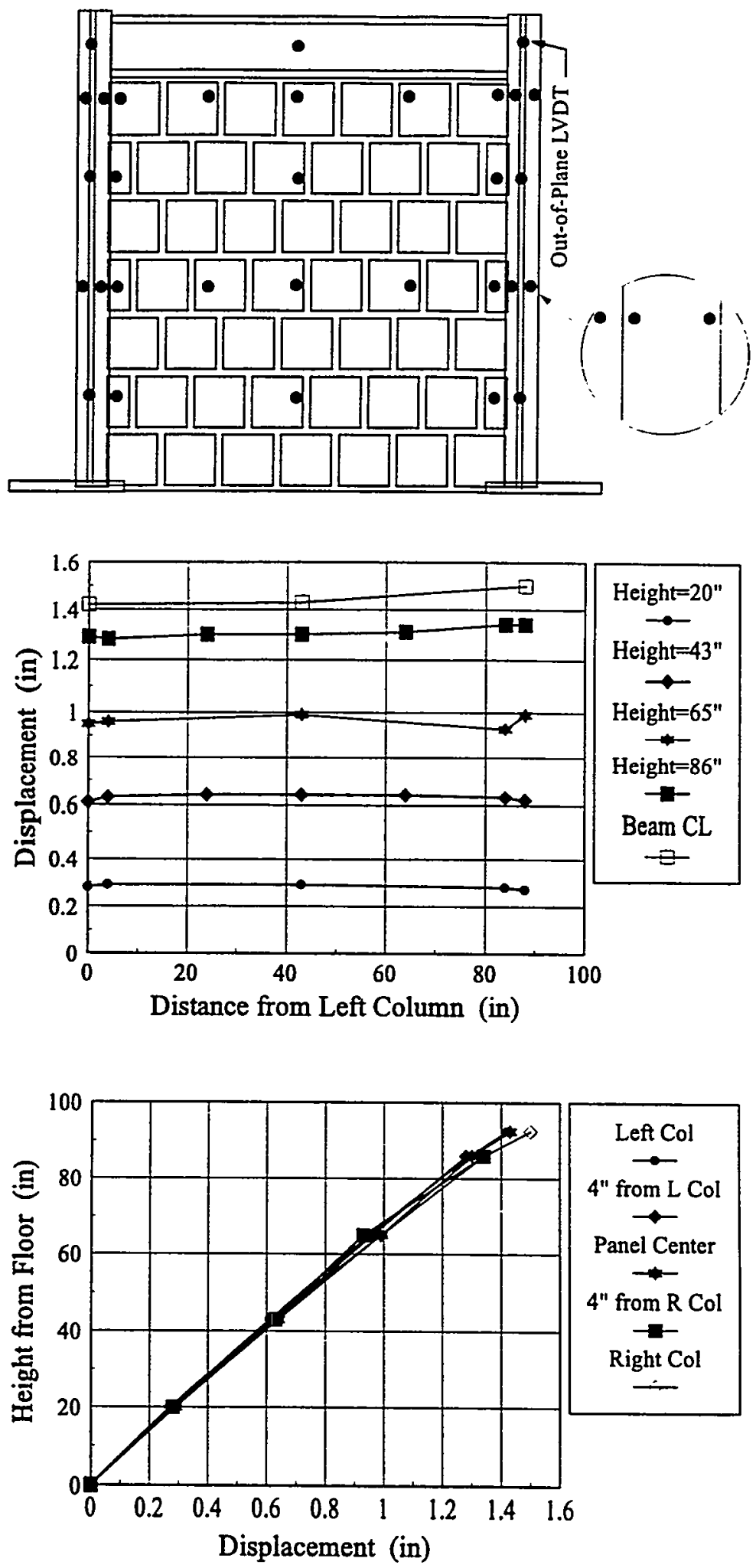

Figure 7.4 Specimen 11 Displaced Shape at Peak Out-of-Plane Drift Load (12.8 kips) 
A measure of the damage to infill 11 from the drift loading was obtained by conducting low amplitude vibrations tests. These impact hammer tests were performed before and after the out-of-plane loading. Although the infilled frame is not a homogeneous linear system, consistency of the modal analysis technique was confirmed by varying the driving and recording points on the specimen.

In-plane frequencies for the infilled frame were obtained from measurements taken on the exposed face of the column web. Out-of-plane frequencies were obtained from measurements taken on both the masonry infill and the steel frame. Fundamental out-of-plane frequencies extracted from the frame and the infill were quite close (within 3\%) indicating a good bond between the framing and masonry. This was the case both before and after the drift loading.

The percentage decrease in the first out-of-plane frequency of the infilled frame due to drift loading was 17 percent, and the percentage decrease in the first in-plane frequency was 29 percent. Damage to the infill is evident from the frequency shifts and is consistent with the crack patterns observed.

Specimen 13 was first loaded out-of-plane using the beam curvature loading, Figure 3.21. Next, the upper restraint and load cell were removed and the specimen was loaded out-of-plane as a cantilever with the actuator at midheight.

For the beam mode of deformation, a peak load of 49.4 kips was applied to the specimen and a peak midheight displacement of 0.13 inch was measured. The corresponding load at the top restraint was 27.4 kips. The specimen exhibited slight horizontal cracking in the bed joints near midheight and vertical hairline cracks in the head joints of the upper half of the panel, Figure 7.5. A horizontal crack along most of the panel and beam interface also developed. Similar out-of-plane movement of the frame and infill were observed with only slightly higher displacements of the frame than the infill at midpanel. 
For the cantilever mode of deformation, a peak load of 10.8 kips was applied with a corresponding midheight displacement of 0.53 inch (1.2 percent of the height of measurement). As with specimen 11, a pronounced horizontal crack at the base of the infill was observed, Figure 7.5. The percentage decrease in the first out-of-plane frequency of the infilled frame due to the drift loading was 16 percent, and the percentage decrease in the first in-plane frequency was 17 percent. Again the wall remained stable and moved with the frame during the drift.

Complete hystereses of specimen 13 cantilever and beam drift loadings are contained in Figures 7.6 and 7.7 respectively. The cantilever loading is linear and quite similar to that of specimen 11. Displacements of Figure 7.7 were taken from the beam centerline near the midpanel. The hysteretic deformations of Figure 7.6 were taken from midheight of the panel. For the out-of-plane beam mode, nonlinear behavior is noted, primarily due to deformation in the restraining fixture.

Out-of-plane displacements of the beam curvature drift loading are given in Figure 7.8. The nearly linear relationship of displacement over height indicates that, in fact, a beam type curvature of the panel was not achieved. However, since there was a significant reaction at the top restraint (approximately $50 \%$ of midpanel load), the curvature was a composite of beam and cantilever modes. Again, the wall remained stable moving with the enclosing frame.

After completion of the drift loadings, specimens 11 and 13 were loaded cyclicly in-plane to failure. Another identical infill (specimen 2), having no previous loading history, was likewise loaded in-plane to failure. Specimen 2 served as a control specimen for comparison with the inplane response of specimens 11 and 13 , thus determining the effect drift on in-plane capacity. 


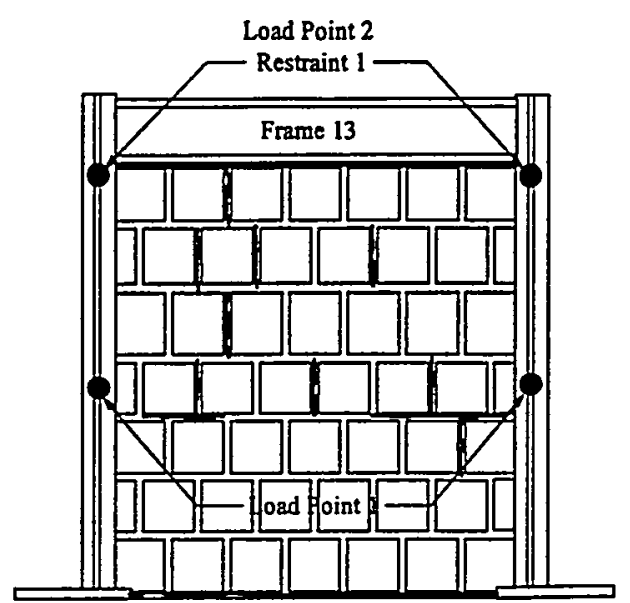

Figure 7.5 Specimen 13 Out-of-Plane Drift Crack Map

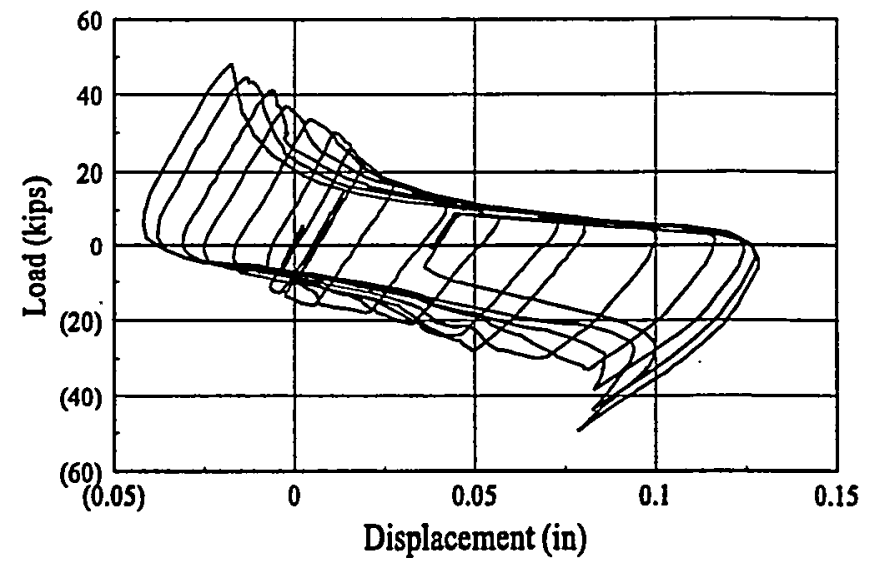

Figure 7.6 Specimen 13 Beam Curvature Drift Hysteresis

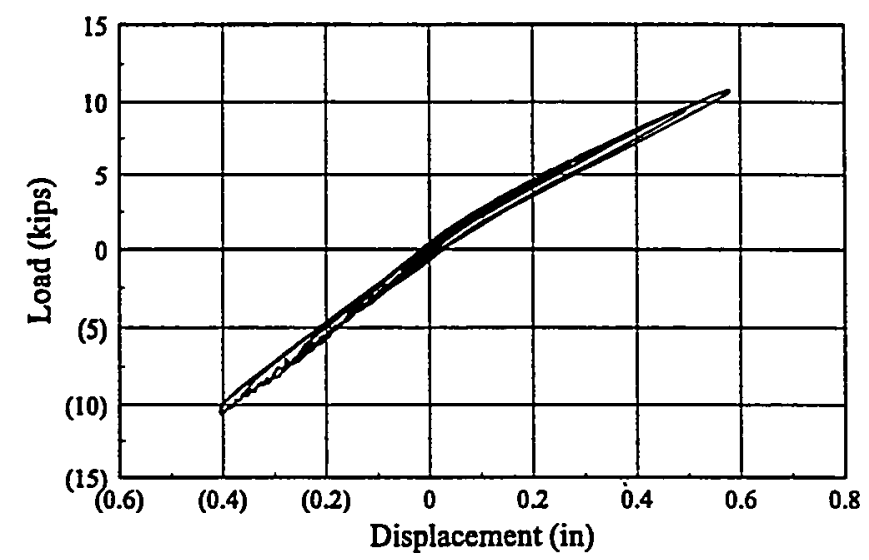

Figure 7.7 Specimen 13 Cantilever Curvature Drift Hysteresis 

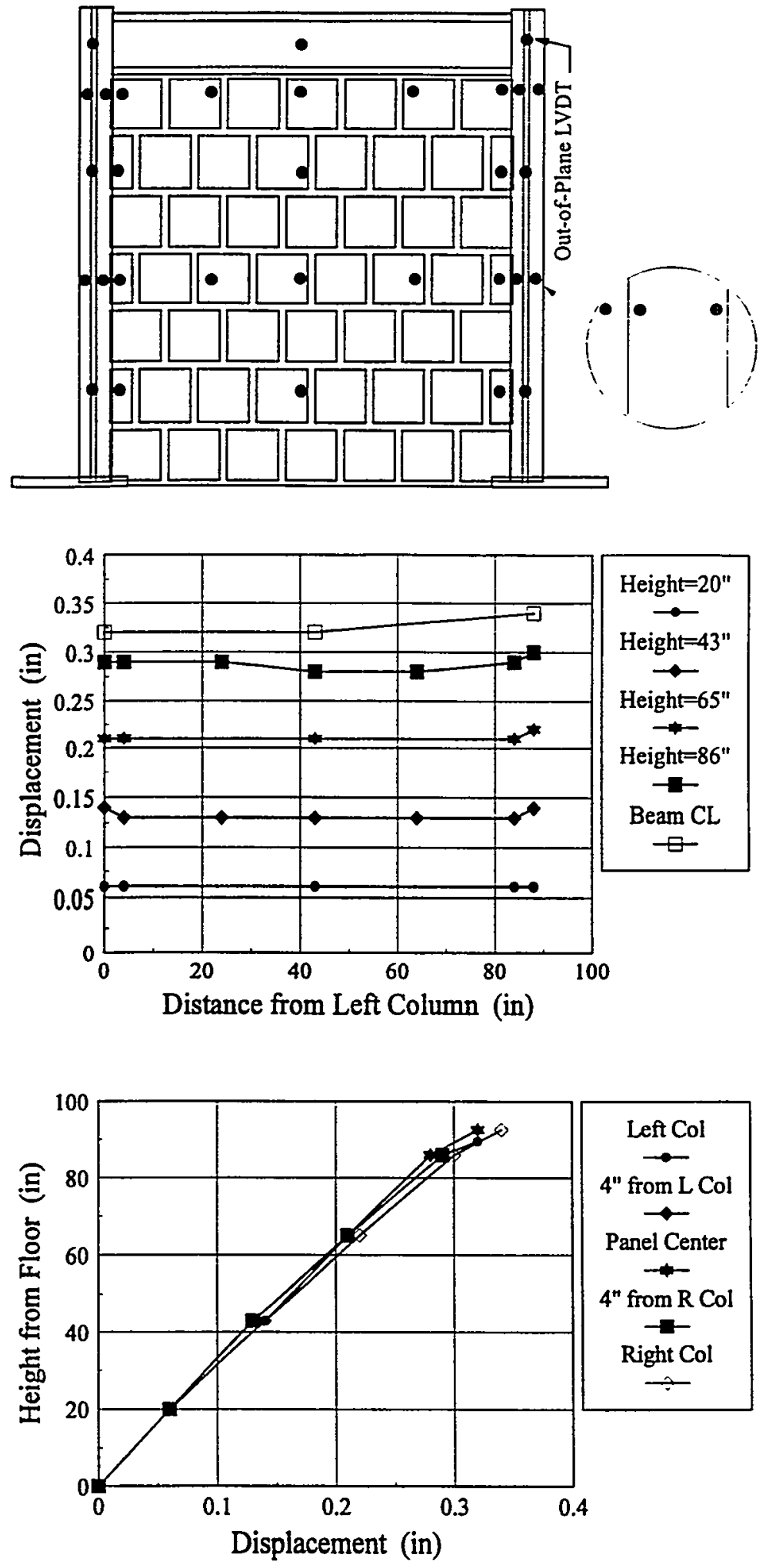

Figure 7.8 Specimen 13 Displaced Shape at Peak Beam Curvature Drift Load (49.4 kips) 
The in-plane behavior of all three specimens was characterized by mortar cracking and separation at the base and top of the panels followed by compression cracking in the mortar near the upper corners. As previously indicated, specimens 11 and 13 had been cracked at the base and specimen 13 had been cracked at the top interface during the drift loading. Next, diagonal cracking throughout the panel mortar joints occurred and finally the faceshells of the upper course tiles split away from their webs, section 5.1.1.

Initial stiffness and peak loads in tension and compression are given in Table 7.1. Ultimate loads (larger of the two peaks) are underlined in the table. The ultimate compression load for specimen 11 occurred during the initial loading, when control problems were experienced with the hydraulic system. An inadvertent monotonic compression load was applied to the specimen. After the hydraulic problems were corrected, the normal cyclic loading resumed. It is suspected that this inadvertent load and resulting damage lowered the peak capacity experienced during the cyclic loading. The largest compressive load reached during subsequent loading was 26.5 kips. The secant stiffness reported is for the first compression cycle of loading at approximately 0.05 inch displacement. Good in-plane initial stiffness and ultimate capacity correlations exist for all three infilled frames.

Complete in-plane hysteresis curves for specimens 11 and 13 are provided in Figures 7.9 and 7.10. Ultimate load was reached just before the clay tiles split along the intersections of web and faceshell. Capacity in the remaining load cycles was reduced significantly due to the damage of the tiles. Each infill experienced degradation at the interface. This resulted in the hysteretic loop being nearly identical to that of the frame for small displacements. Larger displacements caused the infill to engage, greatly increasing the stiffness of the system. The degradation of the interface caused a reduction in the energy absorbing capability of the infilled system. 
Table 7.1 In-Plane Ultimate Load and Initial Stiffness

\begin{tabular}{||c|c|c|c||}
\hline \multirow{2}{*}{ Test } & \multicolumn{2}{|c|}{ Ultimate Load (kips) } & \multirow{2}{*}{$\begin{array}{c}\text { Initial } \\
\text { Stiffness } \\
\text { (kips/in) }\end{array}$} \\
\cline { 2 - 4 } & Compression & Tension & 165 \\
\hline \hline Specimen 2 (Control) & 37.3 & $\underline{41.1}$ & 154 \\
Specimen 11 (Cantilever) & $\underline{34.2}$ & 33.6 & 177 \\
Specimen 13 (Beam) & $\underline{41.8}$ & 37.3 & \\
\hline
\end{tabular}

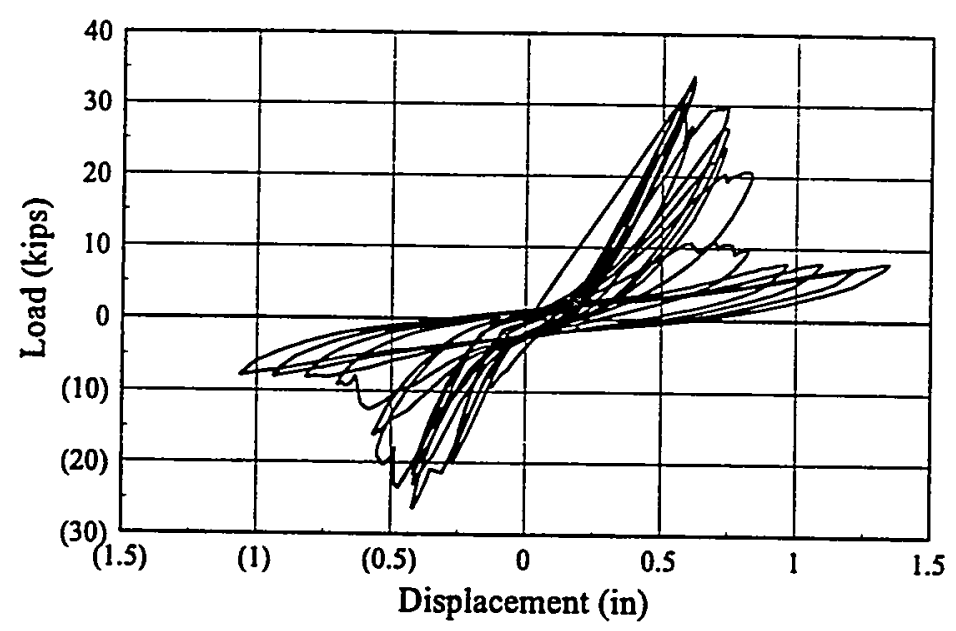

Figure 7.9 Specimen 11 In-Plane Loading

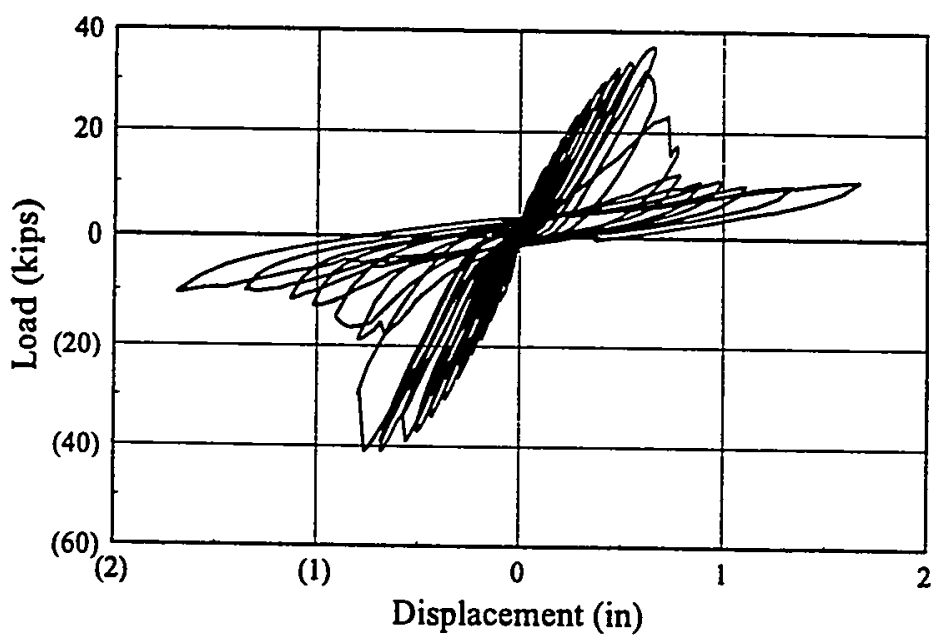

Figure 7.10 Specimen 13 In-Plane Loading 
Specimens 11 and 13 reached ultimate capacity at lower displacement levels than specimen 2, Figure 5.13. Although initial stiffness and ultimate capacity of the infills were comparable, drift damage of panels 11 and 13 may have weakened the infill reducing the deformations at failure. This is perhaps the most notable influence of the drift loading on inplane response.

The cantilever drift mode of specimen 11 was evaluated using an elastic isotropic finite element analysis. The frame members were modeled using 3D beam elements and the infill was modeled with 4 node plane stress plate elements. The connectivity of the frame base to the floor was represented with a pinned support having a rotational spring. The rotational capacity of the base was estimated using the results of the bare frame tests and the empirical procedures of Frye and Morris (1975) and Kishi and Chen (1986).

Two conditions were used for modeling the infill base to the floor. First, a three degree of freedom fixed connection was used and the results of the analysis matched ( $<5 \%$ difference) the out-of-plane frequencies measured in the low amplitude vibrations testing of the virgin specimen. Second, a two degree of freedom pinned connection was used and the results of the analysis also compared well ( $<10 \%$ difference) with the measured drift displacements and the frequencies of the post-drift low amplitude vibrations testing.

Results of the in-plane testing were compared with the numerical procedures of sections 5.2.1 and 5.2.3. As with specimen 2 , good agreement was found for ultimate capacity prediction and stiffness degradation approximation of specimens 11 and 13. It thus appears that out-of-plane drift has negligible effect on in-plane behavior. The cracking has eliminated the diagonal cracking capacity, and forced the failure to be through corner crushing. 


\subsection{In-Plane Racking Followed By Uniform Lateral Load}

Buildings with infills are usually analyzed by evaluating the effect of in-plane and out-ofplane forces separately. Consider the determination of the capacity of an infill panel out-of-plane under inertial loadings. The frequency of the panel is typically much greater than that of the building structure and thus the panel is assumed to have no dynamic amplification beyond that of the overall structure. However, the effect of current or prior in-plane loading on the same infill may change the behavior of the panel under uniform lateral loading.

Tests on specimen 19 were conducted to assess the effect of prior in-plane loads on the inertial behavior of infills. Specimen 19 was constructed identical to specimen 2 and 18 which served as in-plane and uniform laterally loaded controls.

First, specimen 19 was loaded cyclically in-plane to approximately $80 \%$ of its peak capacity (maximum load of $32.7 \mathrm{kips}$ at a beam centerline displacement of 0.70 inch). Figure 7.11 shows the racking load versus beam centerline displacement. Similar to the other in-plane tests, the specimen developed single diagonal cracks followed by banded diagonal cracking as the displacement cycles increased. Loading was stopped before corner crushing began.

After the in-plane loading was complete, the panel was loaded with uniform lateral pressure increments using an air bag. The air bag covered virtually the entire area of the panel. The maximum pressure reached was $3.15 \mathrm{psi}$ at a midpanel displacement of 0.76 inch. The peak capacity of specimen 19 was $80 \%$ of the control specimen 18 . The peak capacity of specimen 19 occurred at a midpanel displacement $65 \%$ greater than that of control specimen 18 .

Results of the out-of-plane loading are given in Figure 7.12. Considerable softening of the panel from the in-plane loading is evident when comparing the response to that of specimen 18, Figure 6.3. An initial offset of approximately $0.2^{\mathrm{n}}$ is observed in the out-of-plane pressure cycles. This offset is believed to have resulted from inelastic deformations along the panel 


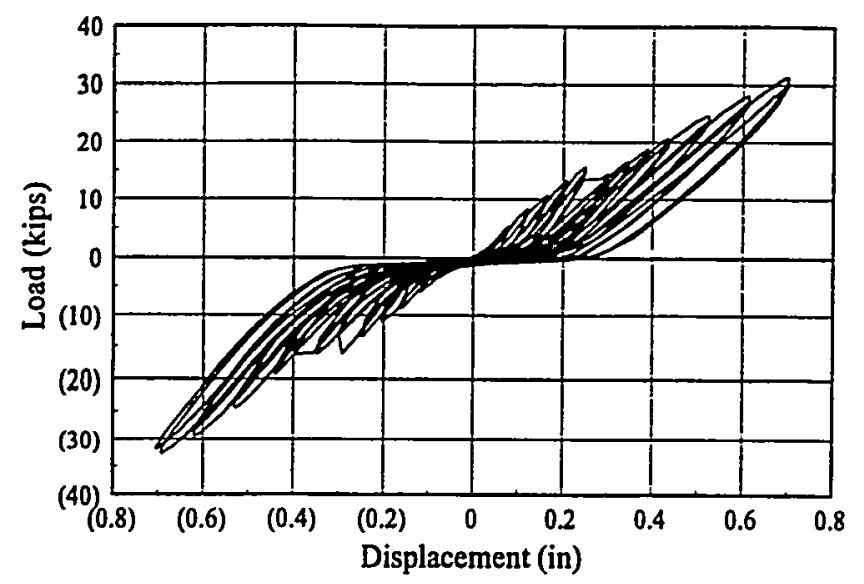

Figure 7.11 Specimen 19 In-Plane Loading

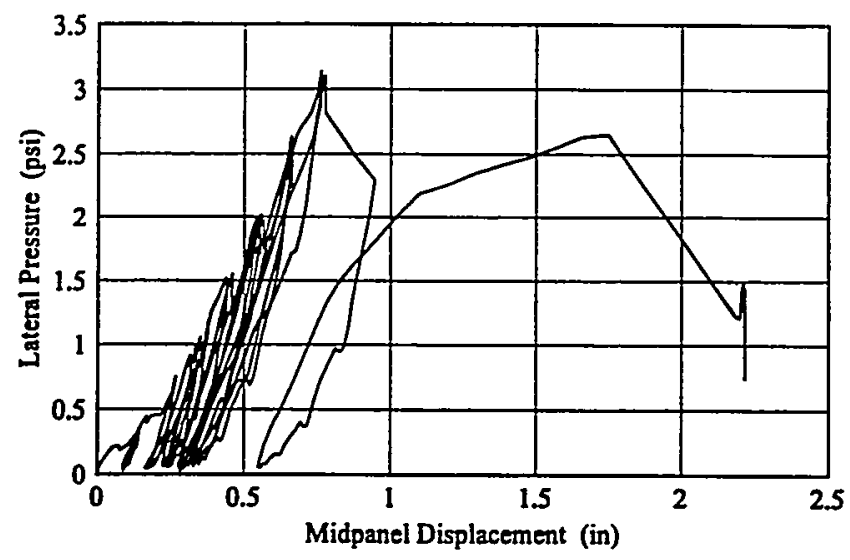

Figure 7.12 Specimen 19 Uniform Lateral Loading

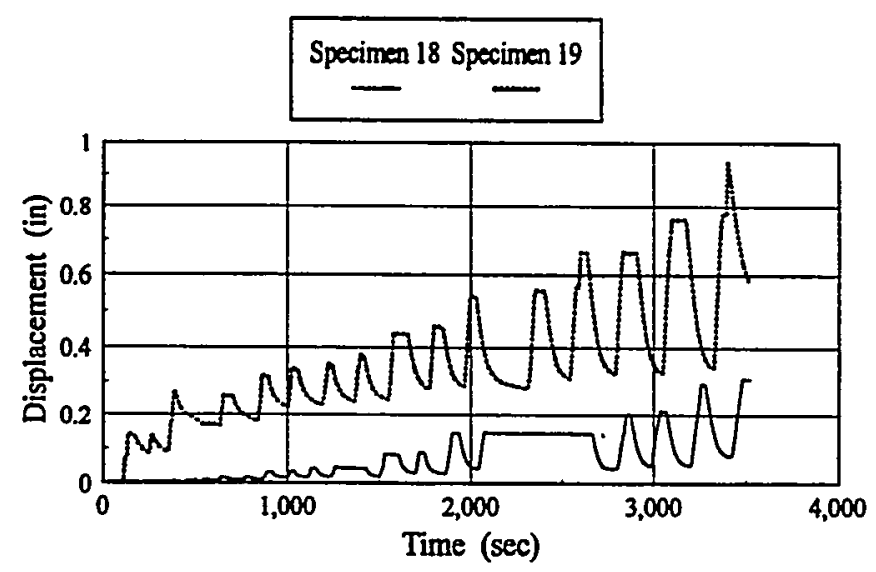

Figure 7.13 Comparison of Specimens 18 and 19 Midpanel Displacements 
boundary sustained in the in-plane testing. As the panel fully engages the frame under pressure loading, one way vertical arching developed similar to specimen 18 . However, the effect of the prior in-plane loading is evident throughout the pressure cycles as the panel deformations do not rebound as elastically as those of specimen 18, Figure 7.13. A similar contrast of specimen 18 and 19 may be made for displacements along the panel edge.

Displacements of the entire panel under uniform lateral loading are shown in Figure 7.14. Late in the loading the panel slipped enough to engage the column flanges. Again, vertical arching is the primary mode of behavior. The conclusion reached is that heavily damaged panels possess significant out-of-plane capacity, although deformations may be greater than for undamaged panels. This is consistent the findings of Dawe and Seah (1989b) dealing with the lateral capacity of dry stacked concrete block infills.

\subsection{Uniform Lateral Load Followed by In-Plane Racking}

Tests on specimen 20 were conducted to assess the effect of prior uniform lateral loading on the in-plane behavior of clay tile infills. Specimen 20 was constructed similar to specimens 18 and 2 which served as out-of-plane and in-plane controls.

First specimen 20 was subjected to increasing pressure load-unload cycles to approximately $75 \%$ of capacity (maximum pressure of $3.0 \mathrm{psi}$ at a midpanel displacement of 0.43 inch). Figure 7.15 gives the pressure loading versus midpanel displacement. Similar to specimen 18, the panel developed a horizontal crack above the fourth course and vertical arching governed the behavior. No tile failure had occurred when the out-of-plane loading was stopped.

Results of the uniform lateral loading are given in Figures 7.17 and 7.18. The displaced shapes indicate vertical arching with some slip and rotation of the panel edges. The partial time histories of Figure 7.17 show similar displacements near the edge and the midpanel of the infill. 

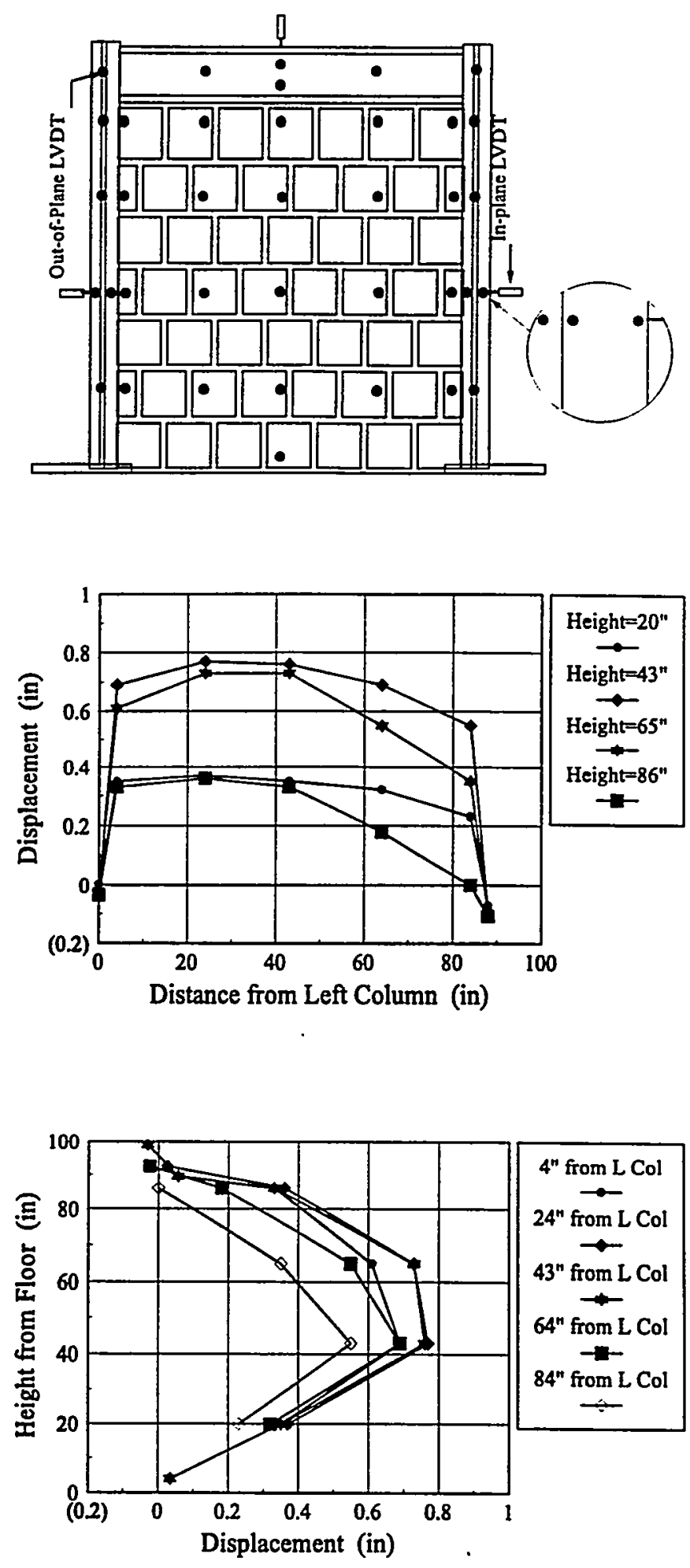

Figure 7.14 Specimen 19 Displaced Shape Under Lateral Loading (3.0 psi) 


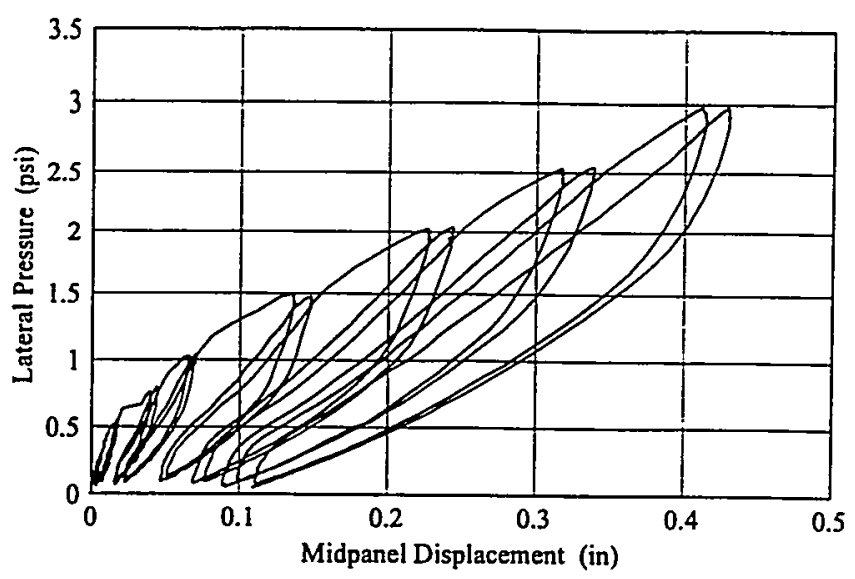

Figure 7.15 Specimen 20 Uniform Lateral Loading

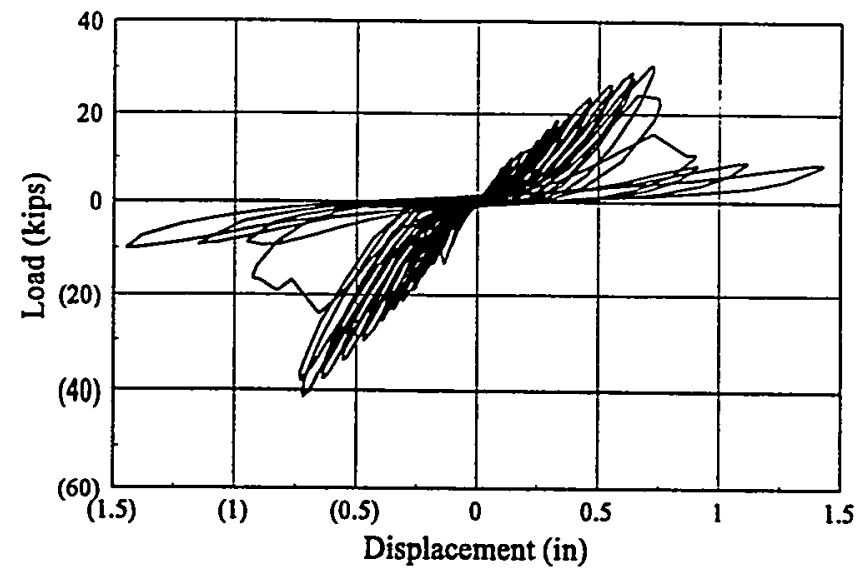

Figure 7.16 Specimen 20 In-Plane Loading

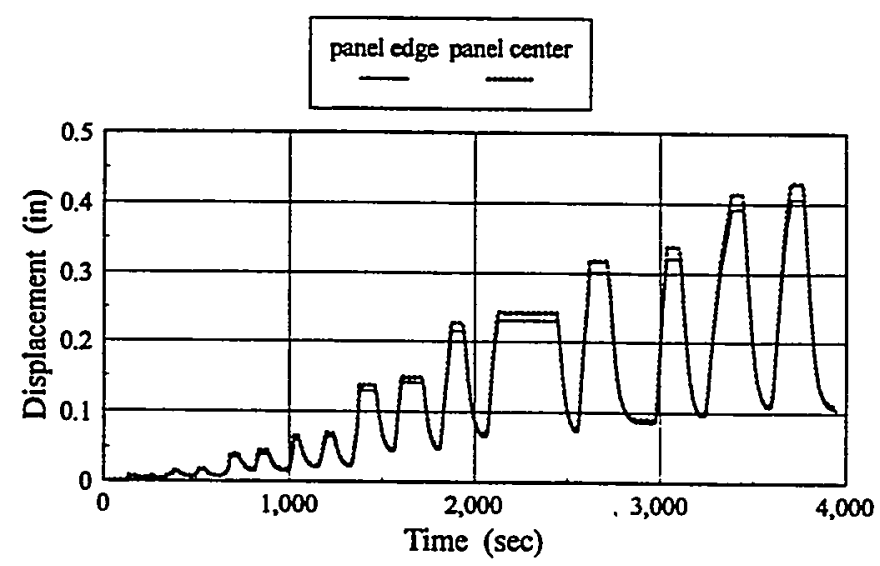

Figure 7.17 Specimen 20 Out-of-Plane Midheight Displacements 

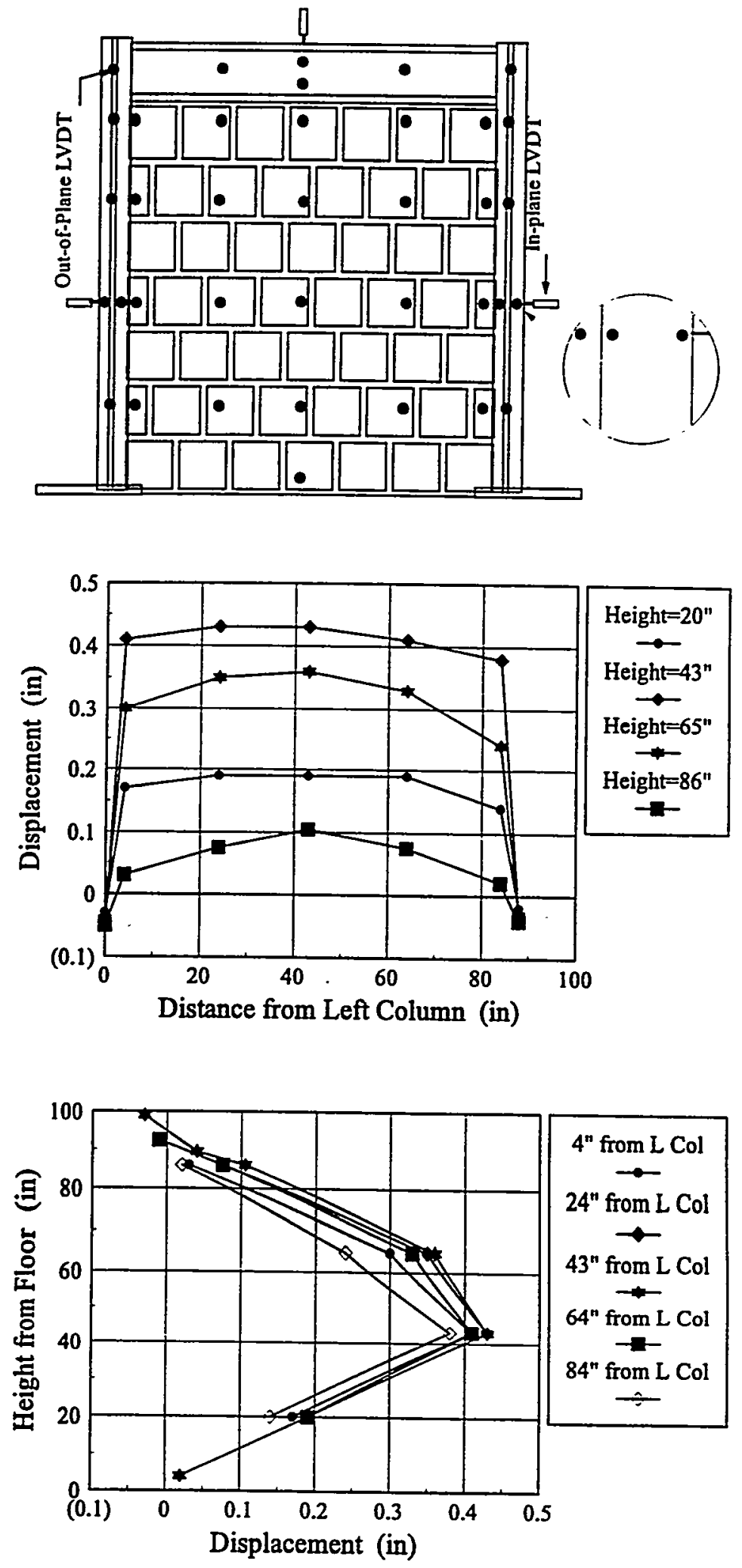

Figure 7.18 Specimen 20 Displaced Shape at Peak Uniform Lateral Load (3.0 psi) 
After the uniform out-of-plane loading was complete, the panel was loaded in-plane until ultimate capacity was reached. The maximum racking load was 41.1 kips at a beam centerline displacement of 0.72 inch. The ultimate in-plane capacity of specimen 20 was effectively the same as that of in-plane control specimen 2 . The ultimate capacity of specimen 20 was reached at a slightly lower in-plane displacement. The initial in-plane stiffness of specimen 20 was $50 \%$ of that of control specimen 2. This is due to mortar crushing along the frame-infill boundary and permanent deformations of the masonry induced by the previous air bag loading.

Results of the in-plane loading are given in Figure 7.16. The in-plane behavior was similar to that of control specimen 2 and the other in-plane tests. Early in the in-plane loading, the existing cracks and softened interface affected the stiffness and propagation of diagonal cracks. Prior lateral loading effectively eliminated the panel diagonal cracking limit state as usually observed. However, at higher displacements, the in-plane stiffness and infill degradation evolved to that of the virgin racking specimens.

\subsection{In-Plane Racking and Uniform Lateral Load Combined}

Finally, one specimen was tested to assess the combined in-plane and out-of-plane behavior of clay tile infills. Specimen 23 was tested under combined in-plane racking and uniform lateral loading. The sequence of loading for the experiment included progressively increasing cyclic racking forces. At certain points of the in-plane loading, the beam centerline displacement was held in compression while out-of-plane pressure cycles were applied with an air bag, Figure 7.19 and 7.20. As constant in-plane displacement was held, the amount of inplane force need to sustain the displacement reduced with time and applied lateral pressure. This is due to the permanent deformation of the damaged infill under in-plane load and the plastic deformation of the infill boundary as arching develops under lateral pressure. 

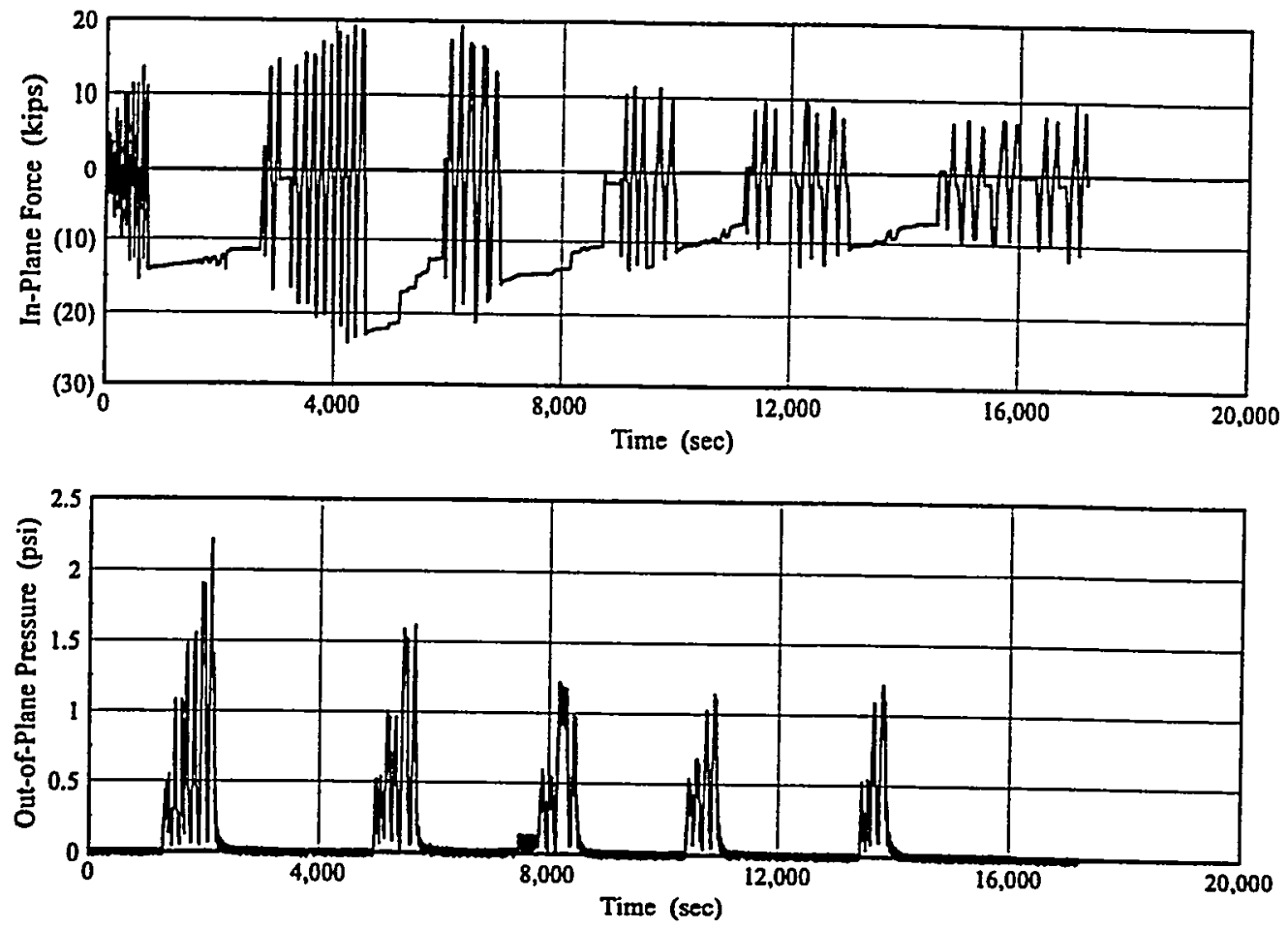

Figure 7.19 Specimen 23 In-Plane Racking Force and Out-of-Plane Uniform Pressure
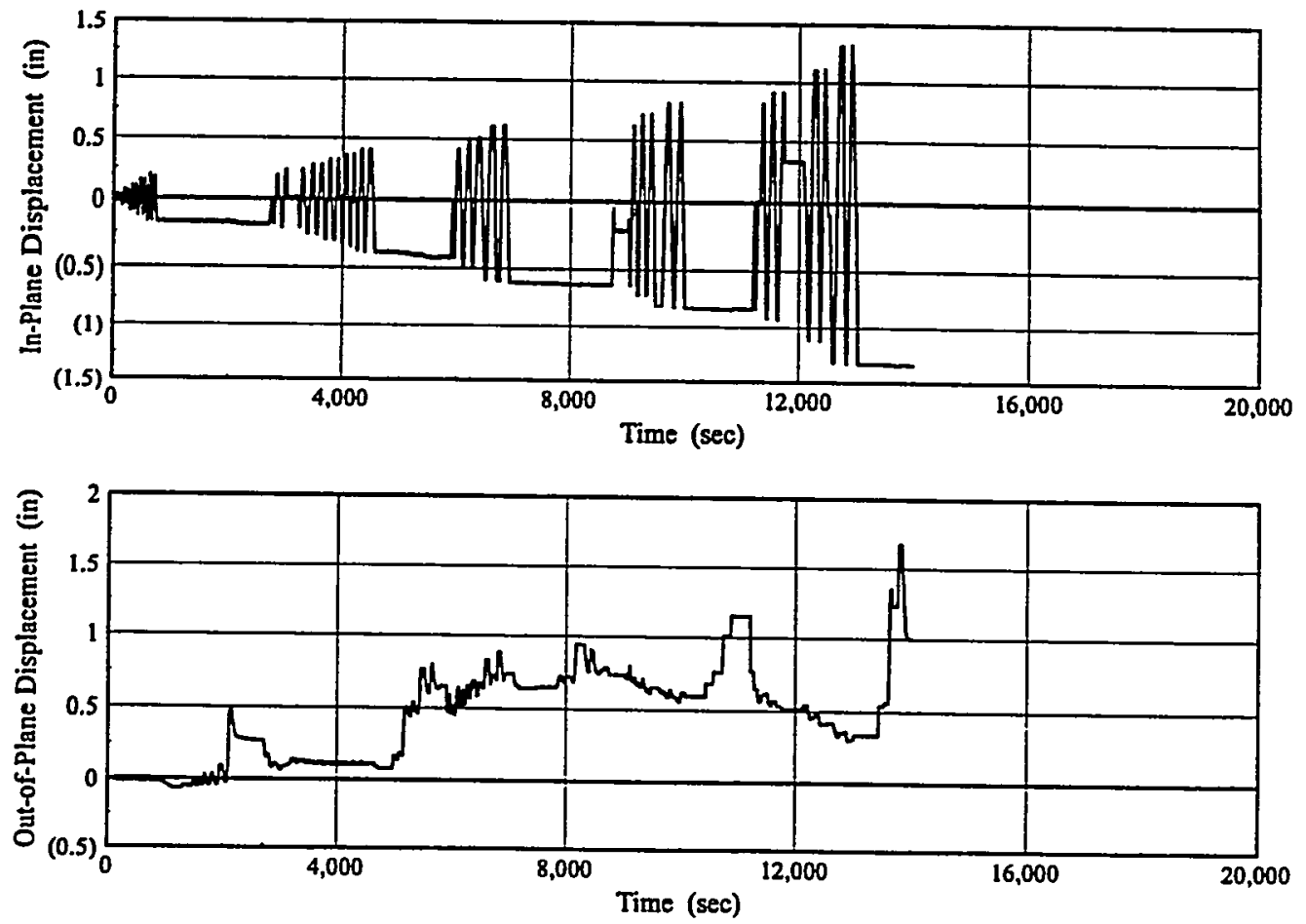

Figure 7.20 Specimen 23 In-Plane Beam and Out-of-Plane Midpanel Displacements 127 
The response of the system in terms of in-plane beam centerline displacements and out-ofplane midpanel displacements is presented in Figure 7.20. Displacement monitoring was ceased at these locations after 14000 seconds to prevent damage to the LVDTs. Specimen 23 had the weakest mortar of all infills constructed (1190 psi), Table 4.6. A summary of the test sequence follows.

Loading 1 consisted of five in-plane cycles ( 2 each) from $0.05 "$ to $0.20 "$. A complete diagonal crack developed by the end of this sequence. Considerable distress was audible from the specimen. Loading 2 consisted of an in-plane displacement of $0.18^{\text {" }}$ (14.3 kips initially) being held while four out-of-plane pressure cycles ( 2 each) of 0.5 to 2.3 psi were applied. During the 2.3 psi pressure, a loud pop was heard and a horizontal crack opened in the bed joint above the entire fourth course. As the pressure was being reduced after the last cycle, the wall moved out at the bottom and the tiles of the bottom course cracked, Figure 7.21.

Loading 3 consisted of five in-plane cycles (2 each) from $0.2^{\text {" to }} 0.45^{\prime \prime}$. Diagonal cracking became more banded and mortar spalled along the diagonal cracks. Loading 4 consisted of an in-plane displacement of 0.41 " (23.2 kips initially) being held while three out-of-plane pressure cycles ( 2 each) of 0.5 to 1.6 psi were applied. The in-plane load dropped by $50 \%$ during the three sets of pressure cycles.

Loading 5 consisted of two in-plane cycles ( 2 each) of $0.5^{\prime \prime}$ and $0.65^{n}$. The upper course compression corner and midpanel tiles cracked and their faceshells moved out. Loading 6 consisted of an in-plane displacement of 0.63 " (16.1 kips initially) being held while two out-ofplane pressure cycles ( 2 each) of 0.6 and 1.2 psi were applied. The midpanel tile of the second course failed and shifted out.

Loading 7 consisted of two in-plane cycles ( 2 each) of $0.75^{\prime \prime}$ and $0.85^{\prime \prime}$. Two more tiles cracked as midpanel tile were visibly rotating under racking load. Loading 8 consisted of an in- 
plane displacement of 0.84 " (11.3 kips initially) being held while two out-of-plane pressure cycles (2 each) of 0.65 and 1.1 psi were applied, Figure 7.22.

Loading 9 consisted of three in-plane cycles ( 2 each) from $0.95^{\prime \prime}$ to $1.35^{\prime \prime}$. The faceshells of some upper course tiles were removed by hand. Loading 10 consisted of an in-plane displacement of 1.35" (10.9 kips initially) being held while two out-of-plane pressure cycles (2 each) of 0.55 and $1.2 \mathrm{psi}$ were applied. The wall shifted at the center. The two lower courses of tiles are effectively gone. Horizontal arching at low pressures appears to be stabilized by the presence of in-plane racking loads. Loading 11 consisted of four in-plane cycles ( 2 each) from $1.55 "$ to $2.4 "$. A relatively constant peak load was observed in each of these cycles (10-12 kips). Complete displacements normal to the panel are given in Figure 7.23 for loading 6. The failure of the bottom course is evident from the measured displacements $20^{\prime \prime}$ from the floor. Early development of horizontal arching is also indicated in the displacement profile at midheight ( $43^{n}$ from floor). Like specimen 18 , vertical arching dominated the early portion of the loading until the top and bottom courses failed, then horizontal arching allowed the panel to remain stable under static loads.

The strains in the steel frame are most influenced by the in-plane forces. Figure 7.24 provides a comparison of average strains at the inside and outside of the column flange near the bottom of the left column. Only small fluctuations in average strain are noticed as the in-plane displacements are held and lateral pressure applied. Figures 7.25 and 7.26 provide individual strain readings at the 4 corners of the left column flange near midheight. No averaging of strain was performed across the section. Some torsion is indicated in the column for both in-plane and lateral loading, however, the variation of the strain across the section is much less than the strain magnitude at either extreme point. 


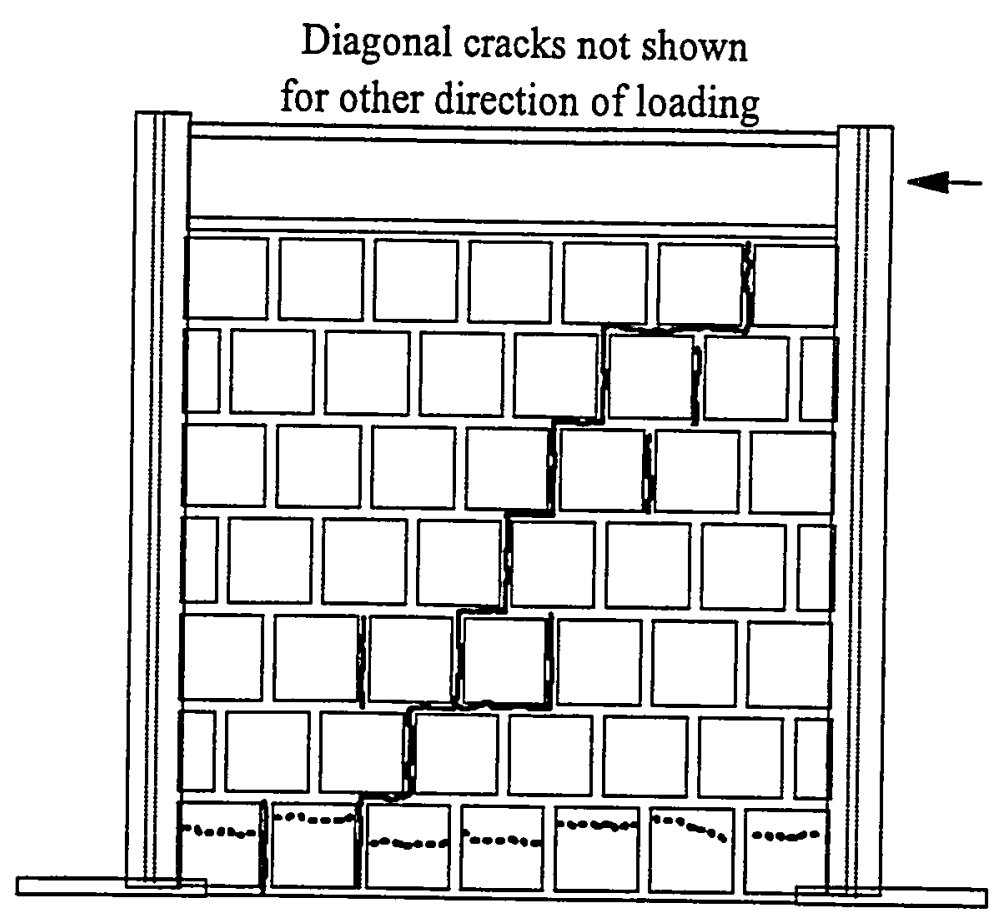

Figure 7.21 Specimen 23 Crack Map After Loading 2

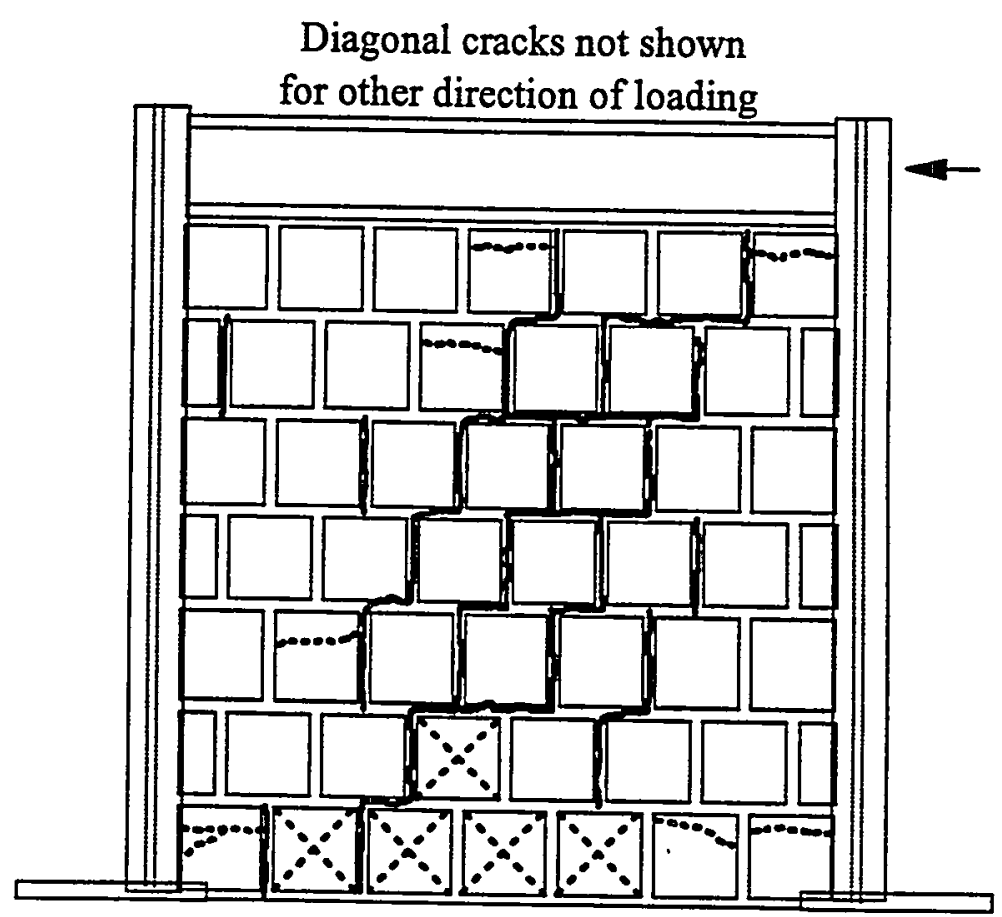

Figure 7.22 Specimen 23 Crack Map After Loading 8 

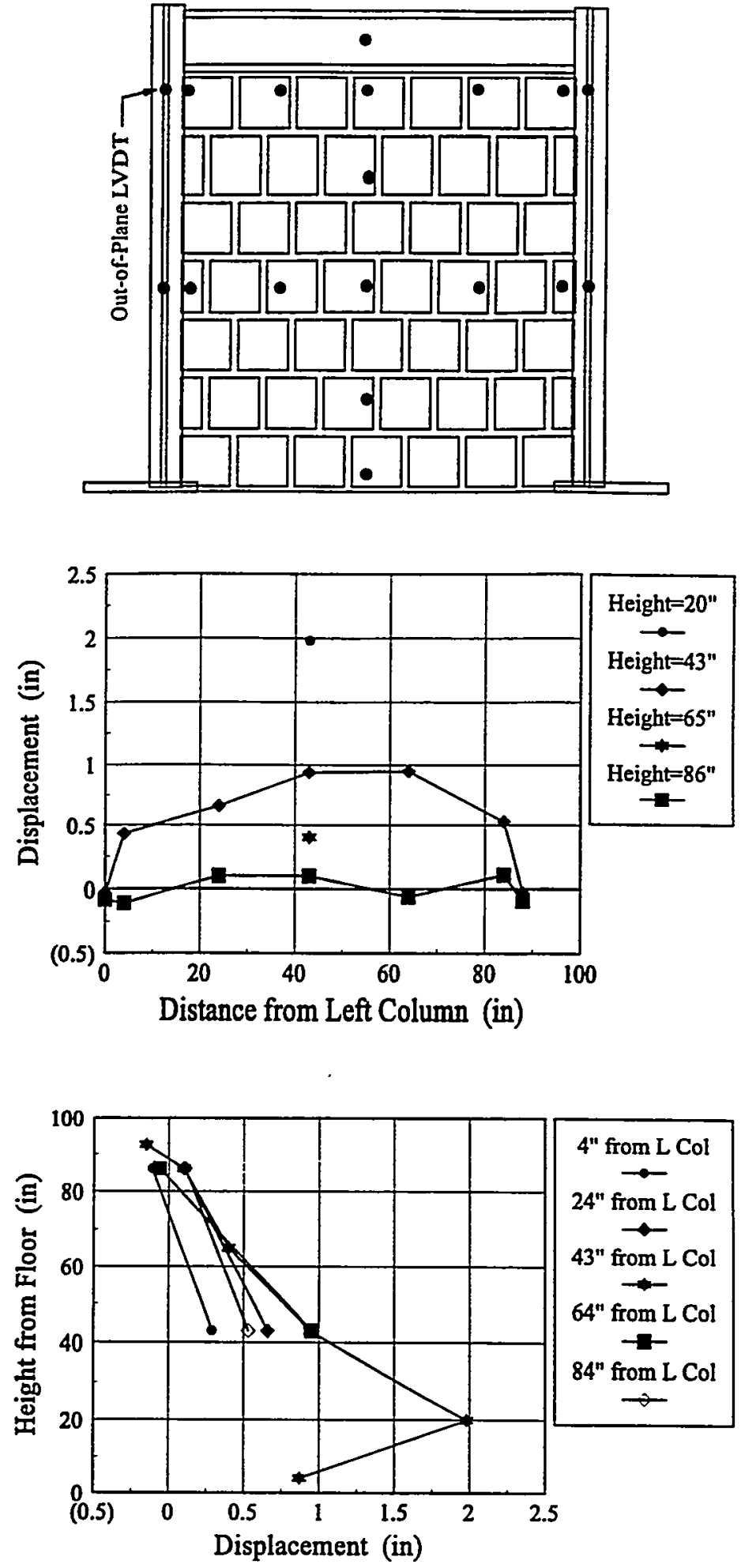

Figure 7.23 Specimen 23 Out-of-Plane Displaced Shape During Loading 6 $($ Time $=8190 \mathrm{sec}$, Pressure $=1.22 \mathrm{psi}$, In-Plane Force $=11.5 \mathrm{kips}$, In-Plane Disp $=0.64 \mathrm{inch})$ 


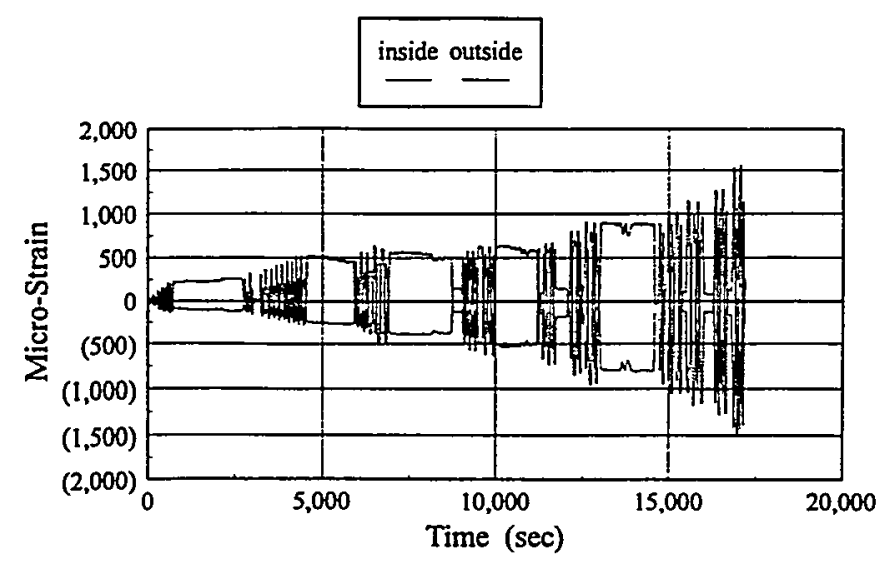

Figure 7.24 Comparison of Average Strains Near Left Column Base

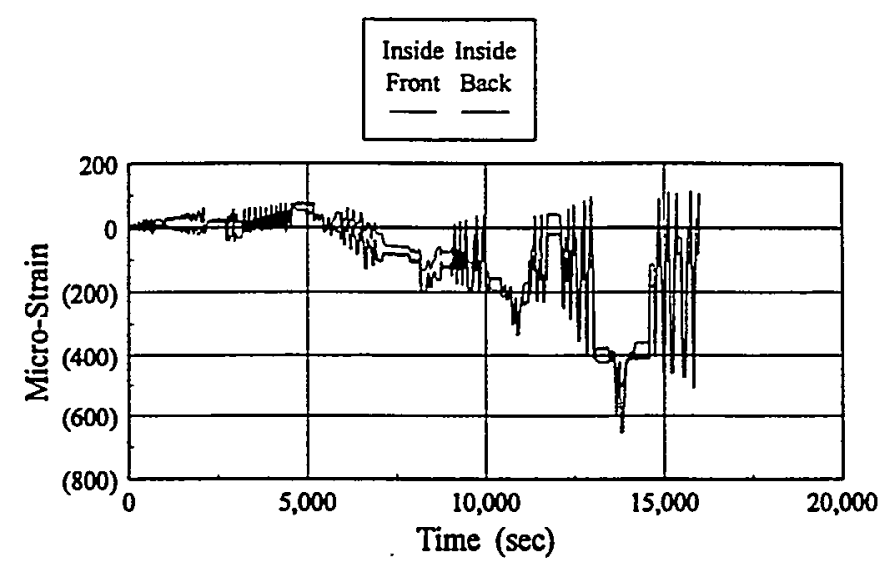

Figure 7.25 Comparison of Left Column Strains Near Midheight (Inside)

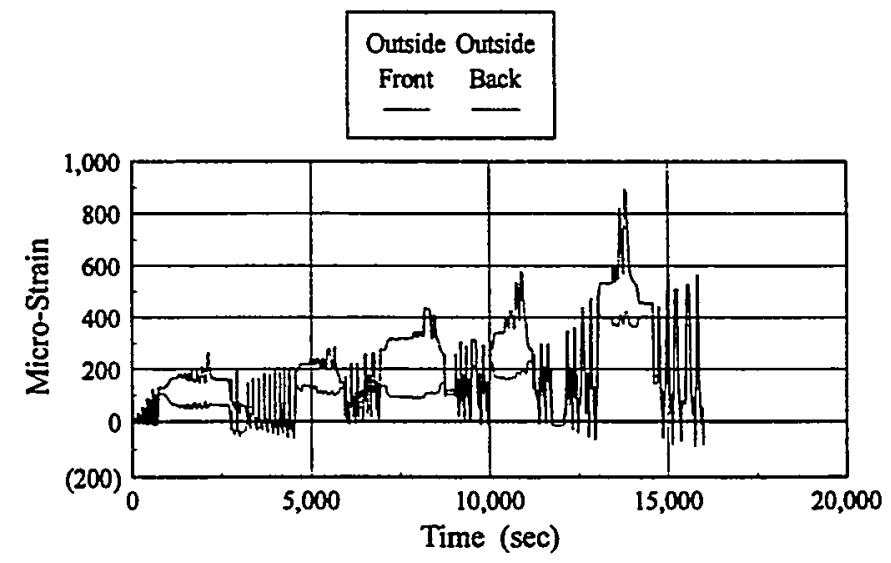

Figure 7.26 Comparison of Left Column Strains Near Midheight (Outside) 


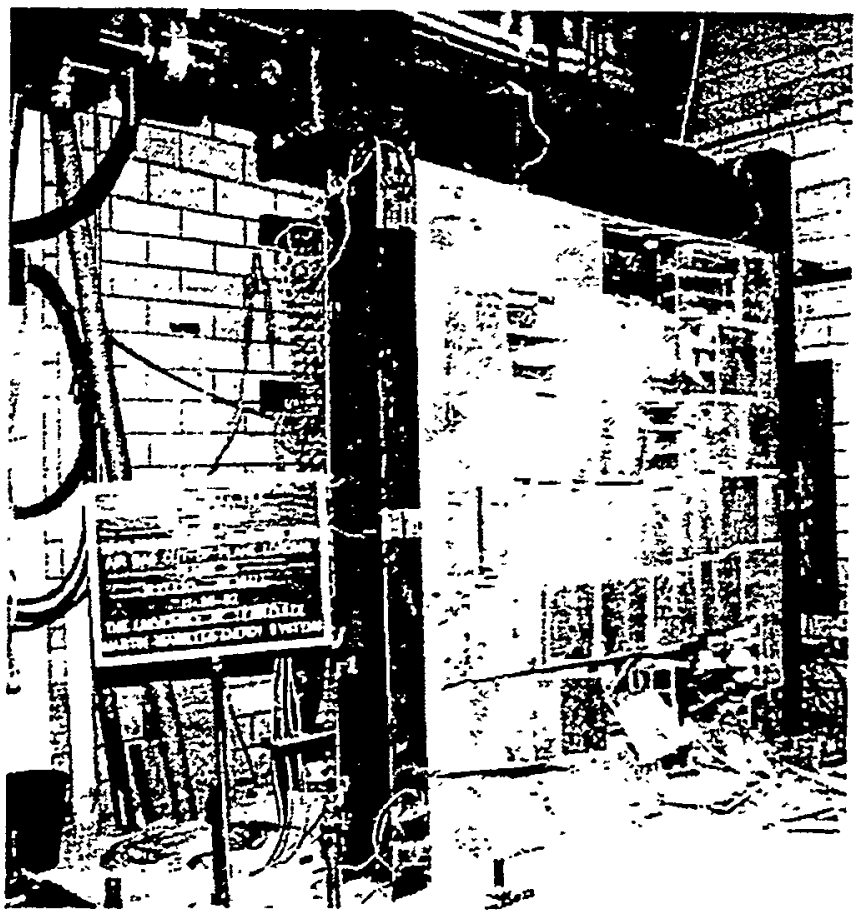

Figure 7.27 Specimen 23 After Testing

The condition of the panel after all loadings is presented in Figure 7.27. At this point, the panel appears to be so much rubble, but it was surprisingly difficult to destruct as the large tiles are wedged between the frame and other tile.

Complete hysteresis of the in-plane load versus beam centerline displacement is given in Figure 7.28. Likewise the hysteresis of the uniform lateral pressure versus midpanel displacement is given in Figure 7.29. Although complicated by the combined loading, these relationships are remarkably similar to the in-plane and out-of-plane control specimens 2 and 18. Moments computed from specimen 23 are given in Figures 7.30 through 7.32. As with the purely in-plane tests, the moments at the base are somewhat linear with respect to displacement. Moments at midheight of the left column were computed by averaging strain across the section. Spikes in the moment can be seen at points where in-plane displacement is held. The moments are approaching plastic behavior at the highest in-plane drift (2.4"). 


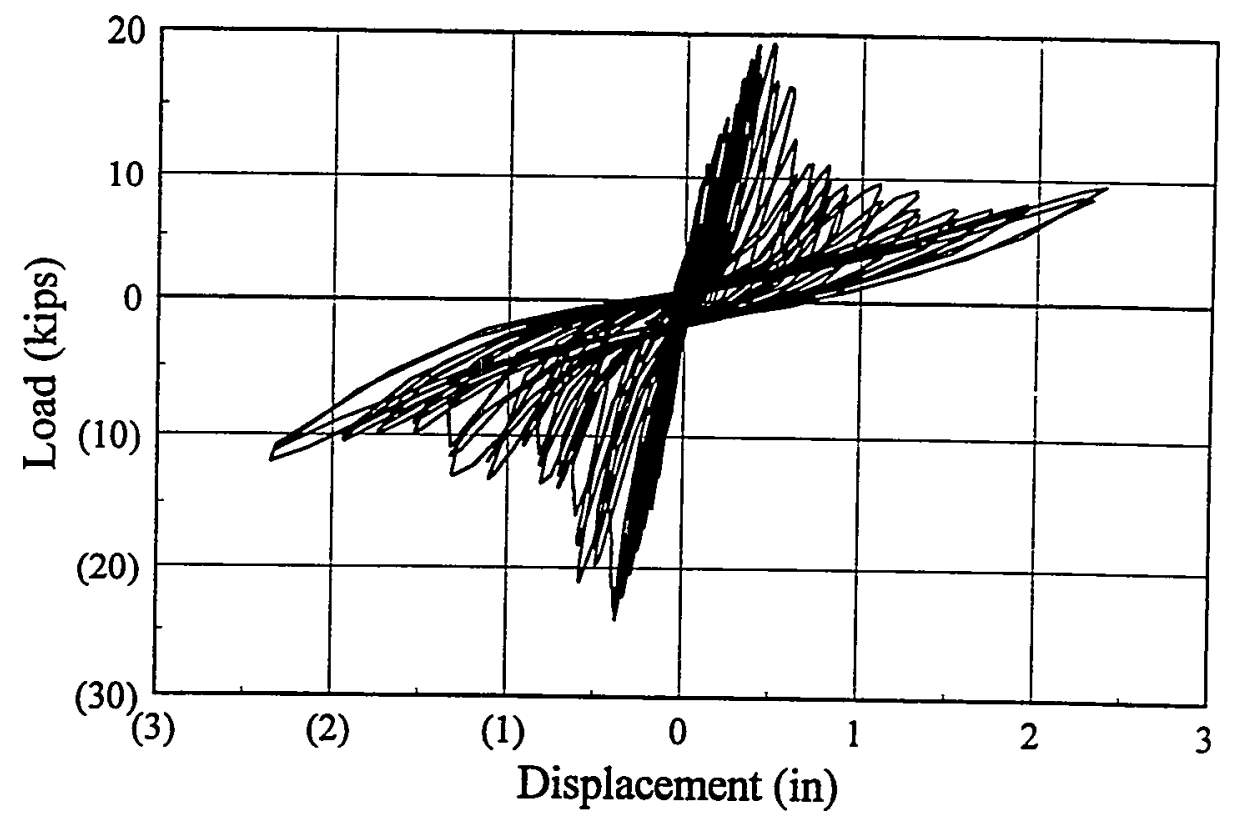

Figure 7.28 Specimen 23 In-Plane Hysteresis

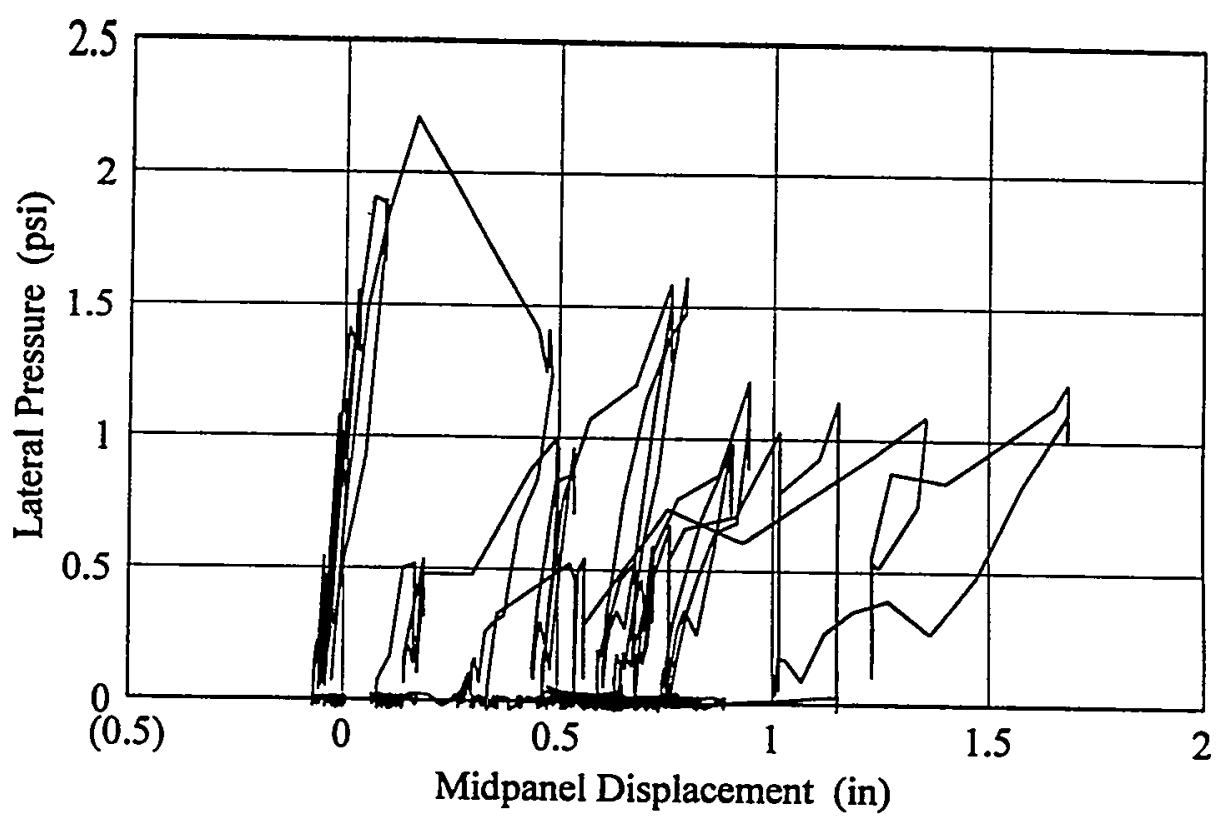

Figure 7.29 Specimen 23 Uniform Lateral Load Hysteresis 


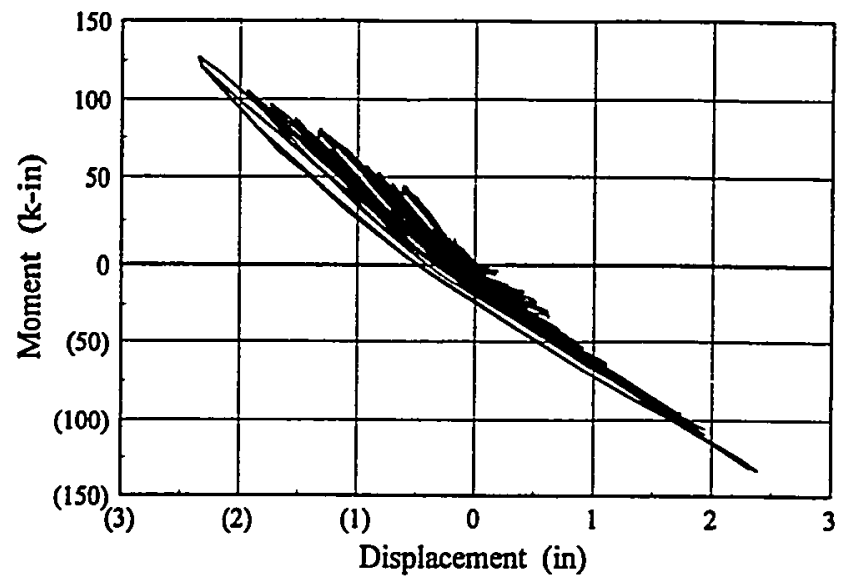

Figure 7.30 Specimen 23 Moments Near Right Column Base

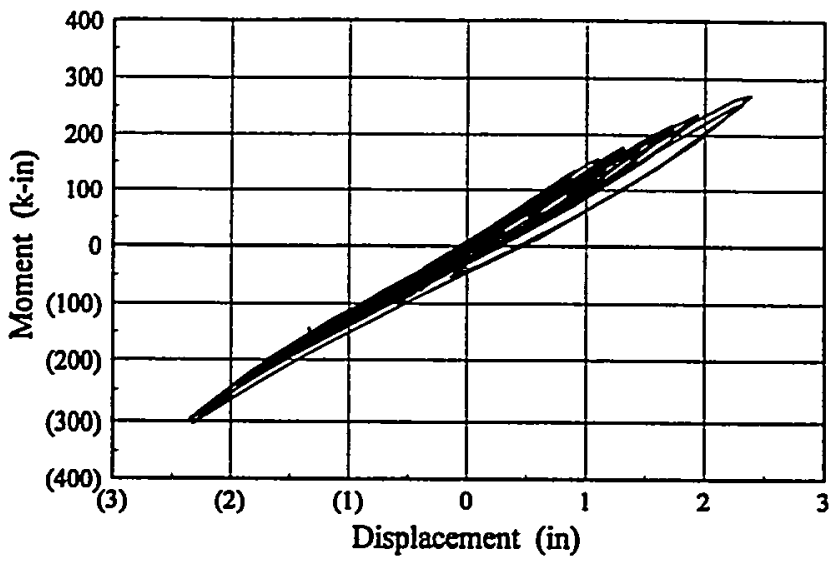

Figure 7.31 Specimen 23 Moments Near Left Column Base

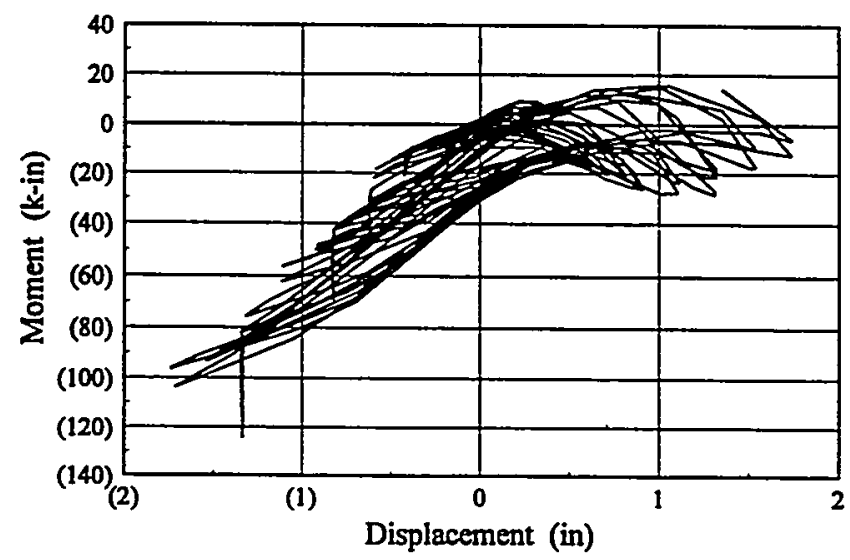

Figure 7.32 Specimen 23 Moments Near Left Column Midheight 
In summary, there is little interaction of frame forces for panels under combined in-plane racking and uniform out-of-plane loading. The panel remains remarkably stable, even after much damage. The infill contributes to the in-plane strength even after significant damage. Combined loading reduces the lateral pressure capacity. Both lateral and in-plane loadings tend to cause inplane compression. Failure of the bottom course initially is quite reasonable. Strut forces are transferred directly to the base, not into the column. This creates high vertical compression at the base. Vertical arching also creates high vertical compression. The additive effect of the two leads to failure. 


\section{CHAPTER 8}

\section{CONCLUSIONS AND RECOMMENDATIONS}

\subsection{Structural Clay Tile Infill Behavior}

Twenty-one large-scale specimens consisting of steel frames infilled with unreinforced structural clay tile were tested to determine the behavior of the infills. The in-plane behavior was characterized first by diagonal panel cracking at a shear stress of approximately $\sqrt{f}_{m}^{\prime}$ followed by corner crushing at ultimate capacity. The presence of the infill stiffens the steel framing while the framing confines the masonry allowing greater strength and ductility. The infill tends to perform as a compressive strut, bracing the otherwise unstable framing. Significant postpeak strength was observed indicating continued energy absorption capability.

In-plane tests that evaluated varying frame stiffness, single and double wythe construction, varying panel aspect ratio, weak column/infill interface, and repaired panels exhibited remarkably different stiffness characteristics, but relatively similar ultimate strengths. The contribution to total strength by the framing is small and the contribution of the infill is nearly constant.

Infills with the panel offset from the frame centerline developed peak capacities proportional to the effective net area enclosed in the framing. An infill with a significant upper corner opening developed a compressive strut lower in the panel and resulted in a $60 \%$ loss of capacity in the corresponding direction.

Infills of different thickness were tested out-of-plane with a uniform lateral loading to simulate the inertial effects of the panel normal to its plane. The behavior was dominated by arching action of the masonry. Typically, vertical arching developed until failure of the top and bottom course tiles, then horizontal arching developed, maintaining stability of the panel. The 
failure mechanism of the masonry along the panel boundary indicated a combined shear and compression failure in the tile units.

The stability of clay tile infills under out-of-plane drift loading and the subsequent effect on in-plane behavior were investigated. There was little relative movement of the infill panels with respect to the steel framing, and stability of the infill was maintained. Consequently, only minimal degradation of in-plane stiffness and strength was observed.

Additional infills were tested to examine the interaction between in-plane and out-of-plane forces. These tests consisted of sequential and simultaneous in-plane and out-of-plane loading. The interaction between in-plane and out-of-plane loads was not significant, particularly at moderate levels of loading.

A sequential test of in-plane racking followed by uniform lateral loading reduced the outof-plane capacity by $20 \%$. The out-of-plane stiffness was also reduced by the prior in-plane loading, resulting in a $65 \%$ increase in midpanel displacement.

A sequential test of uniform lateral loading followed by in-plane racking resulted in no in-plane strength degradation as compared to a similar specimen loaded purely in-plane. Interface degradation and plastic strains from the prior out-of-plane loading resulted in a $50 \%$ decrease in initial in-plane stiffness. Prior lateral loading cracked the panel mortar joints, eliminating the inplane diagonal cracking limit state.

A combined in-plane racking and uniform lateral load test resulted in reduced lateral pressure capacity. Lateral loads producing thrust forces around the panel perimeter and in-plane loads producing strut forces along the diagonal combined, creating high vertical compression near the panel base and causing failure of the bottom course tiles. However, even after much damage to the masonry panel, the infill remained remarkably stable under combined loading. 


\subsection{Infilled Frame Member Forces}

Under in-plane racking loads, column moments of the infilled frames are similar to those of the bare frames, especially near the bottom and midheight. This indicates that strut forces are transferred into the floor through the infill, not the column. Infilled frame beams remain in upward curvature through both cycles of loading as the masonry attempts to expand.

The infill provides diagonal compressive strut behavior under in-plane loading. Axial tension forces in the windward column are similar to the applied loads while only small axial tension forces develop in the leeward column. Axial forces in the beams vary from compression (applied load) near the windward column to slight tension near the leeward column. This indicates a significant shear transfer due to friction along the top panel interface.

Under uniform lateral loading, thrust forces in the plane of the panel result in axial tension and upward bending in the beams. The beams undergo out-of-plane (weak axis) bending as the lateral load is transferred from the panel to the beam through friction. Finally, the moments in the beams reduce after ultimate capacity (vertical arching) as the damage to the top courses continues.

Forces in the columns are typically low until late in the loading as horizontal arching develops, resulting in outward bending of the column. The columns are also in tension resisting the upward thrust of the beam. The columns also undergo out-of-plane bending from the shear transfer of lateral loads along the column-panel interface.

Under combined in-plane racking and uniform lateral loads, there is little effect of interaction of frame forces. For example, column moments are most influenced by the in-plane drift, with little added moment from the pressure load-unload cycles. 


\subsection{Numerical Analysis of Structural Clay Tile Infills}

Typically, seismic analysis of complex building structures involves three-dimensional dynamic evaluation by response spectra or other techniques. Components of a building analysis methodology for clay tile infills have been presented in the previous chapters. Based on observations of the testing program, the infills may be evaluated in the in-plane and out-of-plane directions separately.

The panels may be represented in-plane by an equivalent compressive strut. Two approaches for determining the properties of the compressive strut were presented in sections 5.2.2 and 5.2.3. The first method is a nonlinear compressive strut formulation with changing modulus and the second method is a piecewise linear solution in which the area of the compressive strut changes. Both procedures compared well with experimental results. The piecewise linear solution is appropriate for complex building evaluation and the nonlinear solution is useful for hysteretic modeling of one or more individual paneis.

Three equations for predicting in-plane capacity were investigated. Of these, the plastic collapse theory (Equation 5.2) and the simplified strut formulation (Equation 5.5) compared well with experimental results. Member forces may be approximated using the superposition procedure of section 5.2.4.

Out-of-plane inertial capacity of the panel may be evaluated locally based on building accelerations. Because local panel frequencies are typically much higher than the building structure, an equivalent panel capacity (allowable panel acceleration) may be computed and compared to the building acceleration at the infill elevation. Equation 6.1 has effectively predicted the uniform lateral capacities of the test specimens, and the procedure defined in section 6.3 envelopes the time history response of the infills. 


\subsection{Recommendations}

Several technical areas merit further investigation of clay tile infills. First is the development of more realistic properties of the masonry as they exist in an infill. A comprehensive testing program to evaluate biaxial properties of clay tile masonry should greatly increase the understanding of panel behavior and facilitate numerical methods. Second are additional tests not covered in the infill parameter study of the current research. These specimens would include combined in-plane racking and column (or beam) vertical load, torsional loading, in-plane racking tests for a variety of openings, and further dynamic tests to confirm the results of the current static test program.

In the area of numerical analysis, many approaches could be taken. Further investigation of the current research methods should be compared and/or validated with experimental results of concrete and brick masonry infills. With results of a biaxial testing program, detailed modeling of the masonry infill would be possible. 


\section{BIBLIOGRAPHY}


ABAQUS (1993). ABAQUS Theory Manual, Hibbitt, Karlsson and Sorenson, Inc., Pawtucket, RI, Version 5.3.

ASTM C-10 (1924). "Report of Committee C-10 on Hollow Masonry Building Units," Proceedings, American Society for Testing and Materials, Vol. 24, p. 411-422.

ASTM C-10 (1926). "Report of Committee C-10 on Hollow Masonry Building Units," Proceedings, American Society for Testing and Materials, Vol. 26, p. 285-291.

ATC (1987). Evaluating the Seismic Response of Existing Buildings, Applied Technology Council, ATC-14, Redwood City, CA.

ATC (1989a). A Handbook for Seismic Evaluation of Existing Buildings: (Preliminary), Applied Technology Council, ATC-22, FEMA-178, Redwood City, CA.

ATC (1989b). Seismic Evaluation of Existing Buildings: Supporting Documentation, Applied Technology Council, ATC-22-1, FEMA-175, Redwood City, CA.

BSSC (1992). NEHRP Handbook for the Seismic Evaluation of Existing Buildings, Building Seismic Safety Council, FEMA-178, Washington, D.C.

CPIC (1929). Earthquakes and Building Construction, Clay Products Institute of California.

ICBO (1992). Uniform Building Code, International Conference of Building Officials, Whittier, CA.

LABC (1985). Los Angeles Building Code, Division 88, City of Los Angeles, CA.

MMES (1992). "Proceedings of the National Workshop on Unreinforced Hollow Clay Tile," Martin Marietta Energy Systems, Inc. and the Structural Engineers Association of Northern California, San Francisco, CA.

NEHRP (1990). "National Earthquake Hazards Reduction Program Reauthorization Act," 101st U.S Congress, Public Law 101-614.

NCEER (1994). "Proceedings of the NCEER Workshop on Seismic Response of Masonry Infills," National Center for Earthquake Engineering and Research, San Francisco, CA.

RCSC (1988). "Load and Resistance Factor Design Specification for Structural Joints Using ASTM A325 or A490 Bolts," Research Council on Structural Connections, American Institute of Steel Construction, Chicago, IL.

SCPI (1967). "Compressive, Transverse, and Racking Strength Tests of Four-Inch Structural Clay Facing Tile Walls," Structural Clay Products Institute, Research Report No. 11, Reston, VA. 
SCPI (1969). "Compressive, Transverse and Shear Strength Tests of Six and Eight-Inch Single-Wythe Walls Built with Solid and Heavy Duty Hollow Clay Masonry Units," Structural Clay Products Institute, Research Report No. 16, Reston, VA.

Abrams, D.P., Angel, R., and Uzarski, J. (1993). "Transverse Strength of Damaged URM Infills," Proceedings of the Sixth North American Masonry Conference, Philadelphia, PA, 347-358.

Adham, S.A. (1994). "Impact of Infilled Masonry Walls on the Response of Buildings in Moderate Seismic Zones." Proceedings from the NCEER Workshop on Seismic Response of Masonry Infills. NCEER-94-0004, 2-23 to 2-29.

Barclay, G.A. (1993). "Behavior of Structural Clay Tile Infilled Steel Frames Subjected to InPlane Loading," Masters Thesis, The University of Tennessee, Knoxville, TN.

Benjamin, J.R. and Williams, H.A. (1958). "The Behaviour of One-Storey Brick Shear Walls," Journal of the Structural Division, ASCE, May, pp. 1723, I-30.

Benedetti, D. and Benzoni, G.M. (1984). "A Numerical Model for Seismic Analysis of Masonry Buildings: Experimental Correlations, " Earthquake Engineering and Structural Dynamics, 12(6), 817-831.

Boyd, K.A. (1993). "Compressive Strength and Constitutive Behavior of Clay Tile Prisms," Masters Thesis, The University of Tennessee, Knoxville, TN.

Bruneau, M., and Saatcioglu, M. "Behavior of Unreinforced Masonry Structures During the 1992 Erzincan, Turkey, Earthquake." The Masonry Society Journal, 12(2), 79-87.

Columber, C.E. (1994). "Structural Clay Tile Component Behavior," Masters Thesis, The University of Tennessee, Knoxville, TN.

Dawe, J.L., and Seah, C.K. (1989a). "Behavior of Masonry Infilled-Steel Frames." Canadian Journal of Civil Engineering, 16, 865-876.

Dawe, J.L., and Seah, C.K., (1989b). "Out-of-plane Resistance of Concrete Masonry Infilled Panels," Canadian Journal of Civil Engineering, 16, 854-864.

Dhanasekar, M., Page, A.W., and Kleeman, P.W. (1985). "The Behavior of Brick Masonry under Biaxial Stress with Particular Reference to Infilled Frames." Proceedings of Seventh International Brick Masonry Conference, 814-824.

El-Ouali, T., Houde, J. and Tinawi, R. (1991). "Comportement d'un cadre rempli soumis à un chargement cyclique: modélisation pour une analyse dynamique non linéaire," Canadian Journal of Civil Engineering, 18.

Fattal, S.G. (1977). "The Capacity of Unreinforced Masonry Shear Walls under Membrane Loads," National Bureau of Standards Building Science Series 106, 177-197. 
Flanagan, R.D., Bennett, R.M., and Butala, M.B. (1993a). "Properties of Structural Clay LoadBearing Wall Tile," Sixth North American Masonry Conference, Philadelphia, PA, 8798.

Flanagan, R.D., Barclay, G.A., and Bennett, R.M. (1993b). "In-Plane Behavior and Strength of Structural Clay Tile Infilled Frames," Sixth North American Masonry Conference, Philadelphia, PA, 371-382.

Flanagan, R.D., and Bennett, R.M. (1992). "Inter-Story Drift Effects on the In-Plane Capacity of Infilled Frames." Proceedings of the Third International Masonry Conference, London, England.

Flanagan, R.D., and Bennett, R.M. (1993). "Large-Scale Testing of Structural Clay Tile Infilled Frames," Canadian Society of Civil Engineering Conference, Fredericton, New Brunswick, Canada, 533-540.

Flanagan, R.D., and Bennett, R.M. (1994a). "Seismic Evaluation of Industrial Facilities with Unreinforced Structural Clay Tile Infills, " Fifth U.S. National Conference on Earthquake Engineering, Chicago, IL 365-374.

Flanagan, R.D., and Bennett, R.M. (1994b). "Uniform Lateral Load Capacity of Infilled Frames," Structures Congress XII, Atlanta, GA, Vol. 1, 785-790.

Fricke, K.E., Jones, W.D., and Huff, T.E. (1992). "In Situ Lateral Load Testing of an Unreinforced Masonry Hollow Clay Tile Wall," Sixth Canadian Masonry Symposium, Saskatoon, Saskatchewan, Canada, Vol. 2, 519-530.

Frye, M.J., and Morris, G.A. (1975). "Analysis of Flexibly Connected Steel Frames, " Canadian Journal of Civil Engineering, 2, 280-291.

Gabrielsen, B.L., and Kaplan, K. (1977). "Arching in Masonry Walls Subjected to Out-of-Plane Forces." Earthquake Resistant Masonry Construction, NBS Building Science Series 106, 283-313.

Hathcock, B.D., and Skillman, E. (1918). "Tests of Hollow Building Tiles," Technologic Papers of the Bureau of Standards No. 120.

Henderson, R.C., Jones, W.D., and Porter, M.L. (1993). "Factors Affecting the Ductility of Double-Wythe Masonry Infills Subjected to Seismic Drift," Sixth North American Masonry Conference, Philadelphia, PA, Vol. 1, 223-234.

Hill, J.A. (1994). "Out-of-Plane Response of Unreinforced Masonry Infill Frame Panels," Proceedings of the NCEER Workshop on Seismic Response of Masonry Infills, San Francisco, CA.

Hetenyi, M. (1946). Beams on Elastic Foundations, University of Michigan Press, Ann Arbor. 
Holmes, M. (1961). "Steel Frames with Brickwork and Concrete Infilling," Proceedings of the Institution of Civil Engineers, 19, 473-478.

Holmes, M. (1963). "Combined Loading on Infilled Frames," Proceedings of the Institution of Civil Engineers, 25, 31-38.

Johnson, F.B., and Matthys, J.H. (1973). "Structural Strength of Hollow Clay Tile Assemblages," Journal of the Structural Division, ASCE, 99(ST2), 259-275.

Kishi, N., and Chen, W.F. (1986). Data Base of Steel Beam-to-Column Connections, Purdue University, Civil Engineering Report CE-STR-86-26, West Lafayette, IN.

Klingner, R.E., and Bertero, V.V. (1978). "Earthquake Resistance of Infilled Frames," Journal of the Structural Division, ASCE, 104(ST6), 973-989.

Klingner, R.E., Beiner, R., and Amrhein, J. (1987). "Performance of Masonry Structures in the Mexican Earthquake of September 19, 1985, " Proceedings of the Fourth North American Masonry Conference, 70:1-70:14.

Liauw, T.C. and Kwan, K.H. (1983). "Plastic Theory of Non-Integral Infilled Frames," Proceedings of the Institution of Civil Engineers, 75, 379-396.

Lawrence, S.J. (1979). "Lateral Loading of Masonry Infill Panels: A Literature Review," Technical Record 454, Experimental Building Station, Sydney, Australia.

Mainstone, R.J. (1970). "The Influence of a Bounding Frame on the Racking Stiffness and Strength of Brick Walls," Proceedings of the Second International Brick Masonry Conference, Stoke-on-Trent, UK, 165-171.

Mainstone, R.J. (1971). "On the Stiffness and Strength of Infilled Frames," Proceedings of the Institution of Civil Engineers, Supplement IV, paper 7360S, 57-90.

Mainstone, R.J. (1974). "Supplementary Note on the Stiffness and Strengths of Infilled Frames," Building Research Station, Garston, Watford, UK.

Mander, J.B., Nair, B. Wojtowski, K., Ma, J. (1993). "The seismic Performance of Brick Infilled Steel Frames With and Without Retrofit," Technical Report NCEER-93-0001, National Center for Earthquake Engineering Research, State University of New York at Buffalo.

Mander, J.B., Aycardi, L.E., Kim, D.-K. (1994). "Physical and Analytical Modeling of Brick Infilled Steel Frames," Proceedings of the NCEER Workshop on Seismic Response of Masonry Infills, San Francisco, CA.

Matthys, J.H. (1972). "Structural Performance of Hollow Clay Tile Wall Assemblages," PhD Dissertation, The University of Texas at Austin. 
McDowell, E.L., McKee, K.E., and Sevin, E. (1956). "Arching Action Theory of Masonry Walls." Journal of the Structural Division, ASCE, 82(ST2). 915-1 to 915-18.

Parsons, D.E. (1931). "Factors Affecting the Strength of Masonry of Hollow Units," Journal of Research of the National Bureau of Standards, 6, Research Paper RP310, 857-867.

Parsons, D.E., and Watstein, D. (1937). "Compressive Strength of Structural Tile Masonry," Journal of Research of the National Bureau of Standards, 18, Research Paper RP972, 215-226.

Plummer, H.C. (1962). "Brick and Tile Engineering," Brick Institute of America, Reston, VA.

Polyakov, S.V. (1960). "On the Interaction Between Masonry Filler Walls and Enclosing Frame when Loaded in the Plane of the Wall," Translations in Earthquake Engineering, Earthquake Engineering Research Institute, San Francisco, 36-42.

Polyakov, S.V. (1963). "Masonry in Framed Buildings," (Gosudarstvennoe izdatel' stvo Literatury po stroitel' stvu i arkhitekture, Moscow, 1956). Translated by G. L. Cairns. National Lending Library for Science and Technology, Boston Spa, Yorkshire, U.K.

Riddington, J.R. (1984). "The Influence of Initial Gaps on Infilled Frame Behavior", Proceedings of the Institution of Civil Engineers, Part 2, Vol 77, London, 295-310.

Schuller, M., Mehrabi, A.B., Noland, J.L, and Shing, P.B. (1994). "Performance of MasonryInfilled R/C Frames under In-Plane Lateral Loads: Experiments," Proceedings of the NCEER Workshop on Seismic Response of Masonry Infills, San Francisco, CA.

Stafford-Smith, B. (1962). "Lateral Stiffness of Infilled Frames." Journal of the Structural Division, ASCE, 88(ST6), 183-199.

Stafford-Smith, B. (1966). "Behavior of Square Infilled Frames." Journal of the Structural Division, ASCE, 92(ST1), 381-403.

Stafford-Smith, B. (1968). "Model Tests of Vertical and Horizontal Loading of Infilled Frames." Journal of the American Concrete Institute, 65(8), 618-624.

Stafford-Smith, B., and Carter C. (1969). "A Method for the Analysis of Infilled Frames." Proceedings of the Institution of Civil Engineers, 44, 31-48.

Stang, A.H., Parsons, D.E., and Foster, H.D. (1926). "Compressive and Transverse Strength of Hollow Tile Walls," U.S. Bureau of Standards, Technologic Papers No. 311, Washington, D.C.

Thomas, F.G. (1953). "The Strength of Brickwork." The Structural Engineer, 31(2), 35-46.

Wood, R.H. (1958). "The Stability of Tall Buildings." Proceedings of the Institution of Civil Engineers, 11, 69-102. 
Wood, R.H. (1978). "Plasticity, Composite Action and Collapse Design of Unreinforced Shear Wall Panels in Frames," Proceedings of the Institution of Civil Engineers, Part 2, 65, $381-411$.

Whittemore, H.L, and Hathcock, B.D. (1923). "Some Compressive Tests of Hollow-Tile Walls," U.S. Bureau of Standards, Technologic Papers No. 238, Washington, D.C.

Whittemore, H.L, Stang, A.H., and Parsons, D.E., (1938). "Structural Properties of Six Masonry Wall Constructions," U.S. National Bureau of Standards, Building Materials and Structures Report No. 5, Washington, D.C. 
APPENDIX 

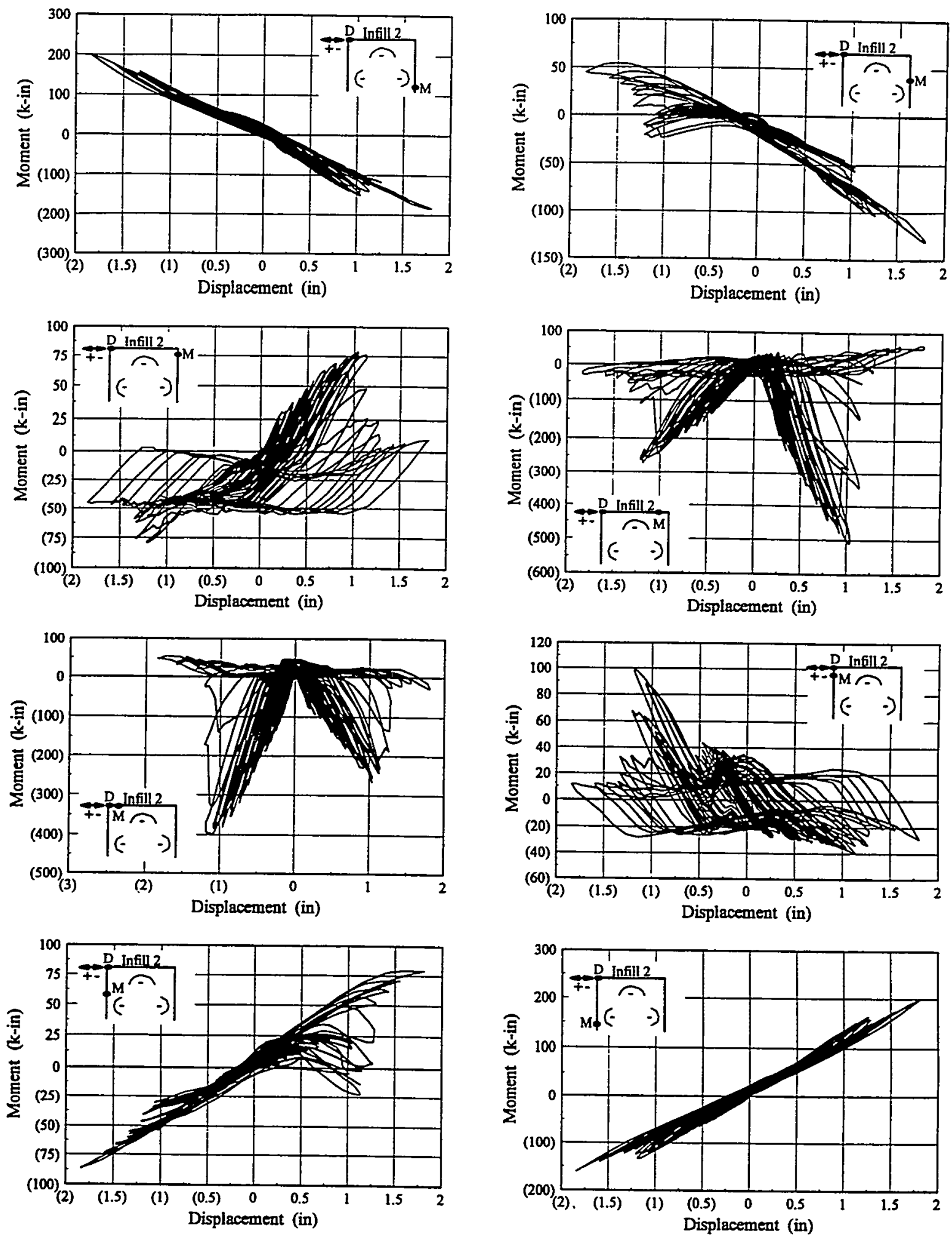

Infilled Frame 2 Moment-Displacement Hysteresis 

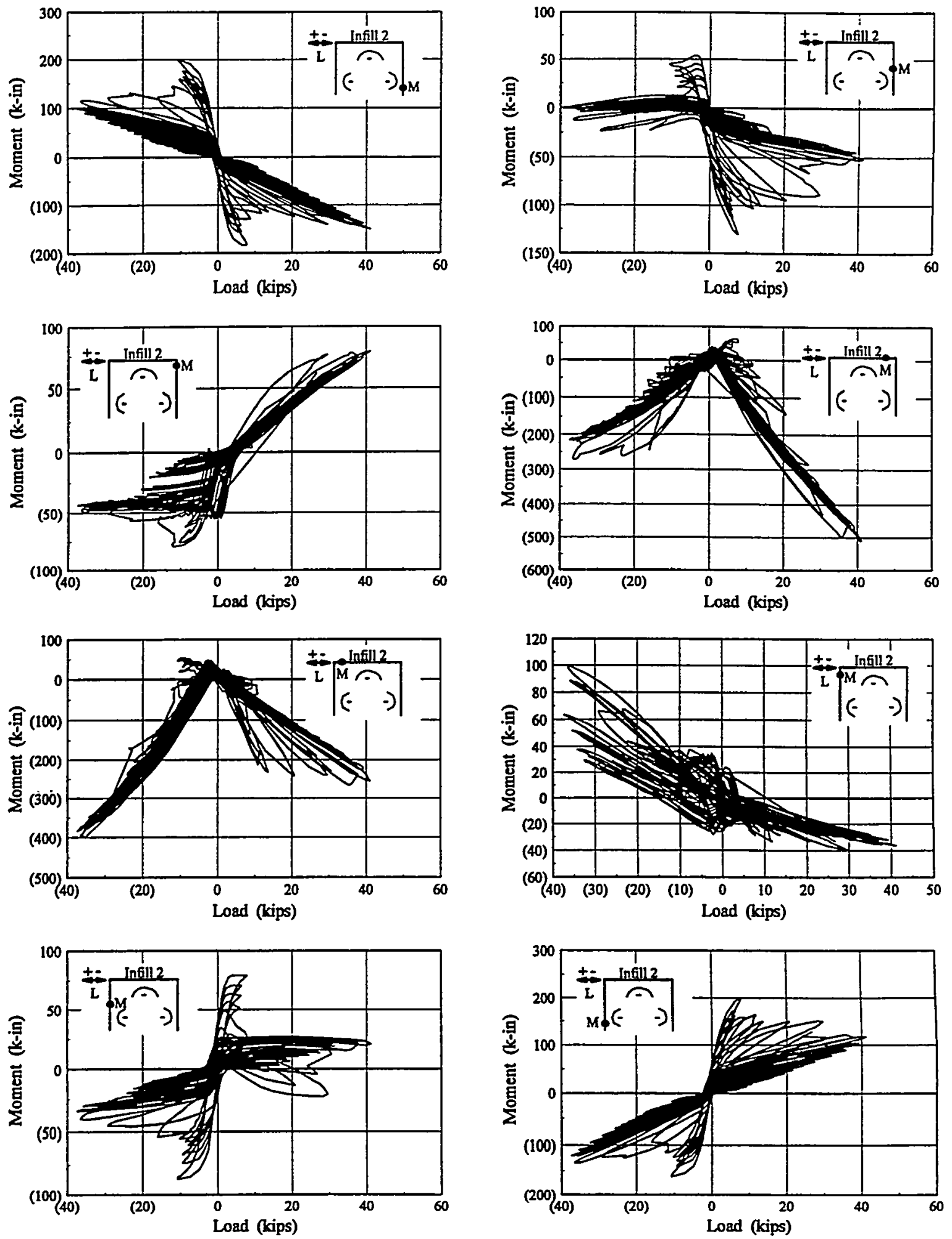

Infilled Frame 2 Moment-Load Hysteresis 

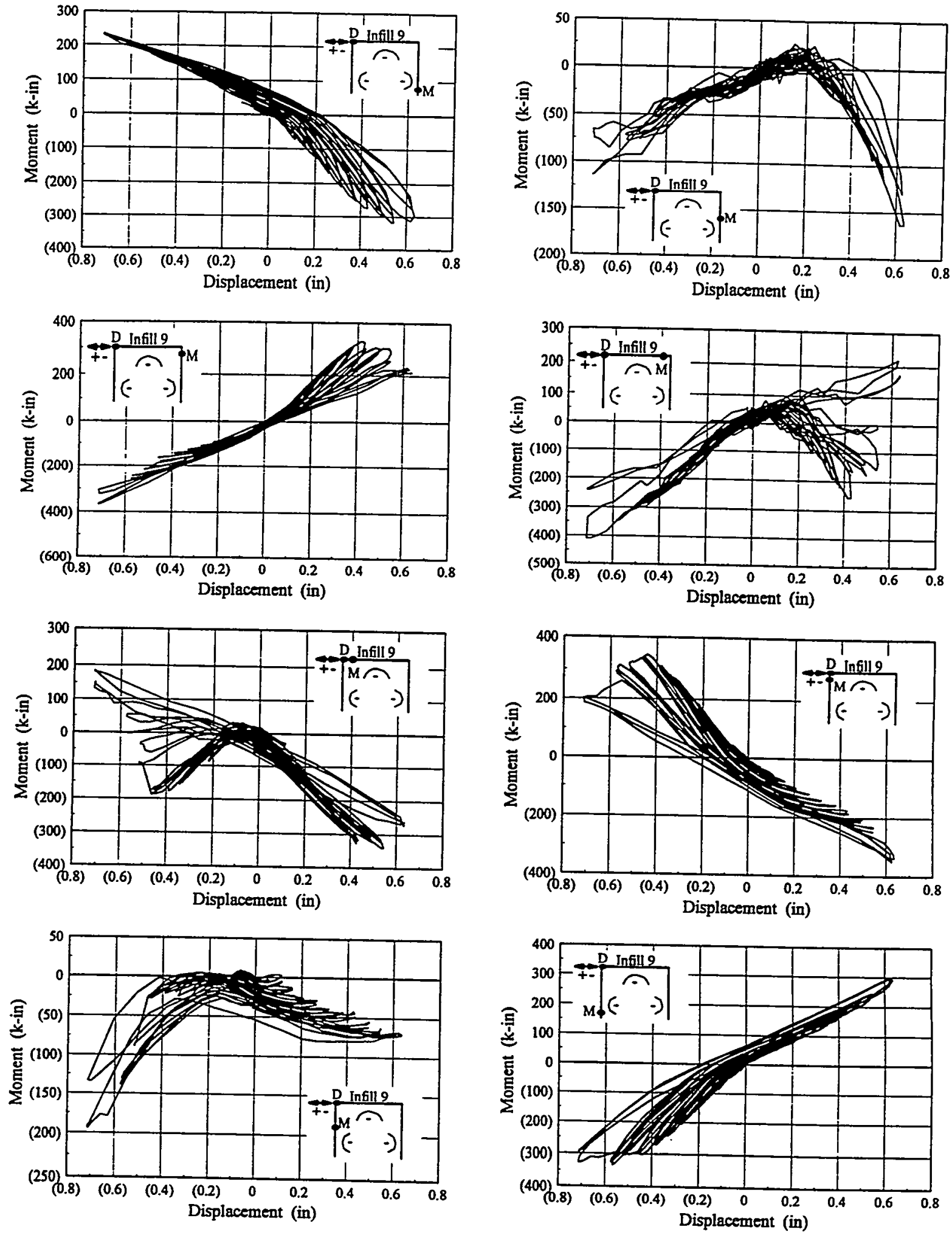

Infilled Frame 9 Moment-Displacement Hysteresis 

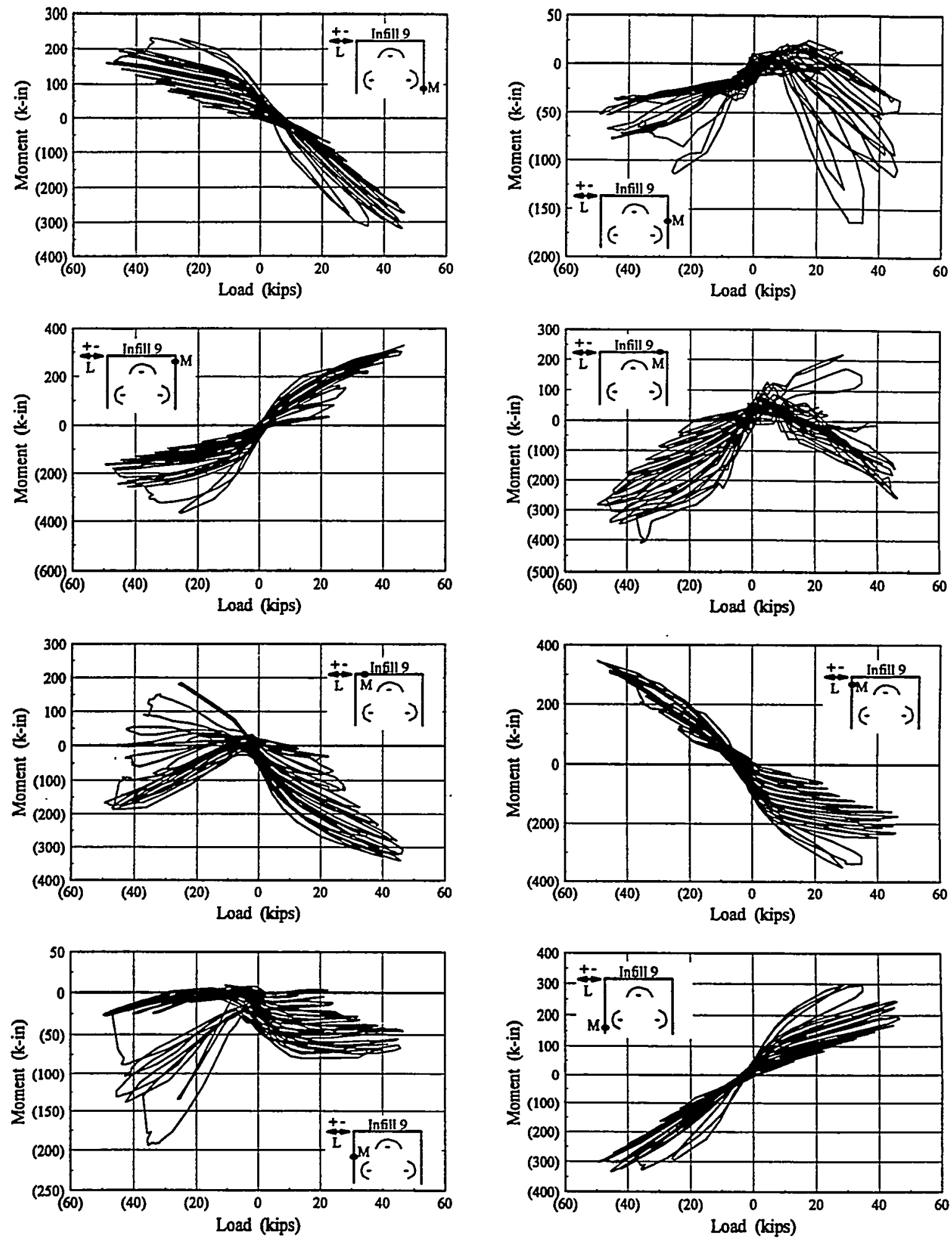

Infilled Frame 9 Moment-Load Hysteresis 

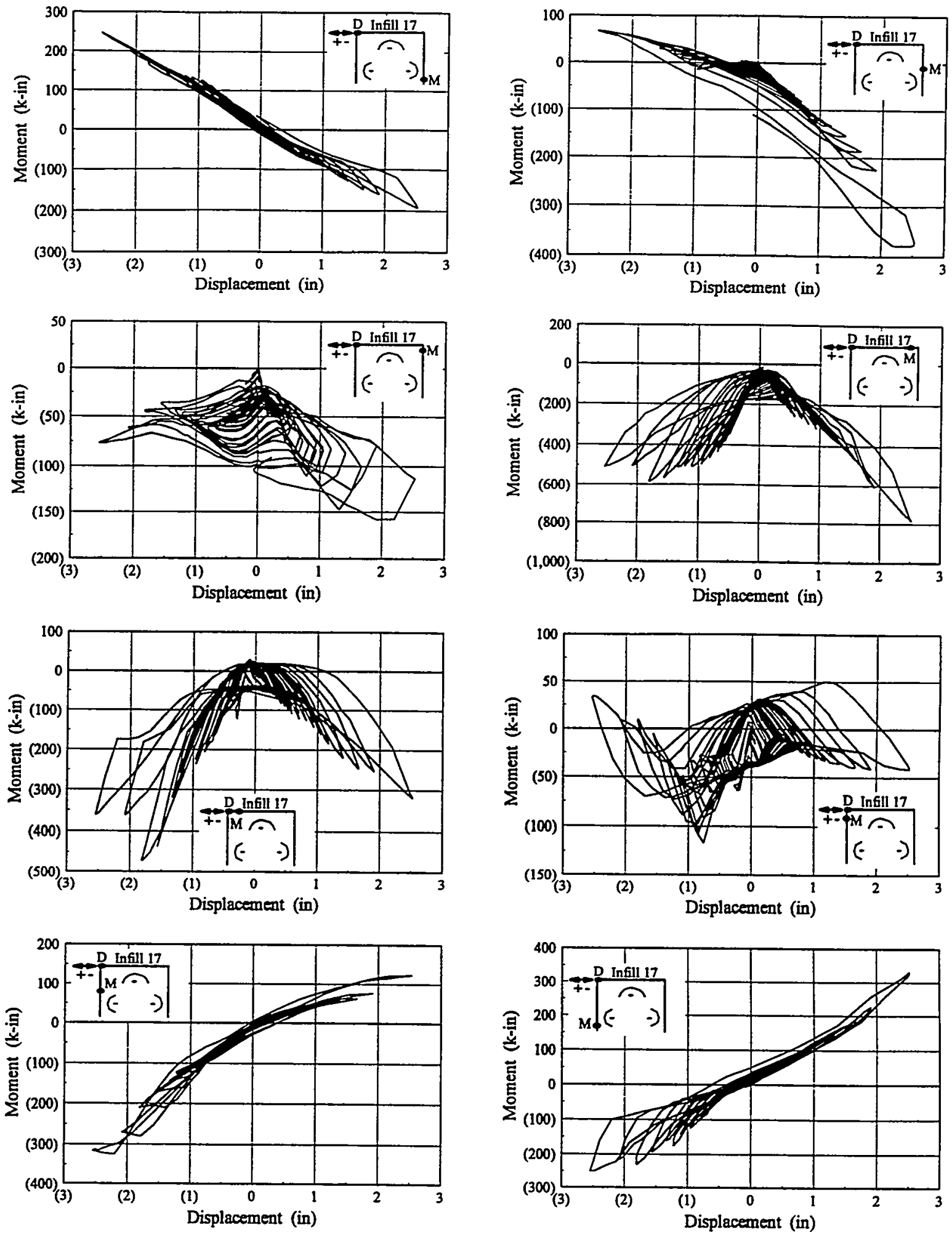

Infilled Frame 17 Moment-Displacement Hysteresis 

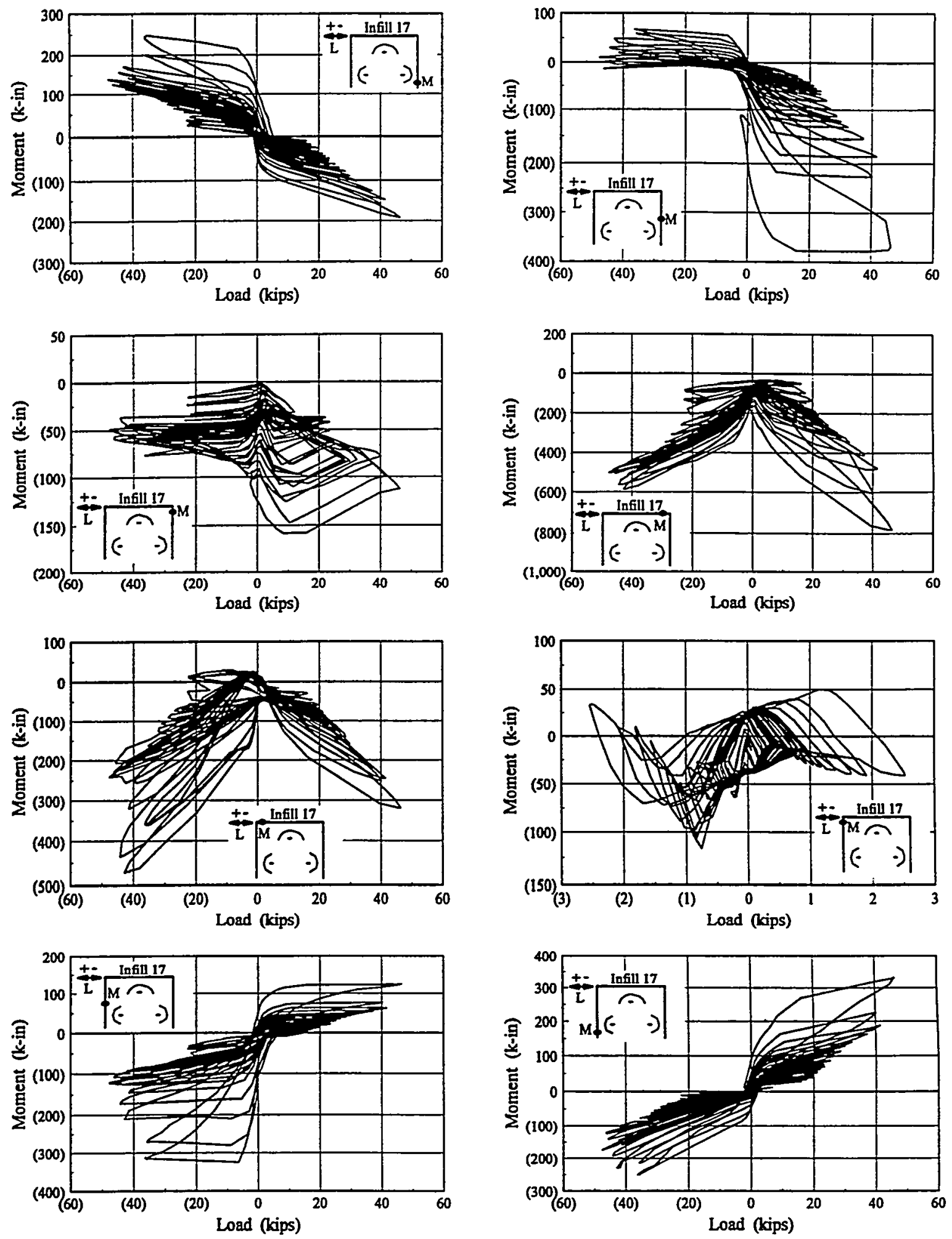

Infilled Frame 17 Moment-Load Hysteresis 

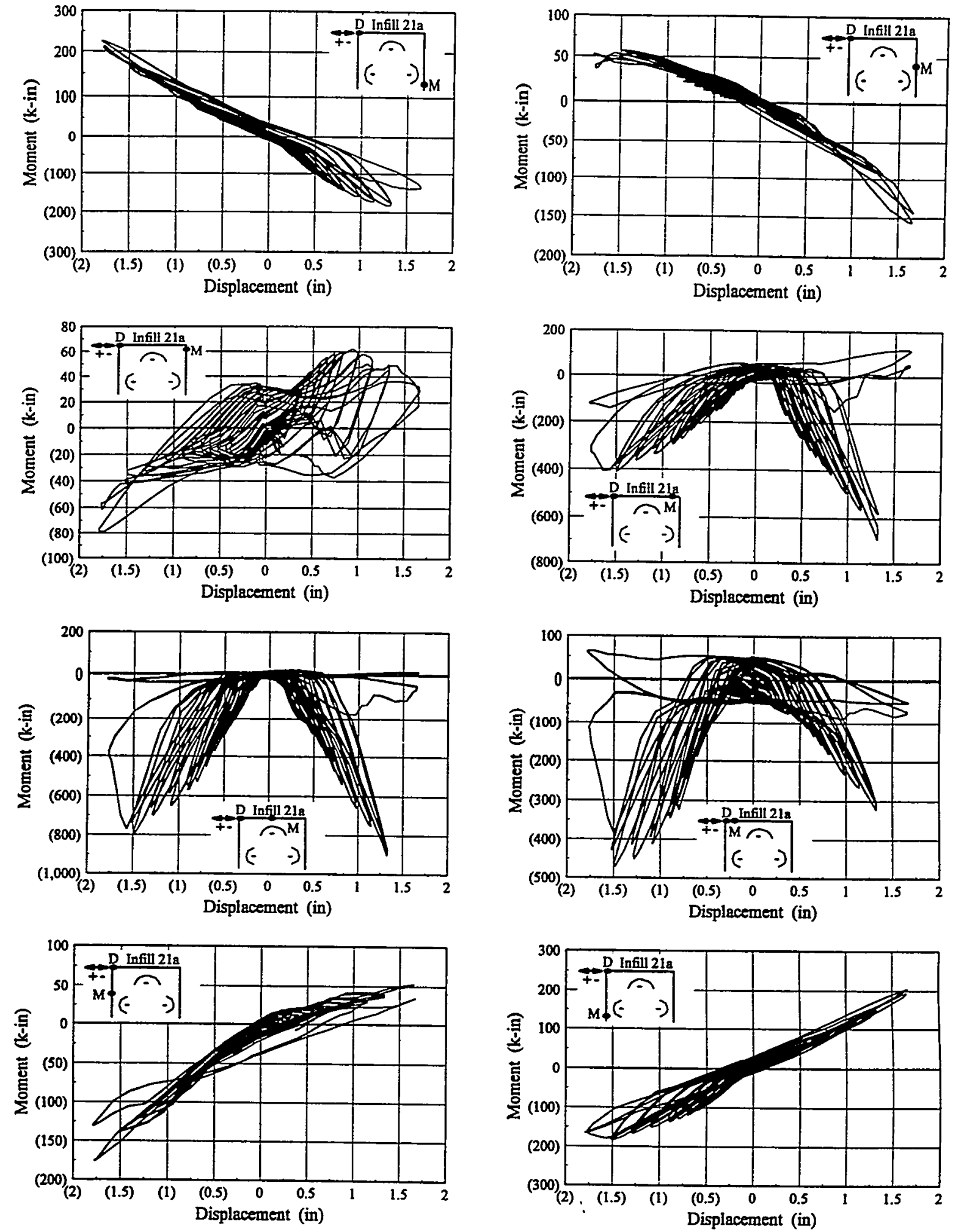

Infilled Frame 21a Moment-Displacement Hysteresis 

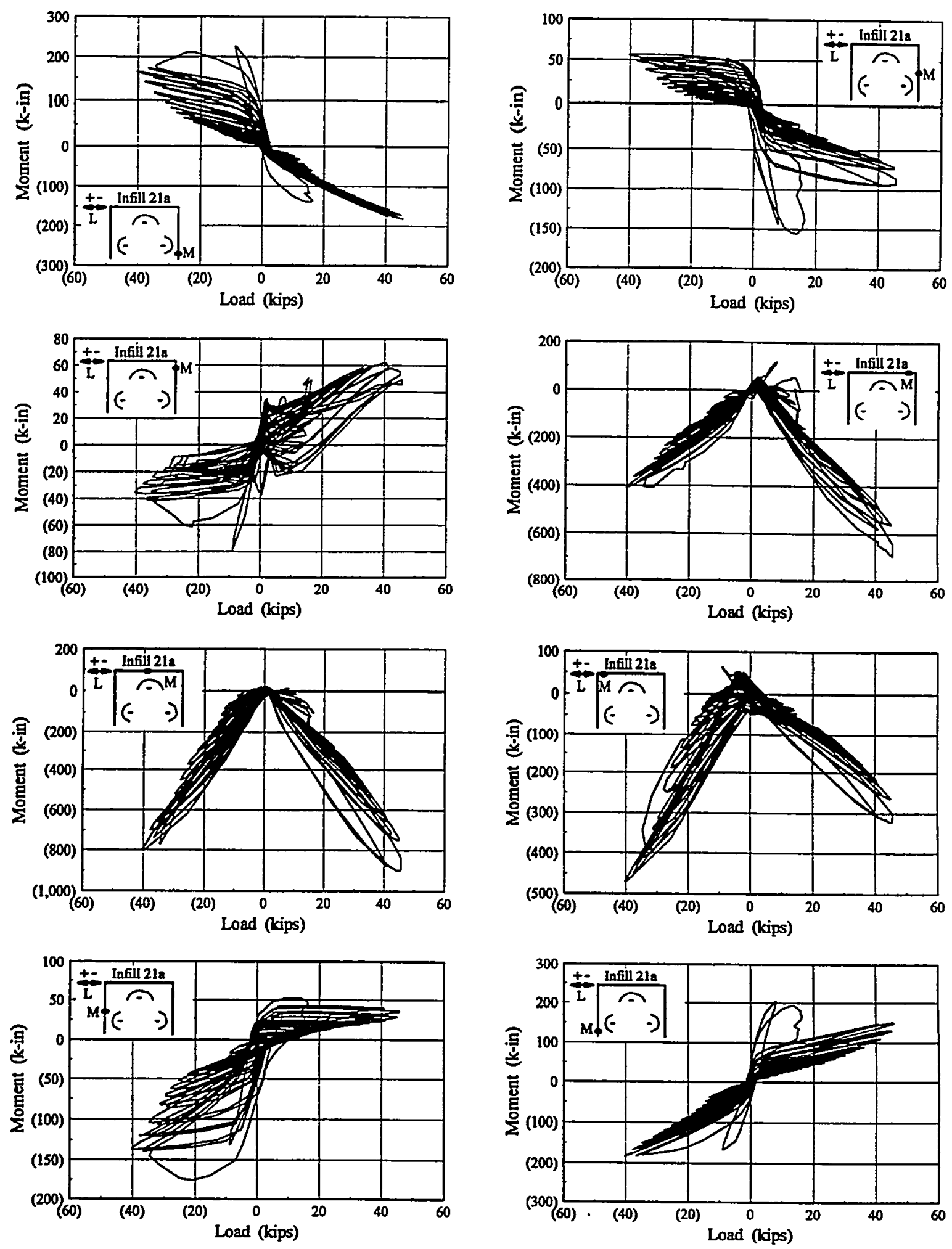

Infilled Frame 21a Moment-Load Hysteresis 

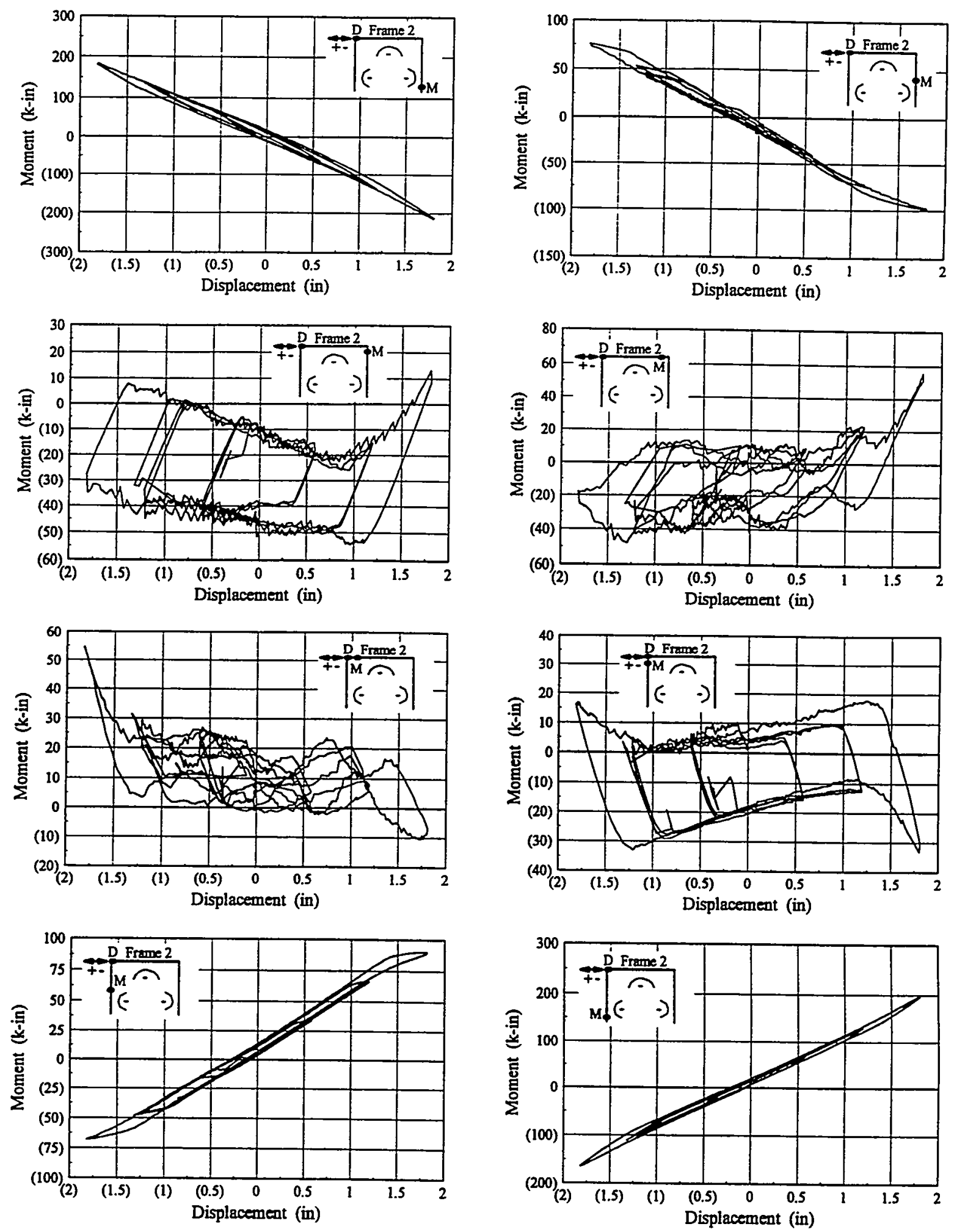

Bare Frame 2 Moment-Displacement Hysteresis 

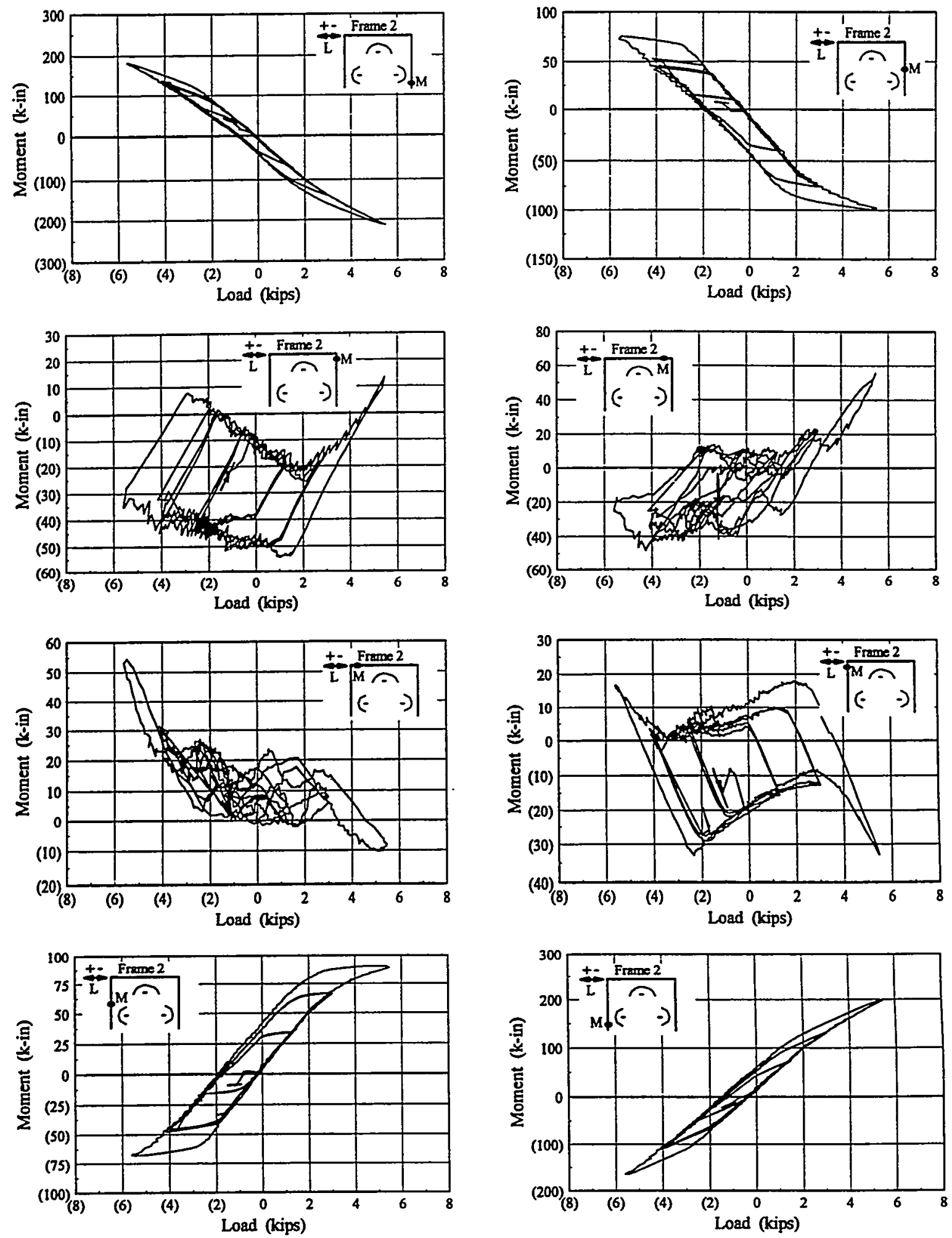

Bare Frame 2 Moment-Load Hysteresis 

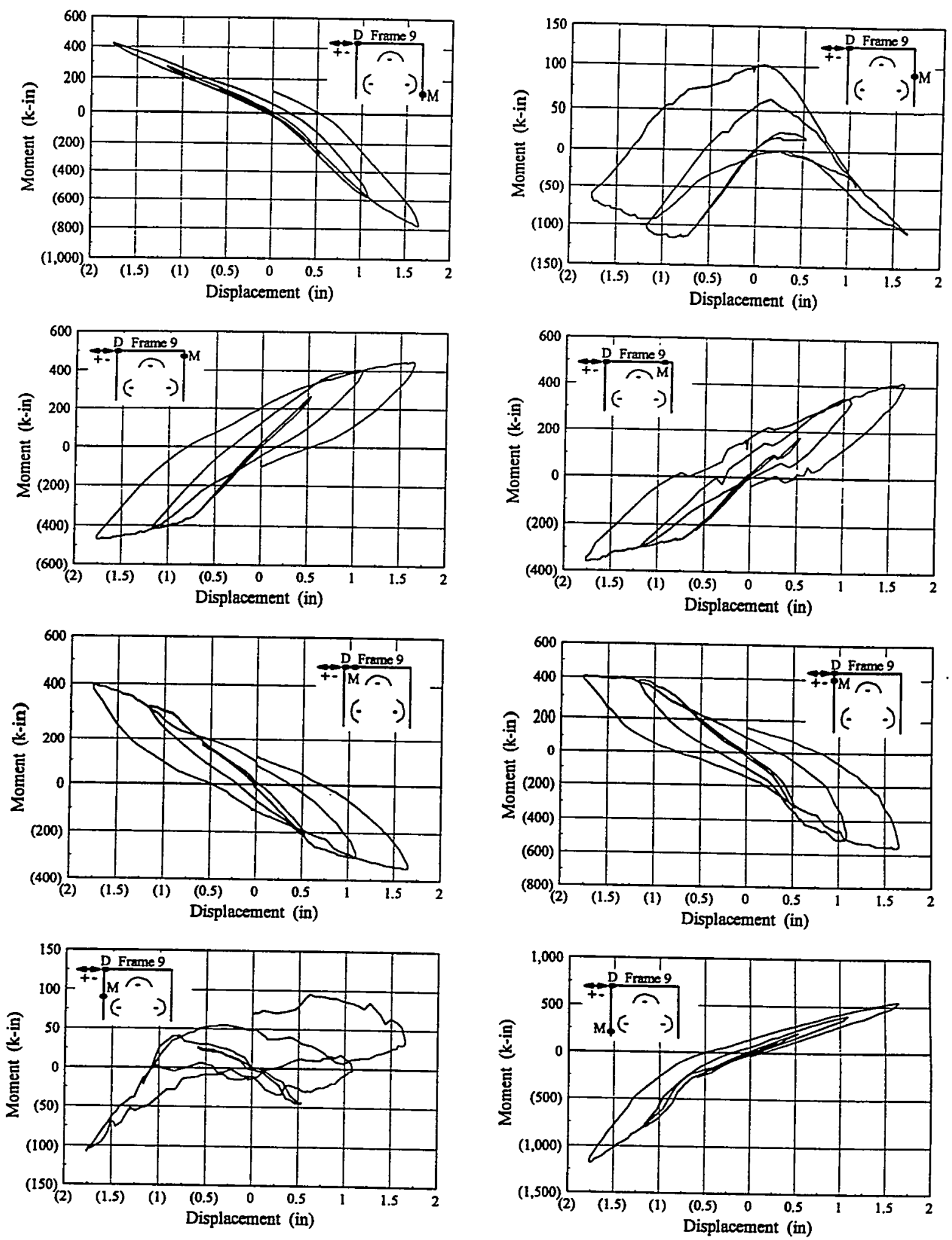

Bare Frame 9 Moment-Displacement Hysteresis 

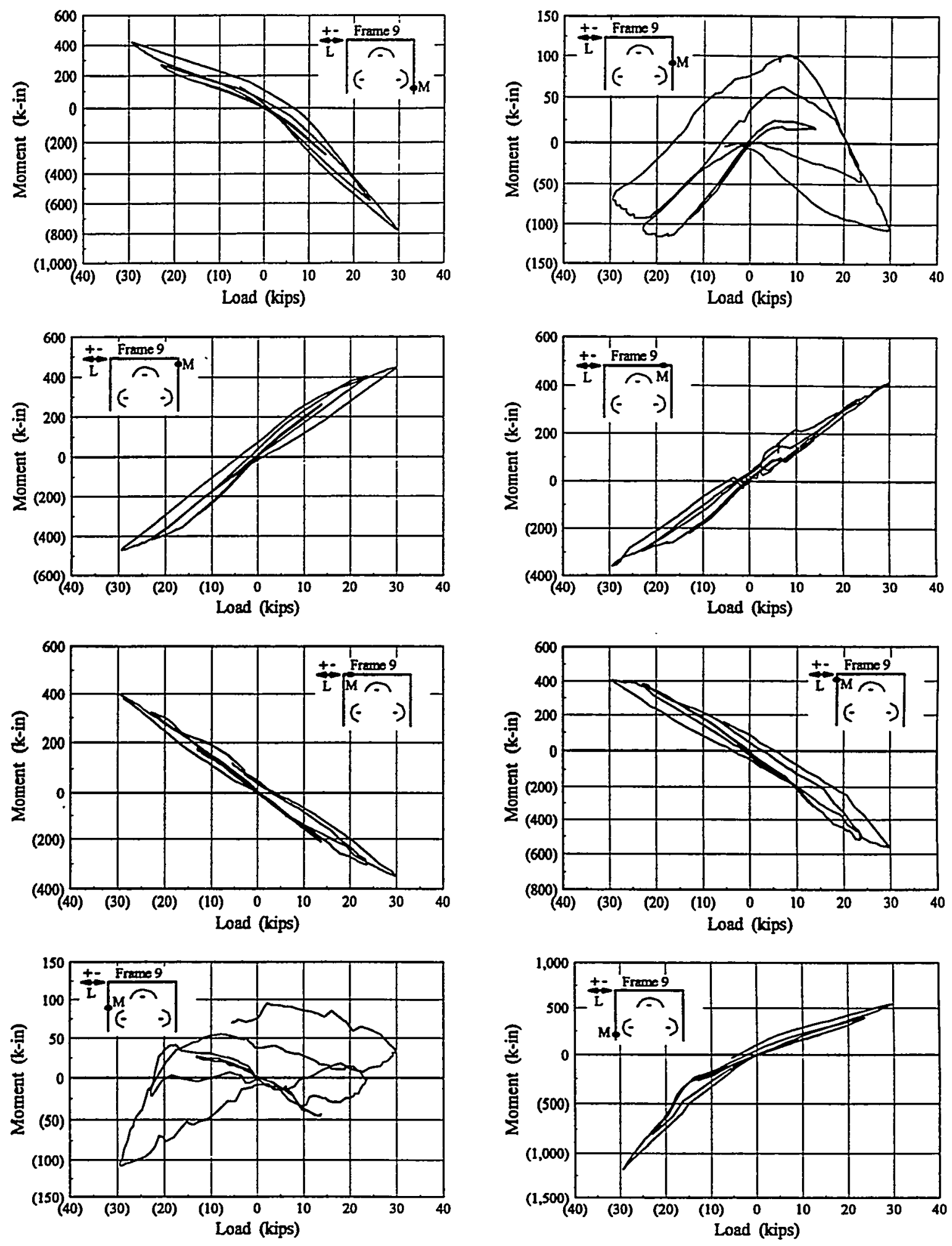

Bare Frame 9 Moment-Load Hysteresis 

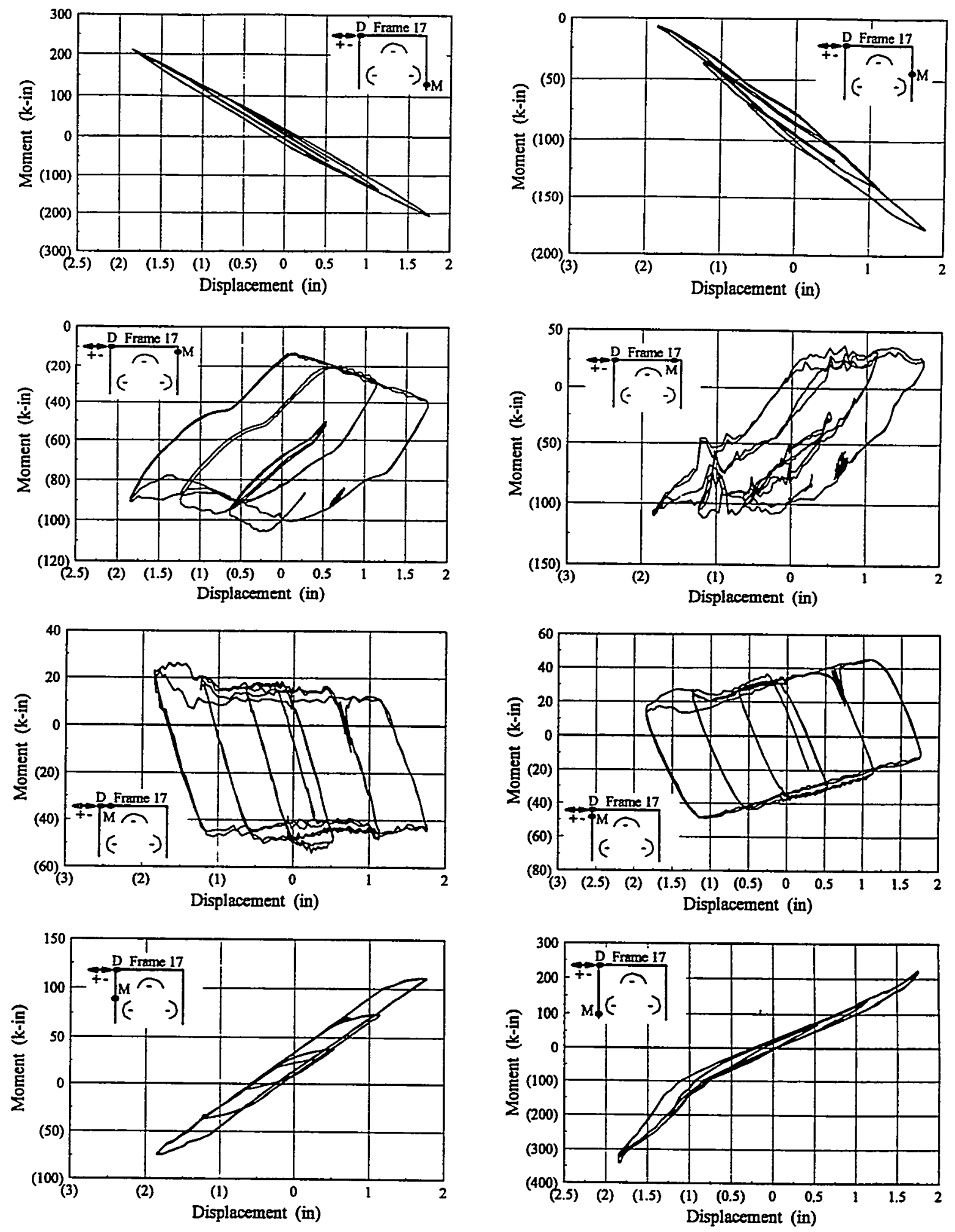

Bare Frame 17 Moment-Displacement Hysteresis 

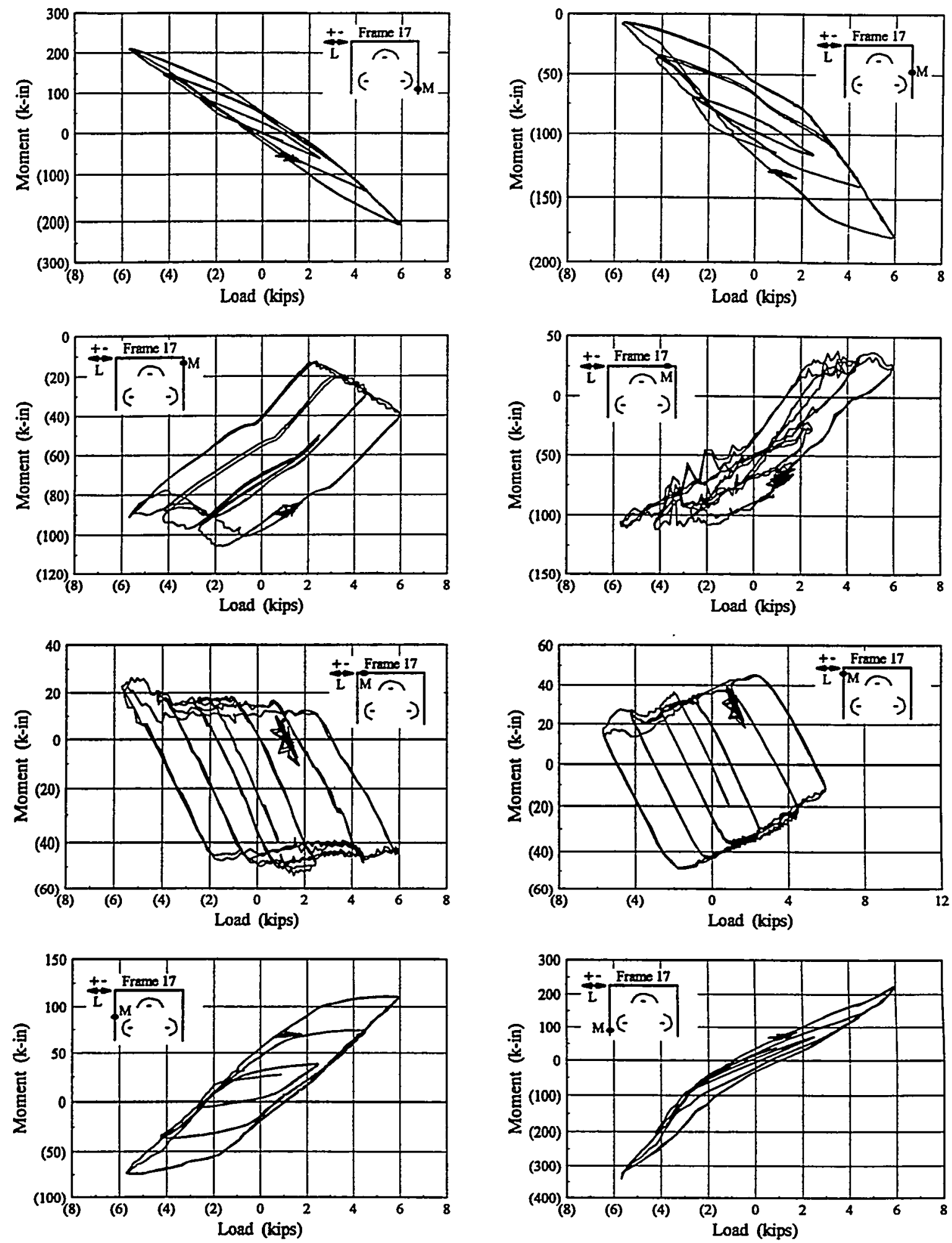

Bare Frame 17 Moment-Load Hysteresis 

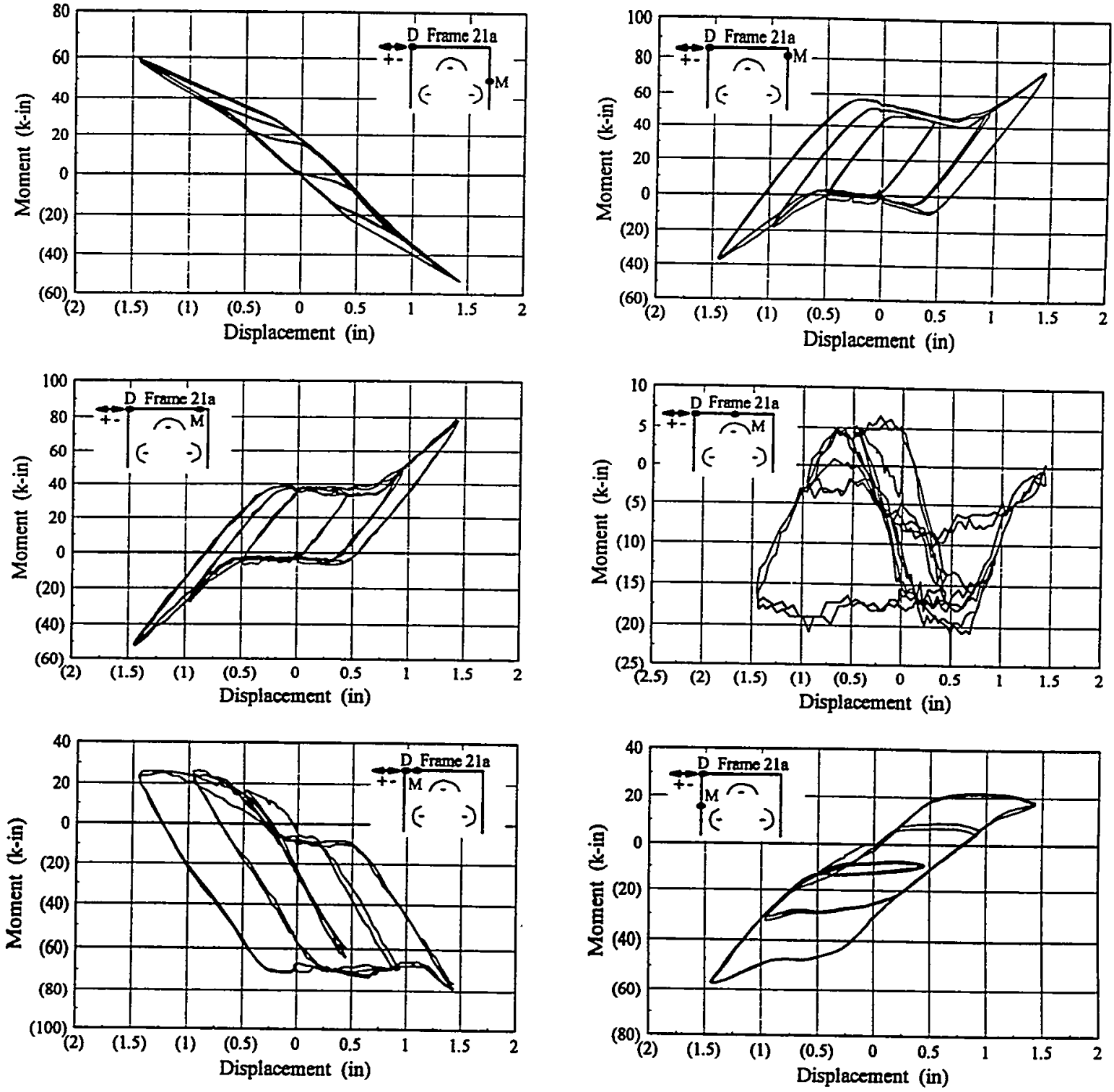

Bare Frame 21a Moment-Displacement Hysteresis 

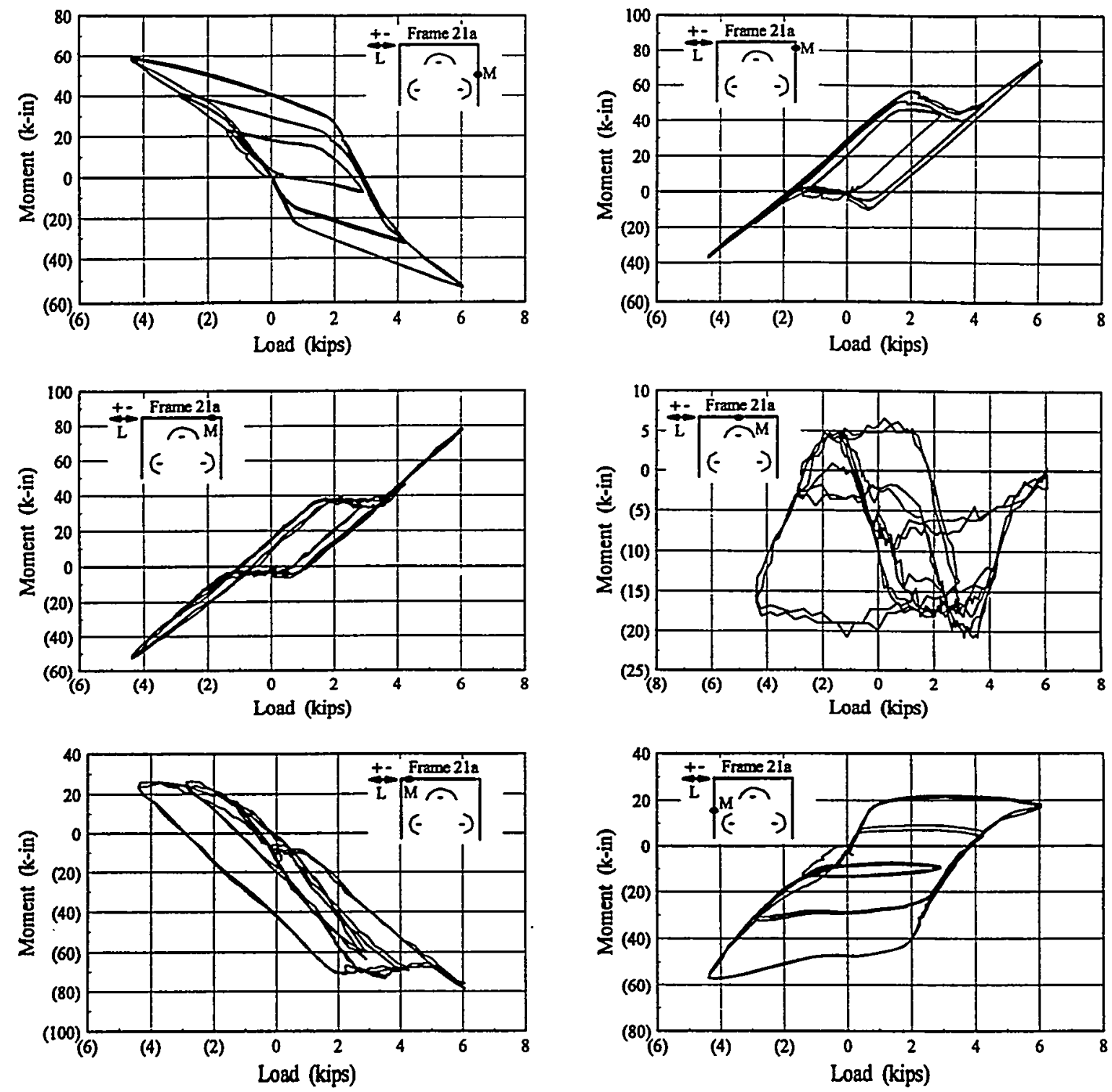

Bare Frame 21a Moment-Load Hysteresis 

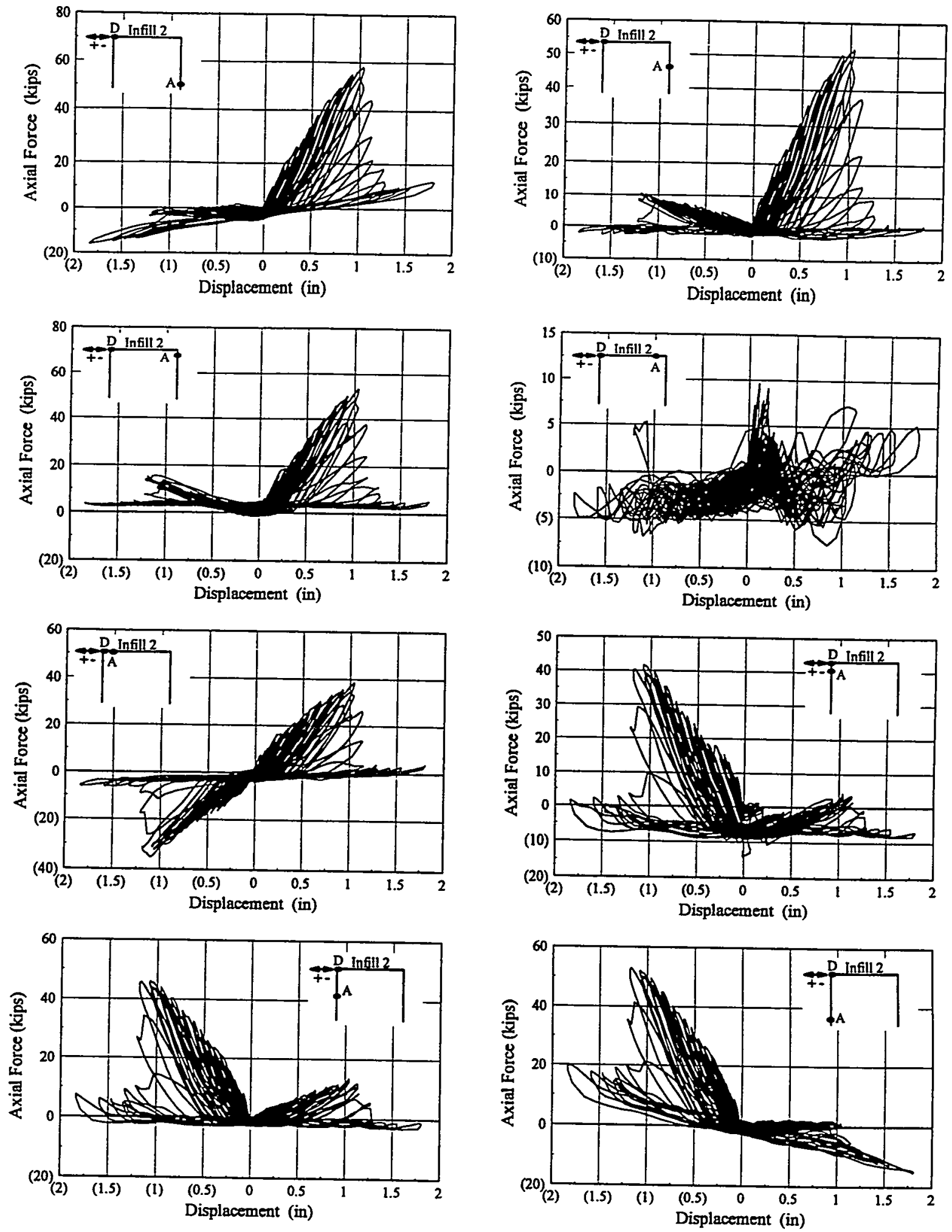

Infilled Frame 2 Axial Force-Displacement Hysteresis 

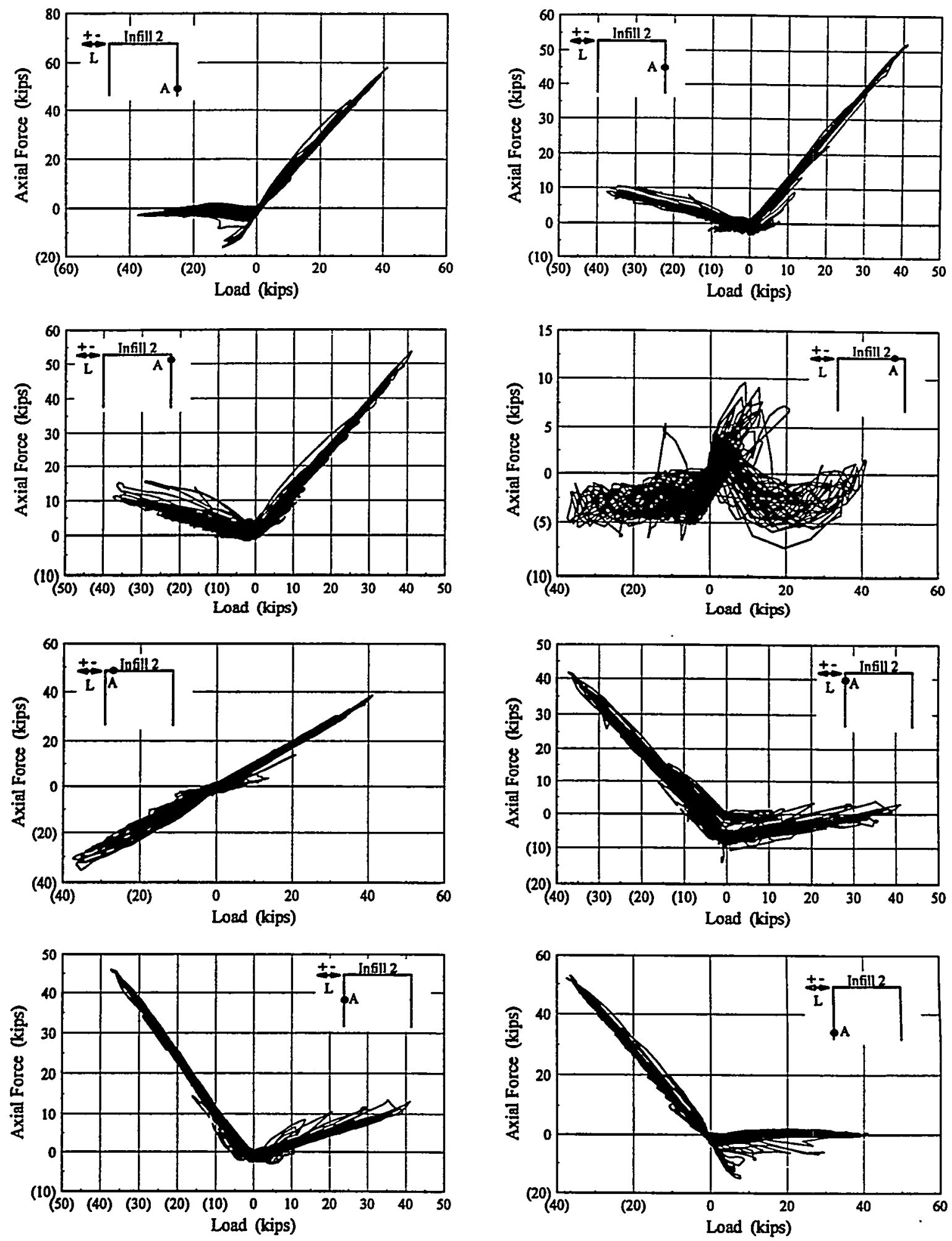

Infilled Frame 2 Axial Force-Load Hysteresis 

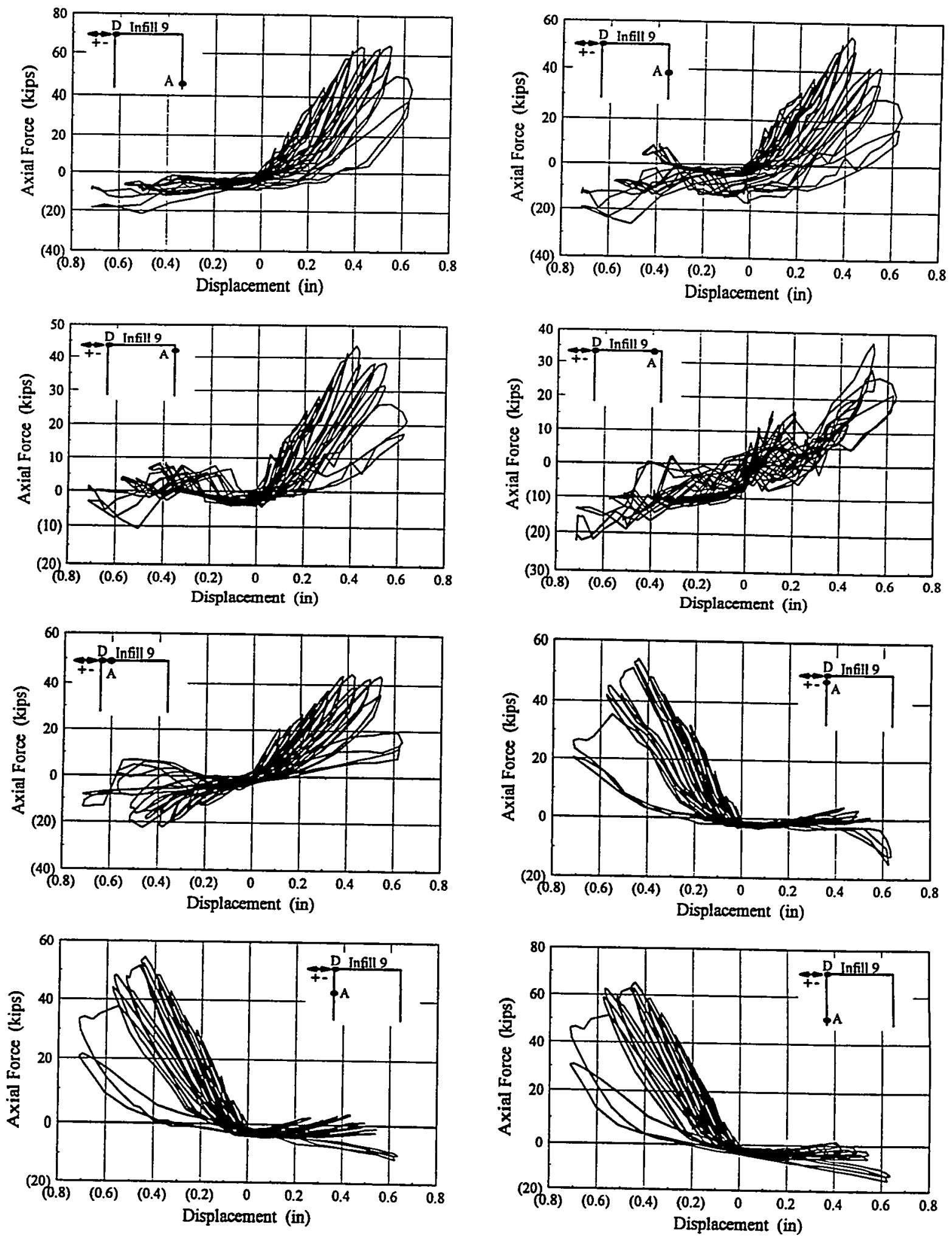

Infilled Frame 9 Axial Force-Displacement Hysteresis 

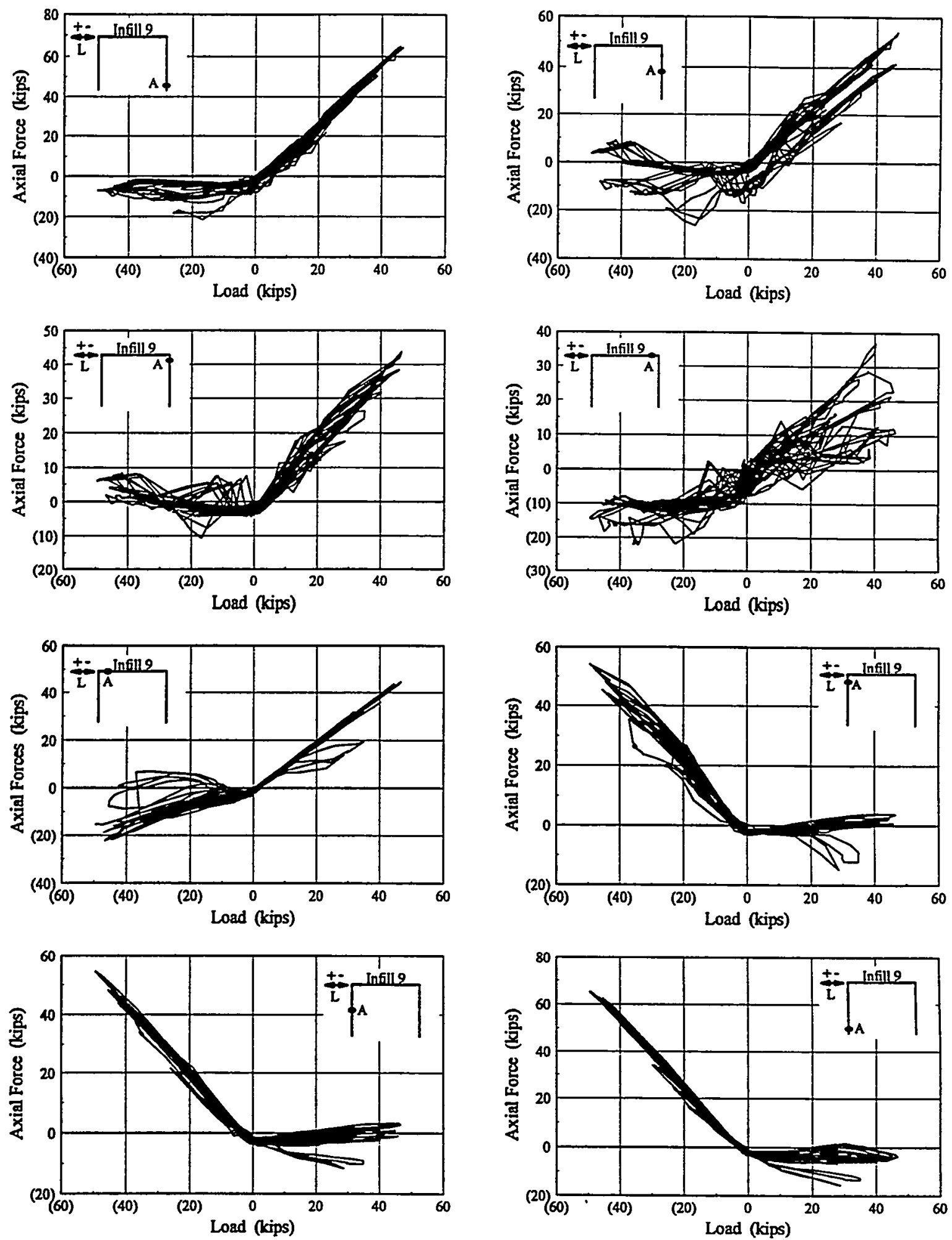

Infilled Frame 9 Axial Force-Load Hysteresis 

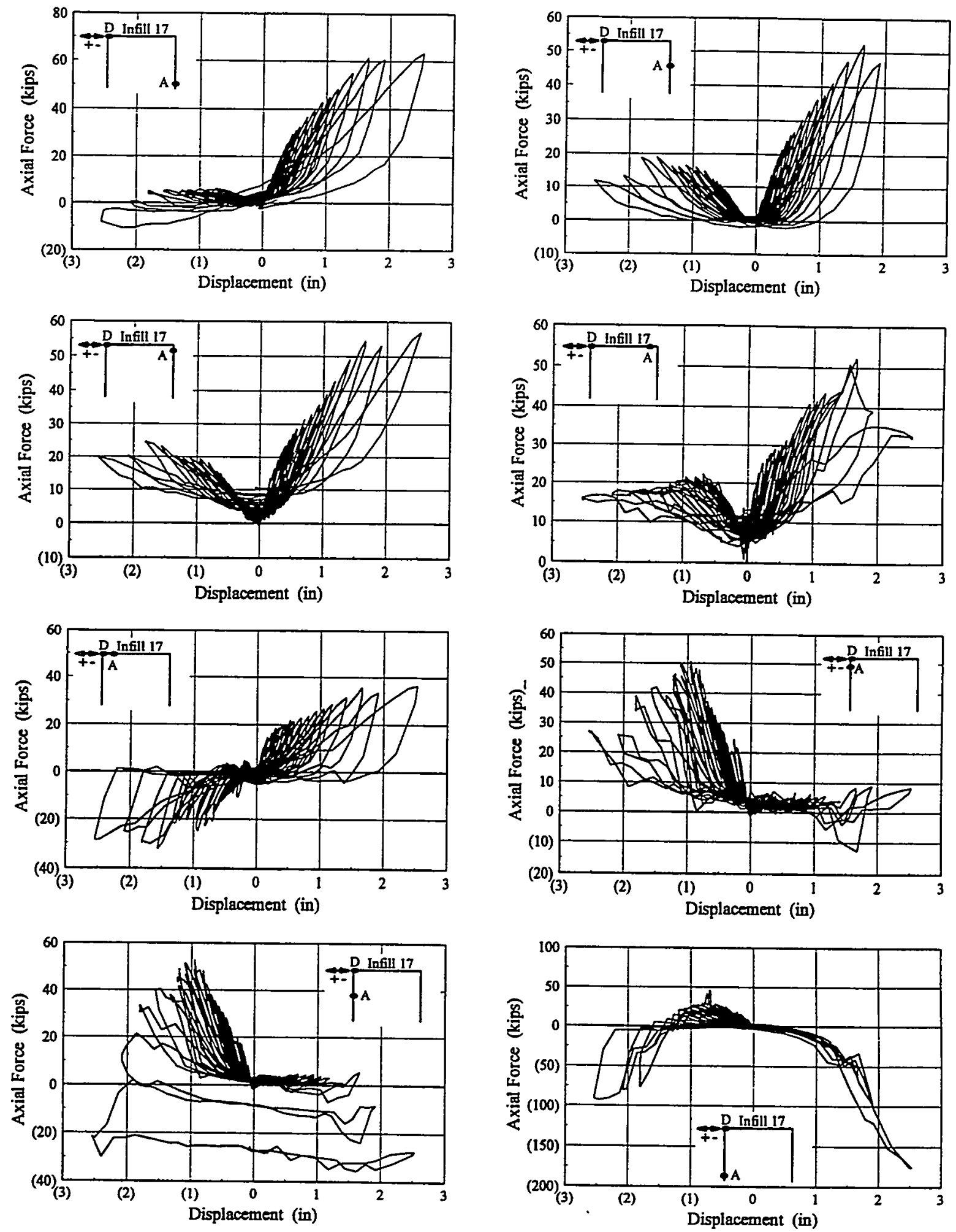

Infilled Frame 17 Axial Force-Displacement Hysteresis 

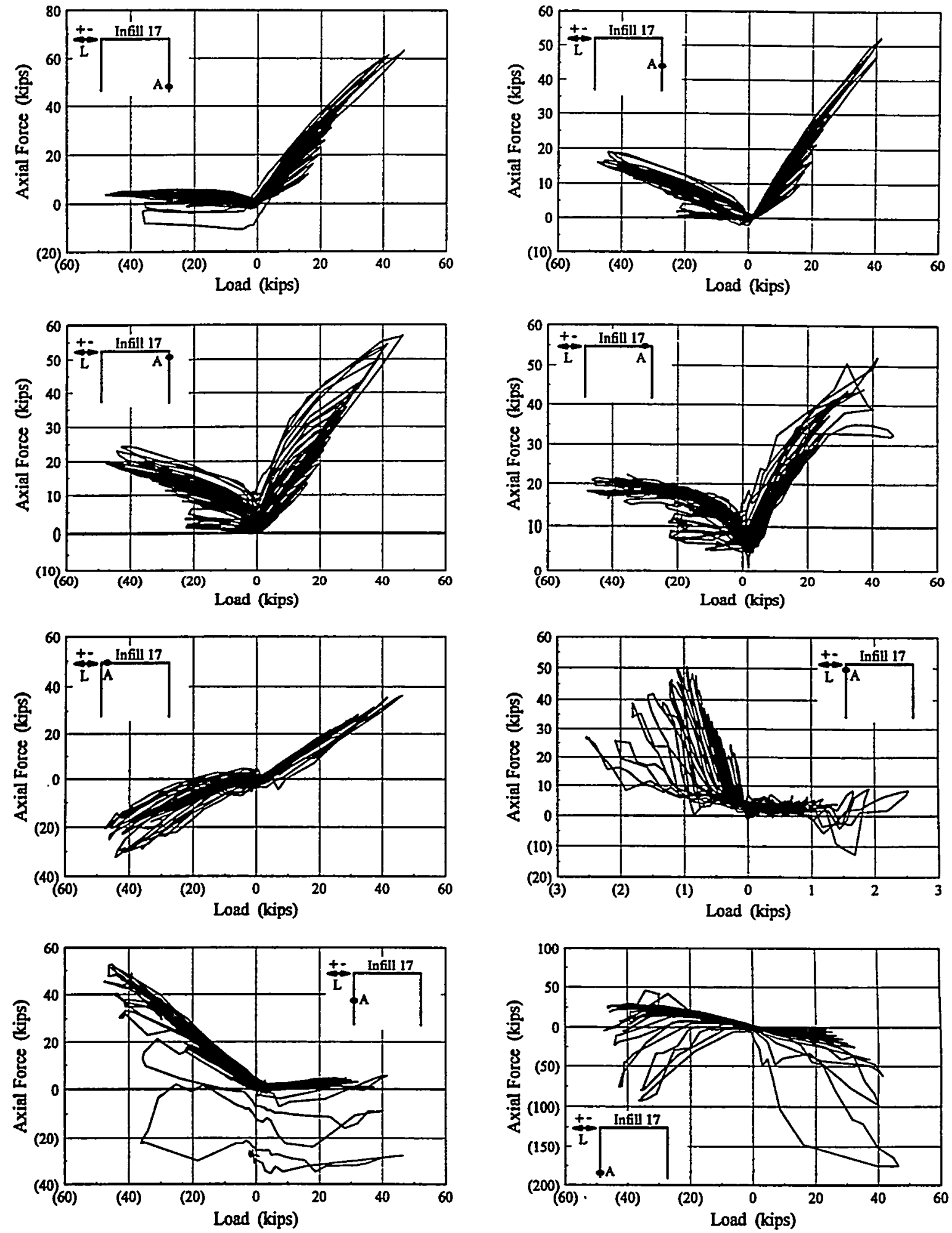

Infilled Frame 17 Axial Force-Load Hysteresis 

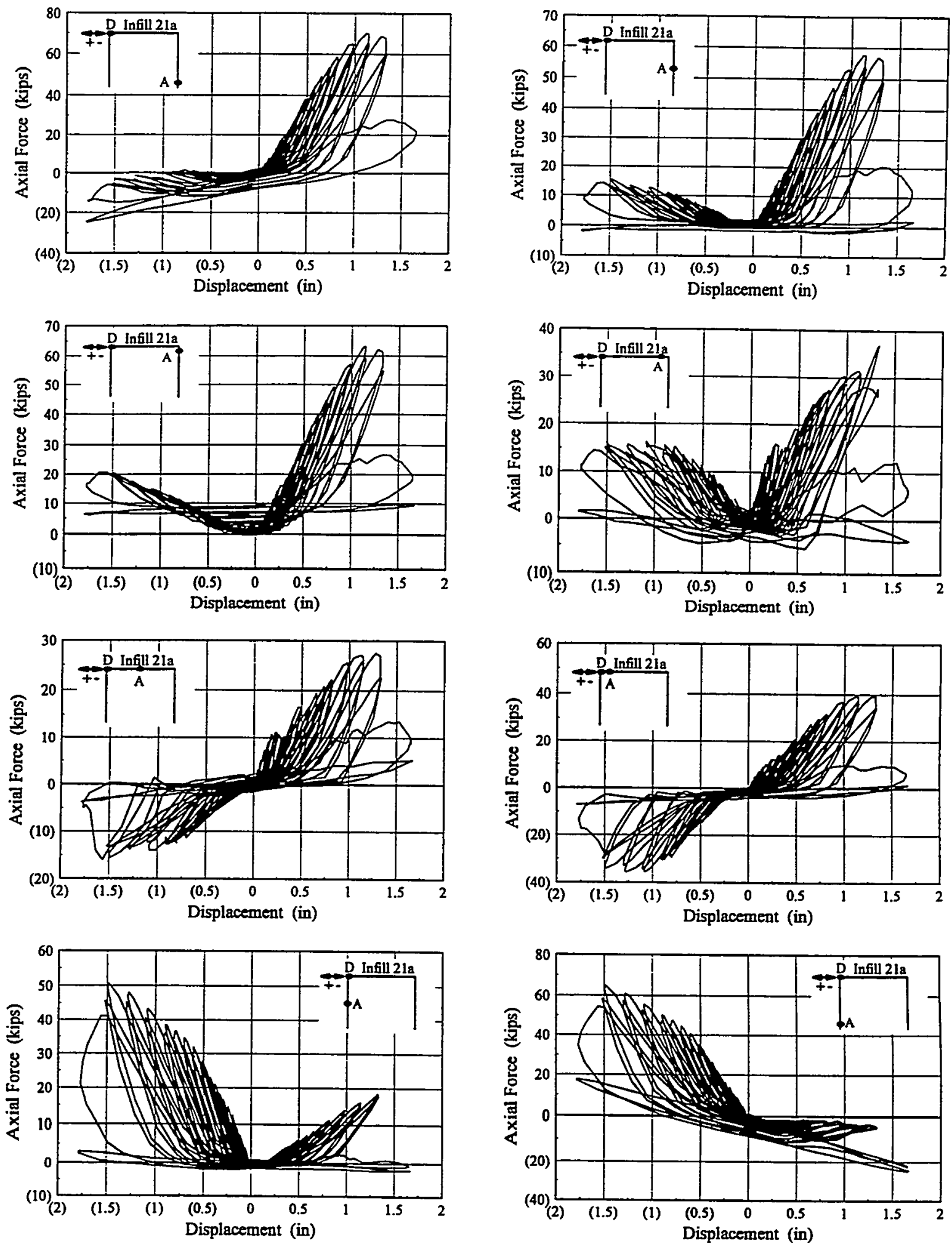

Infill 21a Axial Force-Displacement Hysteresis 

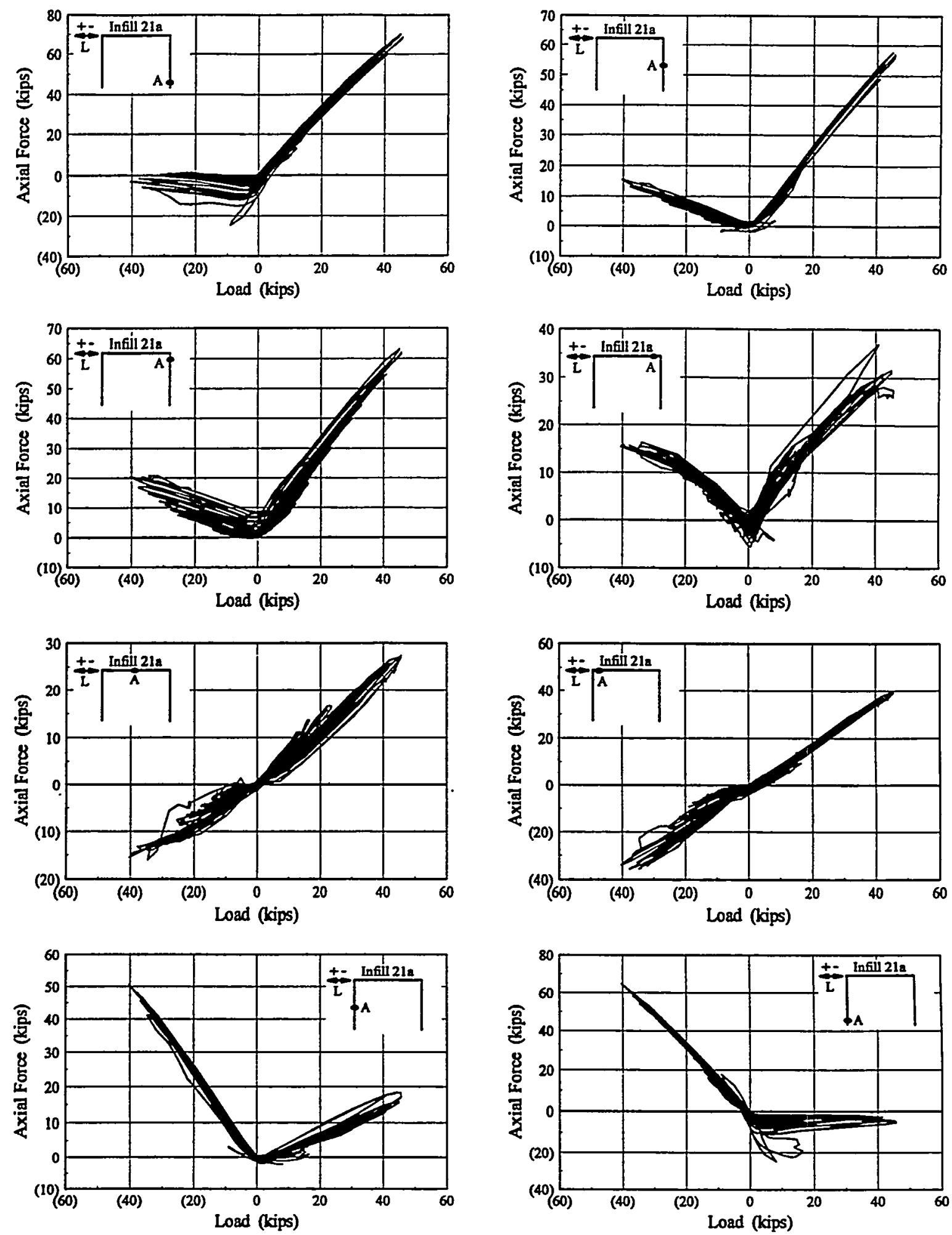

Infill 21a Axial Force-Load Hysteresis 

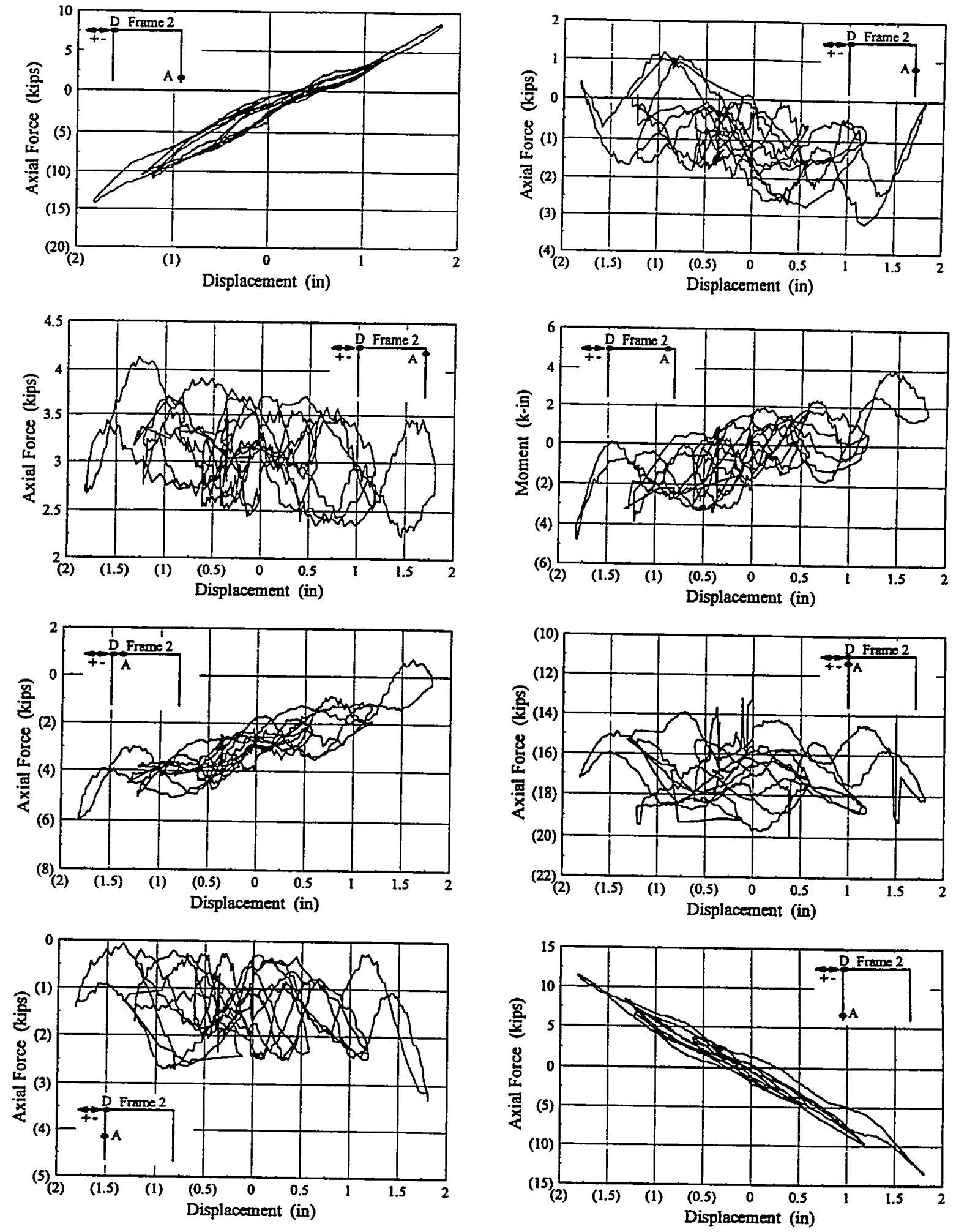

Bare Frame 2 Axial Force-Displacement Hysteresis 

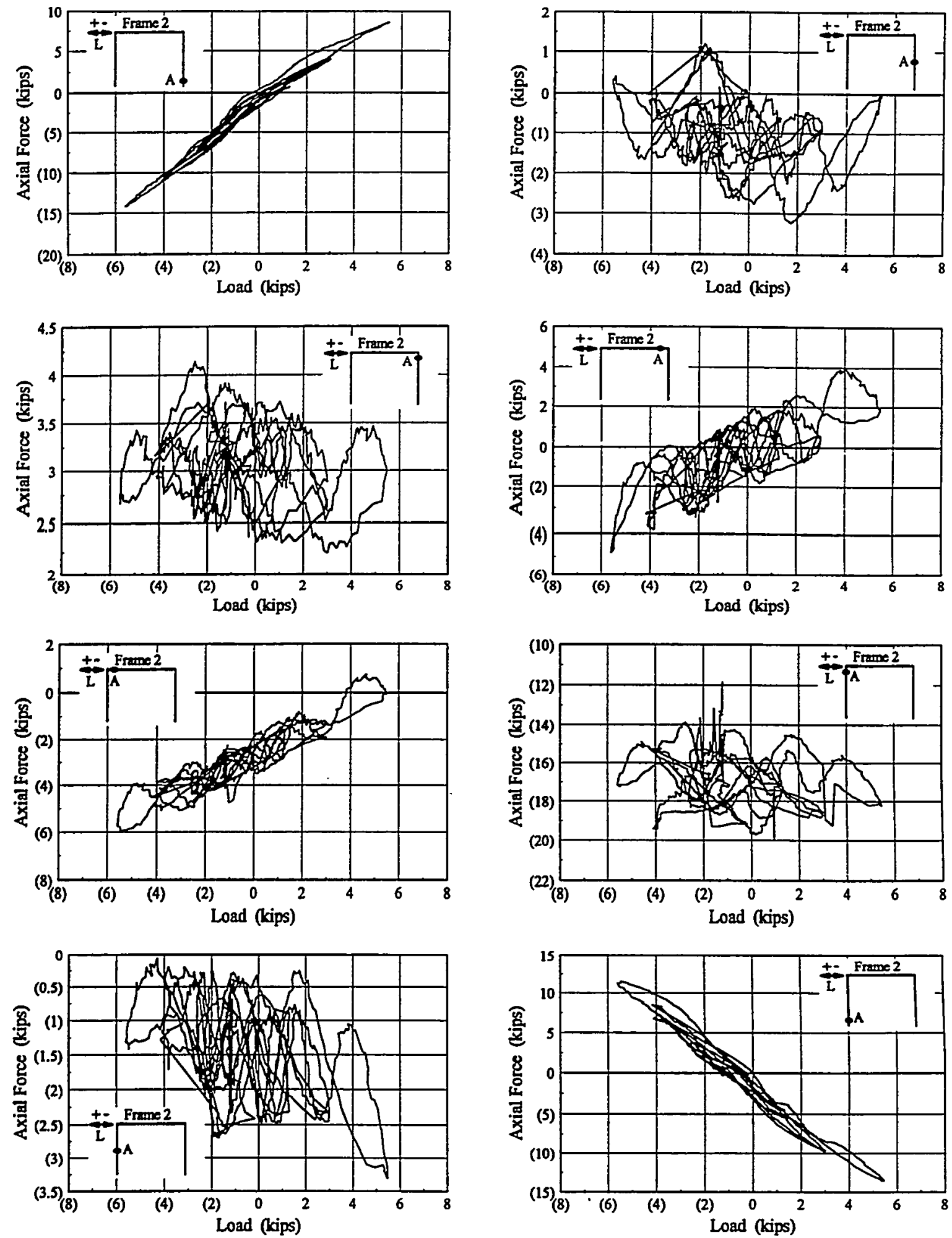

Bare Frame 2 Axial Force-Load Hysteresis 

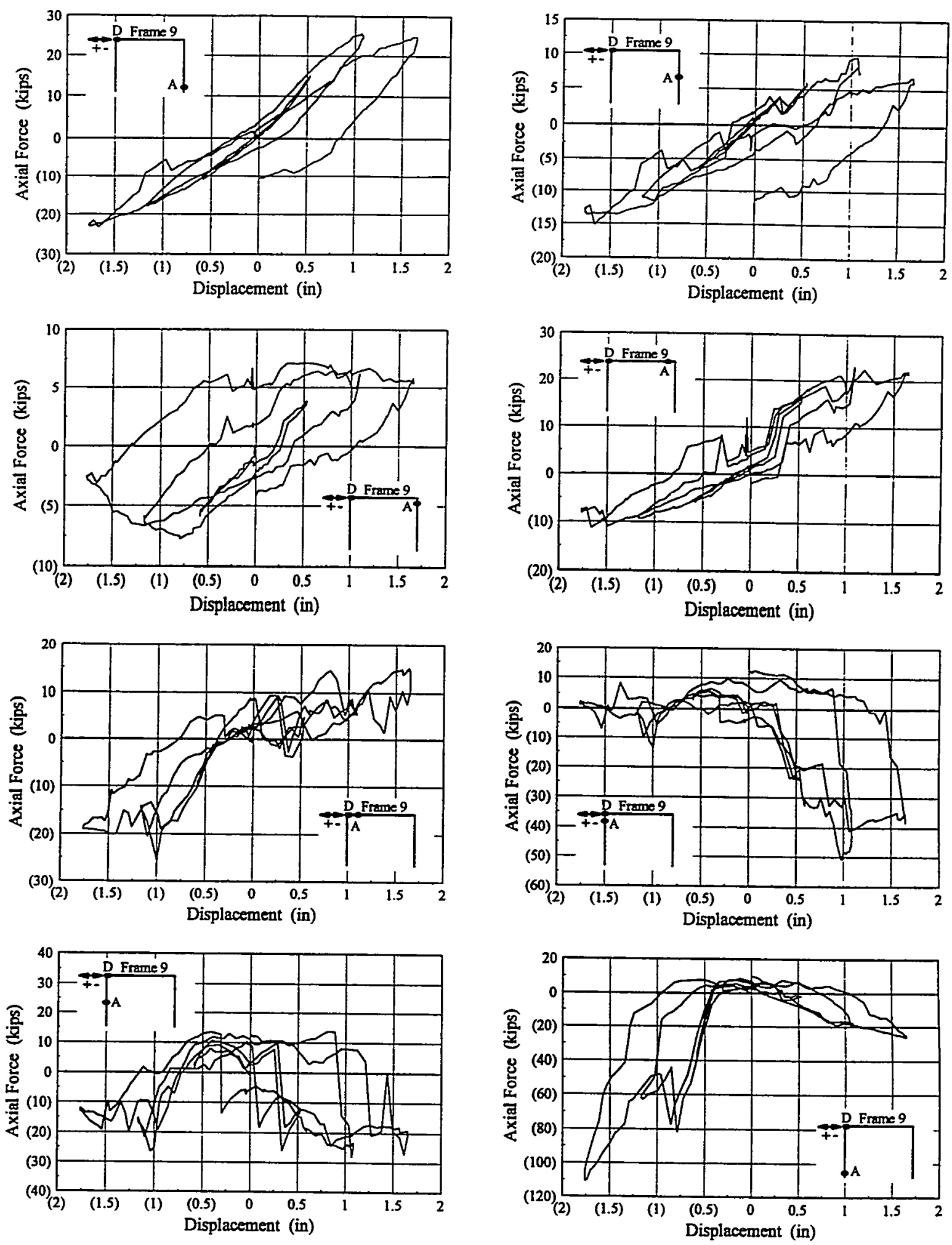

Bare Frame 9 Axial Force-Displacement Hysteresis 

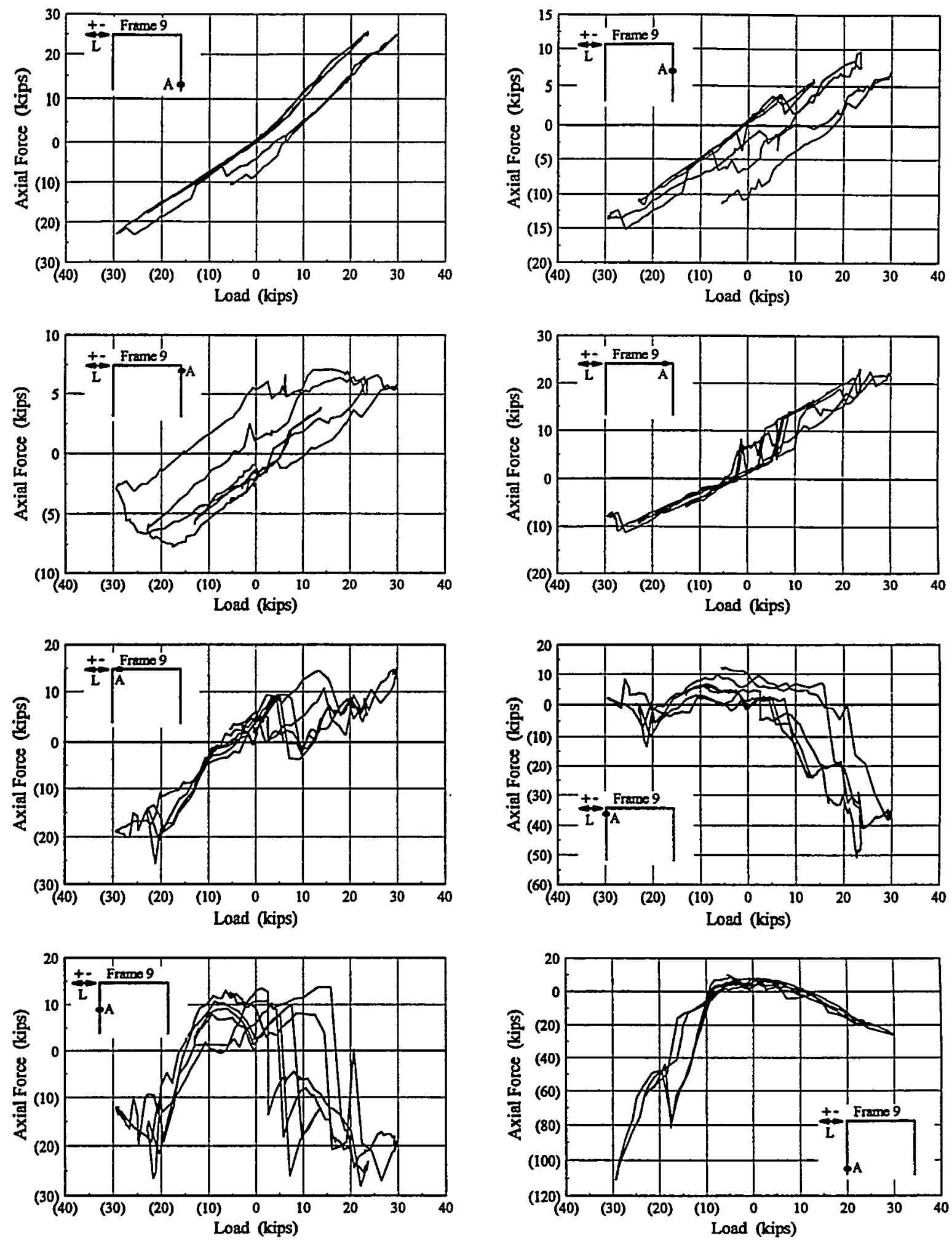

Bare Frame 9 Axial Force-Load Hysteresis 

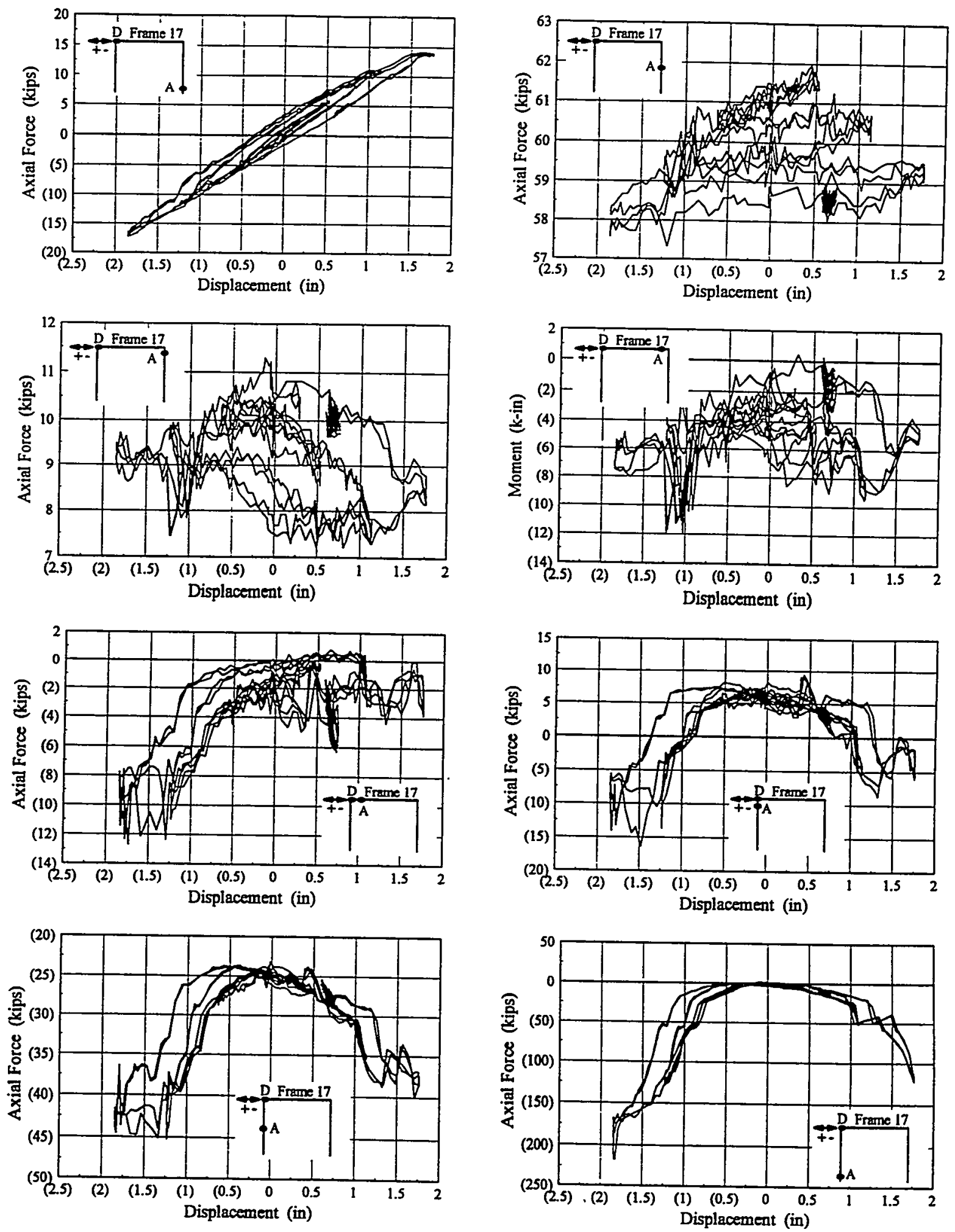

Bare Frame 17 Axial Force-Displacement Hysteresis 

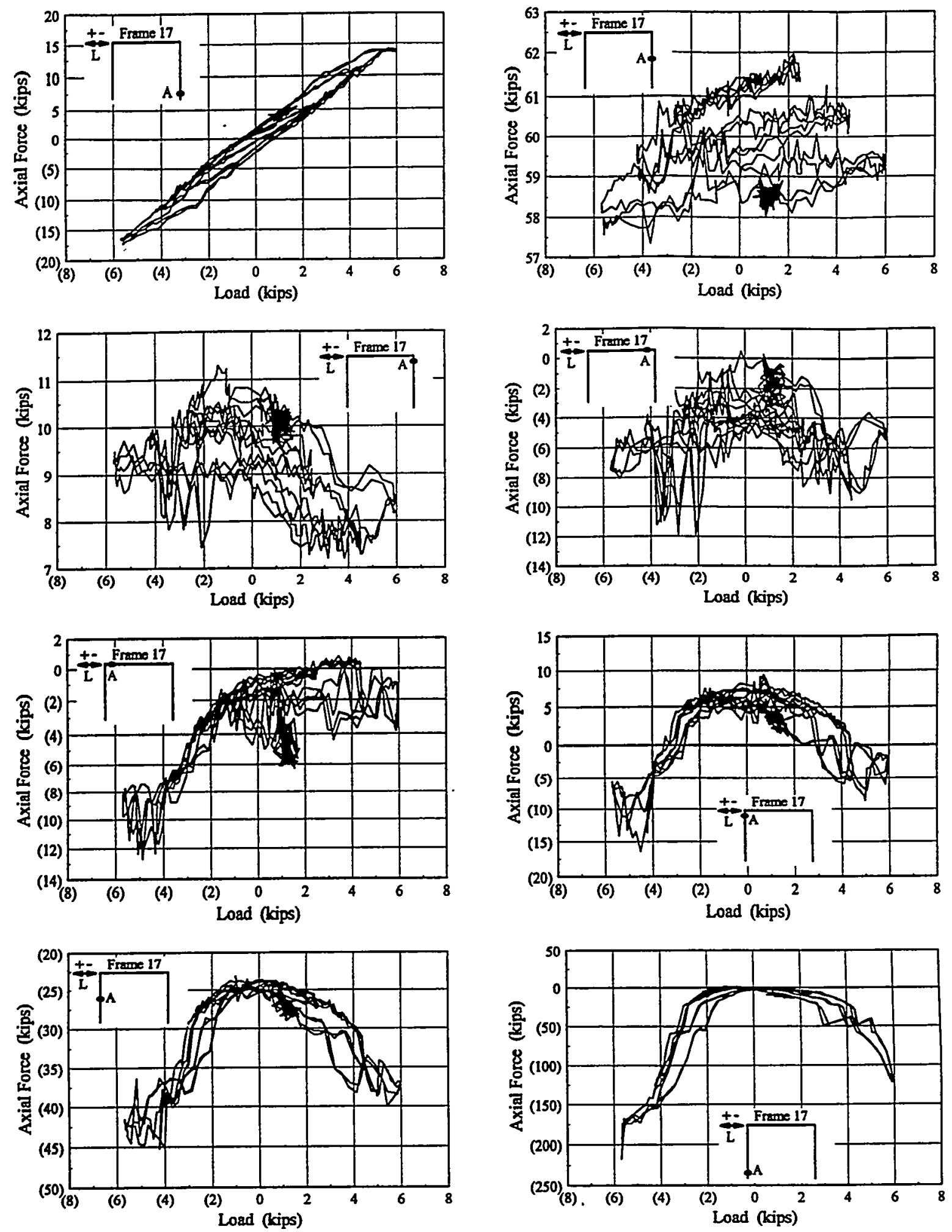

Bare Frame 17 Axial Force-Load Hysteresis 

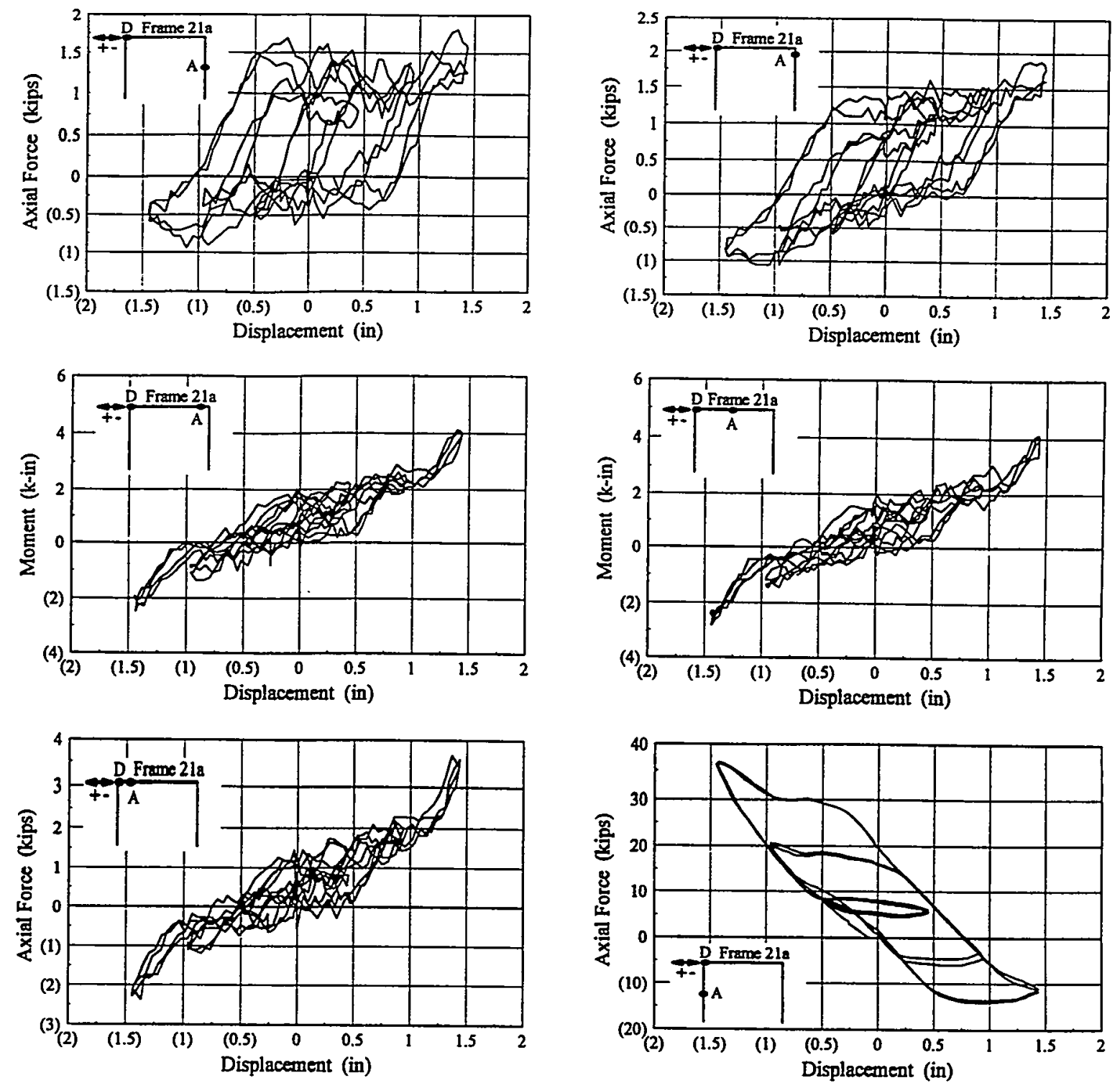

Bare Frame 21a Axial Force-Displacement Hysteresis 

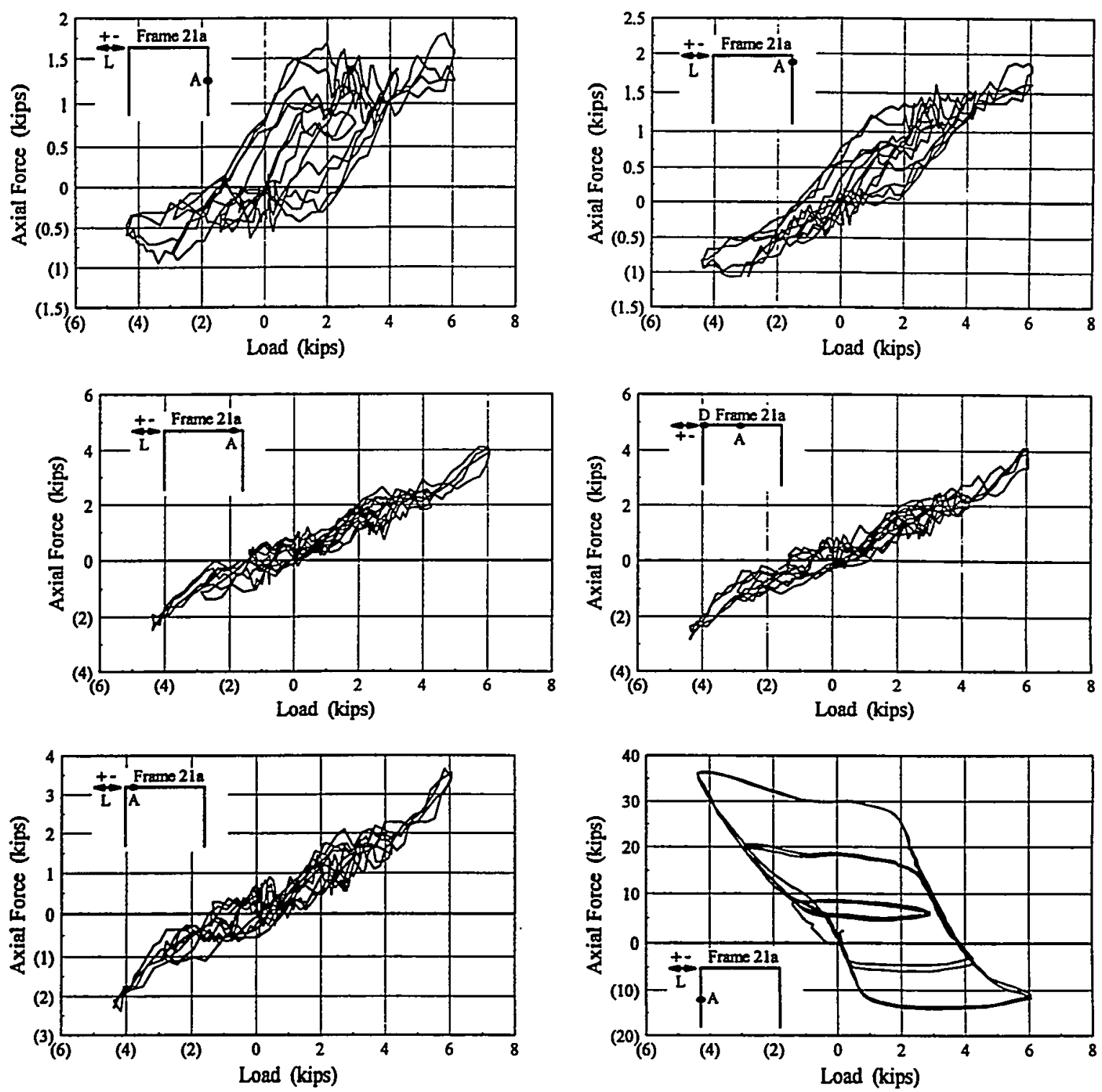

Bare Frame 21a Axial Force-Load Hysteresis 


\section{VITA}

Roger D. Flanagan w He graduated from Greenbrier West High School in May 1977. He received Bachelors of Science and Masters of Science degrees in Civil Engineering from West Virginia University in 1981 and 1983 respectively. While pursuing these degrees, he worked in the summers and part-time during the academic year for Triad Engineering Consultants, Inc., a geotechnical engineering firm. He taught undergraduate structural analysis at West Virginia University while he was a Masters candidate.

Mr. Flanagan began work in Pittsburgh with Mackin Engineering Company as a structural engineer involved in transportation and industrial projects. He later worked for the Tennessee Valley Authority as a structural engineer and computer aided engineering specialist in their electric power program. He is currently a senior engineer with Martin Marietta Energy Systems, Inc. at the U.S. Department of Energy's Oak Ridge Operations.

Mr. Flanagan has taught foundation analysis and design and light gage metal design at The University of Tennessee. He has numerous publications in the fields of structural engineering and computer aided engineering. 


\title{
DISTRIBUTION:
}

\author{
J. E. Beavers \\ R. M. Bennett \\ D. R. Denton \\ R. D. Flanagan (2) \\ K. E. Fricke \\ M. S. Guthrie (RC) \\ R. J. Hunt \\ W. D. Jones \\ A. K. Lee/DOE-OTSI (2) \\ W. C. Stoddart \\ Y-12 Central Files
}

